Carlos Alberto Sampaio de Araújo

\title{
Aplicações de técnicas de Sensoriamento Remoto na análise multitemporal do ecossistema manguezal na Baixada Santista, SP
}

\begin{abstract}
Dissertação apresentada ao Instituto Oceanográfico da Universidade de São Paulo, como parte dos requisitos para obtenção do grau de Mestre em Ciências, área de Oceanografia Química e Geológica.
\end{abstract}

Orientador:

Prof. Dr. Luis Américo Conti 


\section{Universidade de São Paulo Instituto Oceanográfico}

Aplicações de técnicas de Sensoriamento Remoto na análise multitemporal do ecossistema manguezal na Baixada Santista, SP

Carlos Alberto Sampaio de Araújo

Dissertação apresentada ao Instituto Oceanográfico da Universidade de São Paulo, como parte dos requisitos para obtenção do grau de Mestre em Ciências, Programa de Oceanografia Química e Geológica.

Julgada em_l_ $/ 20 \_$por: 


\section{Sumário}

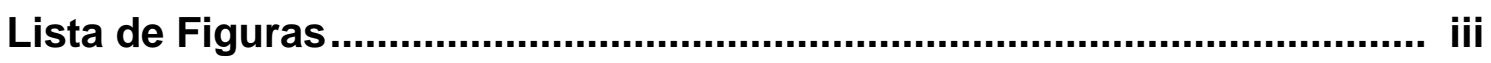

Lista de Tabelas ................................................................................ vii

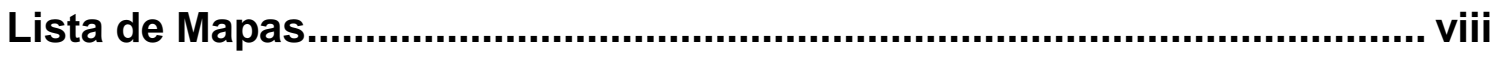

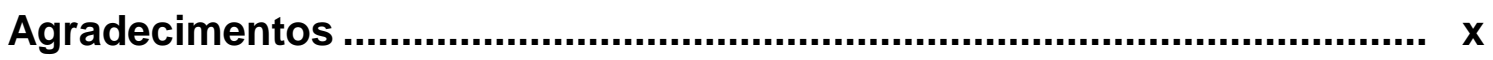

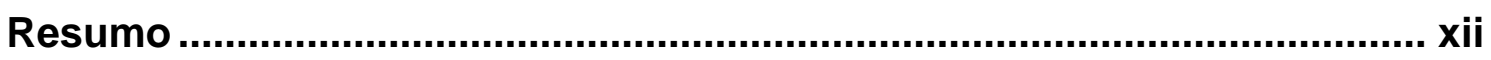

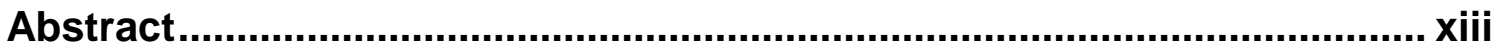

1 INTRODUÇÃO .............................................................................. 1

1.1 Sistemas costeiros e o ecossistema manguezal.............................. 1

1.2 Técnicas de Sensoriamento Remoto aplicadas ao estudo de

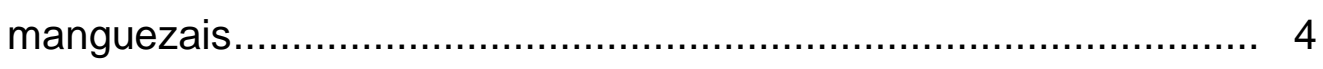

1.2.1 O programa Landsat ..................................................... 10

1.2.2 Medidas de métricas da paisagem ................................... 12

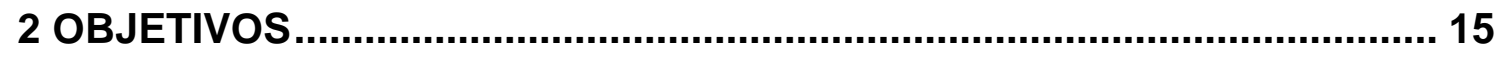

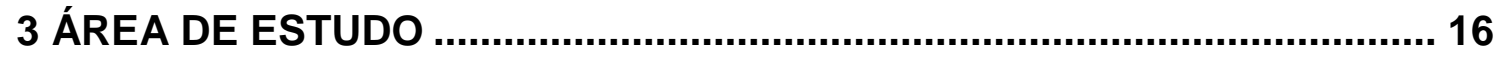

3.1 Aspectos gerais e delimitação da área de estudo.............................. 16

3.2 Gênese e geomorfologia........................................................... 18

3.3 Processos costeiros atuais .......................................................... 19

3.4 Aspectos da ocupação humana na Baixada Santista ....................... 20

3.5 Os manguezais da Baixada Santista ............................................... 22

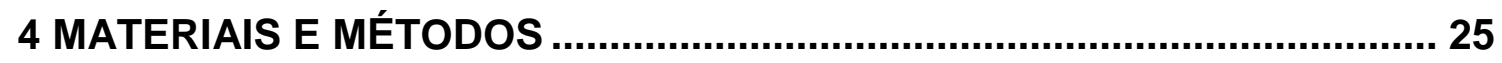

4.1 Conjunto de imagens Landsat e mosaico das cenas ........................ 27

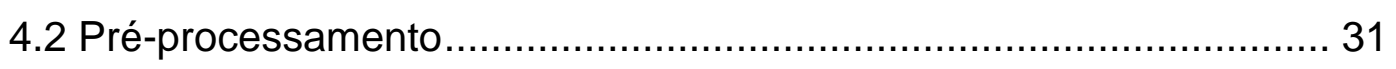

4.2.2 Correção Geométrica....................................................... 31

4.2.2 Correção Atmosférica ..................................................... 34

4.3 Dados auxiliares: fotografias aéreas verticais analógicas e digitais, imagens Quickbird, fotografias aéreas oblíquas, MDE e maré

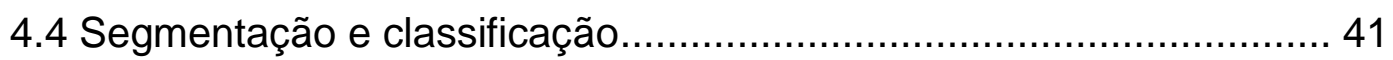

4.5 Cálculo de Índices de Vegetação e métricas de paisagem................. 44 
4.6 Estruturação do Banco de Dados baseado em um Sistema de Informações Geográficas ............................................................ 45

5 RESULTADOS E DISCUSSÃO

5.1 Considerações sobre o processamento digital de imagens ................ 46

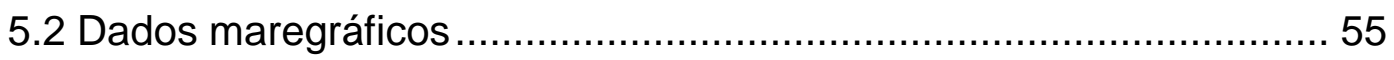

5.3 Mudanças na cobertura de manguezais do Sistema Estuarino

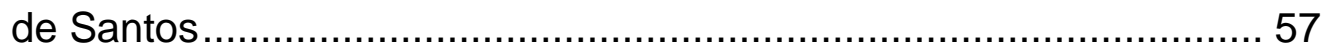

5.4 Métricas da estrutura da paisagem ao nível da classe "manguezal" para o Sistema Estuarino de Santos............................ 67

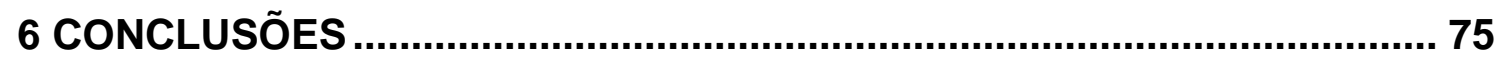

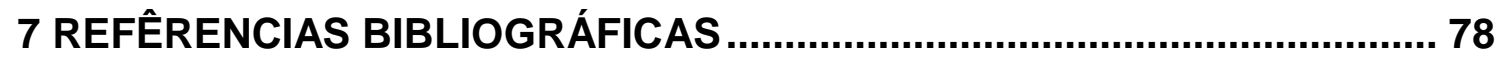

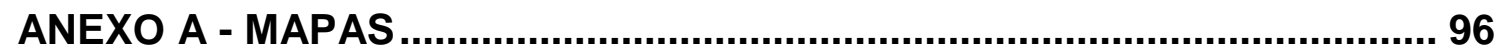

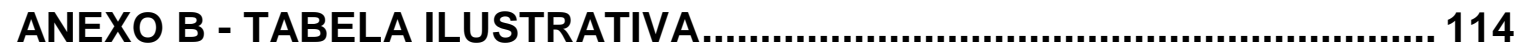




\section{Lista de Figuras}

Figura 1 Localização da área de estudo e principais toponímias relativas a ilhas, canais estuarinos e rios (Fonte: carta topográfica SF-23-Y-DIV-3, IBGE). A imagem é uma composição colorida das bandas 453 do satélite Landsat TM nos canais RGB, respectivamente, do ano de 2010.

Figura 2 Parte da Carta Tática de Sensibilidade Ambiental ao Derramamento de Óleo. Bacia de Santos - de Bertioga à Barra do Una - SP (SAN 14 - 2007). Em tom de vermelho nota-se a distribuição dos manguezais na área de estudo. Extraído de Gherardi \& Cabral (2007).

Figura 3 Esquema conceitual dos métodos empregados no presente estudo.

Figura 4 Localização das cenas Landsat para o estado de São Paulo, enfatizando àquelas que foram utilizadas no presente trabalho (em vermelho) e destacando a área de estudo (em amarelo).

Figura 5 Mosaico de fotografias aéreas obtidas através de levantamento realizado no ano de 2001 (as coordenadas estão em Sistema de Referência UTM em relação ao meridiano 23S).

Figura 6 Detalhes de fotografias aéreas da região do Canal da Cosipa (Cubatão) em 1962 (esquerda) e em1994 (direita).

Figura 7 Imagens Quickbird de 2008: (a) entorno de Cubatão, (b) entorno de manguezais no município de Praia Grande e São Vicente e (c) entorno do Largo do Candinho (Canal da Bertioga).

Figura 8 Fotografias áreas oblíquas da região de Cubatão (esquerda) e Canal da Bertioga (extraídas do site www.imagensaereas.com.br).

Figura 9 Exemplo de mosaico realizado em dois WRS distintas e recorte para a área de estudo.

Figura 10 Imagens de NDVI e respectivos histogramas de freqüência para os anos de 1985 e 1989, sem e com a aplicação da correção atmosférica

Figura 11 Imagens de NDVI e respectivos histogramas de freqüência para os anos de 1992 e 1995, sem e com aplicação da correção atmosférica. 
Figura 12 Imagens de NDVI e respectivos histogramas de freqüência para os anos de1999 e 2002, sem e com aplicação da correção atmosférica.

Figura 13 Imagens de NDVI e respectivos histogramas de freqüência para os anos de 2005 e 2008, sem e com aplicação da correção atmosférica

Figura 14 Imagens de NDVI e respectivos histogramas de freqüência para o ano de 2010, sem e com aplicação da correção atmosférica.

Figura 15 Parte da imagem do ano de 2008, nas proximidades da parte oeste do Canal da Bertioga, mostrando o procedimento realizado na delimitação das áreas de manguezal. a) Composição RGB 7/4 $5 / 34 / 2$; b) imagem segmentada sobre a composição; c) área classificada; d) comparação com imagem Quickbird.

Figura 16 Fotografias aéreas oblíquas da região mostrada na figura 15, mostrando as áreas de manguezal na porção oeste do canal da Bertioga. Fonte: www.imagensaereas.com.br.

Figura 17 Dados de maré referentes aos dias de aquisição de algumas imagens utilizadas neste trabalho (horário local).

Figura 18 Composição falsa-cor R4G5B3 da região do Mar Pequeno e Largo de São Vicente, dos anos de 1995 (a), 1999 (b) e 2005 (c), evidenciando a presença de baixios. .56

Figura 19 Evolução da cobertura dos manguezais no entorno da llha Barnabé no período compreendido entre 1985 e 2010. As figuras na parte superior (a-h) correspondem a imagens de NDVI em pseudocor, enquanto as na parte inferior, em maior detalhe, contém as delimitações obtidas pela classifica-ção, correspondentes aos anos (a-i)1985, (b) 1989, (c) 1992, (d-j) 1995, (e) 1999, (f) 2005, (g) 2008 e (k-h) 2010. 59

Figura 20 Evolução da cobertura dos manguezais no entorno do Canal da Bertioga, próximo ao Canal de Piaçaguera. As figuras na parte superior (a-c) correspondem a imagens de NDVI em pseudocor, e as na parte inferior contém as delimitações obtidas pela classificação, correspondentes aos anos (a-d)1985, (b-e) 1989 e (c-f) 2010 . 
Figura 21 Detalhe de área degradada ao Norte da llha Barnabé mostrando aparente recomposição natural entre 1994 (a, fotografia aérea) e 2008 (b, imagem Quickbird).

Figura 29 Manguezais associados a llha dos Bagres e ao leste do Canal da Cosipa. A esquerda as imagens de NDVI em pseudocor e a direita as respectivas classificações (a-c:1985 e b-d: 2010).

Figura 30 Fotografia aérea oblíqua do empreendimento da Embraport supressão de manguezais verificados a partir da imagem de 2008. (Fonte: www.imagensaereas.com.br).

Figura 31 Estágios sucessionais na cobertura de área classificada como manguezal em área na porção oeste do Canal da Cosipa. De 1985 a 2010 (a-i), contendo toda a série de imagens analisadas, e NDVI em pseudocor do ano de 1985 (j) e 2010 (k).

Figura 32 Detalhe em fotografia aérea obliqua da região com alta dinâmica de recomposição de vegetação mostrada na figura 32. (Fonte: www.imagensaereas.com.br).

Figura 33 Principais áreas (assinaladas em branco) da área de estudo onde houve dinâmica no uso e ocupação do solo, relacionadas principalmente a supressão de manguezais pela ocupação urbana desordenada. As mudanças ocorridas podem ser verificadas nos mapas do Anexo A.

Figura 34 Detalhe da área de manguezais no Canal da Bertioga. Em verde são os manguezais classificados para o ano de 2010, e em vermelho as áreas ocupadas por manguezais em 1985.

Figura 36 Gráfico mostrando a evolução temporal da área e do perímetro total dos manguezais no período estudado.

Figura 37 Gráfico mostrando a evolução temporal da área e do número de manchas dos manguezais no período estudado.

Figura 38 Gráfico do comportamento da maré e dos valores médios de NDVI no período estudado.

Figura 39 Gráfico mostrando a evolução temporal das áreas médias de "manchas" de mangue e de seu número no período estudado.

Figura 40 Gráfico mostrando a evolução temporal do índice médio de forma e a área total dos manguezais no período estudado.

Figura 41 Gráfico mostrando a evolução temporal do NDVI médio e greeness médio para os manguezais do Sistema Estuarino de Santos. 
Figura 42 Gráfico mostrando a evolução temporal do NDVI médio e greeness médio, ao nível de manchas... 


\section{Lista de Tabelas}

Tabela 1 Medidas de áreas de manguezais e outros ambientes associados no estado de São Paulo, realizadas pelo levantamento publicado por Herz (1991).

Tabela 2 Características dos sensores TM e ETM+, carreados a bordo dos satélites Landsat 5 e 7, respectivamente (Fonte: Chander et al., 2009).

Tabela 3 Áreas de manguezais relacionadas ao Sistema Estuarino de Santos, publicadas no trabalho de Herz (1991). Unidades em $\mathrm{km}^{2}$.

Tabela 4 Datas e principais informações das imagens utilizadas como base no presente trabalho. Informações fornecidas pelo DGI - INPE

Tabela 5 Valores de subtração dos ND's originais das imagens obtidos através da correção atmosférica.

Tabela 6 Métricas da estrutura da paisagem da classe "manguezal" para o Sistema Estuarino de Santos no decorrer do período analisado. Também inclusos as médias de NDVI e alturas de maré. 


\section{Lista de Mapas}

Mapa 1 Distribuição dos manguezais no ano de 1985........................................ 96

Mapa 2 Distribuição dos manguezais no ano de 1989. ........................................ 96

Mapa 3 Distribuição dos manguezais no ano de 1992. ....................................... 97

Mapa 4 Distribuição dos manguezais no ano de 1995 ....................................... 97

Mapa 5 Distribuição dos manguezais no ano de 1999. ........................................ 98

Mapa 6 Distribuição dos manguezais no ano de 2002. ...................................... 98

Mapa 7 Distribuição dos manguezais no ano de 2005..................................... 99

Mapa 8 Distribuição dos manguezais no ano de 2008. ....................................... 99

Mapa 9 Distribuição dos manguezais no ano de 2010 .....................................100

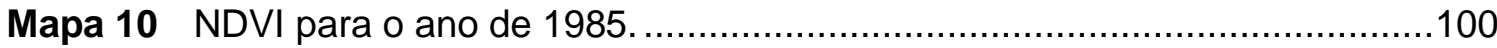

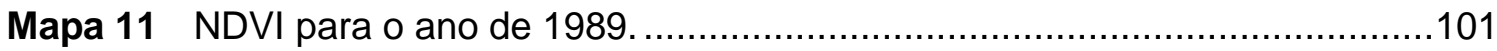

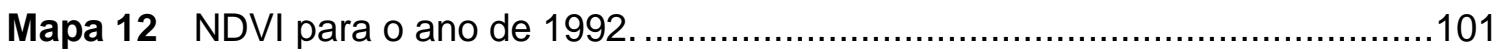

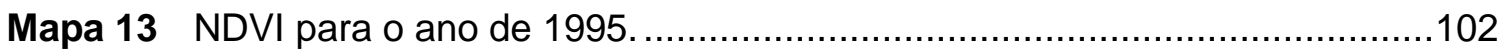

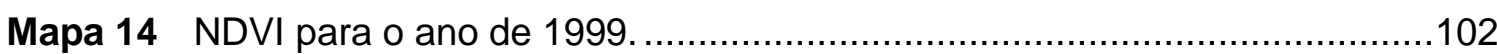

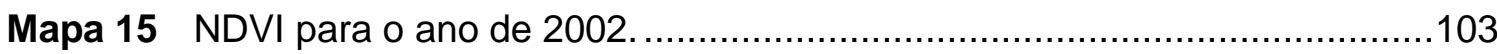

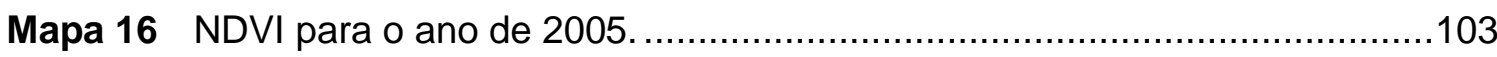

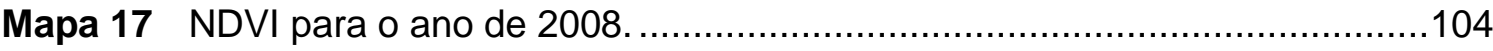

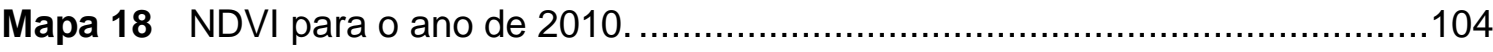

Mapa 19 Comparação pós-classificação entre os anos de 1989 e 1985 ..................105

Mapa 20 Comparação pós-classificação entre os anos de 1992 e 1989..................105

Mapa 21 Comparação pós-classificação entre os anos de 1995 e 1992 ..................106

Mapa 22 Comparação pós-classificação entre os anos de 1999 e 1995..................106

Mapa 23 Comparação pós-classificação entre os anos de 2002 e 1999..................107

Mapa 24 Comparação pós-classificação entre os anos de 2005 e 2002 ...................107

Mapa 25 Comparação pós-classificação entre os anos de 2008 e 2005 ...................108

Mapa 26 Comparação pós-classificação entre os anos de 2010 e 2008..................108

Mapa 27 Comparação dos valores de NDVI entre os anos de 1989 e $1985 . . . . . . . . . . . .109$

Mapa 28 Comparação dos valores de NDVI entre os anos de 1992 e 1989.............109

Mapa 29 Comparação dos valores de NDVI entre os anos de 1995 e 1992 .............110

Mapa 30 Comparação dos valores de NDVI entre os anos de 1999 e $1995 \ldots \ldots \ldots \ldots . . . .110$

Mapa 31 Comparação dos valores de NDVI entre os anos de 2002 e 1999.............111

Mapa 32 Comparação dos valores de NDVI entre os anos de 2005 e 2002.............111 
Mapa 34 Comparação dos valores de NDVI entre os anos de 2008 e $2005 \ldots \ldots \ldots \ldots . . .112$

Mapa 35 Comparação dos valores de NDVI entre os anos de 2010 e $2008 \ldots \ldots \ldots \ldots . . . .112$

Mapa 36 Comparação pós-classificação entre os anos de 2005 e 2002. .................113

Mapa 37 Comparação dos valores de NDVI entre os anos de 2010 e $1985 \ldots \ldots \ldots \ldots . . .113$ 


\section{Agradecimentos}

Os meus sinceros agradecimentos ao orientador e amigo Prof. Dr. Luis Américo Conti (Meco), pela confiança depositada e sempre presença compartilhando seus conhecimentos, até os últimos momentos.

Ao Prof. Dr. Valdenir Veronese Furtado (Foca), por estar sempre disposto a discutir qualquer tema em sua alçada, principalmente relacionados à Oceanografia Geológica, e pelas conversas diversas ao longo de todo o mestrado, principalmente sobre o Tricolor Paulista.

Aos queridos colegas de laboratório e da Oceanografia Geológica do IOUSP, Pisetta, Betinho, Carlos, Marcelo e Samara, sempre presentes.

Aos professores que muito contribuíram em minha formação nessa jornada na pós-graduação, Profa. Dra. Yara Schaeffer-Novelli, Prof. Dr. Teodoro Isnard Ribeiro de Almeida, Prof. Dr. Luiz Bruner de Miranda e Profa. Dra. Dilce de Fátima Rossetti.

Ao Laboratório de Informática Geológica (LIG- IGC) pelo apoio nas fases iniciais deste trabalho e por sempre estar de portas abertas quando algum programa específico é requisitado.

Ao Departamento de Dasonomia do Instituto Florestal do estado de São Paulo por disponibilizarem o acervo de fotografias aéreas digitais e ortorretificadas da Baixada Santista.

Ao Prof. Dr. Moysés Gonsalez Tessler, por disponibilizar todo o seu acervo de fotografias aéreas em formato analógico da Baixada Santista e, ainda, por me apoiar profissionalmente.

Ao Prof. Dr. Joseph Harari, por fornecer os dados de maré utilizados neste trabalho.

À Prof. Dra. Rosalinda Carmela Montone, coordenadora do programa de pós-graduação em Oceanografia Química e Geológica, pela sempre simpatia e disposição em ajudar no que preciso.

Ao amigo Leandro Ponsoni, pela ajuda com o Matlab na fase final dessa dissertação. 
À Dra. Marília Cunha-Lignon, por compartilhar informações sobre aspectos gerais dos manguezais da Baixada Santista e ainda por proporcionar minha ida a campo em seu projeto relacionado a manguezais de Cananéia.

Ao Dr. Ricardo Palamar Menghini (Menga), por me incluir nas proveitosas idas a campo e por compartilhar todo o seu conhecimento relacionado aos manguezais, de forma geral.

A todos os funcionários da biblioteca "Prof. Dr. Gelso Vazzoler", sempre muito prestativos.

As Periplaneta americana, companheiras de laboratório nas solitárias madrugadas em que parte dessa dissertação foi redigida.

A Fundação de Amparo a Pesquisa do Estado de São Paulo (FAPESP), pela concessão de bolsa através do Processo no 2008/51579-0, a qual possibilitou a concretização do presente trabalho.

A meus pais, Carlos e Fátima, por proporcionarem as condições adequadas para que eu chegasse até aqui.

A inestimável Inês, sem você do meu lado o esforço pra chegar até aqui teria sido muito mais penoso. 


\section{Resumo}

Este trabalho examina as características evolutivas de manguezais (Sistema Estuarino de Santos, estado de São Paulo) através da oportunidade de acessar os impactos cumulativos de mudanças ambientais e suas consequências na vegetação. Para atingir este objetivo foi testado uma metodologia de detecção de mudança baseado no processamento de 9 imagens Landsat. Fora estabelecido uma rotina de trabalho o qual proporcionou a extração de bosques de mangue através de uma classificação orientada a objetos. Análises subseqüentes de índices de vegetação foram efetuadas para caracterizar a evolução de aspectos espectrais relativos aos manguezais. Também foram aplicados a extração de medidas de métricas relativas a estrutura da paisagem. Dados auxiliares, como um Modelo Digital de Elevação e imagens de alta resolução espacial propiciaram um melhor entendimento das análises efetuadas. Todos os dados gerados foram integrados em Sistema de Informação Geográfica (SIG). Os resultados apontaram que a área como um todo apresentou tendências de recobrimento de manguezais em termos de área e vigor entre 1985 e 1999, quando se tronou relativamente estável, mostrando variações locais de regeneração e degradação. A avaliação geral das formas e padrões dos bosques de manguezais baseados na delimitação de áreas e medidas da estrutura da paisagem mostraram melhores resultados quando comparados com análises de índices de vegetação, que parecem ser sensíveis a flutuações ambientais ocorridas quando da aquisição das imagens.

Palavras chave: manguezais, Landsat, Baixada Santista, detecção de mudança 


\begin{abstract}
This work examines the evaluative characteristics of an impacted mangrove system (Santos/São Vicente region, São Paulo State) providing opportunities to assess the cumulative impact of environmental changes and their consequences on the vegetation. To achieve this objective it was tested a methodology of Time Change Detection techniques (TCD) based on the processing of series of 9 Landsat images. It was established a detailed study framework based on the individual mangroves extraction from object oriented classification. Subsequently analysis of vegetation indices values was performed in order to characterize the evolution of the spectral aspects of the mangroves. This work also assessed models of landscape patterns and structure. Other types of data such as High Resolution Satellite images, Aerial photographs and Satellite altimetry were also used to better understand the whole estuarine system. Thus it was also proposed the implementation of a geographically referenced database in a GIS in order to analyze variables which could affect mangrove dynamics. The results of the analysis demonstrated that the area as a whole confirms a tendency of recovering in terms of area and vigor since 1985 until 1999 when it became quite stable showing local variations in terms of recovering and degradation. The overall evaluation of form and shape of the mangrove forests, based in the delimitation of areas and landscape metrics, showed better results when comparing with the Vegetation Indices analysis, which seems quite influenced by the environmental conditions at the time satellite images were taken.
\end{abstract}

Keywords: mangrove, Landsat, Baixada Santista, change detection 


\section{INTRODUÇÃO}

\subsection{Sistemas costeiros e o ecossistema manguezal}

Os sistemas costeiros são caracterizados por serem zonas de transição entre o oceano e o continente, e apresentam um elevado grau de complexidade nos processos geológicos, físicos, químicos e biológicos que neles atuam. Esses sistemas estão, historicamente, ligados às atividades humanas e, cerca de $60 \%$ das grandes cidades, que se encontram distribuídas ao redor da Terra, estão localizadas nas suas proximidades (Geophysics Study Committee, 1977; apud Miranda et al., 2002).

Os estuários constituem um dos principais ambientes costeiros, uma vez que possuem relevada importância ecológica, econômica e recreativa. Do ponto de vista hidrodinâmico, um estuário é definido classicamente por Pritchard (1955) e Cameron \& Pritchard (1963), como um corpo de água costeiro semifechado que possui uma conexão livre com o oceano aberto, onde a água do mar é mensuravelmente diluída pela água doce oriunda da drenagem continental. Essa definição permite inferir que tanto a circulação como os processos de mistura estão intimamente influenciados pelas bordas laterais que o delimitam (sua geometria), pela entrada de água salgada bem como pela descarga de água doce e pela circulação da área oceânica adjacente (Pritchard, 1967).

São nesses ambientes estuarinos, localizados em regiões tropicais e subtropicais, que se desenvolvem os manguezais. De acordo com a definição apresentada por Schaeffer-Novelli (1995), este ecossistema costeiro, de transição entre os ambientes marinho e terrestre, sujeito ao regime das marés, é constituído de espécies vegetais lenhosas típicas (angiospermas), além de micro e macroalgas (criptógamas), adaptadas à flutuação de salinidade e caracterizadas por colonizarem sedimentos predominantemente pelíticos, com baixos teores de oxigênio. Uma fauna igualmente adaptada as características peculiares deste ambiente também compõem esse ecossistema. 
Dentre os inúmeros fatores que fazem do manguezal um ecossistema único e de extrema importância, podemos destacar (Soares, 1997):

- sua vegetação mantém o equilíbrio da produção secundária dos estuários e formam a base de grande parte das estruturas tróficas de espécies com relevância econômica e/ou ecológica, através da constante produção de matéria orgânica ao longo do ano;

- é área de abrigo, reprodução, desenvolvimento (berçário) e alimentação de espécies marinhas, estuarinas, límnicas e terrestres;

- muitas espécies são endêmicas dos manguezais, sendo esse ecossistema importante em termos da biodiversidade global;

- é área de pouso (alimentação e repouso) para diversas espécies de aves migratórias, ao longo de suas rotas de migração;

- protege a linha de costa, evitando erosão da mesma e assoreamento dos corpos de água adjacentes;

- é um filtro biológico natural de poluentes e;

- é fonte de alimento e produtos diversos para comunidades tradicionais que vivem em suas áreas vizinhas.

As condições ideais para o desenvolvimento dos manguezais, considerando parâmetros climatológicos, são: temperaturas médias acima de $20^{\circ} \mathrm{C}$, média das temperaturas mínimas não inferior a $15^{\circ} \mathrm{C}$, amplitude térmica anual menor que $5^{\circ} \mathrm{C}$ e precipitação acima de $1500 \mathrm{~mm} / \mathrm{ano}$, sem prolongados períodos de seca (Walsh, 1974). Tais fatores explicam o controle geográfico que a latitude exerce na sua ocorrência.

No contexto brasileiro, os manguezais possuem uma ampla distribuição geográfica, podendo ser encontrados até os limites latitudinais entre $04^{\circ} 30^{\prime} \mathrm{N}$ (Rio Oiapoque) e $28^{\circ} 30$ 'S (Laguna, SC). De acordo com Saenger et al. (1983) há aproximadamente $25.000 \mathrm{~km} 2$ de florestas de mangue no Brasil, no entanto Herz (1991) estima uma área aproximada de 10.000 km2.

Schaeffer-Novelli et al. (1990) propuseram uma divisão em segmentos do litoral brasileiro com base numa avaliação da variação das principais forçantes que determinam a estrutura de um manguezal. Tais autores descrevem 7 espécies, distribuídas em 4 gêneros, de plantas típicas de mangue no Brasil, são elas: Rhizophora mangle, $R$. harrisonii, $R$. racemosa, 
Avicennia schaueriana, A. germinans, Laguncularia racemosa e Conocarpus erecta. Destas, apenas $R$. mangle e $L$. racemosa são encontradas desde 0 Amapá até Santa Catarina. A. schaueriana distribui-se desde Santa Catarina até o Pará, A. germinans do Amapá ao Rio de Janeiro e $R$. harrisonii e $R$. racemosa do Amapá ao Maranhão.

Apesar de sua robusta aparência os manguezais são ecossistemas frágeis, sensíveis a flutuações das condições ambientais, bem como à pressão exercida pelas atividades antrópicas. As atividades humanas ligadas à economia e crescimento das populações vêm aumentando ao longo das costas tropicais ao longo dos anos (Field, 1995). Devido a esta pressão, a explotação de áreas de manguezais, embora insustentável, são comumente não notificadas e muito menos quantificadas.

Esforços internacionais vêm demonstrando uma preocupação com este ecossistema e talvez o mais notório deles seja a Convenção de Ramsar ${ }^{1}$, um tratado intergovernamental que provê uma estrutura de ações no âmbito nacional e cooperação internacional para a conservação e o uso sábio de terras úmidas (wetlands) e seus recursos. Ele foi negociado ao longo da década de 1960 por países e organizações não-governamentais que estavam atentas para o crescimento da perda e degradação de terras úmidas que serviam de habitats para aves migratórias. $O$ tratado foi adotado na cidade iraniana de Ramsar em 1971 e tomou força em 1975. Dentre os ecossistemas contemplados por esta convenção estão os manguezais.

No Brasil, o Código Florestal de 1965 estabelece o mangue como Área de Preservação Permanente (APP), e a Resolução CONAMA N. 369 de 28 de março de 2006 estabelece que as áreas de mangue não podem sofrer supressão de sua vegetação ou qualquer tipo de intervenção, salvo em casos de utilidade pública.

Dada a importância dos manguezais, a sua fragilidade e a intervenção antrópica que este ecossistema sofreu historicamente, é imperativo a utilização de técnicas que visem monitorar este ambiente, afim de que se tornem aliadas 
na detecção de rápidas mudanças e possíveis intervenções na ação de medidas mitigadoras.

A recém-publicada segunda edição do "World Atlas of Mangroves" (Spalding, et al., 2010) traz informações atualizadas da distribuição de manguezais ao redor do mundo, e ressalta a necessidade de se possuir uma base cartográfica atualizada para fins de monitoramento.

Tendo em vista esta crescente necessidade de monitoramento, é notória a utilização de produtos de Sensoriamento Remoto no mapeamento dos manguezais, e a utilização destas técnicas serão discutidas a seguir.

\subsection{Técnicas de Sensoriamento Remoto aplicadas ao estudo de manguezais}

Há centenas de trabalhos na literatura que utilizam e/ou discorrem sobre técnicas de sensoriamento remoto aplicadas no estudo de manguezais. Embora este grande número de trabalhos pareça exagerado, tal fato pode ser explicado pela facilidade que o imageamento por sensoriamento oferece quando comparado a técnicas empregadas in situ:

- Continuidade espacial da imagem, podendo cobrir grandes áreas simultaneamente;

- Possibilidade de mapear lugares muitas vezes inacessíveis ou de difícil acesso;

- Possibilidade de mapear áreas rapidamente e com baixo custo, facilitando assim o manejo costeiro;

- Possibilidade de extrair informações ecológicas e do estado de conservação de bosques e;

- Capacidade de detectar mudanças temporais, avaliando muitas vezes os impactos causados por desastres naturais e/ou antrópicos, como a pressão exercida nas últimas décadas pelas fazendas de cultivo de camarões, entre outras vantagens; 
De maneira geral e simplista, três grandes grupos de tipos de sensoriamento remoto são identificados, a saber: fotogrametria (empregada nas tradicionais fotografias aéreas), o sensoriamento remoto multi $e$ hiperespectral (operando nas regiões do visível, infravermelho próximo e de infravermelho de ondas curtas do espectro eletromagnético) e o sensoriamento remoto por radar (que opera na região do microondas). Jensen (2009) discorre sobre os princípios de cada técnica e mostra suas principais aplicações.

Considerando o mapeamento espaço-temporal dos manguezais em sistemas costeiros complexos, onde se encontram sistemas estuarinos bem desenvolvidos, e com intervalos de tempo da ordem anual, verificando tendências naturais e intervenções antrópicas ocorridas nesta escala de tempo, os produtos utilizados se limitam a imagens multiespectrais e, em menor escala, a fotografias aéreas, uma vez que estas últimas não possuem cobertura temporal curta e é necessário um grande esforço para se cobrir a totalidade da área dependendo do local que se quer estudar, o que nem sempre é possível devido ao elevado custo e dificuldades logísticas.

Como ressalta Green et al. (1998), contrapondo-se a mais de 80 anos de utilização de fotografias aéreas, é muito difícil traçar um panorama de aplicações de sensoriamento remoto em áreas de manguezais. Os autores afirmam que tal fato não é razão para o questionamento do sucesso de aplicação dessa técnica, mas provavelmente reflexo da pouca ênfase que órgãos governamentais, agências ambientais ou firmas de consultoria dão na publicação dos resultados na literatura científica.

Em muitos casos, dados de sensores orbitais nem sempre são disponíveis, o que leva alguns estudos a utilizarem fotografias aéreas. Soma-se o fato de que nos últimos anos alguns autores vêm destacando a vantagem de utilizar fotografias aéreas em trabalhos que requerem uma maior acurácia espacial, utilizando-as, por exemplo, em uma escala de trabalho local, e também em trabalhos que priorizem dados históricos, acessando fotografias aéreas adquiridas em datas anteriores aos lançamentos dos satélites (Terchunian et al., 1986; Tam et al., 1997; Chauvaud et al., 1998; DahdouhGuebas et al., 2000; Manson et al., 2001; Dahdouh-Guebas et al., 2002; Kairo et al., 2002; Verheyden et al., 2002; Lucas et al., 2002; Manson et al., 2003; 
Dahdouh-Guebas et al., 2004; Benfield et al., 2005; Dahdouh-Guebas et al., 2006; Mitchell et al., 2007).

Os trabalhos que envolvem fotografias aéreas utilizam, em sua maioria, da interpretação visual na discriminação dos manguezais, e o sucesso de tal processo é dependente, em grande parte, do treinamento que a pessoa possui e do conhecimento prévio que a mesma possui do local.

Muitos estudos utilizam de fotografias aéreas como complemento de dados de sensores orbitais (Panapitukkul et al., 1998; Ramírez-García et al., 1998; Gao, 1998; Kovacs et al., 2001; Mitchell \& Lucas, 2001; Sulong et al., 2002; Giri et al., 2007; Giri et al., 2008).

No que diz respeito ao sensoriamento remoto multiespectral, diversos trabalhos utilizaram do processamento digital de imagens para extrair informações sobre os manguezais, principalmente através dos sistemas sensores Landsat TM e SPOT XS. Embora haja um grande número de trabalhos que vem utilizando de tais técnicas, não há consenso na literatura sobre qual o melhor processamento para a discriminação e quantificação de áreas de manguezais.

As técnicas de processamento de imagens empregadas no mapeamento de manguezais incluem a Interpretação Visual, Índices de Vegetação como o NDVI (do inglês, Normalized Difference Vegetation Index), Classificação Não-Supervisionada, Classificação Supervisionada, Razões entre Bandas, Análise de Componentes Principais, IAF (Índice de Área Foliar) e Redes Neurais Artificiais (Aschbascher et al., 1995; Long \& Skewes, 1996; Green et al., 1997; Ramírez-García et al., 1998; Panapitukkul et al., 1998; Gao, 1998; Green et al., 1998; Rasolofoharinoro et al.,1998; Blasco et al., 1998; Gao, 1999; Manson, et al., 2001; Blasco, et al., 2001, Sulong et al., 2002; Souza Filho \& Paradella, 2002; Wang et al., 2003, Cohen \& Lara, 2003; Mas, 2004; Tong et al., 2004; Souza Filho \& Paradella, 2005; Souza Filho, 2005; Souza Filho et al., 2006; Reddy et al., 2007). Tais processamentos forneceram bases para diversas aplicações como 0 inventário de área ocupadas desse ecossistema, o manejo de áreas costeiras, acompanhamento de atividades de aquicultura e análises de mudança. 
Alguns trabalhos empregaram o sensor ASTER, que possui 14 bandas espectrais (2 no domínio do visível, 1 no infra-vermelho próximo, 6 no infravermelho de ondas curtas e 5 no infra-vermelho termal), no mapeamento de manguezais (Saito et al., 2003; Vaiphasa et al., 2006). Ainda, ao utilizar este sensor, Vaiphasa et al. (2006) empregaram uma técnica utilizando probabilidade Bayesiana incorporando dados ecológicos no desenvolvimento de um pós-classificador.

No que diz respeito a análises de mudança em manguezais, uma variedade de métodos foram aplicadas, incluindo comparações pósclassificação, diferenças de índices de vegetação e subtração de imagens (Mas, 1999; Kovacs et al., 2001; Hosking et al., 2001, Giri et al., 2007; Thu \& Populus, 2007; Giri et al, 2008; Giri \& Muhlhausen, 2008; Paling et al., 2008). Mais recente, técnicas de deteç̧ão de mudança baseado em orientação a objetos (Conchedda et al., 2008) e em árvores de decisão, através de dados incorporados em um SIG (Liu et al., 2008), vêm sendo utilizadas.

Outro grupo de imagens de sensoriamento remoto utilizados no mapeamento de manguezais são aquelas obtidas por sensores de alta resolução espacial, como o lkonos e Quickbird, que possuem 1 banda pancromática (de maior resolução espacial), 3 bandas que operam no visível (azul, verde e vermelho) e 1 banda no infra-vermelho (características em comum de ambos os sensores). Assim como fotografias aéreas, tais imagens permitem a realização de estudos em escalas locais e também a aferição de classificações supervisionadas em imagens de menor resolução espacial, porém com a vantagem de realizarem uma cobertura sinóptica de uma mesma área (salvo condições de nuvens) e também de possuírem uma banda no infravermelho próximo. Exemplos de estudos utilizando tais imagens podem ser encontrados em Wang et al. (2004a,b), Kovacs et al. (2005), Kanniah et al. (2007), Saleh (2007), Everitt et al. (2008) e Proisy et al. (2007). 
Quanto ao sensoriamento remoto hiperespectral, de alta resolução espectral ${ }^{2}$ e grande número de bandas (da ordem de dezenas), é destacado no estudo de manguezais pela maior capacidade de discriminação de espécies de árvores e também da possibilidade de se quantificar a biomassa verde (Lucas et al.,2003; Held et al.,2003; Jusoff et al.,2006).

O sensoriamento remoto ativo ${ }^{3}$ por radar, especificamente o Radar de Abertura Sintética (SAR, da abreviatura do termo em inglês Synthetic Aperture Radar) são amplamente utilizados nos estudos de manguezais envolvendo, principalmente, inferências de biomassa e parâmetros estruturais das árvores, como a altura do dossel (Wang \& Imhoff,1993; Proisy et al., 1996; Mougin et al., 1999; Proisy et al., 2000; Proisy et al., 2001; Proisy et al., 2002; Thirion et al., 2003; Kovacs et al., 2006; Lucas et al., 2007). Alguns estudos comprovaram a eficácia da utilização de SAR conjuntamente com sensoriamento remoto óptico (Aschbacher et al., 1995; Sery et al., 1995; Ramsey \& Jensen, 1996; Ramsey et al., 1998; Pasqualini et al., 1999; Mitchell \& Lucas, 2001; Souza Filho \& Paradella, 2002; Held et al., 2003; Cohen \& Lara, 2003; Souza Filho \& Paradella, 2005; Souza Filho et al., 2006).

Mais recentemente, ainda em se tratando de sensoriamento remoto ativo, alguns trabalhos utilizando LIDAR (do inglês Light Detection and Ranging) vêm sendo aplicados na deteç̧ão de alturas do dossel e da topografia do terreno simultaneamente (Simard et al., 2006; Simard et al., 2008; Zhang, 2008 e Proisy et al., 2009).

No contexto brasileiro, Herz (1991) publicou o primeiro e único estudo consolidado sobre a quantificação das áreas de manguezal de todo o Brasil. Baseado em imagens de sensores remotos aerotransportados (RADAR GEMS1000), produzidas pelo projeto RADAMBRASIL (1975-1978), compilou as

2 Definição de resolução espectral no item 1.2.1.

3 O sensor emite a radiação eletromagnética, onde esta interage com a superfície terrestre e retorna ao mesmo. Possui a vantagem de poder operar sob condições atmosféricas adversas, i.e., com nuvens, uma vez que a faixa espectral em que opera não sofre interferência das mesmas. 
informações sobre os mangues brasileiros em um macro zoneamento apresentado na escala de 1:250.000, em que foram delimitados limites e aplicados cálculos de áreas. Trata-se do estudo mais detalhado publicado até a época e que serviu como base para diversos programas de conservação e gerenciamento das áreas costeiras.

Ainda no trabalho de Herz (1991) o autor realizou uma caracterização estrutural dos manguezais do estado de São Paulo com base na interpretação de fotografias áreas, produzindo produtos cartográficos em escalas da ordem de 1:50.000, agrupando os bosques de mangue em seis grupos distintos: Mangue Alto, Mangue Baixo, Mangue Degradado, Mangue Alterado, Apicum ${ }^{4} \mathrm{e}$ Marismas ${ }^{5}$. Os resultados obtidos para o estado se encontram na tabela 1.

Se considerarmos somente as áreas com coberturas de manguezais "sadios" na tabela 1, ou seja, aquelas que não sofreram degradação ou foram alteradas, temos que para o estado de São Paulo havia, na época do levantamento, 203,261 $\mathrm{km}^{2}$.

$\mathrm{Na}$ região em questão os sistemas costeiros que maior possuem representatividade em cobertura de áreas de manguezal são os Sistema Costeiro de Cananéia-Iguape e o Sistema Estuarino de Santos. O primeiro encontra-se relativamente em alto grau de preservação (salvo áreas próximas a cidade de Iguape) enquanto que o segundo historicamente vem sofrendo com as intervenções humanas, tais como as atividades portuárias, as atividades industriais, a construção de terminais e marinas e a própria expansão urbana.

Após este trabalho, vários outros estudos realizaram aplicações de metodologias empregadas no sensoriamento remoto para o estudo de manguezais no Brasil, em sua maior parte em uma escala local, seja abordando o emprego da técnica, seja quantificando, qualificando ou caracterizando esse ecossistema ou, ainda, enfocando os mais diversos

4 Ecossistema associado ao manguezal, apresentando sedimentos arenosos expostos e com elevada salinidade.

5 Ecossistema de plantas herbáceas situado em zonas entremarés. No Brasil ocorre em latitudes mais altas, às vezes associados às franjas de manguezais e na região sul do país os substitui, por tolerar condições de temperatura mais baixas. 
problemas de origem antrópica (Hadlich et al., 2009; Guimarães et al., 2009, Espinoza \& Rosa, 2009; Zagaglia et al., 2007; Menghini et al., 2007; Carvalho et al., 2007; Thevand \& Gond., 2005; Kampel et al., 2005; Rangel et al., 2001; entre outros).

Tabela 1 Medidas de áreas de manguezais e outros ambientes associados no estado de São Paulo, realizadas pelo levantamento publicado por Herz (1991).

\begin{tabular}{cccc|c}
\hline Área & Mangue Alto & $\begin{array}{c}\text { Mangue } \\
\text { Baixo }\end{array}$ & $\begin{array}{c}\text { Mangue } \\
\text { Alterado }\end{array}$ & \multirow{2}{*}{ Total $\left.\mathbf{( k m}^{2}\right)$} \\
$\left.\mathbf{( k m}^{2}\right)$ & 157,301 & 45,960 & 19,550 & \\
\cline { 1 - 3 } & $\begin{array}{c}\text { Mangue } \\
\text { Degradado }\end{array}$ & Apicum & Marismas & \multirow{2}{*}{240,578} \\
\cline { 1 - 2 } $\begin{array}{c}\text { Área } \\
\left.\mathbf{k m}^{2}\right)\end{array}$ & 8,290 & 7,260 & 2,217 & \\
\hline
\end{tabular}

\subsubsection{O programa Landsat}

A série de satélites do programa Landsat provê a aquisição mais contínua de observações da Terra baseada em satélites. E como tal, se torna um recurso inestimável no monitoramento de mudanças globais e uma fonte primária utilizada no suporte de decisões.

O programa começou no começo de 1972 com o lançamento do primeiro satélite da série, e com o aumento da tecnologia no decorrer do programa, a qualidade das imagens capturadas pelos satélites também aumentavam (Chander, et al., 2009).

Os satélites Landsat podem ser classificados em três grupos, sendo o primeiro deles os satélites Landsat 1, 2 e 3, com o sensor MSS (do inglês Multispectral Scanner), o segundo os satélites Landsat 4 e 5, com o sensor TM (do inglês Thematic Mapper), e o terceiro os satélites Landsat 6 e 7 com os sensores ETM (do inglês, Enhanced Thematic Mapper) e ETM+ (Enhanced Thematic Mapper Plus), respectivamente. O satélite Landsat 6 não chegou a atingir a órbita e falhou em sua missão. 
Antes de traçar as principais diferenças entre cada sensor, cabe algumas definições:

- Resolução Espacial: indica o tamanho do menor objeto que é possível representar na imagem, em outras palavras, determina o tamanho do pixel no terreno;

- Resolução Espectral: indica a quantidade de regiões do espectro eletromagnético nas quais o sensor é capaz de gerar uma imagem, e cada imagem gerada é denominada de banda espectral e;

- Resolução Radiométrica: indica o número de bits utilizados para armazenar o número digital em níveis de cinza (que representa a forma computacional das medidas de radiância obtidas pelo sensor). A resolução radiométrica determina a quantidade máxima de níveis de cinza que podem ser utilizados para representar uma imagem.

A resolução espacial do sensor MSS é de aproximadamente $79 \mathrm{~m}$, sendo este fator limitante pra algumas aplicações.

A data de lançamento, a resolução espacial, espectral e temporal dos sensores TM e ETM+, ambos com faixa imageada de aproximadamente 185 $\mathrm{km}$ e tempo de revisita de 16 dias, são apresentadas na tabela 2.

Tabela 2 Características dos sensores TM e ETM+, carreados a bordo dos satélites Landsat 5 e 7, respectivamente (Fonte: Chander et al., 2009).

\begin{tabular}{|c|c|c|c|c|}
\hline Sensor & $\begin{array}{c}\text { Data de } \\
\text { Lançamento }\end{array}$ & Bandas & $\begin{array}{c}\text { Resolução espectral } \\
(\mu \mathrm{m})\end{array}$ & $\begin{array}{c}\text { Resolução } \\
\text { Espacial (m) }\end{array}$ \\
\hline \multirow{7}{*}{ TM } & \multirow{7}{*}{01 / Mar / 1984} & 1 & $0,452-0,518$ & \multirow{5}{*}{30} \\
\hline & & 2 & $0,528-0,609$ & \\
\hline & & 3 & $0,626-0,693$ & \\
\hline & & 4 & $0,776-0,904$ & \\
\hline & & 5 & $1,567-1,784$ & \\
\hline & & 6 & $10,45-12,42$ & 120 \\
\hline & & 7 & $1,097-2,349$ & 30 \\
\hline \multirow{8}{*}{ ETM+ } & \multirow{8}{*}{15 / Abr / 1999} & 1 & $0,452-0,514$ & \multirow{5}{*}{30} \\
\hline & & 2 & $0,519-0,601$ & \\
\hline & & 3 & $0,631-0,692$ & \\
\hline & & 4 & $0,772-0,898$ & \\
\hline & & 5 & $1,547-1,748$ & \\
\hline & & 6 & $10,31-12,36$ & 60 \\
\hline & & 7 & $2,065-2,346$ & 30 \\
\hline & & 8 & $0,515-0,896$ & 15 \\
\hline
\end{tabular}


O sensor TM possui três bandas no espectro do visível (bandas 1 a 3), uma no infravermelho próximo (banda 4), duas no infravermelho médio (bandas 5 e 7) e uma no infravermelho termal (banda 6). Já o ETM+, além das bandas espectrais em comuns com o sensor TM, possui uma banda pancromática com resolução espacial de $15 \mathrm{~m}$ (banda 8 ).

O sensor TM continua em operação atualmente e, considerando a sua média resolução espacial, torna-se uma poderosa ferramenta na análise multitemporal, imageando áreas do planeta por mais de duas décadas.

Em se tratando de estudos de vegetação, talvez o produto mais utilizado de ambos os sensores seja o Índice de Vegetação por Diferença Normalizada (NDVI, da abreviação do termo em inglês), extraída da razão entre as bandas nas faixas do infravermelho próximo e no vermelho, dada pela equação 1 (aplicada sobre sensores TM e ETM+, no caso):

$$
\text { NDVI }=(\text { Banda } 4-\text { Banda } 3) /(\text { Banda } 4+\text { Banda } 3)
$$

Eq.1

Dentre as aplicabilidades do NDVI destacam-se o mapeamento da vegetação, a medição de sua quantidade e a sua condição em uma determinada área. Dessa forma, o NDVI pode ser utilizado no estudo do ciclo de crescimento da vegetação e na análise de eventuais perturbações.

\subsubsection{Medidas de métricas da paisagem}

A ecologia de paisagens pode ser entendida como "o estudo da estrutura, função e dinâmica de áreas heterogêneas compostas por ecossistemas interativos" (Forman \& Godron, 1986).

No ramo da ecologia de paisagens as medidas de métrica auxiliam na possibilidade de quantificação da estrutura da paisagem.

Imagens obtidas por sensores remotos são uma fonte primária no reconhecimento de habitats, fornecendo assim bases para a aplicação das medidas de métricas. 
Podemos tratar as métricas relativas à paisagem em três níveis (Lang \& Blaschke, 2009):

- Métricas relativas a manchas (patch-level metrics): descrevem as características geométricas de manchas individuais;

- Métricas relativas a classes (class level ou class-related metrics): resumem todas as manchas de uma determinada classe e;

- Métricas do nível de paisagem (landscape-level metrics): referem-se a toda a paisagem.

Tais medidas permitem descrever a distribuição espacial dos habitats, a interação entre os diferentes tipos de habitats que compõem uma paisagem e as mudanças temporais nesses padrões.

Aplicando estas técnicas em áreas de manguezais na Austrália, tratando tanto como classe de paisagem e também ao nível de manchas, Manson et al. (2003) verificou que a análise somente destas medidas podem fazer com que ocorram perdas valiosas de informações, mas ressaltou que tais medidas podem dar uma visão geral do ecossistema e devem ser analisadas com detecções de mudança em um Sistema de Informação Geográfica (SIG).

Outra conclusão que estes autores obtiveram é que tais medidas podem ser aplicadas em imagens de satélite com resolução espacial de até $30 \mathrm{~m}$ sem perdas significativas de informações quando comparadas com medidas efetuadas em sensores de maior resolução espacial. Tal resultado, dessa forma, é de grande valia para informações derivadas dos sensores Landsat TM e ETM+.

As medidas que mais são utilizadas, por serem relativamente fáceis de aplicar e interpretar, além de possuírem relevância ecológica, são: área, soma das bordas (ou perímetro, Total edge), número de manchas (Number of patches), tamanho médio da mancha (Mean patch size) e índice médio de forma (Mean shape index). 
Lang \& Blaschke (2009) sumarizaram as principais características da análise estrutural-espacial da paisagem e métricas, sendo aquelas relativas as mencionadas listadas abaixo:

- Soma das bordas: indica qual é a extensão total das bordas que ocorrem na região, geralmente é equiparada com riqueza da estrutura e pode significar retalhamento;

- Número de manchas: indica quantas manchas existem no total ou em uma determinada classe; como a soma das bordas, também pode indicar retalhamento;

- Tamanho médio da mancha: como o nome diz, indica qual o tamanho médio das manchas e;

- Índice médio de forma: indica o quão compacta são as manchas em comparação com uma circunferência de área igual, sendo que o valor unitário (1) significa forma circular e valores elevados evidenciam formas irregulares. 


\section{OBJETIVOS}

O objetivo geral deste trabalho é analisar a variabilidade espaçotemporal da cobertura vegetal do tipo manguezal no Sistema Estuarino de Santos, empregando para tanto técnicas consagradas de processamento digital de imagens de Sensoriamento Remoto em nove datas diferentes de imagens Landsat TM e ETM+, no período compreendido entre 1985 e 2010.

Dentre os objetivos específicos pode-se destacar:

- Avaliar o espaçamento temporal adequado na utilização de imagens Landsat TM/ETM+ para fins de monitoramento do ecossistema manguezal;

- Avaliar qual o melhor processamento no que se refere às classificações na discriminação dos manguezais na área de estudo;

- Comparar resultados da classificação dessas imagens com outras de maior resolução, como fotografias aéreas e imagens obtidas pelo sensor Quickbird;

- Implementar uma rotina de processamento de imagens de Sensoriamento Remoto e projetos em Sistemas de Informação Geográfica no intuito de fornecer subsídios para o monitoramento de áreas costeiras, e mais especificamente para a Baixada Santista e;

- Verificar a aplicabilidade de medidas de métricas de paisagem ao nível de classes como auxiliar na detecção de mudanças do ecossistema manguezal na área de estudo. 


\section{3 ÁREA DE ESTUDO}

\subsection{Aspectos gerais e delimitação da área de estudo}

Fúlfaro et al. (1974) dividiram o litoral paulista em três compartimentos distintos (Caraguatatuba, Santos-Itanhaém-Peruíbe e Cananéia-Iguape), cujas características distintivas principais são devidas ao forte controle estrutural e aos diversos processos de sedimentação quaternária que lhes imprimiram feições locais, e cujos limites são dados por linhas estruturais. De acordo com os autores o compartimento Santos-Itanhaém-Peruíbe se estende da Ponta da Boracéia (Bertioga) até a Região da Serra do Itatins (Peruíbe).

Já Suguio \& Martin (1978) dividiram o litoral paulista em quatro grandes unidades (Cananéia-Iguape, Itanhaém-Santos, Bertioga-Illha de São Sebastião e llha de São Sebastião-Serra de Parati), cujos limites naturais são dados pela presença de pontões do embasamento pré-cambriano. Segundo os autores, esta subdivisão contempla, ainda, uma individualização do litoral paulista em dois grandes compartimentos com características geomorfológicas bem diferenciadas entre as planícies costeiras localizadas ao sul e ao norte da região da Baixada Santista. Esta subdivisão é caracterizada pelo grau de distanciamento da Serra do mar com relação a linha de costa atual e, consequentemente, pelas dimensões das planícies costeiras desenvolvidas ao longo dos eventos de variação relativa do nível do mar no Quaternário.

$\mathrm{Na}$ delimitação da área de estudo do presente trabalho considerou-se toda a área ocupada por manguezais do sistema estuarino que envolve a planície de Santos e parte da planície de Bertioga (figura 1). Desta forma a área aqui considerada ocuparia partes dos compartimentos Itanhaém-Santos e Bertioga-llha de São Sebastião, conforme definido por Suguio \& Martin (1978).

Miranda et al. (2002) comenta que o estuário de Santos, por ter múltiplas cabeceiras e mais de uma ligação com o oceano, pode ser considerado como um "sistema estuarino". Dessa forma, a denominação aqui adotada para todo o estuário que propicia o desenvolvimento dos manguezais na área de estudo será referido genericamente como "Sistema Estuarino de Santos", mesmo tendo em vista que o Canal da Bertioga e o Rio Itapanhaú possuem um esquema de circulação a parte (Miranda et al., 1998). 

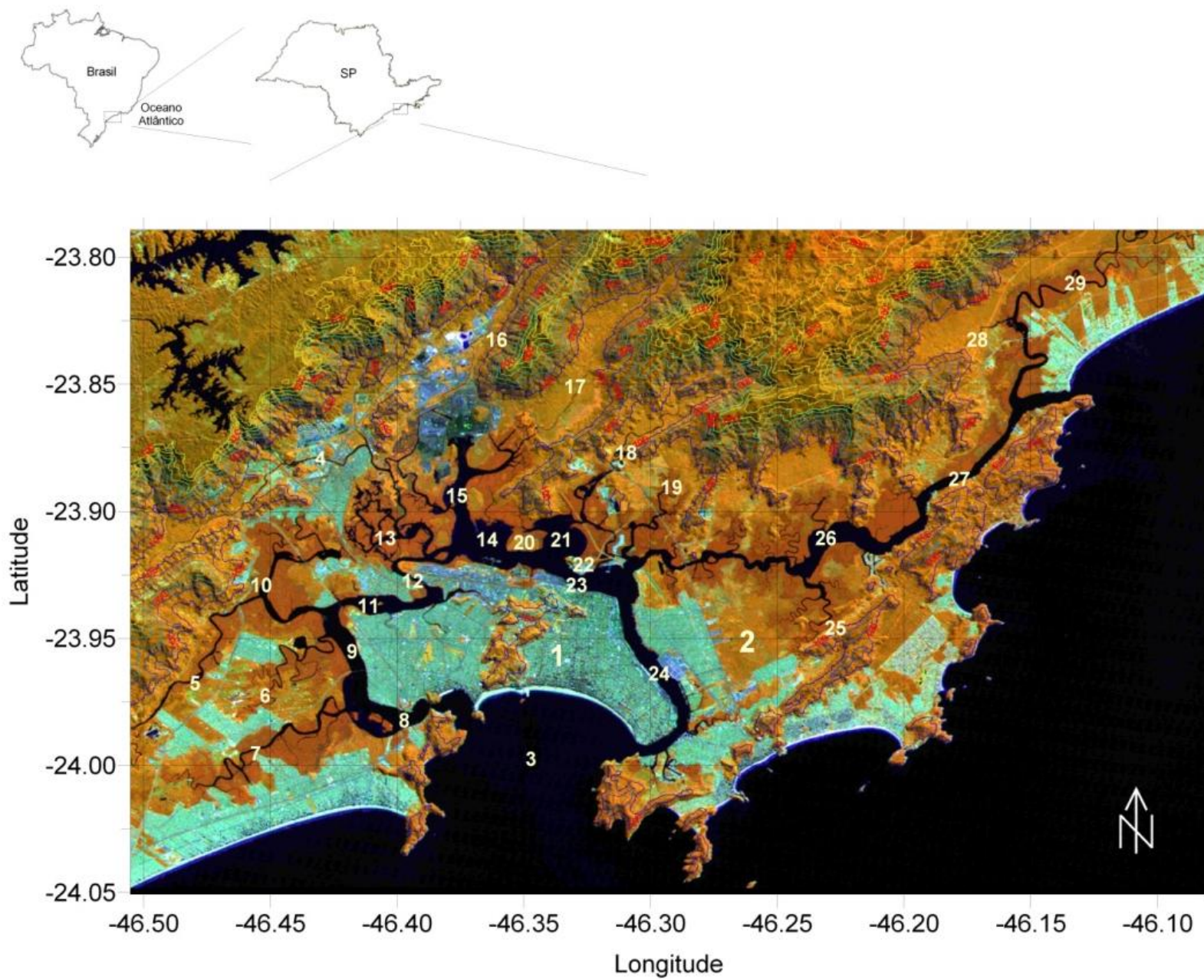

Legenda:

(7) Curvas de Nivel

1- Illa de São Vicente

2- Ilha de Santo Amaro

3- Baía de Santos

5- Rio Cubatẵo

5- Rio Branco (ou

7- Rio Mariana

9- Largo de São Vicente

10-Rio Santana

11- Largo da Pompeba

12- Rio Casqueiro

13- Rio Cascalho

14- Largo do Canéu

15- Canal da Cosipa

16-Rio Mogi

17-Rio Quilombo

19-Rio Jurubatuba

19-Rio Diana

21- Largo de Santa Rita

22- Ilha Barnabé

23- Canal de Piaçaguera

24- Canal de Santos

25- Rio Crumahú

26- Largo do Candinho

27- Canal da Bertioga

28- Rio Jaguareguav

Longitude

Figura 1 Localização da área de estudo e principais toponímias relativas a ilhas, canais estuarinos e rios (Fonte: carta topográfica SF-23-Y-DIV-3, IBGE). A imagem é uma composição colorida das bandas 453 do satélite Landsat TM nos canais RGB, respectivamente, do ano de 2010. 


\subsection{Gênese e geomorfologia}

A planície de Santos está inserida no domínio da Província Costeira, descrito na caracterização geomorfológica do estado de São Paulo (IPT, 1981). Esta província, subdividida em Serra do Mar e Baixada Litorânea, é caracterizada por áreas que drenam diretamente para o mar, constituindo o rebordo do planalto Atlântico, região serrana contínua que, à beira-mar, cede lugar a uma sequência de planícies.

A Serra do Mar apresenta relevo abrupto formado, predominantemente, por escarpas festonadas desenvolvidas ao longo de anfiteatros de erosão sucessivos, separadas por espigões, com desníveis totais da ordem de 800 a 1200 metros entre as bordas do Planalto Atlântico e a Baixadas Litorânea. Tal relevo acentuado propicia a principal fonte de sedimentos terrígenos para a planície adjacente (Fukumoto, 2007).

A drenagem continental oriunda da Serra do Mar é responsável pelo abastecimento de água doce que supre o Sistema Estuarino de Santos/São Vicente, sendo as principais bacias as dos rios Cubatão, Perequê, Quilombo, Jurubatuba, Branco (ou Buturoca), Diana-Sandi, Onça e Piaçabuçu (Bonetti Filho, 1996).

De acordo com Suguio \& Martin (1978), a gênese das planícies da área de estudo está diretamente vinculada aos mecanismos de variação do nível marinho ocorrido ao longo do Quaternário quando, nos máximos transqressivos do Pleistoceno superior (Transgressão Cananéia - \pm 120.000 anos A.P.), e do Holoceno (Transgressão Santos - \pm 5.100 anos A.P.), a área foi recoberta pelas águas marinhas que atingiram, respectivamente, cotas entre 8 e $10 \mathrm{~m}$ acima do nível atual, no evento pleistocênico, e entre 4 e $5 \mathrm{~m}$, no evento holocênico. $\mathrm{Na}$ área de estudo, por ocasião da Transgressão Cananéia o mar atingiu o sopé da Serra do Mar.

No intervalo entre esses máximos transgressivos, com o recuo pronunciado do nível marinho durante o Último Máximo Glacial ( $\pm 130 \mathrm{~m}$ abaixo do nível atual), que expôs totalmente as atuais planícies costeiras e quase toda a plataforma continental paulista, foram depositados cordões arenosos sobre 0 conjunto de sedimentos argilo-arenosos transicionais e de areias litorâneas transgressivas. 
Na planície costeira de Santos é possível que as areias regressivas dos cordões litorâneos tenham recoberto apenas parte da planície atual (Suguio \& Martin, op. cit.).

Neste evento regressivo que teve seu máximo há cerca de 18.000 anos, os sedimentos expostos sofreram erosão, originando os vales que, durante $o$ evento transgressivo subsequente, foram afogados formando-se extensas lagunas onde se depositaram sedimentos argilo-arenosos, ricos em matéria orgânica. Suguio \& Martin (op. cit.) indicam, a partir de numerosas sondagens, que em certas partes da planície costeira de Santos esses depósitos lagunares podem atingir até cerca de 50 metros de espessura.

Ainda ao longo desse evento ocorreu, também, a erosão das partes mais elevadas dos cordões arenosos pleistocênicos, possibilitando a resedimentação holocênica desses materiais erodidos.

A partir do máximo transgressivo holocênico, quando a linha de costa recuou para o seu nível atual, originou-se um segundo conjunto de cordões arenosos. Na planície costeira de Santos, à medida que o nível do mar assumia sua posição atual, foi formada, por trás desses depósitos arenosos, uma vasta laguna que foi parcialmente colmatada e colonizada pela vegetação de mangue.

\subsection{Processos costeiros atuais}

Fúlfaro \& Ponçano (1976) estabeleceram um modelo de circulação e sedimentação no estuário e Baía de Santos através de estudos sedimentológicos, com o objetivo de determinar sua faciologia, bem como as principais tendências de movimentação desses sedimentos.

A drenagem oriunda da Serra do Mar adentra o estuário, em especial na região do canal do Porto, originando um predomínio de fluxo unidirecional que se propaga em direção à baía.

Tais autores, ao descreverem as características dos fluxos fluviais do alto estuário, demonstraram que a faixa de mangue que circunda o estuário detém grande parte da carga de sedimentos transportada por tração liberando, para os canais, apenas a carga transportada em suspensão, de natureza 
síltico-argilosa. A área do médio estuário é palco da influência de correntes de maré sofrendo a movimentação provocada por ação marinha a partir da Baía de Santos.

Os mesmos autores destacam que o sistema estuarino é uma região de grande equilíbrio no que se refere à sedimentação, onde taxas elevadas de sedimentação ocorrem apenas localmente, destacando-se as extremidades sul dos canais de São Vicente e do Porto, junto à desembocadura da baía, o Canal da Bertioga e o Largo do Canéu.

O regime de marés é de caráter semi-diurno, com duração de $12 \mathrm{~h}$ e 42 min, atingindo amplitudes médias de $1,23 \mathrm{~m}$ na sizígia e 0,27m na quadratura. No entanto, as passagens de frentes-frias, que podem causar a elevação do nível do mar, podem ultrapassar 0,5m (Harari et al., 1990).

\subsection{Aspectos da ocupação humana na Baixada Santista}

Por ser uma região estrategicamente localizada, diversos estudos, envolvendo as mais diversas temáticas, foram conduzidos na Baixada Santista. No que se refere a estudos multidisciplinares, o trabalho de Azevedo (1965) pode ser considerado um dos maiores e mais importantes sobre a geografia do local. Mais recentemente, Afonso (2006) realizou também um estudo com enfoque multidisciplinar sobre os aspectos da paisagem na região.

O crescimento da Baixada Santista é caracterizado por fases sucessivas de desenvolvimento social e econômico, e não ocorreu de forma contínua.

Uma primeira fase de desenvolvimento esteve ligada à ampliação do porto e construção, no final do século XIX, das estradas de ferro que ligaram diretamente o Planalto Paulista à Baixada Santista.

A partir do ano de 1918, quando da instalação de uma fábrica de papel e, principalmente, a partir dos anos 20, quando foi construída a usina hidrelétrica da Light, a região experimentou um segundo surto de crescimento. Esta fase marcou a primeira mudança significativa na dinâmica estuarina visto que a indústria de papel utilizava a água do Rio Cubatão, tanto para a alimentação de sua planta industrial, como também como corpo receptor de 
seus rejeitos de processamento. Por outro lado, a usina hidrelétrica liberava, neste mesmo canal fluvial, um volume significativo de água doce, proveniente do Planalto Paulista, que induziu modificações nas condições de salinidade e circulação na região do alto estuário, além da própria contaminação característica dessa água.

A partir da construção da via Anchieta, no início da década de 1940, a região passou a experimentar um aumento de fluxo turístico e de serviços. Porém, foi apenas a partir da ampliação da capacidade de geração de energia pela Light, com a construção de uma usina subterrânea, entre os anos de 1956 e 1962, possibilitando a instalação de uma refinaria de petróleo, um pólo petroquímico e, posteriormente, um complexo siderúrgico (1959-1963), que as condições hidrodinâmicas e ambientais do estuário foram sensivelmente modificadas. Tal pólo petroquímico e siderúrgico utilizava ou utiliza, pelo menos em parte, como fonte de água doce para suas plantas industriais, água dos rios que cortam a planície costeira, além de pequenas quedas d'água, existentes nos sopés da Serra do Mar.

A partir da ampliação da capacidade hidroelétrica instalada, o volume de ingresso de água de doce no estuário, proveniente do planalto, sofreu um sensível incremento sendo que, a este aporte de água doce, está associado um volume considerável de material em suspensão, rico em elementos metálicos e orgânicos, resultantes das atividades industriais e urbanas existentes nas áreas do alto estuário e da escarpa adjacente. De fato, alguns trabalhos conduzidos em testemunhos do alto estuário e até em manguezais revelam a presença de tais resíduos, como em Fukumoto (2007) e Oliveira et al. (2007), entre outros trabalhos.

Tais fatores implicaram, não apenas a ampliação da área portuária, mas também a necessidade de dragagens contínuas do leito do estuário, a fim de possibilitar o acesso ao porto de embarcações de maior tonelagem, como também o acesso até regiões do alto estuário onde foram construídos cais exclusivos para a indústria siderúrgica.

Somente após a construção de uma nova rodovia, no início dos anos 1970, a Rodovia dos Imigrantes, construída a partir da serra do mar sobre a área de manguezal que circunda o estuário, foram implantados programas de controle ambiental visando diminuir o aporte de rejeitos industriais ao estuário, 
e de bombeamento das águas do planalto para geração de energia e posterior deságue no alto estuário, alterando novamente a dinâmica do sistema.

No contexto do litoral paulista a Baixada Santista é uma das áreas que mais sofreu mudanças nas últimas décadas, seja pela ocupação humana, pela presença do porto ou pela instalação do pólo industrial localizado no município de Cubatão. O pólo industrial presente em Cubatão contém mais de uma centena de fábricas, incluindo indústrias químicas, petroquímicas e de fertilizantes, além de uma grande siderúrgica (COSIPA), as quais são as principais fontes de contaminação do sistema local (Luiz-Silva et al., 2002).

\subsection{Os manguezais da Baixada Santista}

No levantamento de Herz (1991), considerando á área de estudo abordada neste trabalho, foi estimada uma área de manguezais (excluindo as áreas degradadas, alteradas e apicuns) de aproximadamente $81,96 \mathrm{~km}^{2}$. A tabela 3 mostra as áreas de cada classe de manguezal dividida pelo trabalho, correspondentes as folhas M1, M2, M4, N1, N2, N3, N4, B1 e B2, do produto cartográfico gerado.

Tabela 3 Áreas de manguezais relacionadas ao Sistema Estuarino de Santos, publicadas no trabalho de Herz (1991). Unidades em km².

\begin{tabular}{ccccccc}
\hline Folha & $\begin{array}{c}\text { Mangue } \\
\text { Alto }\end{array}$ & $\begin{array}{c}\text { Mangue } \\
\text { Baixo }\end{array}$ & $\begin{array}{c}\text { Mangue } \\
\text { Degradado }\end{array}$ & $\begin{array}{c}\text { Mangue } \\
\text { Alterado }\end{array}$ & Apicum & Total \\
\hline M1 & 1,097 & 1,200 & - & - & 0,052 & 2,349 \\
M2 & 7,889 & 1,116 & - & - & 0,095 & 9,100 \\
M4 & 12,099 & 39 & - & 0,036 & - & 12,174 \\
N1* & - & - & - & - & - & 1,568 \\
N2* & - & - & - & - & - & 1,920 \\
N3 & 17,523 & 1,203 & 2,572 & 3,298 & 0,018 & 24,614 \\
N4 & 30,328 & 1,306 & 2,782 & 4,661 & 0,066 & 39,143 \\
B1 & 1,904 & - & 0,014 & 0,035 & - & 1,953 \\
B2 & 2,032 & 0,678 & - & - & 0,080 & 2,790 \\
\hline TOTAL & 72,872 & 5,542 & 5,368 & 8,030 & 0,311 & 95,611
\end{tabular}

* Pequenas áreas não incluídas no produto cartográfico, embora quantificadas. 
Em contraste com esses valores, Andrade \& Lamberti (1965) apontaram, na época em questão, uma área aproximada de $100 \mathrm{~km}^{2}$ somente de manguezais em estados normais de conservação.

De fato, estudos realizados pela Companhia de Tecnologia de saneamento Ambiental (CETESB, 1991) apontavam que apenas $40 \%$ dos manguezais da Baixada Santista encontram-se em bom estado de conservação, com relação a área originalmente ocupada.

Estudos localizados foram realizados no intuito de avaliar mudanças ocorridas na cobertura vegetal dos manguezais. Dentre eles, podemos destacar Santos et al. (2007), que analisou fotografias aéreas do período compreendido entre 1962 e 1994 para uma região do canal de Bertioga avaliando o impacto da construção de uma marina, e Menghini (2008), que também analisou uma série temporal de fotografias áreas para a região da llha Barnabé.

Pode-se destacar o trabalho do naturalista $\mathrm{H}$. Lwederwaldt, intitulada "Os manguesaes de Santos" (Lwederwaldt, 1919) como um dos primeiros a descrever cientificamente este ecossistema na região. $\mathrm{O}$ autor discorre sobre a paisagem enfatizando a sua fauna e flora, muitas vezes dando um caráter lúdico à sua descrição. $\mathrm{Na}$ área de estudo são encontradas as três espécies vegetais típicas de manguezal que ocorrem no litoral paulista: Rhizophora mangle, Laguncularia racemosa e Aviccennia schaueriana.

Muitos trabalhos realizados na Baixada Santista tratam do ecossistema manguezal, seja caracterizando-o estruturalmente, avaliando diferentes tipos de impactos ambientais ou a viabilidade de replantio em áreas degradadas (CETESB, 1988, 1990 e 1991; Comelli et al., 1994; Lamparelli, 1995; Menghini 2004, 2008; Menezes et al., 2005. Ponte et al., 1987, 1990; Pozzi-Neto, 2001; Rodrigues et al.,1990; Schmiegelow, 2009; entre outros).

Embora a bibliografia seja vasta tratando-se da Baixada Santista, estudos considerando o sistema estuarino como um todo não são frequentes. Os mapeamentos de manguezais, a maior parte das vezes, deram-se através da utilização de produtos fotogramétricos. 
Recentemente, a publicação do "Atlas de sensibilidade ambiental ao óleo da Bacia Marítima de Santos" (Gherardi \& Cabral, 2007), exprime que os ambientes de manguezal possuem máximo índice de vulnerabilidade, e para compor a carta que contém suas delimitações a base utilizada provavelmente foi um produto de sensoriamento remoto, como mostra a figura 2 .

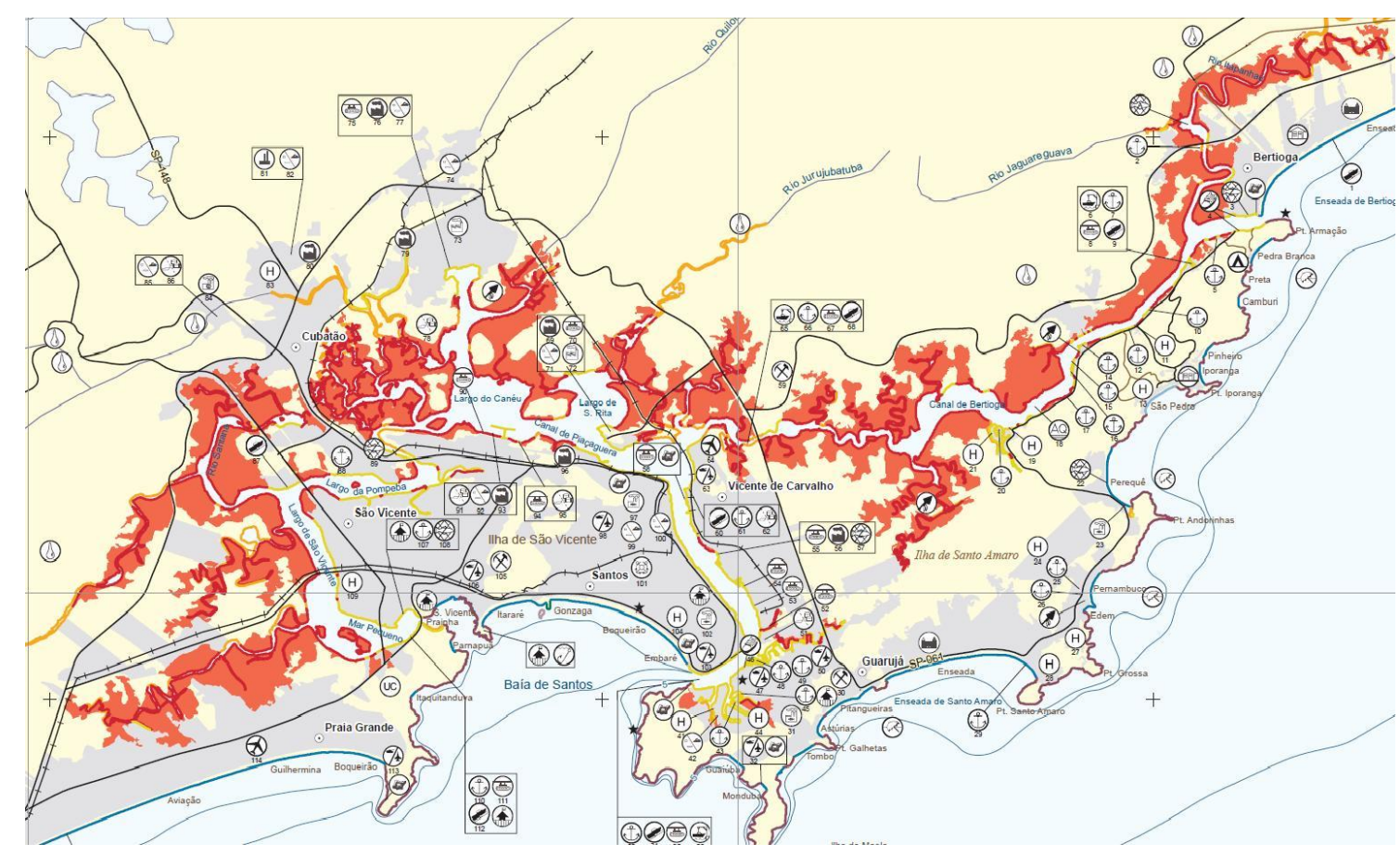

Figura 2 Parte da Carta Tática de Sensibilidade Ambiental ao Derramamento de Óleo. Bacia de Santos - de Bertioga à Barra do Una - SP (SAN 14 - 2007). Em tom de vermelho nota-se a distribuição dos manguezais na área de estudo. Extraído de Gherardi \& Cabral (2007). 


\section{MATERIAIS E MÉTODOS}

O presente estudo teve como base dezoito cenas de duas órbitasponto distintas de imagens da série Landsat, sendo dezesseis do satélite Landsat 5 TM e duas do Landsat 7 ETM+.

Foi implementada uma rotina clássica em processamento digital de imagens de sensoriamento remoto, tais como pré-processamento, classificação e detecção de mudança.

O pré-processamento consiste na correção e preparação das imagens para normalizá-las, permitindo assim realizar os próximos passos. As classificações são os processamentos realizados para a discriminação dos alvos (no caso, o alvo de interesse é a classe manguezal), usando como base levantamentos prévios, comparando com imagens de maior resolução espacial (e.g. fotografias aéreas) ou utilizando de conhecimentos obtidos em campo. Já a análise de mudanças consiste no conjunto de técnicas empregadas para avaliar as mudanças ocorridas no(s) alvo(s) em questão ao longo do tempo.

O uso de dados de satélite (TM e ETM+) multitemporais requer uma série de considerações: correção dos erros geométricos, ruídos ocasionados por efeitos atmosféricos, erros inerentes a diferenças da geometria de iluminação e erros do instrumento (Homer et al., 2004). Tais erros podem introduzir tendências e/ou ruídos na classificação de bosques de mangue e análises de mudança. Uma revisão dos métodos de detecção de mudança envolvendo imagens de sensoriamento remoto pode ser obtida em Lu et al., 2004.

Parâmetros auxiliares foram utilizados no decorrer do processamento de imagens, tais como fotografias aéreas verticais (analógicas e digitais) e oblíquas da região, um Modelo Digital de Elevação (MDE) da área de estudo e medidas de maré de algumas datas das cenas Landsat.

Todos os produtos gerados pelos processamentos de imagens Landsat foram incorporados em um banco de dados baseado em Sistemas de Informações Geográficas (SIG) para posterior análise dos resultados. A figura 3 demonstra o esquema conceitual no qual este trabalho se estruturou, evidenciando cada etapa até o produto final. 


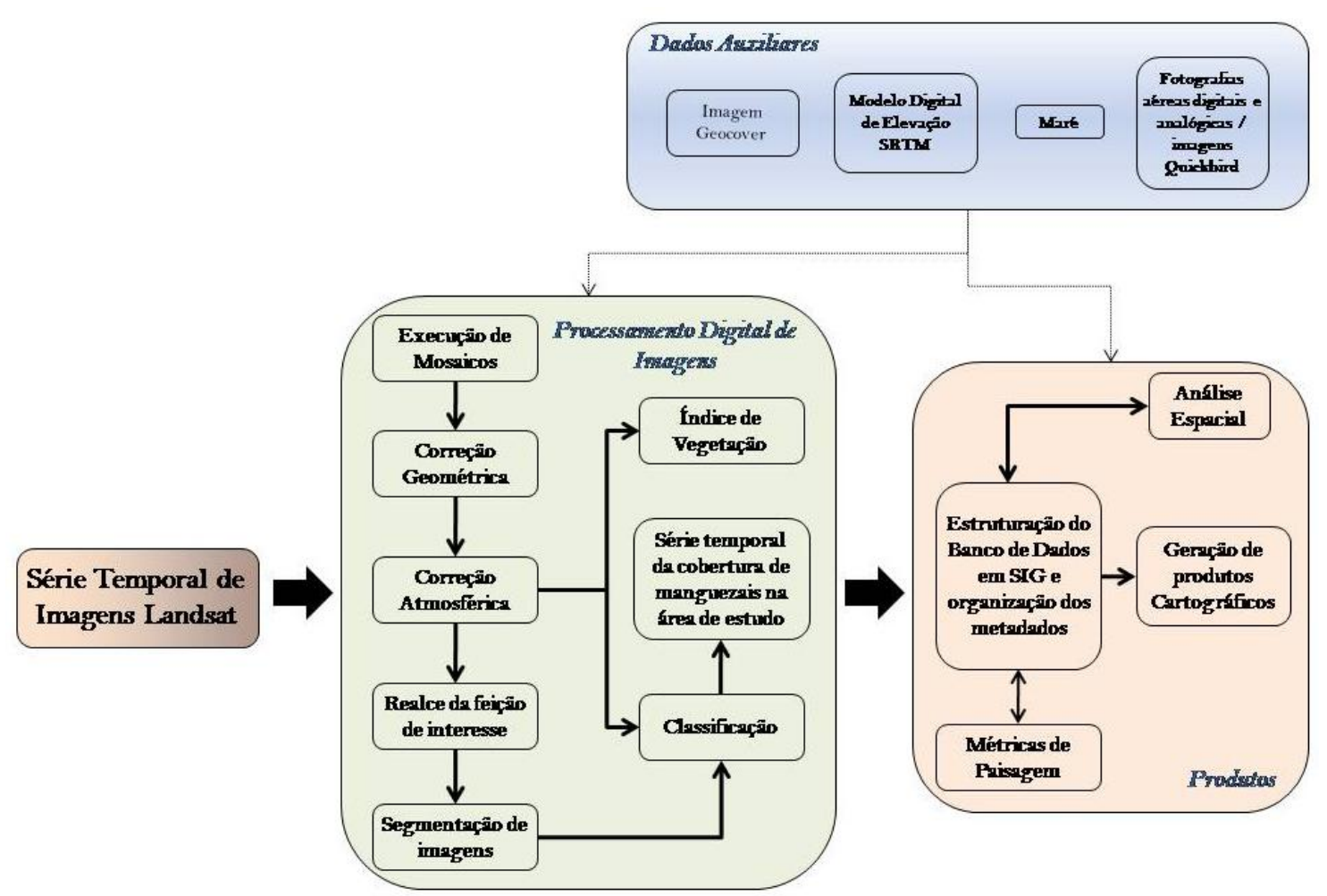

Figura 3 Esquema conceitual dos métodos empregados no presente estudo.

Os pacotes computacionais utilizados no processamento digital de imagens e SIG foram variados, e tal fato decorre principalmente devido às facilidades que alguns desempenham em determinadas funções quando comparadas aos outros, e também pelo grau de familiarização que o operador possuía com relação a cada software na manipulação dos dados. Foram eles:

- ER Mapper ${ }^{6}$ (version 7.0.1): produzido pela Earth Resource Mapping Inc., incorporada atualmente pela Earth Resource Data Analysis System (ERDAS);

- $E N V I^{7}$ - Environment for Visualizing Images (version 4.5): produzido pela ITT Visual Information Solutions;

- Spring ${ }^{8}$ - Sistema de Processamento de Informações Georreferenciadas (versão 5.1.6): produzido pela Divisão de Processamento de

\footnotetext{
6 www.erdas.com

7 www.ittvis.com

8 www.dpi.inpe.br/spring
} 
Imagens (DPI), do Instituto Nacional de Pesquisas Espaciais (INPE) software de uso livre;

- $\operatorname{ArcGIS}$ (version 9.2): produzido pela ESRI Inc.

Em cada nível de processamento, como serão descritos a seguir, se fará referência, quando necessário, dos softwares utilizados.

\subsection{Conjunto de imagens Landsat e mosaico das cenas}

As imagens que compõem a base do estudo constituem-se de passagem dos sensores TM e ETM+, dos satélites Landsat 5 e 7, respectivamente, e todas elas foram adquiridas junto ao banco de dados da Divisão de Geração de Imagens (DGl), do Instituto de Pesquisas Espaciais (INPE), disponível em < www.dgi.inpe/CDSR >.

Neste banco de dados as imagens são adquiridas sem nenhum custo, disponibilizadas via Protocolo de Transferência de Arquivos, em formato Tiff (Tagged Image Format File).

O programa Landsat utiliza de um sistema de referência próprio para discriminar as cenas da passagem do satélite, conhecido como WRS (da sigla em inglês, Worldwide Reference System), sendo a primeira parte relativa a órbita ( ou path) e a segunda ao ponto (ou row), sendo comum a expressão em português "órbita-ponto".

O litoral do estado de São Paulo é imageado por cinco órbitas-ponto distintas (figura 4). Em estudo realizado na região, Bonetti Filho (1996) constatou que são geradas localmente, em média, apenas três cenas por ano com coberturas inferior a 10\%, geralmente associados a condições atmosféricas semelhantes, principalmente quando da passagem de sistemas pré-frontais onde, de maneira geral, os dias apresentam características em comuns de baixa pressão atmosférica, alta temperatura, baixa umidade relativa do ar e ventos do quadrante N-NW. De fato, analisando o banco de dados do DGI constata-se, de modo geral, que esta porcentagem se mantém atualmente.

9 www.esri.com 


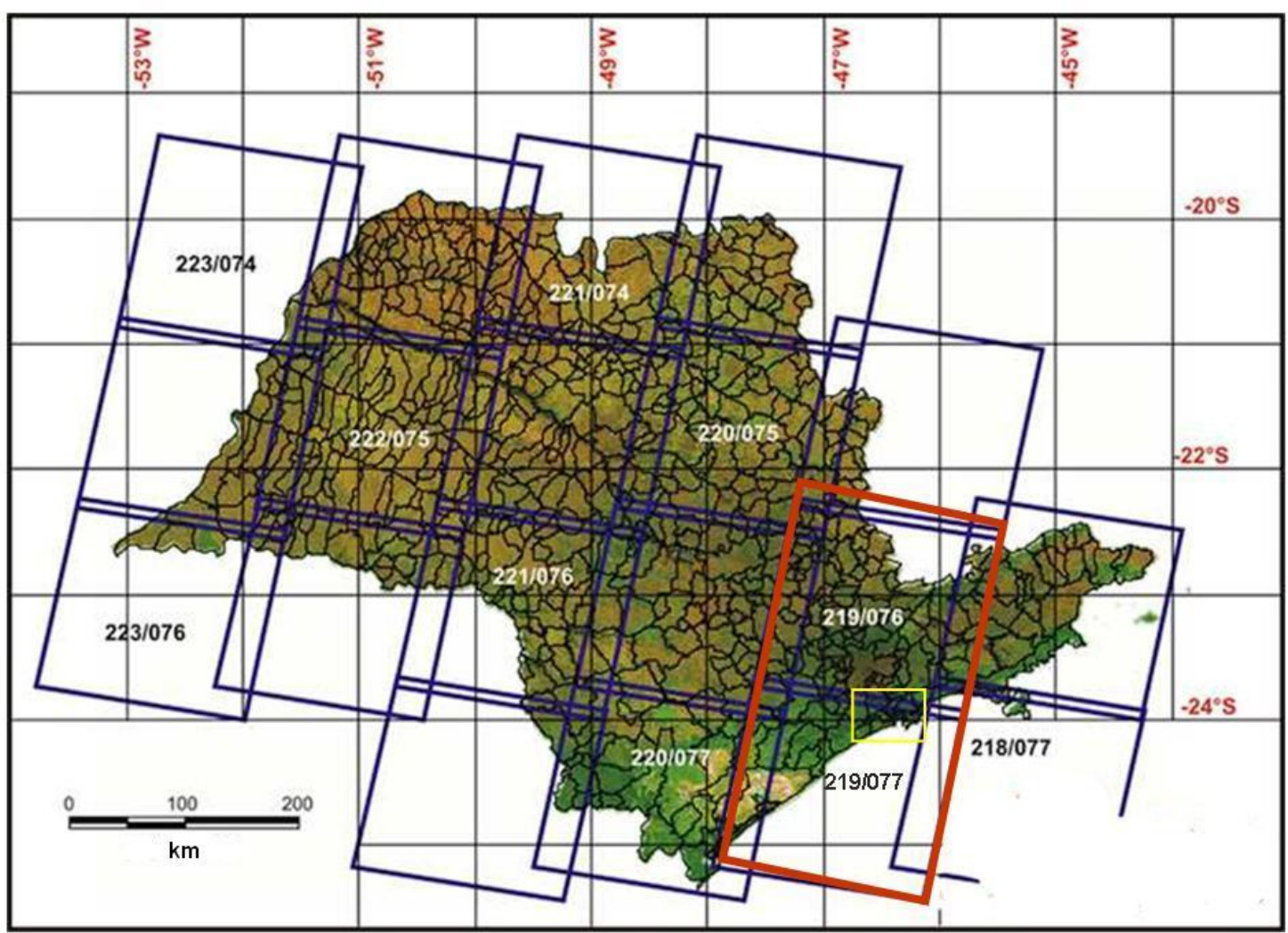

Figura 4 Localização das cenas Landsat para o estado de São Paulo, enfatizando àquelas que foram utilizadas no presente trabalho (em vermelho) e destacando a área de estudo (em amarelo).

A órbita-ponto 219-077 cobre quase a totalidade da área de estudo, no entanto uma considerável área de manguezais localizados ao largo do Rio Itapanhaú, bem como parte do Canal da Bertioga, comumente fica fora desta cena. Portanto foram consideradas no projeto as cenas correspondentes a órbita-ponto 219-076 (figura 4), de modo a normalizar a cobertura total da área de estudo, permitindo assim realizar análises quantitativas absolutas do Sistema Estuarino de Santos (salvo os erros inerentes ao método) e comparativas entre os anos.

Foram escolhidas imagens de um total de nove datas, de modo a realizar uma tentativa de análise temporal adequada, com espaçamento aproximado entre dois a quatro anos (tabela 4). Tais imagens foram criteriosamente escolhidas de modo que a data de aquisição fosse o mais próximo possível de uma mesma data (aniversário), para que as oscilações inerentes ao efeito das diferentes estações do ano fossem minimizadas, como ressalta Lu et al. (2004), considerando comparações multitemporais. Cabe 
lembrar que, embora o tempo de revisita dos satélites Landsat 5 e 7 seja de 16 dias, devido as condições climáticas que regem na latitude da área de estudo, conforme discutido, a utilização de imagens em condições de uso (sem nuvens) é muito restrita. A tabela 4 mostra as principais características e propriedades das imagens adquiridas, informações estas que são indispensáveis para a sua melhor manipulação.

Uma vez que duas cenas distintas foram necessárias para cobrir a área de estudo, houve a necessidade de juntá-las, sendo este processo normalmente referido em sensoriamento remoto como mosaico.

As imagens foram escolhidas, através da disponibilização do DGI INPE, de maneira que uma mesma data possuísse as duas cenas, de modo que uma fosse o complemento de outra, não necessitando prévio georreferenciamento ${ }^{10} \mathrm{e} / \mathrm{ou}$ pontos de amarração (tie points), processos normalmente requeridos nos algoritmos de realização de mosaicos.

Deste modo, necessitou-se somente cortar as duas cenas para a região de interesse, e simplesmente sobrepor uma na outra e salvar como uma nova imagem, sendo este um processo rotineiro no ER-Mapper.

10 Conforme discutido no item 4.2.2. 
Tabela 4 Datas e principais informações das imagens utilizadas como base no presente trabalho. Informações fornecidas pelo DGl INPE.

\begin{tabular}{|c|c|c|c|c|c|c|c|}
\hline $\begin{array}{c}\text { DATA DE } \\
\text { AQUISIÇÃO }\end{array}$ & $\begin{array}{l}\text { SENSOR / } \\
\text { ÓRBITA- } \\
\text { PONTO }\end{array}$ & REVOLUÇÃO & $\begin{array}{c}\text { TEMPO } \\
\text { CENTRAL } \\
\text { (GMT) }\end{array}$ & ORIENTAÇÃO & $\begin{array}{c}\text { ÂNGULO } \\
\text { NADIR }\end{array}$ & $\begin{array}{l}\text { AZIMUTH } \\
\text { SOL }\end{array}$ & $\begin{array}{c}\text { ÁNGULO DE } \\
\text { ELEVAÇÃO DO } \\
\text { SOL }\end{array}$ \\
\hline \multirow{2}{*}{ 06/Out/1985 } & TM - p219r077 & 8501 & 12:33:44 & 9,09191 & 38,8366 & 65,5185 & 51,1634 \\
\hline & TM - p219r076 & 8501 & $12: 33: 25$ & 9,09191 & 38,0503 & 66,9657 & 51,9497 \\
\hline \multirow{2}{*}{ 13/Jul/1989 } & TM - p219r077 & 28539 & 12:32:08 & 8,19998 & 60,3773 & 43,0466 & 29,6227 \\
\hline & TM - p219r076 & 28539 & 12:31:44 & 8,19998 & 59,1739 & 43,4270 & 30,8261 \\
\hline \multirow{2}{*}{ 05/Jul/1992 } & TM - p219r077 & 44384 & 12:27:53 & 8,19998 & 61,5672 & 42,9863 & 28,4328 \\
\hline & TM - p219r076 & 44384 & 12:27:29 & 8,19998 & 60,3624 & 43,3427 & 29,6376 \\
\hline \multirow{2}{*}{ 28/Jun/1995 } & TM - p219r077 & 60227 & 12:10:21 & 8,19998 & 64,4318 & 54,5070 & 25,5682 \\
\hline & TM - p219r076 & 60227 & 12:09:56 & 8,19998 & 63,2629 & 45,8349 & 26,7371 \\
\hline \multirow{2}{*}{ 26/Ago/1999 } & TM - p219r077 & 82365 & 12:42:08 & 8,19998 & 49,9761 & 49,5447 & 40,0239 \\
\hline & TM - p219r076 & 82365 & 12:41:44 & 8,19998 & 48,8761 & 50,2648 & 41,1239 \\
\hline \multirow{2}{*}{ 07/Jun/2002 } & $\mathrm{ETM}_{+}-\mathrm{p} 219 \mathrm{r} 077$ & 16730 & 12:53:19 & 8,19998 & 0 & 36,4840 & 33,0664 \\
\hline & ETM+ - p219r076 & 16730 & 12:52:56 & 8,19998 & 0 & 36,8377 & 34,3567 \\
\hline \multirow{2}{*}{ 23/Jun/2005 } & TM - p219r077 & 13354 & 12:52:21 & 8,19998 & 0 & 36,9421 & 31,8948 \\
\hline & TM - p219r076 & 13354 & 12:51:57 & 8,19998 & 0 & 37,2818 & 33,1800 \\
\hline \multirow{2}{*}{ 17/Jul/2008 } & TM - p219r077 & 29664 & 12:51:31 & 8,19998 & 0 & 39,592 & 33,0310 \\
\hline & TM - p219r076 & 29664 & $12: 51: 08$ & 8,19998 & 0 & 39,9921 & 34,2812 \\
\hline \multirow{2}{*}{ 04/Mai/2010 } & TM - p219r077 & 39217 & 12:55:34 & 8,19998 & 0 & 40,6014 & 39,1241 \\
\hline & TM - p219r076 & 39217 & 12:55:10 & 8,19998 & 0 & 41,1433 & 40,3613 \\
\hline
\end{tabular}




\subsection{Pré-processamento}

\subsubsection{Correção Geométrica}

Conforme descrito em Schowengerdt (2007), vários termos são utilizados, em sensoriamento remoto, em se tratando da correção geométrica de imagens:

- Registro: alinhamento de uma imagem com outra de uma mesma área;

- Retificação: alinhamento de uma imagem através de um mapa ou outra imagem planimétrica, também conhecido como georreferenciamento;

- Geocodificação: um caso especial da retificação que inclui um escalonamento para um tamanho de pixel padrão, permitindo assim utilizar planos de informação de diferentes sensores e mapas em um SIG.

- Ortorretificação: correção da imagem, pixel a pixel, das distorções topográficas, resultando assim como se cada visada da superfície terrestre fosse diretamente acima do pixel, que se encontra em uma projeção ortográfica.

O georreferenciamento de pontos da imagem com pontos de controle que podem ter sido adquiridos de cartas, GPS ou de outra imagem corrigida previamente é uma etapa presente em quaisquer das correções baseadas em pontos de controle. A qualidade da correção dependerá, dentre outros fatores, da precisão com que estes pontos foram adquiridos, de sua distribuição sobre a imagem e da perfeita marcação dos mesmos na imagem.

A ortorretificação requer um Modelo Digital de Elevação (MDE), uma vez que cada localização do pixel deve ser ajustada para as condições topográficas existente.

Toutin (2004) fez uma revisão dos processamentos geométricos de imagens de sensoriamento remoto, onde discute os aspectos das fontes de distorções geométricas, compara os diferentes modelos matemáticos utilizados na modelagem da distorção geométrica, detalha os algoritmos, métodos e etapas do processamento e discorre sobre a propagação de erros nos projetos. 
Muitos trabalhos vêm utilizando, o catálogo de imagens GeoCover ${ }^{11}$, que contém um série de imagens Landsat, como base de referência para registrar outras imagens.

Tucker et al. (2004) descreve toda a mobilização e processamentos realizados para gerar o catálogo GeoCover, que é uma base de imagens MSS, TM e ETM+ ortorretificadas e geodésicamente acuradas. O banco de dados consiste de uma série de cenas adquiridas em três épocas distintas: 1970 (MSS), 1990 (TM) e 2000 (ETM+). Cada cena foi selecionada de modo que a cobertura de nuvens fosse sempre inferior a $10 \%$. As imagens foram reamostradas através do método "vizinho mais próximo", gerando um tamanho de pixel de 28,5m, excetuando-se as bandas 6 (TM e ETM+) e 8 (ETM+). As imagens ortorretificadas resultaram em uma acurácia posicional de menos de $50 \mathrm{~m}$, considerando o erro quadrático médio. Também, as imagens foram projetadas para o sistema de coordenadas UTM (Universal Transverse Mercator - hemisfério Norte) e para o datum WGS-84.

O nível de correção (nível 1) ${ }^{12}$ das imagens Landsat adquiridas do INPE não são acuradas geometricamente, ou seja, não servem para serem utilizadas em um SIG, quanto menos em se tratando de análises multitemporais.

Desta forma, foram utilizadas duas imagens GeoCover, datadas de 30 de maio de 2000 (WRS 219p076r e 219p077r), de modo que servissem de referência para todas as outras imagens utilizadas no projeto. Ambas as imagens foram escolhidas de modo que a cobertura de nuvens fosse a mínima possível na área de estudo, embora o acervo para estas órbitas-pontos ser pequeno (cerca de somente três imagens ortorretificadas para cada no catálogo GeoCover).

Inicialmente foi realizado o mosaico das duas cenas, como discutido no item 4.1, e depois a imagem obtida foi reprojetada para o sistema de coordenadas adotado neste projeto, UTM 23S, datum SAD 69 (South American Datum, 1969).

11 Disponível em < http://glcf.umiacs.umd.edu >.

12 Imagens calibradas radiometricamente. 
Foram realizados alguns testes no georreferenciamento das imagens base. Inicialmente todas as imagens foram georreferenciadas com base nas imagens GeoCover, no entanto, devido aos pontos de controle terem sidos distribuídos uniformemente na cena cortada, com pontos em cima do planalto e, muitas vezes em cima de morros, obteve-se um resultado de má qualidade (RMS alto). Acredita-se que tais erros foram ocasionados devido a interferências que a topografia irregular, devido a Serra do Mar e outros morros isolados, proporcionam às imagens, não possibilitando a utilização das mesmas para uma análise de mudanças multi-temporais devido a diferenças geométricas.

Cabe ressaltar que o erro quadrático médio (RMS, do termo em inglês Root Mean Square) pode ser considerado, em sensoriamento remoto, como a média dos valores obtidos pela diferença entre a posição estimada e a posição real elevada ao quadrado. Em outras palavras, o RMS exprime o erro posicional inerente ao modelo criado no registro entre uma imagem e outra.

Foi testado, também, a extração automática de pontos de controle, através do software Regeemy ${ }^{13}$ (Fonseca et al., 2006), desenvolvido pelo INPE em cooperação com a Universidade de Santa Bárbara, Califórnia (UCSB). No entanto, mesmo com muitos pontos de controle (mais do que 100), as tentativas produziram um erro muito grande, não sendo adequado também aos propósitos deste projeto.

Bons resultados só foram obtidos quando pontos de controle foram distribuídos manual e uniformemente somente na planície costeira, utilizando um Modelo Digital de Elevação (MDE) como base. O MDE foi obtido com base em dados SRTM, conforme será mostrado no item 4.3.

Foram distribuídos uma média de 30 pontos de controle para cada imagem, ajustando um polinômio de $1^{\circ}$ ordem para a correção e usando o método de interpolação vizinho mais próximo, fazendo referência a Jensen (1995), sendo os resultados satisfatórios para os objetivos aqui propostos.

Inicialmente a imagem GeoCover obtida do ano de 2000 foi utilizada para georreferenciar a do ano de 1999, segundo um critério de proximidade de data.

13 Disponível em < http://regima.dpi.inpe.br/ >. 
A imagem de 1999 servira para registrar todas as outras, uma vez que estavam com o mesmo tamanho de pixel (30 m, contra os 28,5 da imagem GeoCover). Ressalta-se que a mesma imagem foi utilizada para registrar todas as outras, no intuito de evitar a propagação de erros, no entanto a medida que datas mais próximas iam sendo registradas, estas serviam como apoio na obtenção de pontos de controle para as datas mais distantes, uma vez que mudanças significativas ocorreram na região no período analisado.

Toda esta etapa de correção geométrica foi realizada no software ENVI.

\subsubsection{Correção Atmosférica}

Os sinais da radiação eletromagnética coletadas por satélites no espectro solar são modificados pelo espalhamento e absorção de gases e aerossóis enquanto atravessam a atmosfera ao percorrer da superfície terrestre até o sensor. A correção atmosférica é uma importante etapa de préprocessamento requerida em muitas aplicações de sensoriamento remoto. Quando e como corrigir os efeitos atmosféricos depende dos dados de sensoriamento remoto e atmosféricos disponíveis, da informação desejada e dos métodos analíticos utilizados para extrair a informação.

Muitas análises em sensoriamento remoto requerem que dados do sensor TM de diferentes épocas e áreas de estudo tenham os valores do número digital (ND) convertidos em reflectância, ou mesmo que sejam comparáveis, através de correções atmosféricas.

Há essencialmente dois tipos de correções atmosféricas: a absoluta, que converte os números digitais em reflectância superficial ou radiância, removendo os efeitos causados pela atenuação atmosférica, condições topográficas e outros parâmetros e; a relativa, que é utilizada para remover ou normalizar a variação de uma cena normalizar as intensidades entre imagens de um mesmo local coletadas em diferentes datas.

De acordo com as características do modelo e sua complexidade, pode-se agrupar as correções atmosféricas em três tipos. 
O primeiro grupo são os modelos físicos, que requerem muitas simulações em sub-modelos que usam muitos parâmetros. Tais modelos podem produzir alta acurácia na obtenção de reflectância superficial. Esses modelos incluem o 6S (da abreviação do termo em inglês Second Simulation of the Satellite Signal in the Solar Spectrum), o LOWTRAN e o MODTRAN (Moderate Resolution Atmospheric Radiance and Transmittance Model), que são comumente muito complexos e requerem muitos parâmetros da atmosfera coletados in situ simultaneamente à obtenção da cena imageada. Estes modelos não foram levados em conta no presente trabalho, dada a sua complexidade e ausência de dados coletados em cada data de aquisição das imagens utilizadas.

A segunda classe de modelos é a Subtração de Objetos Escuros (DOS, do termo em inglês Dark Object Subtraction), que se baseiam na própria imagem e assumem que o impacto da atmosfera é uniforme em toda área de estudo e que objetos escuros existem. Esses modelos não requerem informações in situ da atmosfera. Alguns dados de entrada que implementam esses modelos são principalmente baseados em medidas da própria imagem e do arquivo de cabeçalho do dado de sensoriamento remoto, que provê informações importantes como data de aquisição, ângulo de elevação do sol, etc.

Já o terceiro grupo foca na calibração relativa e desenvolvem modelos baseados em pareamento dos histogramas, subtração de pixel escuro e equações de regressão.

Lu et al. (2002), em estudo utilizando uma série de imagens TM na região da Amazônia, compararam diferentes métodos de correção atmosférica e concluíram que para a aplicação em questão (medidas de biomassa, classificação de sucessão secundária, mudanças no uso e ocupação do solo e assinalação de assinaturas espectrais), que o modelo de DOS melhorado, como o de Chavez (1996), atingiu bons resultados para com os objetivos propostos.

Do mesmo modo, Song et al. (2001) ressalta que para aplicações envolvendo detecções de mudança e classificações que não necessitam de valores acurados de reflectância da superfície (ao contrário de medidas 
quantitativas como, por exemplo, biomassa), correções simples como DOS e correções relativas são recomendadas.

Considerando as aplicações abordadas neste trabalho, que tratam essencialmente de comparações pós-classificação e detecções de mudança baseado em NDVI, necessitou-se realizar uma correção atmosférica nas imagens e, para tanto, aplicou-se o método de Chavez (1988), que apesar de suas limitações por ser um método baseado em informações da própria imagem (DOS), é amplamente utilizado, conforme descrições na literatura.

O método parte do princípio de que existem alvos escuros na imagem, em geral sombras de nuvens ou ocasionadas pela topografia, que deveriam apresentar um número digital muito baixo na imagem, equivalente a cerca de $1 \%$ da reflectância. Chavez (1988) argumenta que não é adequado subtrair os valores mínimos encontrados em cada banda da imagem porque estes valores podem superestimar a correção das demais bandas. Então, o autor propõe um modelo para o cálculo do espalhamento atmosférico para cada banda, partindo apenas do ND de freqüência mais baixa encontrada na banda de menor comprimento de onda. Esse valor é utilizado para identificar a condição atmosférica contemporânea à obtenção de imagem, o que determina o expoente do espalhamento relativo.

Para aplicar este método, foi utilizado a planilha desenvolvida por Gürtler et al. (2005) ${ }^{14}$, onde a aplicação é diretamente sobre imagens TM e ETM+. São inseridos como parâmetro de entrada o histograma de freqüência de uma banda (normalmente a banda 1), o sensor, a data de aquisição da imagem, o ângulo de elevação solar (em graus) e o tipo de ganho (alto ou baixo) para cada banda (este último só quando se tratar do sensor ETM+).

Resumidamente, na utilização desta planilha, foi inserido primeiro o histograma de freqüência da banda 1 e calculado o ND de freqüência mais baixa, obtendo assim o modelo de espalhamento a ser aplicado nos cálculos das correções das demais bandas (com exceção da banda 6, que opera na faixa do infravermelho termal). Em seguida é fornecido qual o sensor utilizado e os parâmetros da imagem obtidas na aquisição, como a data, e o ângulo de 
elevação solar. As informações fornecidas foram as mesmas que as apresentadas na tabela 4, sendo que no caso do ângulo de elevação solar foi utilizada a média dos parâmetros referentes aos WRS 219p077r e 219p076r.

Quando a planilha aplica os cálculos em imagens ETM+, deve-se fornecer o tipo de ganho para cada banda, e tais informações são obtidas em NASA (2004). No caso, a única imagem utilizada, do ano de 2002, para todas as bandas o parâmetro ganho foi "alto".

Ainda, alguns parâmetros utilizados por Gürtler et al. (2005), tais como Radiância Mínima $\left(\operatorname{LMIN}_{\lambda}\right)$ e Máxima $\left(\operatorname{LMAX}_{\lambda}\right)$, e Irradiância solar total para cada banda $\left(\operatorname{ESUN}_{\lambda}\right)$ foram atualizados pelos valores fornecidos por Markham et al. (2009).

O resultado após inserir esses dados de entrada é fornecido em forma de valores a serem subtraídos de cada banda, e foram aplicados em todas as datas utilizando o software ENVI, utilizando a função "Dark Subtract".

\subsection{Dados auxiliares: fotografias aéreas verticais analógicas e digitais, imagens Quickbird, fotografias aéreas oblíquas, MDE e maré}

Alguns dados auxiliares foram utilizados nas mais diversas etapas deste trabalho são eles: fotografias aéreas verticais digitais e ortorretificadas (ano de 2001), fotografias aéreas verticais digitais sem nenhum tratamento (1962 e 1994), fotografias aéreas analógicas (1962, 1977, 1994 e 2000), imagens Quickbird (2008), fotografias aéreas oblíquas, um Modelo Digital de Elevação e dados de altura da maré.

As fotografias aéreas verticais digitais do ano de 2001 foram obtidas junto ao Departamento de Dasonomia do Instituto Florestal, realizadas através de um levantamento para a Secretaria do Meio Ambiente do Estado de São Paulo. As fotografias encontram-se ortorretificadas e com resolução espacial de aproximadamente $1 \mathrm{~m}$ de pixel no terreno. Originalmente estas fotografias se encontravam no sistema de referência UTM, fuso $23 \mathrm{~S}$ e datum SAD 69, motivo pelo qual resolveu adotar esse sistema como base para o projeto Um mosaico dessas fotografias aéreas é mostrado na figura 5. Estas fotografias, 
conjuntamente com as demais que serão descritas a seguir, serviram como base para identificar alvos de treinamento na classificação e também como apoio das discussões nos resultados obtidos.

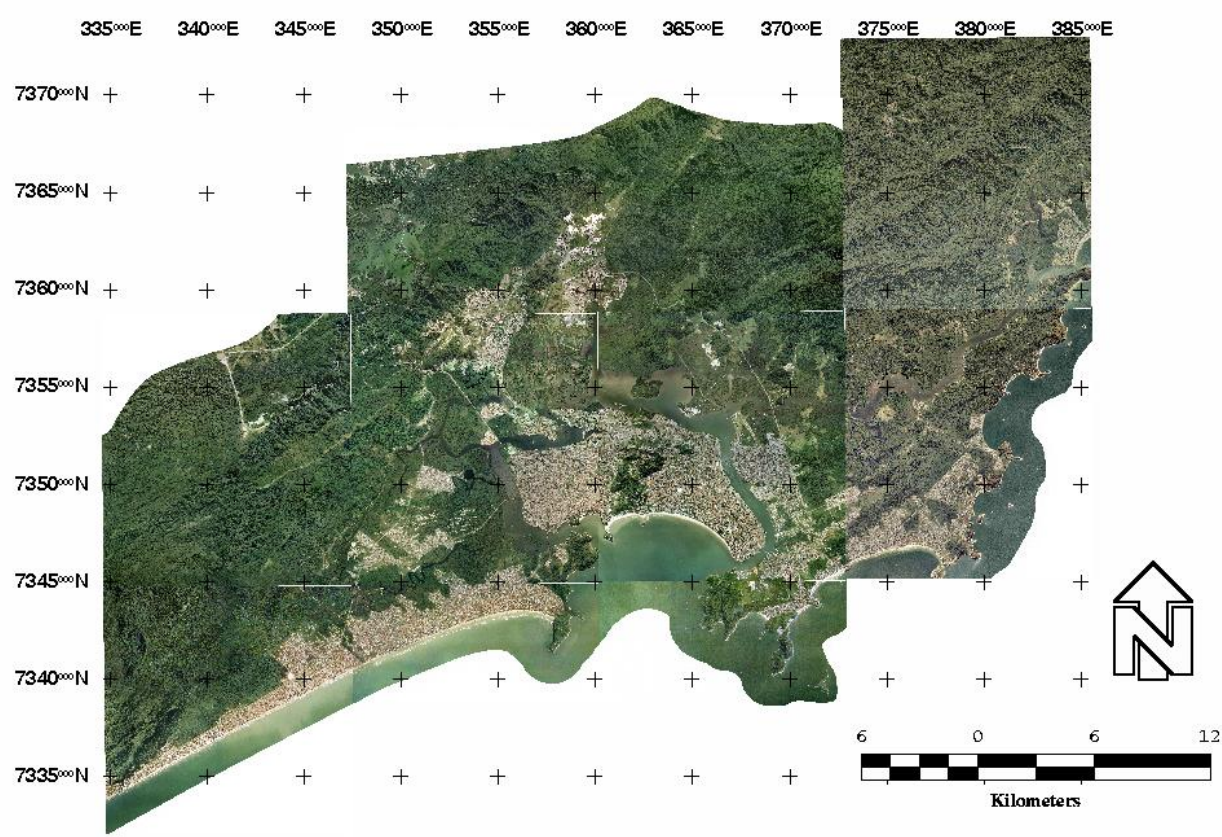

Figura 5 Mosaico de fotografias aéreas obtidas através de levantamento realizado no ano de 2001 (as coordenadas estão em Sistema de Referência UTM em relação ao meridiano 23S).

Fotografias aéreas dos de 1962 e 1994, que não cobrem a área toda, também foram adquiridas junto ao Departamento de Geografia da Faculdade de Filosofia, Letras e Ciências Humanas (FFLCH) da Universidade de São Paulo (figura 6).

Também foram adquiridas, através do projeto "Mapeamento de indicadores ambientais e utilização de técnicas de Sensoriamento Remoto e Geoprocessamento em regiões costeiras. Caso de estudo: Sistema Estuarino de Santos/São Vicente, Estado de São Paulo", o qual este trabalho está inserido, três imagens do satélite Quickbird, de alta resolução espacial, datadas de 08 de maio de 2008. O produto adquirido encontra-se corrigido geometricamente e sob a forma de imagens fusionadas para a banda pancromática, de 0,6m de resolução espacial, não contendo a banda que opera no infravermelho próximo. Os três locais são: i) entorno do Canal da Cosipa e Largo do Canéu; ii) entorno dos manguezais de Praia Grande e iii) entorno do 
Largo do Candinho (Canal da Bertioga). Tais locais foram escolhidos devido aos diferentes graus de impacto os quais os manguezais estiveram submetidos, sendo o primeiro exposto a diversos tipos de dejetos industriais e aterros, o segundo com evidências de expansão urbana, e o terceiro com relativo alto grau de preservação. A figura 7 mostra as três cenas adquiridas do satélite Quickbird.
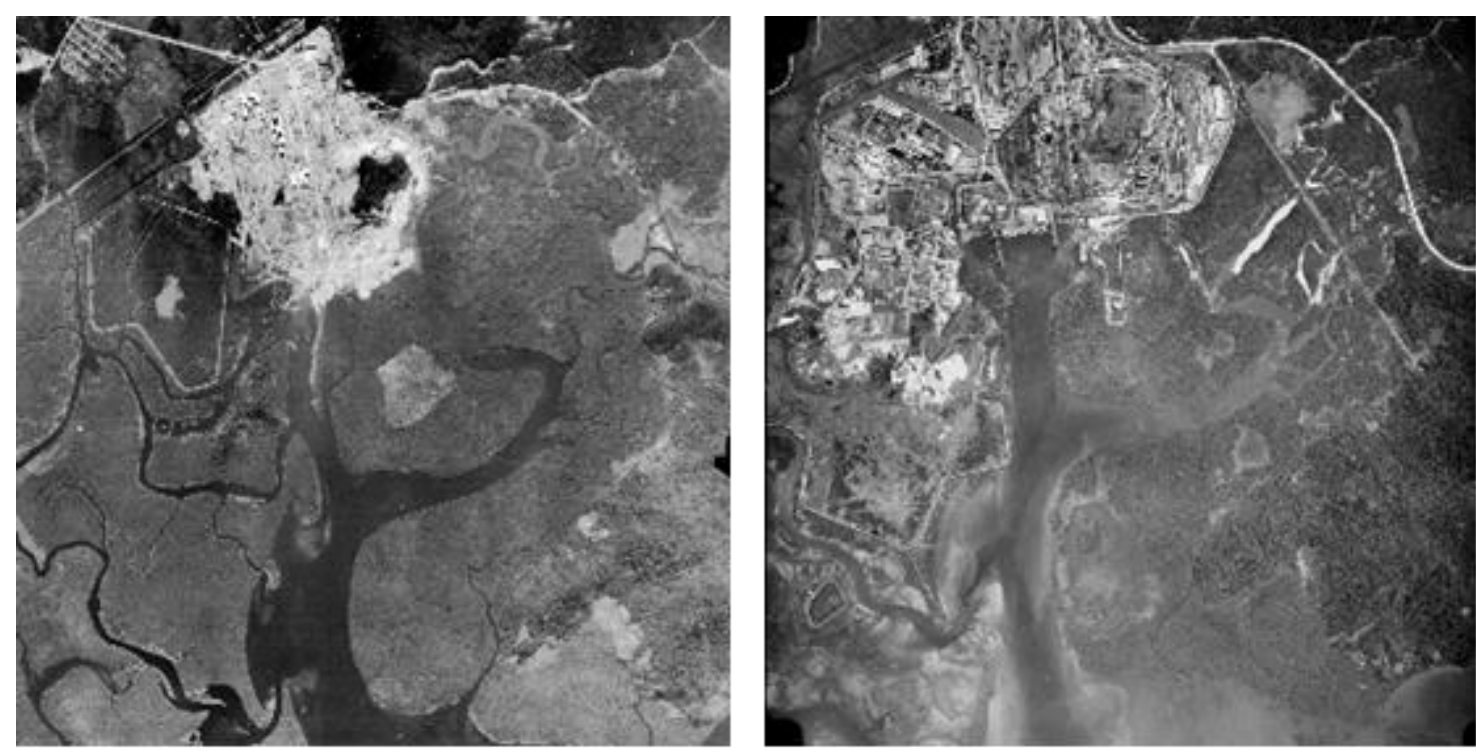

Figura 6 Detalhes de fotografias aéreas da região do Canal da Cosipa (Cubatão) em 1962 (esquerda) e em1994 (direita).

Também foram consideradas fotografias aéreas verticais, em formato analógico, dos anos de 1962, 1977, 1994 e 2000, realizadas por empresas de aerofotogrametria diversas.. Tais fotografias correspondem a algumas partes da área de estudo, principalmente de regiões próximas ao Canal de Santos.

As fotografias aéreas oblíquas utilizadas foram o banco de dados disponível no endereço < www.imagensaereas.com.br >. Trata-se de um banco de imagens da Baixada Santista, datadas principalmente a partir de 2006 e constantemente atualizadas. Tais imagens cobrem praticamente a totalidade da área de estudo e são de grande valia na averiguação de mudanças nas área de mangue, bem como também na escolha de áreas de treinamento para a classificação (item 4.4). Amostras dessas imagens são exemplificadas na figura 8. 


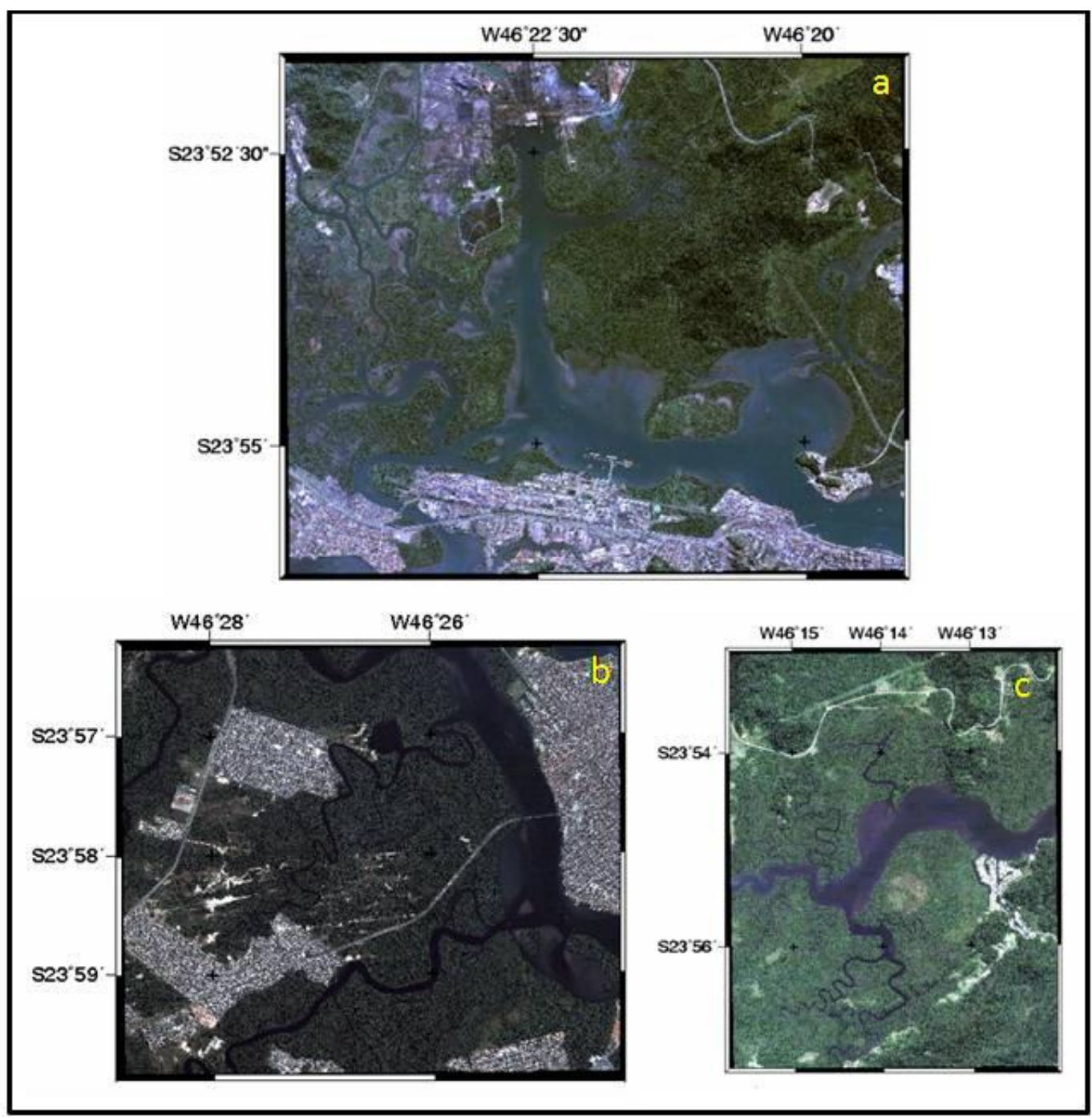

Figura 7 Imagens Quickbird de 2008: (a) entorno de Cubatão, (b) entorno de manguezais no município de Praia Grande e São Vicente e (c) entorno do Largo do Candinho (Canal da Bertioga).
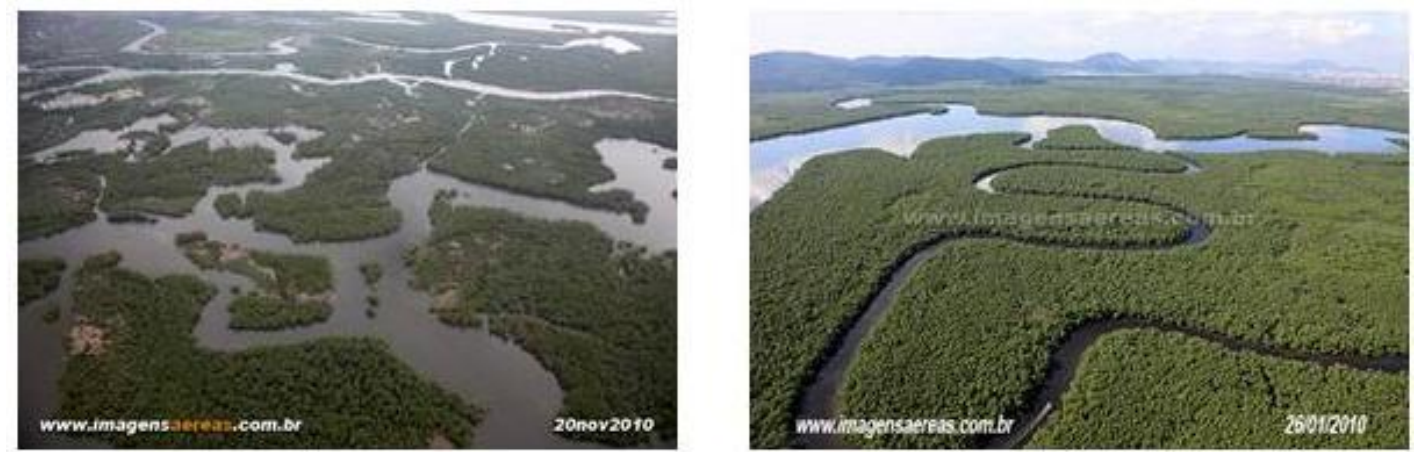

Figura 8 Fotografias áreas oblíquas da região de Cubatão (esquerda) e Canal da Bertioga (extraídas do site www.imagensaereas.com.br). 
Os dados relativos a topografia se referem aos resultados da iniciativa TOPODATA (Valeriano, 2008), que cobrem todo o território nacional. Tais dados resultam da modelagem de dados SRTM (Shuttle Radar Topographic Mission), com resolução espacial original aproximada de $90 \mathrm{~m}$ convertidas, através de krigagem ${ }^{15}$, para $30 \mathrm{~m}$. Vários parâmetros geomorfométricos são calculados e disponibilizados por esta iniciativa. Os dados utilizados neste trabalho se resumem ao MDE disponibilizado em formato GeoTiff, referentes as folhas 23_48, 23_465 e 24_48, de modo a cobrir toda a área de estudo.

As informações maregráficas (altura da maré) quando do imageamento das cenas utilizadas foram adquiridas junto ao Laboratório de Simulação e Previsão Numérica Hidrodinâmica - LabSIP, do Instituto Oceanográfico da USP, coordenado pelo Prof. Dr. Joseph Harari. Por motivos de disponibilidade, foram adquiridos os dados referentes aos anos de 1985, 1989, 1995, 1999, 2002 e 2005. Os dados de 1985 e 1989 referem-se aos medidos em Torre Grande ( $\left.23^{\circ} 56,85^{\prime} S 46^{\circ} 18,50^{\prime} \mathrm{W}\right)$, enquanto que os demais são do Terminal de Fertilizantes de Conceiçãozinha.

\subsection{Segmentação e classificação}

A etapa de classificação consiste na separação de alvos em uma imagem de Sensoriamento Remoto. Basicamente dois grandes grupos são identificados: a classificação não supervisionada e a supervisionada. A primeira utiliza algoritmos automáticos para separar as classes de uma dada imagem automaticamente, utilizando o número de bandas que o usuário estipular. Já na classificação supervisionada o usuário estipula áreas de treinamento, fornecendo ao algoritmo as áreas em que a classificação irá se basear para realizar o processo.

Foram testados diversos tipos de classificação disponíveis nos softwares considerados neste trabalho, tais como os algoritmos ISOCLASS, 
IsoData, K-Means (não supervisionada), Máxima Verossimilhança, Mínima Distância, Paralelepípido e Distância de Mahalanobis (supervisionada).

Os melhores resultados foram obtidos aplicando uma abordagem relativamente recente no que se refere a produtos de sensoriamento remoto, a classificação orientada a objetos. Este tipo de abordagem em sensoriamento remoto é discutido ao nível de detalhe em Blaschke (2010), enquanto que em manguezais, um estudo aplicando esta técnica foi realizado por Conchedda et al. (2008).

Para aplicar tal técnica nas imagens TM e ETM+ na área de estudo foi utilizado o software SPRING (Câmara et al., 1996), que possui um módulo de operação que permite aplicar a classificação considerando "objetos', diferentemente dos classificadores "pixel a pixel", como os descritos acima. A classificação orientada a objetos usualmente resulta em classes visualmente mais consistentes e mais fáceis de se converter para um projeto em SIG (Espíndola et al., 2006).

O primeiro passo para realizar este procedimento é a segmentação, e o SPRING utiliza um método intitulado de crescimento por regiões, descrito em Bins et al. (1996). A segmentação é aplicada em uma imagem, ou composição colorida, que melhor discrimina as feições de interesse. Dessa forma, foram testadas várias combinações de bandas nos canais RGB, utilizando as bandas individualmente, razões entre bandas, transformações IHS (do inglês Intensity, Hue, Saturation), Tasseled Cap e Componentes Principais.

Para a área de estudo a composição que melhor pareceu ressaltar os bosques de mangue foi uma composição colorida utilizando as razões 7/4, 5/3 e 4/2, nos canais RGB, respectivamente. Esta conclusão foi apoiada na delimitação de bosques realizados por estudos anteriores e também na utilização de imagens de maiores resolução, apresentadas no item anterior.

O algoritmo de segmentação requer como parâmetros de entrada 0 "índice de similaridade" e "área mínima". O primeiro considera o grau de similaridade que os pixels vizinhos possuem para agrupá-los em uma mesma região, em termos de valores de número digital, já o segundo estabelece a área mínima, como o próprio nome diz, a ser agrupada em pixels. Após realizados 
alguns testes optou-se por selecionar, para todas as imagens, os parâmetros similaridade 15 e área mínima 5 pixels.

Uma vez segmentada o passo seguinte foi realizar o treinamento de alvos para ser inserido no algoritmo de classificação, e novamente foram consideradas as fotografias aéreas para tanto. Optou-se por determinar somente duas classes: "mangue" e "não mangue". Tal fato se deve aos objetivos propostos neste trabalho, onde a finalidade principal é discriminar as áreas de manguezal e as mudanças relacionadas a sua cobertura vegetal na Baixada Santista.

Utilizando a imagem segmentada e as bandas originais dos sensores, excluindo as bandas 1, $6($ TM e ETM+) e $8(E T M+)$, foi realizada a classificação supervisionada através do algoritmo de distância de Bhattacharya, com limiar de aceitação (parâmetro de entrada do algoritmo) de 99,9\%. A exclusão da banda 1 se deu por ela não apresentar informação significativa na distinção entre tipos de vegetação e outras áreas, conforme descrito na literatura.

É importante ressaltar que na aplicação da classificação foi de extrema importância usar a topografia como máscara $(>20 \mathrm{~m})$, pois sem a mesma 0 algoritmo frequentemente classificava como "mangue" áreas de sombra localizadas em encostas das vertentes da Serra do Mar. Tal fato se tornava crítico quando tais encostas se encontravam nas proximidades de bosques de mangue, levando o algoritmo a classificar tudo como uma coisa só.

Ainda, após a classificação, uma edição matricial foi necessária afim de eliminar áreas classificadas como "mangue", apesar de estarem em regiões conhecidamente de não ocorrência. Tais áreas ocorreram principalmente próximas a margens de rios, longe da influência do Sistema Estuarino de Santos. 


\subsection{Cálculo de Índices de Vegetação e métricas de paisagem}

Para todas as imagens corrigidas foram calculados os valores do Índice de Vegetação Normalizada (NDVI) e também as componentes da transformação Tasseled Cap (obtida por fatores multiplicativos de cada banda, descritos em Crist \& Cicone, 1984), que resultam em três imagens: Brightness, Greenness e Wetness. A transformação Tasseled Cap foi utilizada como complemento das análises, por ser relativamente simples de se obter (rotina do ENVI) e por eventualmente poder ajudar nas detecções de mudança obtidas por comparações pós-classificação e por NDVI.

O NDVI é expresso por unidades variando de -1 a $1 \mathrm{e}$, para realizar a análise temporal, evidenciando possíveis mudanças na cobertura vegetal do tipo de manguezal, estes valores foram normalizados de modo que sua variação fosse de 0 a 2 (somou-se o valor 1), possibilitando realizar uma detecção de mudança subtraindo essas imagens umas das outras. Por exemplo, subtraindo a imagem de NDVI do ano de 2010 da imagem de 2008, têm-se valores variando de -2 a 2, sendo que quanto mais próximo de 2 mais "vigorosa" a vegetação se tornou, ao passo que valores negativos e mais próximos de -2 , houve perda significativa de vegetação ou menos "vigorosa" ela se tornou. Tal análise baseia-se no fato de que valores absolutos originais de NDVI indicam uma estreita relação na proximidade dos dosséis ${ }^{16}$, conforme descrito na literatura.

Já os parâmetros de métrica da paisagem foram obtidos através do programa Patch Analyst ${ }^{17}$, sendo este um aplicativo incorporado (plugin) do ArcGIS. Todas as áreas de mangue, de cada ano, oriunda da classificação, foram inicialmente convertidas do formato raster para vetorial, suavizando as bordas, de modo que as medidas de métrica, principalmente as que envolvem área e perímetro, fossem algo mais próximo do real. Dessa forma, os parâmetros de métrica foram calculados ao nível de classes e manchas.

16 Estrutura de folhagens das árvores.

17 Disponível em < http://flash.lakeheadu.ca/ rrempel/patch/ >. 


\subsection{Estruturação do Banco de Dados baseado em um Sistema de Informações Geográficas}

Todos os dados gerados foram incorporados em um Sistema de Informação Geográfica (SIG), e o sistema utilizado para tanto foi o ArcGIS.

Primeiramente os polígonos de áreas de manguezal de cada ano analisado, gerados na classificação, foram incorporados sob a forma de vetores, tanto com as bordas suavizadas utilizadas para a obtenção das medidas de métrica da paisagem como conservado as suas bordas originais, utilizados nas análises zonais.

As análises zonais se deram utilizando as imagens de NDVI, Brightness, Greenness e Wetness, sob a forma de raster, contendo um valor associado para cada pixel, de $30 \mathrm{~m}$. Tais análises consistem na obtenção de parâmetros relacionados a cada imagem considerando cada "mancha" de mangue, ou seja, cada bosque derivado da classificação por regiões. Os parâmetros obtidos dessa análise zonal para cada bosque são área, contagem de pixels, valores mínimo e máximo, média e desvio padrão. Este procedimento foi executado através da extensão do software ArcGIS, denominada Spatial Analyst.

As análises de detecção de mudança também foram realizadas no SIG, através de comparações pós-classificação e de NDVI.

Dessa forma, todos os dados foram armazenados em uma mesma base, permitindo realizar comparações e operações entre todos os parâmetros calculados, tanto das análises zonais, dos parâmetros de métricas da paisagem e detecção de mudança, possibilitando manipular o banco de dados de uma forma interativa com o usuário e realizando análises espaciais mais refinadas, o que seria muito difícil manipulando os dados manualmente e estabelecendo comparações visuais. 


\section{RESULTADOS E DISCUSSÃO}

Optou-se, neste trabalho, realizar a discussão na medida em que os resultados são apresentados, facilitando a visualização dos mesmos sempre que necessário.

Primeiramente são discutidas algumas considerações sobre 0 processamento digital de imagens, seguida da apresentação das condições de maré quando do momento de aquisição das imagens. Em seguida são tecidas as considerações sobre as principais mudanças ocorridas no período analisado. e, finalmente, os resultados relativos à estrutura da paisagem do ecossistema manguezal no Sistema Estuarino de Santos são discutidos, bem como uma análise conjunta da metodologia e os resultados obtidos.

\subsection{Considerações sobre 0 processamento digital de imagens}

Os mosaicos das cenas das órbitas-ponto 219/077 e 219/076 foram obtidos com êxito, como mostra a figura 9, uma vez que as datas coincidiam e, portanto, o trabalho foi facilitado, não necessitando de processamento separado das mesmas no que diz respeito às classificações, fato este ás vezes rotineiro devido a discrepâncias relativas à diferenças nas condições de atmosfera e ruídos do sensor.

Foram obtidos, para todas as datas, um erro quadrático médio total (RMS total) inferior a 0,3 , ou seja, um erro relativo ao posicionamento das imagens inferior a 9 metros (considerando o tamanho de 30 metros de pixel das imagens TM e ETM+) em relação a imagem utilizada como base, do

catálogo GeoCover. Cabe ressaltar que o RMS total é somente uma média obtida através dos pontos de controle escolhidos, e a acurácia posicional pode variar consideravelmente entre diferentes localidades da área de estudo. De modo geral, não foram verificados erros inerentes ao deslocamento entre as imagens nas análises. 


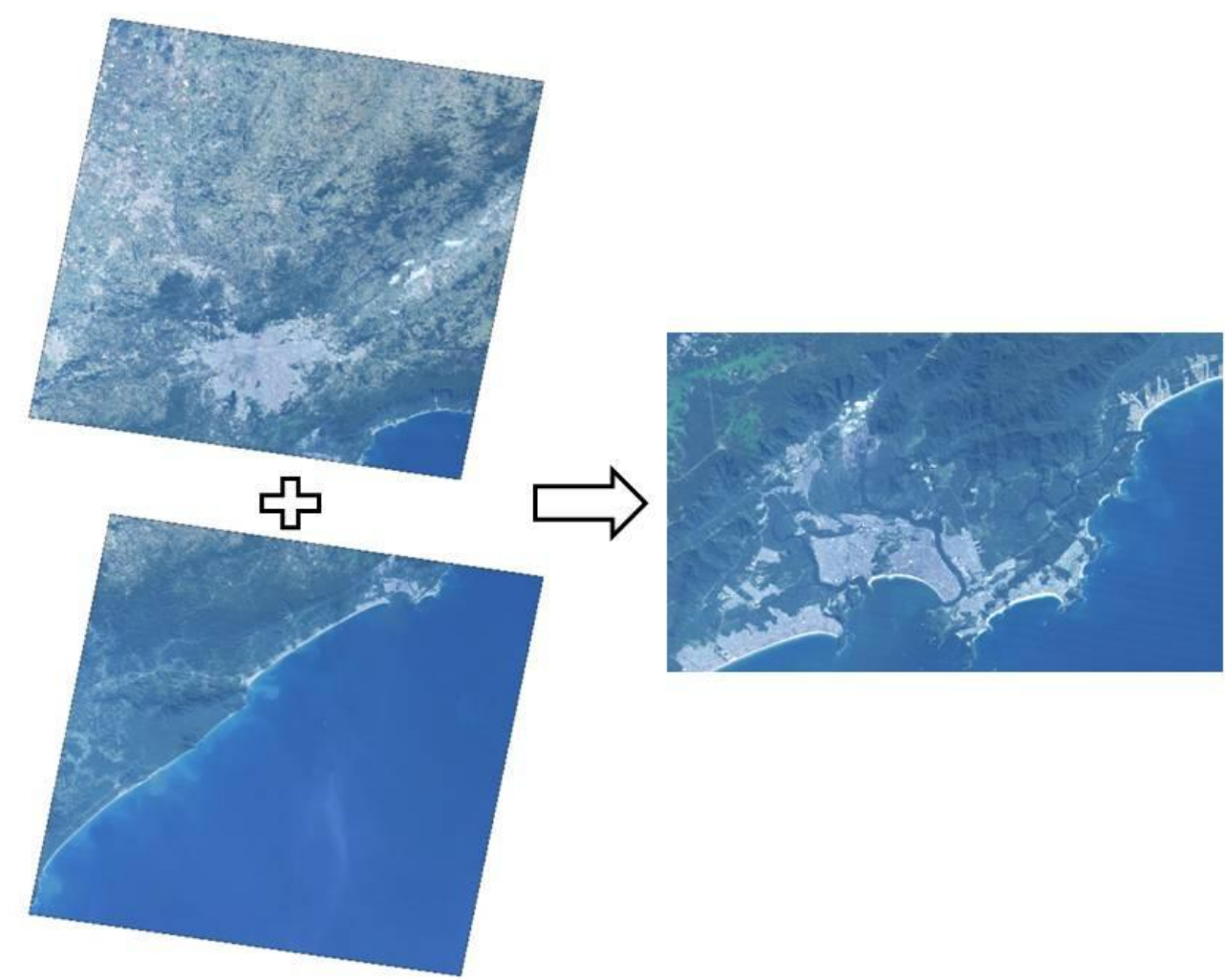

Figura 9 Exemplo de mosaico realizado em dois WRS distintas e recorte para a área de estudo.

Quanto a correção atmosférica, foi obtido para todas as datas uma condição de atmosfera "muito limpa", a exceção da imagem de 1985, a qual obteve uma condição de "limpa", induzindo a utilização dos modelos de espalhamento $\lambda^{-4} \mathrm{e} \lambda^{-2}$, respectivamente, conforme descrito em Chavez (1988), refletindo atmosferas no momento de aquisição da imagem caracterizadas pelo espalhamento Rayleigh ${ }^{18}$. A tabela 5 mostra os valores obtidos na aplicação da correção atmosférica (conforme discutido no item 4.2.2), e que foram subtraídos dos números digitais originais das imagens.

18 Ocorre quando a radiação eletromagnética (REM) interage com moléculas atmosféricas e outras micro partículas que são consideravelmente menores em diâmetro do que o comprimento de onda da radiação. 
Tabela 5 Valores de subtração dos ND's originais das imagens obtidos através da correção atmosférica.

\begin{tabular}{|c|c|c|c|c|c|c|c|c|c|}
\hline Banda & 1985 & 1989 & 1992 & 1995 & 1999 & 2002 & 2005 & 2008 & 2010 \\
\hline 1 & 52 & 34 & 36 & 28 & 48 & 35 & 29 & 22 & 27 \\
\hline 2 & 21 & 11 & 11 & 9 & 15 & 22 & 9 & 7 & 9 \\
\hline 3 & 19 & 7 & 8 & 7 & 11 & 18 & 7 & 5 & 6 \\
\hline 4 & 15 & 4 & 5 & 4 & 6 & 12 & 4 & 4 & 4 \\
\hline 5 & 26 & 4 & 5 & 4 & 5 & 9 & 4 & 4 & 4 \\
\hline 7 & 27 & 3 & 3 & 3 & 4 & 9 & 3 & 3 & 3 \\
\hline
\end{tabular}

Como é verificado na tabela 5, onde maiores valores são subtraídos da imagem do ano de 1985, é identificado a alta dependência do modelo de espalhamento utilizado.

O resultado da aplicação de tal correção afeta diretamente os valores de NDVI, como mostra as figuras 10, 11, 12, 13 e 14. Ao analisar os histogramas de freqüência é notável uma discrepância entre as modas nas imagens sem correção. Por outro lado, quando são comparados os valores nas imagens corrigidas, fica claro que há uma maior coerência entre os dados. Dessa forma, a detecção de mudança utilizando o NDVI pôde ser aplicada considerando mudanças gerais em seus valores.

Um fato a considerar, observando a figura 12, é que a imagem do ano de 2002 mostra uma leve discrepância no histograma, com relação aos outros anos. Isso também é confirmado na detecção de mudança utilizando esta imagem (mapas 31 e 32 , Anexo $\mathbf{A}^{19}$ ) através de comparações com os outros anos, como tratado no item 5.2. Uma possível explicação para esta discrepância pode ser a natureza dos sensores, uma vez que a imagem deste ano é a única oriunda do sensor ETM+.

No que diz respeito às classificações, o procedimento descrito demonstrou, de modo geral, grande fidedignidade na delimitação do contorno dos manguezais, como mostra a figura 15. Logicamente, a detecção de bordas é limitada pela resolução espacial do sensor utilizado.

\footnotetext{
${ }^{19}$ Toda a vez em que for utilizado o termo "mapa", a referência é aqueles situados no Anexo A.
} 
As classificações geradas pelo algoritmo utilizado foram sempre comparadas, quando disponíveis, com as imagens de maior resolução e com as fotografias aéreas oblíquas (figuras 15 e 16).
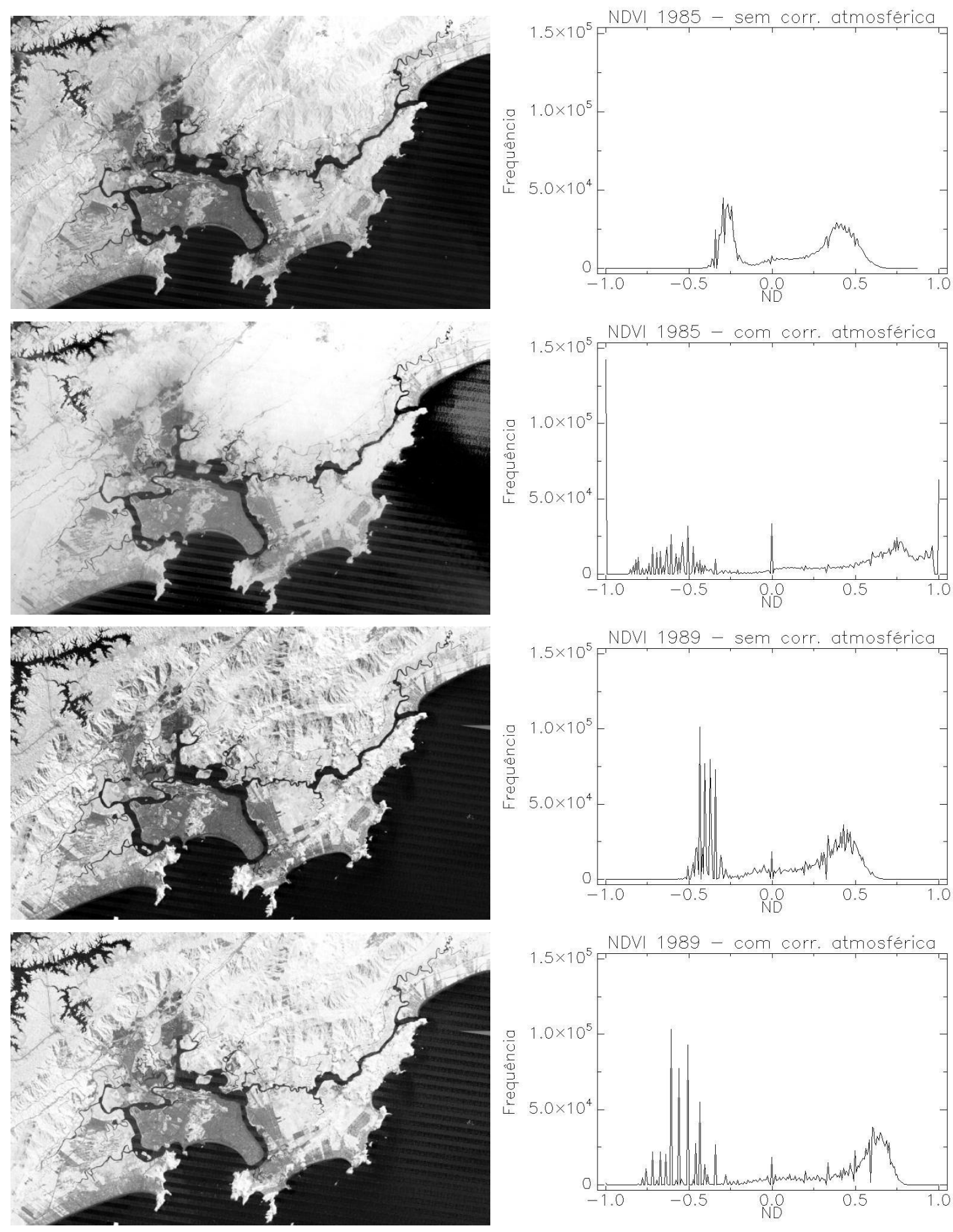

Figura 10 Imagens de NDVI e respectivos histogramas de freqüência para os anos de 1985 e 1989, sem e com a aplicação da correção atmosférica. 

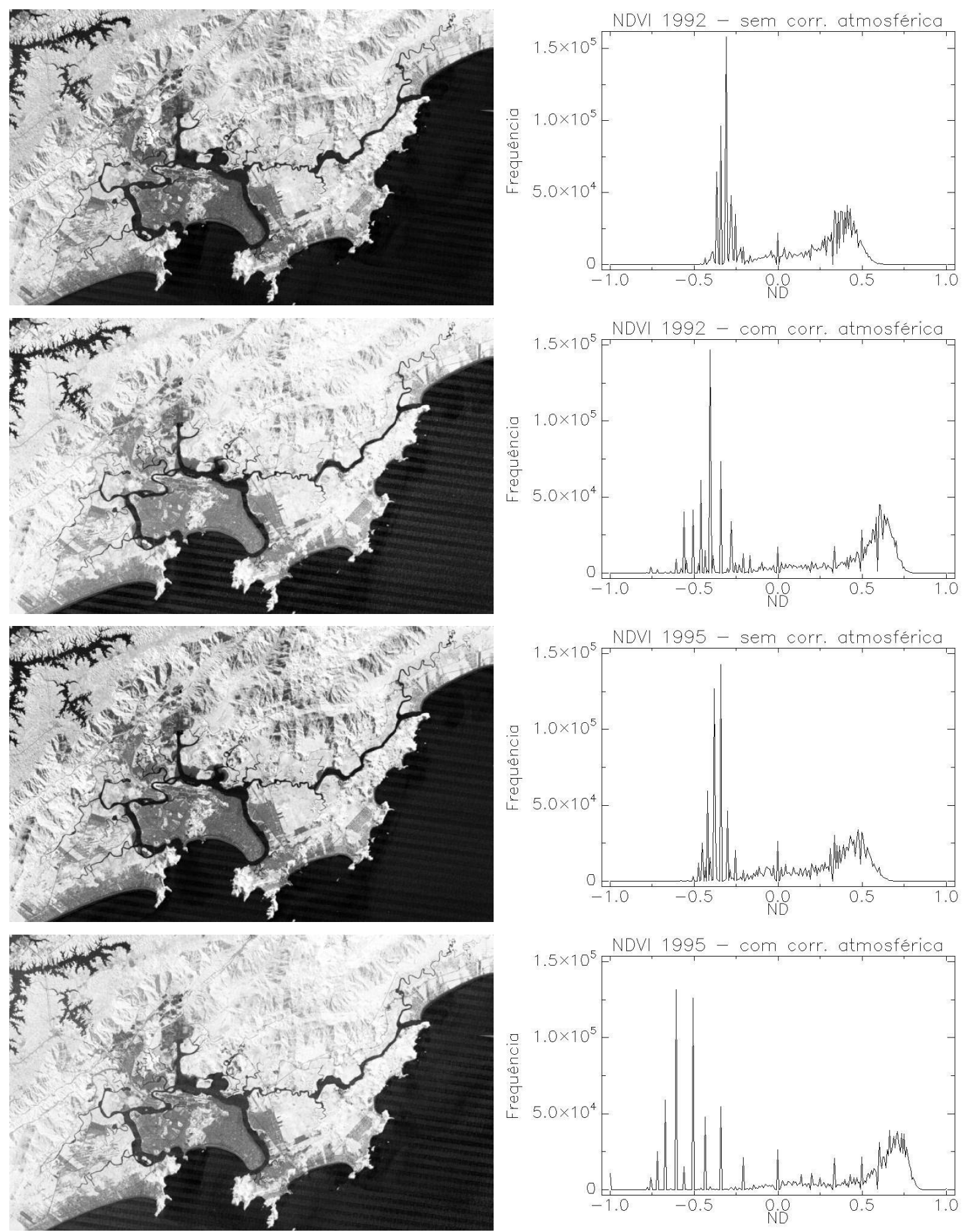

Figura 11 Imagens de NDVI e respectivos histogramas de freqüência para os anos de 1992 e 1995, sem e com aplicação da correção atmosférica. 

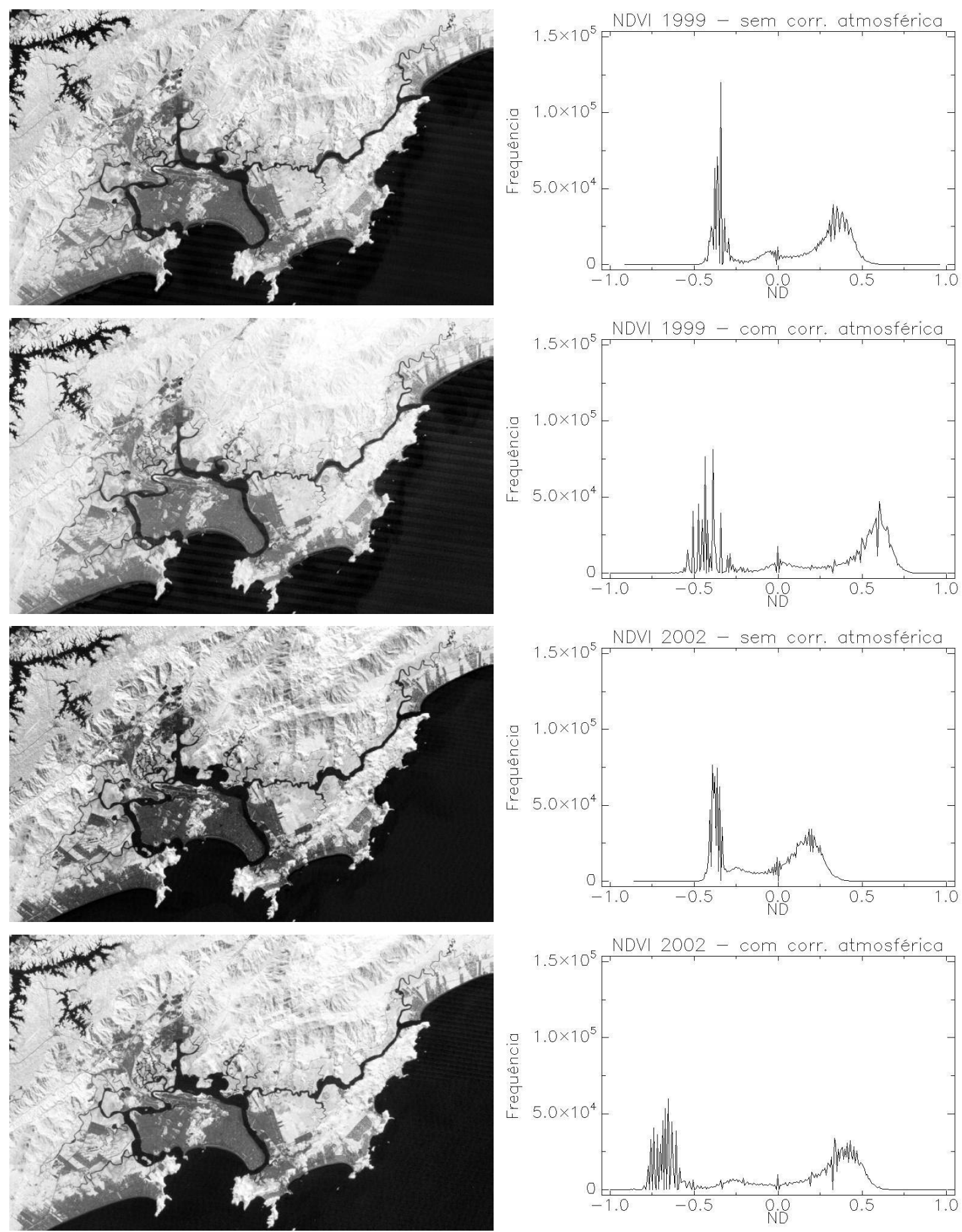

Figura 12 Imagens de NDVI e respectivos histogramas de freqüência para os anos de1999 e 2002, sem e com aplicação da correção atmosférica. 

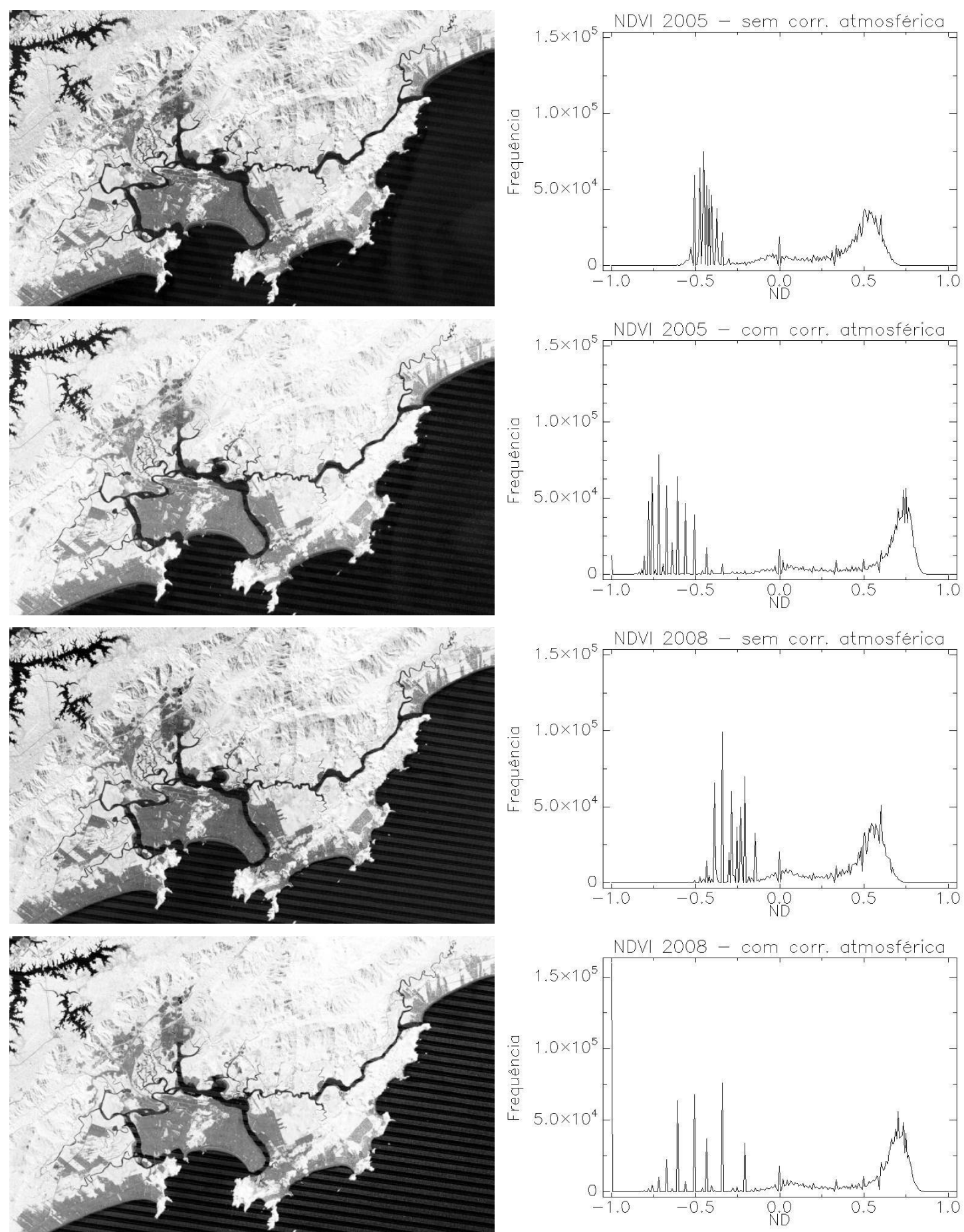

Figura 13 Imagens de NDVI e respectivos histogramas de freqüência para os anos de 2005 e 2008, sem e com aplicação da correção atmosférica. 

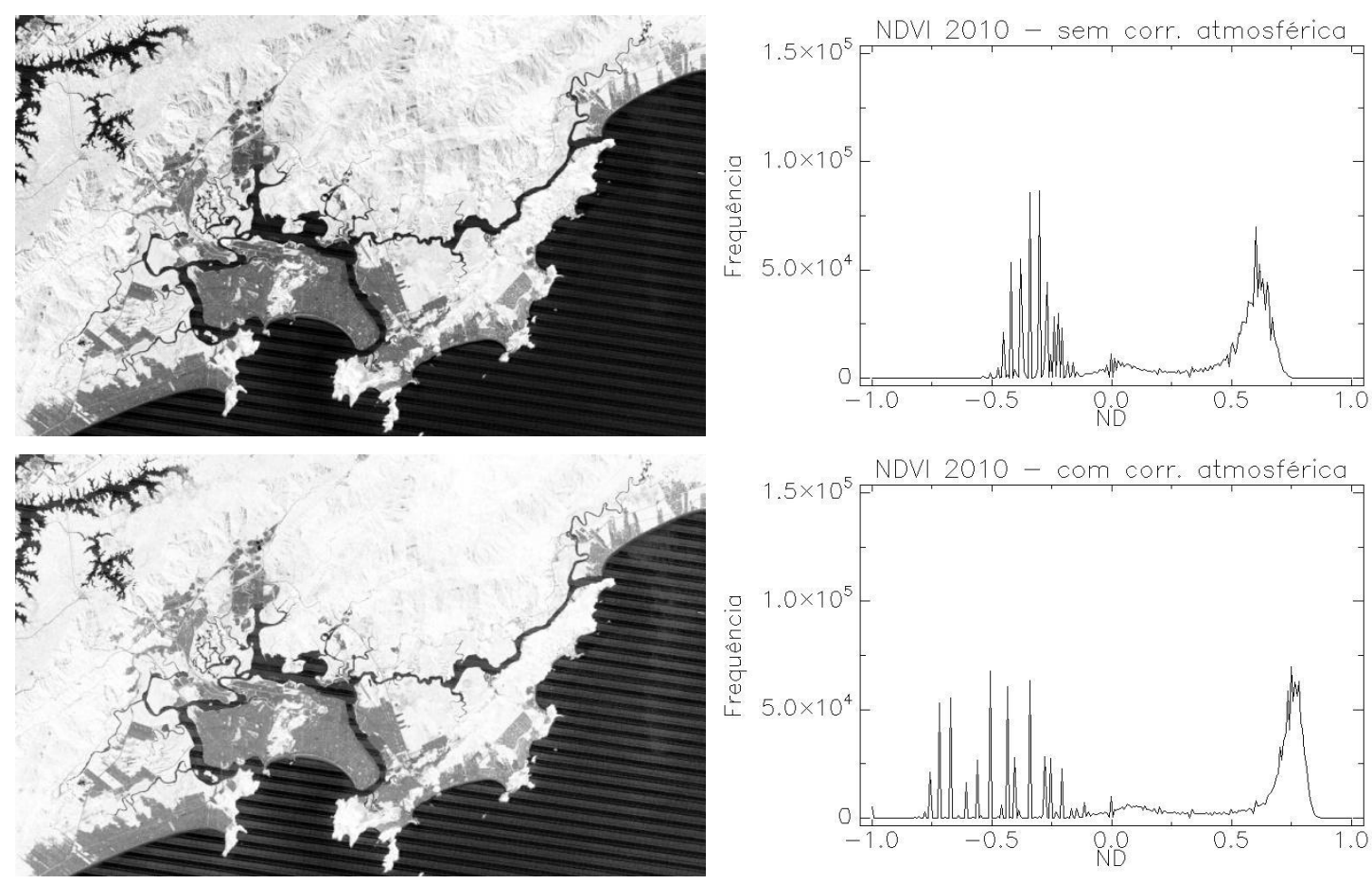

Figura 14 Imagens de NDVI e respectivos histogramas de freqüência para o ano de 2010, sem e com aplicação da correção atmosférica.

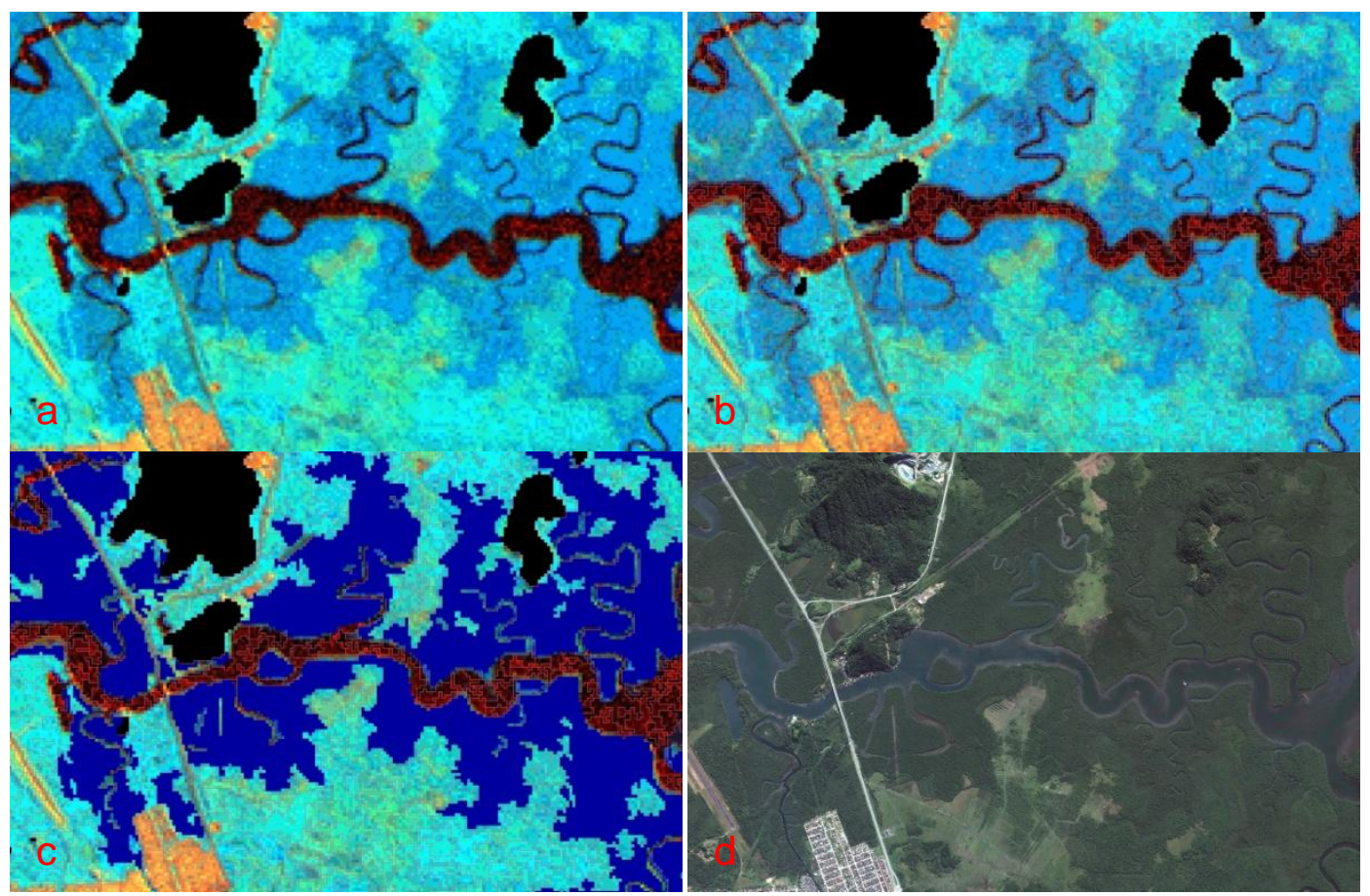

Figura 15 Parte da imagem do ano de 2008, nas proximidades da parte oeste do Canal da Bertioga, mostrando o procedimento realizado na delimitação das áreas de manguezal. a) Composição RGB $7 / 4$ 5/3 4/2; b) imagem segmentada sobre a composição; c) área classificada; d) comparação com imagem Quickbird. 


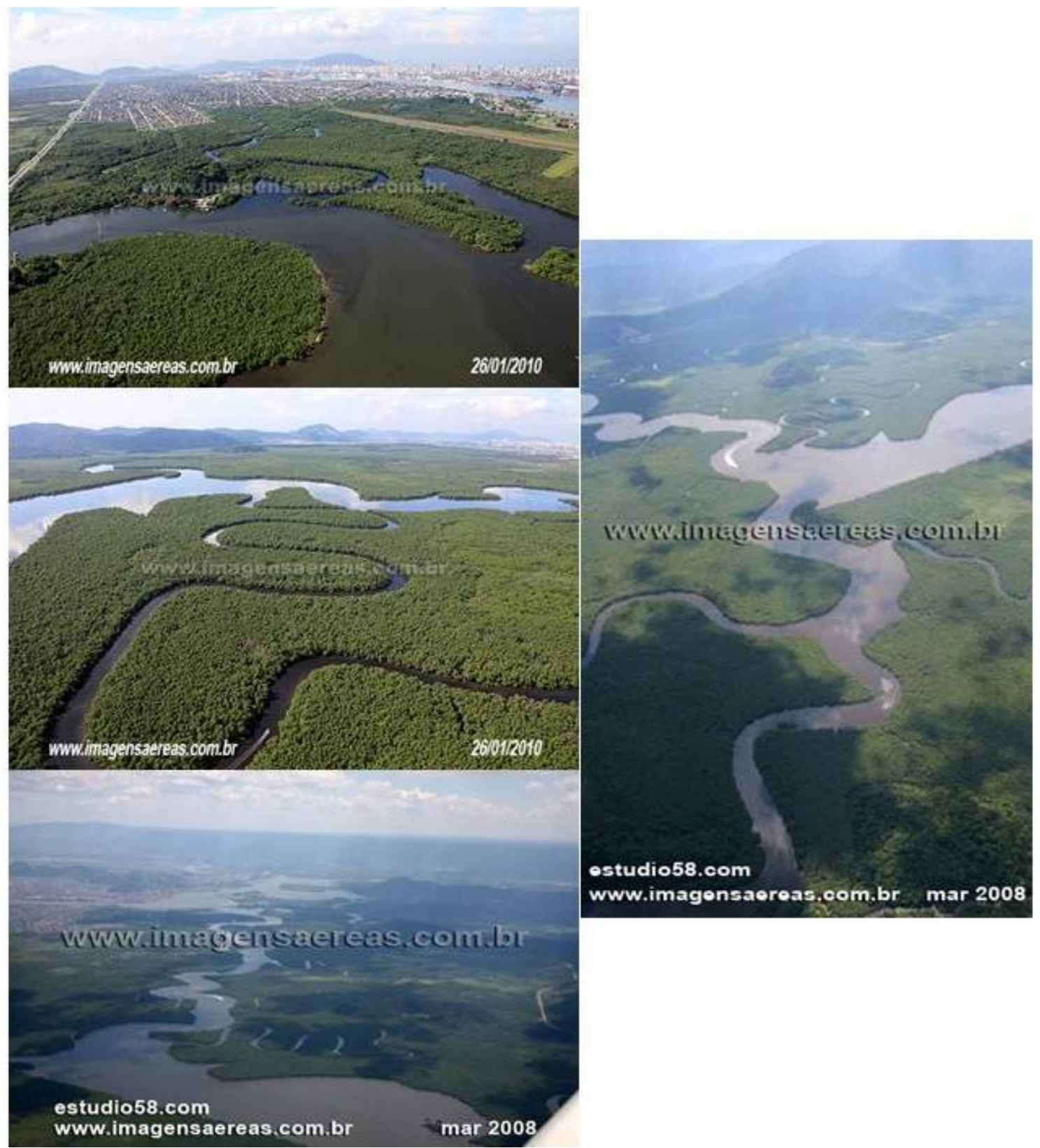

Figura 16 Fotografias aéreas oblíquas da região mostrada na figura 15, mostrando as áreas de manguezal na porção oeste do canal da Bertioga. Fonte: www.imagensaereas.com.br. 


\subsection{Dados maregráficos}

Os dados de maré no momento de aquisição das imagens apresentaram, de modo geral, condições de sizígia em sua maioria, com exceção dos anos de 1985 e 1989, que corresponderam a características mais comuns de quadratura (figura 17), conforme comparação com valores apresentados por Harari et al. (1990)
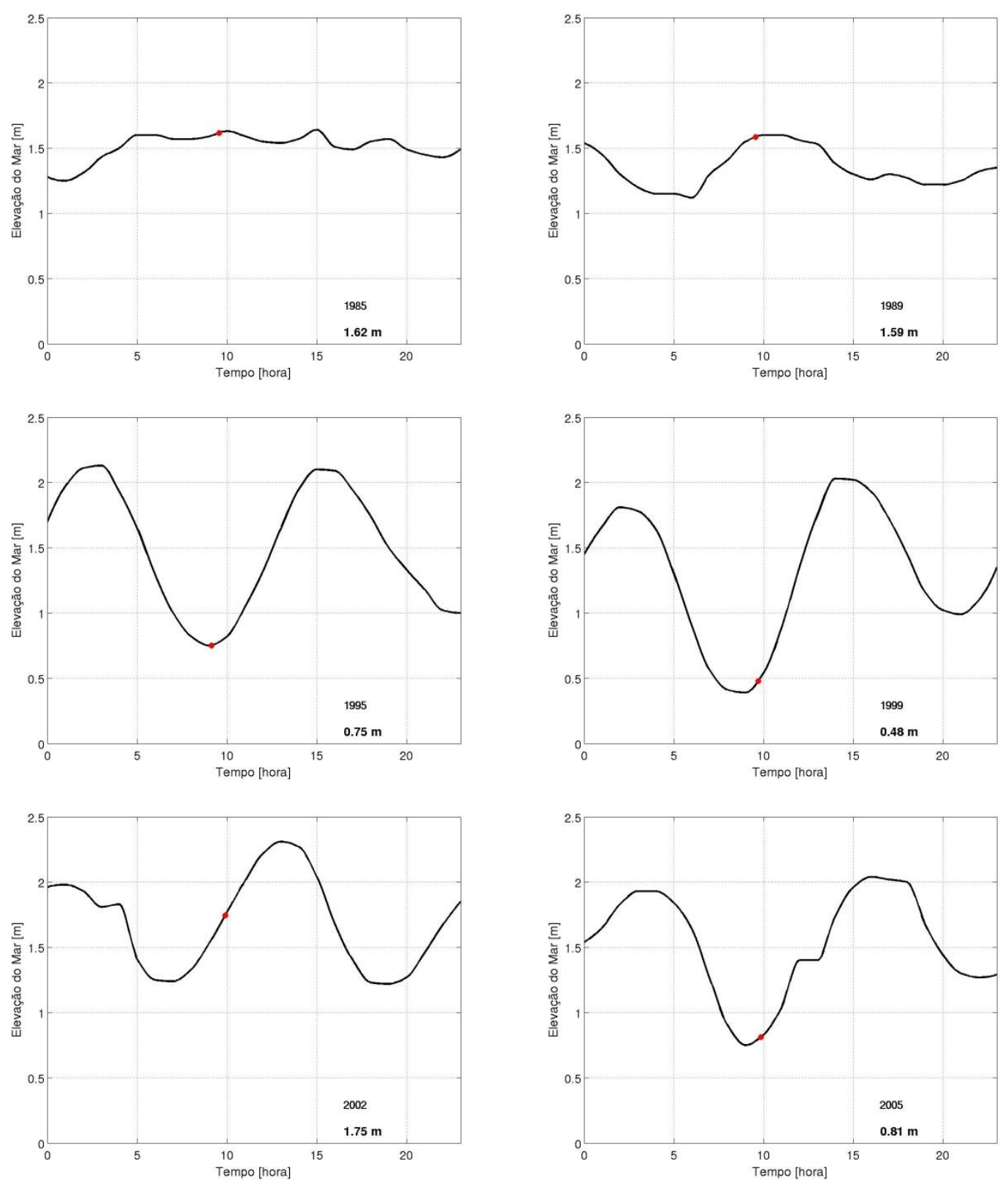

Figura 17 Dados de maré referentes aos dias de aquisição de algumas imagens utilizadas neste trabalho (horário local). 
Um importante aspecto a se notar são as feições de baixios, i.e., bancos de areia e/ou lama que chegam a ficar quase em exposição subaérea em algumas imagens, refletindo exatamente condições de maré baixa, como mostra a figura 18, nos anos de 1995, 1999 e 2005.

A análise conjunta de sensores remotos ópticos e dados de maré representa uma alta possibilidade na extração de batimetria em profundidades rasas, como no estudo de Krug \& Noernberg (2007), na Baía de Laranjeiras, no norte do estado do Paraná, com implicações na navegação, modelagem ambiental e planejamento de estudos. Ainda, se considerar imagens multitemporais, há a possibilidade de verificar a dinâmica sedimentar dessas feições.
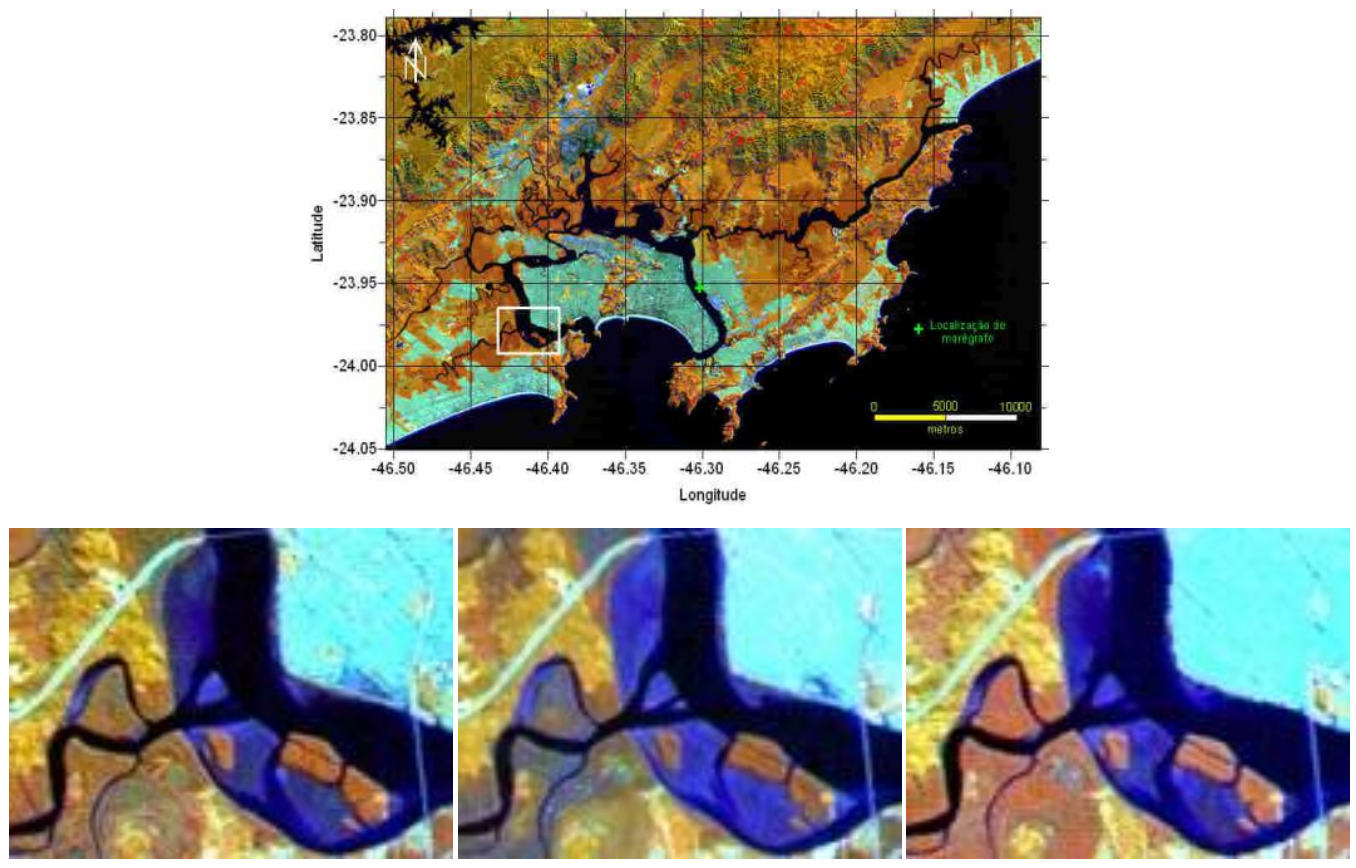

Figura 18 Composição falsa-cor R4G5B3 da região do Mar Pequeno e Largo de São Vicente, dos anos de 1995 (a), 1999 (b) e 2005 (c), evidenciando a presença de baixios.

Ao analisar estas feições nas imagens em que não foi possível obter as informações de maré, é possível estimar a que altura estava a mesma no momento de sua aquisição, comparando com os anos em que este dado estava disponível, aproximadamente, sendo que para o ano de 1992 estimouse uma altura de 1,50m, pra 2008 0,9m e pra $20101,80 \mathrm{~m}$. cabe ressaltar que 
isso é somente uma estimativa visual aproximada, não podendo usar estes valores como verdade absoluta.

Pode-se citar como caso extremo a condição de maré quando do momento de aquisição da imagem do ano de 1999, onde se tinha uma condição de sizígia extrema, e ela foi adquirida próximo a estofa de vazante.

De modo geral, não foi verificada influência da maré no que diz respeito às classificações.

\subsection{Mudanças na cobertura de manguezais do Sistema Estuarino de Santos}

Em um primeiro momento, no intuito de verificar as mudanças ocorridas na cobertura dos manguezais do Sistema Estuarino de Santos, foram analisados o espaço de tempo mais curto considerando a série de imagens utilizadas.

No Anexo A se encontram os mapas gerados, onde são mostradas as áreas de manguezais obtidas para cada ano (mapas de 1 a 9) e também classes de valores de NDVI (mapas de 10 a 18). Em seguida, foram obtidas as análises comparativas ano a ano, i.e., 1989 com 1985, 1992 com 1989, 1995 com 1992 e assim por diante, até 2010 com 2008. Essas análises incluíram as comparações pós-classificação (mapas 19 a 26), evidenciando áreas de perda e acréscimo de manguezais e, também, mudanças nas classes de NDVI normalizados (conforme discutido no item 4.5, mapas de 27 a 34).

Também foram gerados os mapas de mudança considerando todo o período em questão (2010-1985) para se obter as modificações ocorridas nesta escala de tempo (mapas 27 e 28).

A partir dos mapas gerados foram analisadas as áreas onde ocorreram as mudanças mais significativas, que serão descritas a seguir. Optou-se por não dividir em setores a área de estudo, sendo que as mudanças são discutidas ao nível de detalhe em regiões específicas. 
Um dos primeiros fatos a se notar são valores de NDVI relativamente muito baixos no ano de 1985, em regiões de bosques de mangue nas proximidades da porção oeste do Canal da Bertioga, Ilha Barnabé e llha dos Bagres. Tal fato fez com que essas áreas não fossem classificadas como mangue, por estarem associadas a clareiras, regiões desmatadas ou aterros, conferindo uma resposta espectral, na análise, característica de solo exposto.

A figura 19 mostra a evolução temporal da área do entorno da llha Barnabé. Verifica-se claramente que no ano de 1985 havia muitas áreas com valores muito baixos de NDVI, não sendo classificadas como mangue. Ao que tudo indica, houve uma dinâmica de recomposição natural de manguezais na região, como é verificado nas classificações.

De fato, ao realizar estudos na Ilha Barnabé, Menghini (2008) reconheceu diferentes estágios sucessionais de desenvolvimento dos bosques de manguezal utilizando de medidas estruturais, como DAP ${ }^{20}$, altura do dossel e área basal. Os resultados encontrados pelo autor indicam a presença de bosques relativamente "jovens" no local, evidenciando uma possível recomposição, uma vez que na análise de fotografias aéreas mais antigas (1962 e 1972) essas áreas foram interpretadas como mangue.

A figura 20 mostra as áreas do entorno da parte oeste do Canal da Bertioga, próximo ao Canal de Piaçaguera. Os dados levam a crer que, em meados da década de 80 , houve elevada intervenção antrópica nessa região, refletindo na supressão da vegetação de manguezal que, no decorrer dos anos seguintes, mostraram uma gradativa recomposição. Nesta data, esse cenário se espalha por áreas próximas ao largo de São Vicente e ao Canal de Santos, na llha de santo Amaro.

Ainda, no que diz respeito a dinâmica de recomposição de manguezais, nota-se em uma região ao Norte da llha Barnabé (figura 19), um natural crescimento deste tipo de vegetação em torno de um núcleo. Tal processo parece indicar um crescimento gradativo em torno de uma área que

\footnotetext{
${ }^{20}$ Diâmetro Altura do Peito.
} 
um dia teve a vegetação de manguezal suprimida, como mostra a figura 21 , detalhada através de imagens com maior resolução espacial.
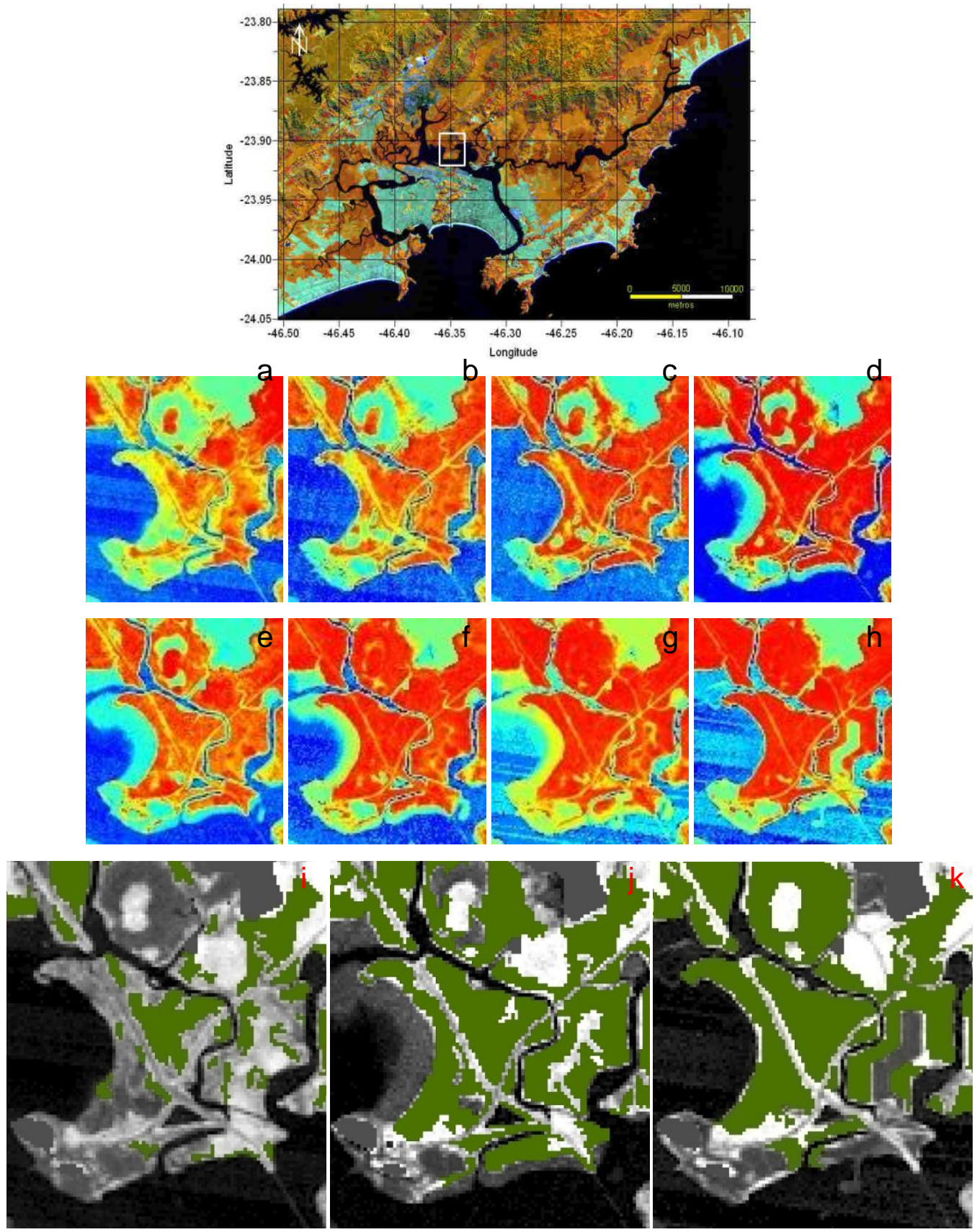

Figura 19 Evolução da cobertura dos manguezais no entorno da llha Barnabé no período compreendido entre 1985 e 2010. As figuras na parte superior (a- $h$ ) correspondem a imagens de NDVI em pseudocor ${ }^{21}$, enquanto as na parte inferior, em maior detalhe, contém as delimitações obtidas pela classificação, correspondentes aos anos (a-i)1985, (b) 1989, (c) 1992, (d-j) 1995, (e) 1999, (f) 2005, (g) 2008 e (k-h) 2010.

\footnotetext{
${ }^{21}$ Tons em vermelho representam maiores valores de NDVI, e tons de azul menores valores.
} 

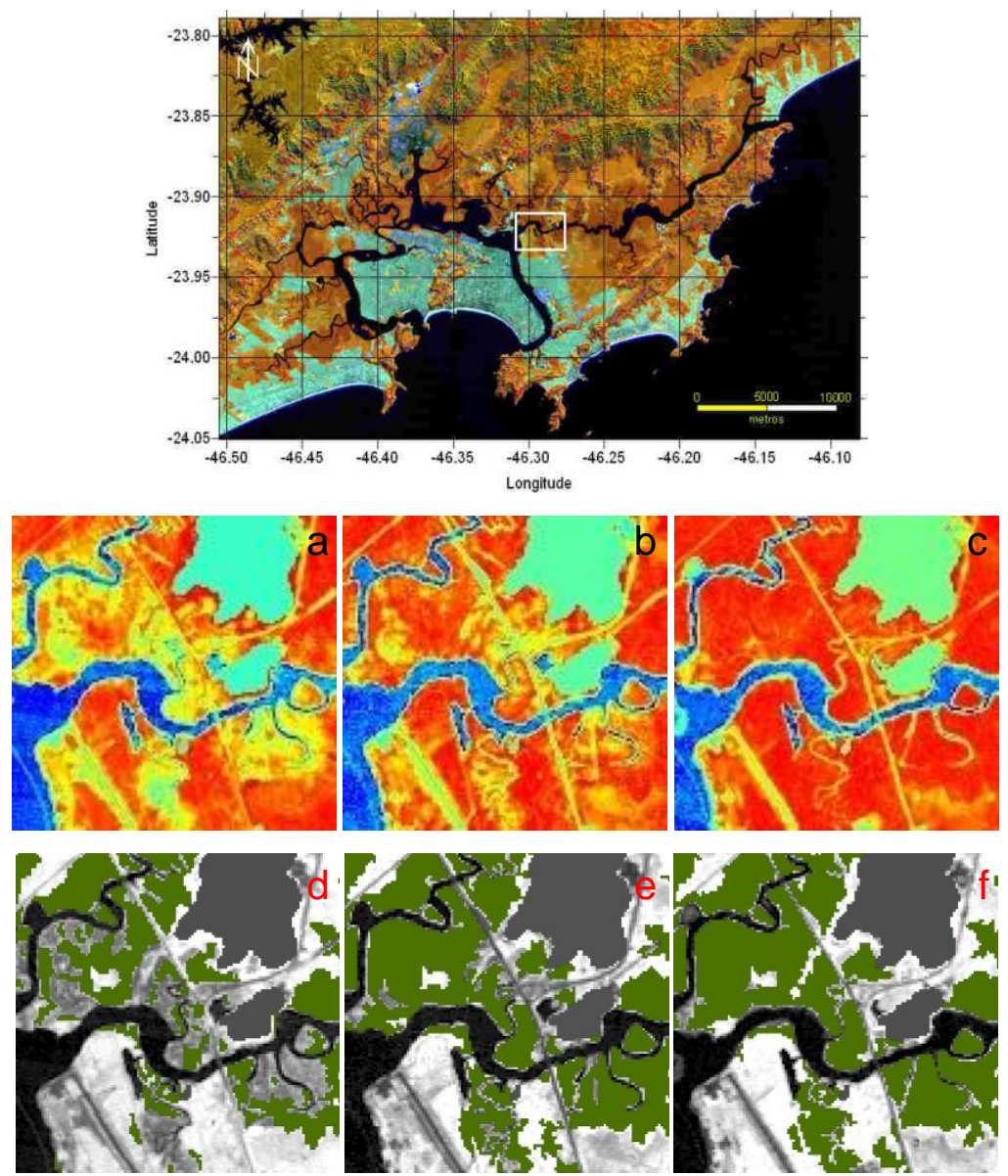

Figura 20 Evolução da cobertura dos manguezais no entorno do Canal da Bertioga, próximo ao Canal de Piaçaguera. As figuras na parte superior (a-c) correspondem a imagens de NDVI em pseudocor, e as na parte inferior contém as delimitações obtidas pela classificação, correspondentes aos anos (a-d)1985, (b-e) 1989 e (c-f) 2010.

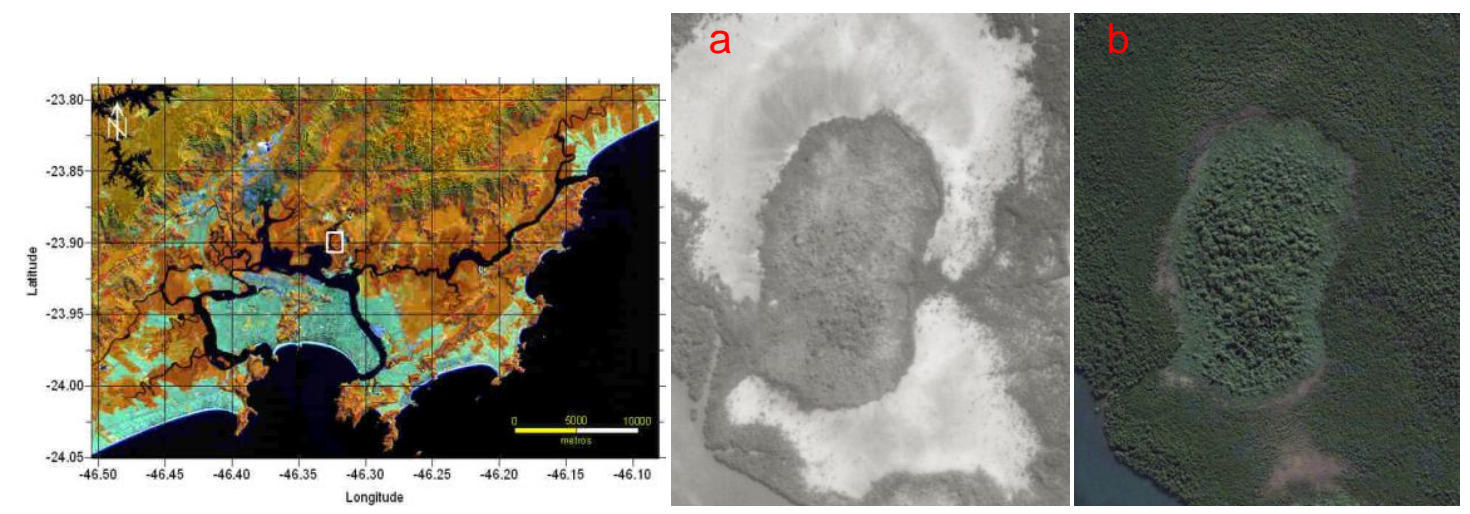

Figura 21 Detalhe de área degradada ao Norte da Ilha Barnabé mostrando aparente recomposição natural entre 1994 (a, fotografia aérea) e 2008 (b, imagem Quickbird). 
Esse processo apresentado na figura 21 é recorrente em algumas localidades, tais como na margem direita do canal da Cosipa e também na llha dos Bagres (figura 22), e é detectável nas imagens TM utilizadas. Tais locais apresentam um histórico de intervenções ligadas às atividades humanas, como é notado no trabalho de Herz (1991), que confere a tais áreas o título de mangue degradado/alterado.

$\mathrm{Na}$ llha dos Bagres ainda, é notado um gradativo aumento do bosque em direção Norte, chegando a juntar-se, a partir do ano de 1995, com a "mancha" de manguezal situado a leste do Canal da Cosipa. Tal fato reflete a dinâmica sedimentar natural da área, uma vez que entre as duas áreas encontrava-se uma zona de franca deposição de sedimentos, propiciando a colonização de novos propágulos de plantas de mangue e, consequentemente, o seu crescimento, até juntar as duas áreas, ajudando a reter ainda mais os sedimentos. Tal análise é um importante fator a considerar quando da realização de obras de dragagem em canais de acesso, comuns na área de estudo, uma vez que essas zonas de colonização de propágulos, proporcionando o aprisionamento de sedimentos, contribuem para um menor assoreamento desses canais, facilitando a sua manutenção.
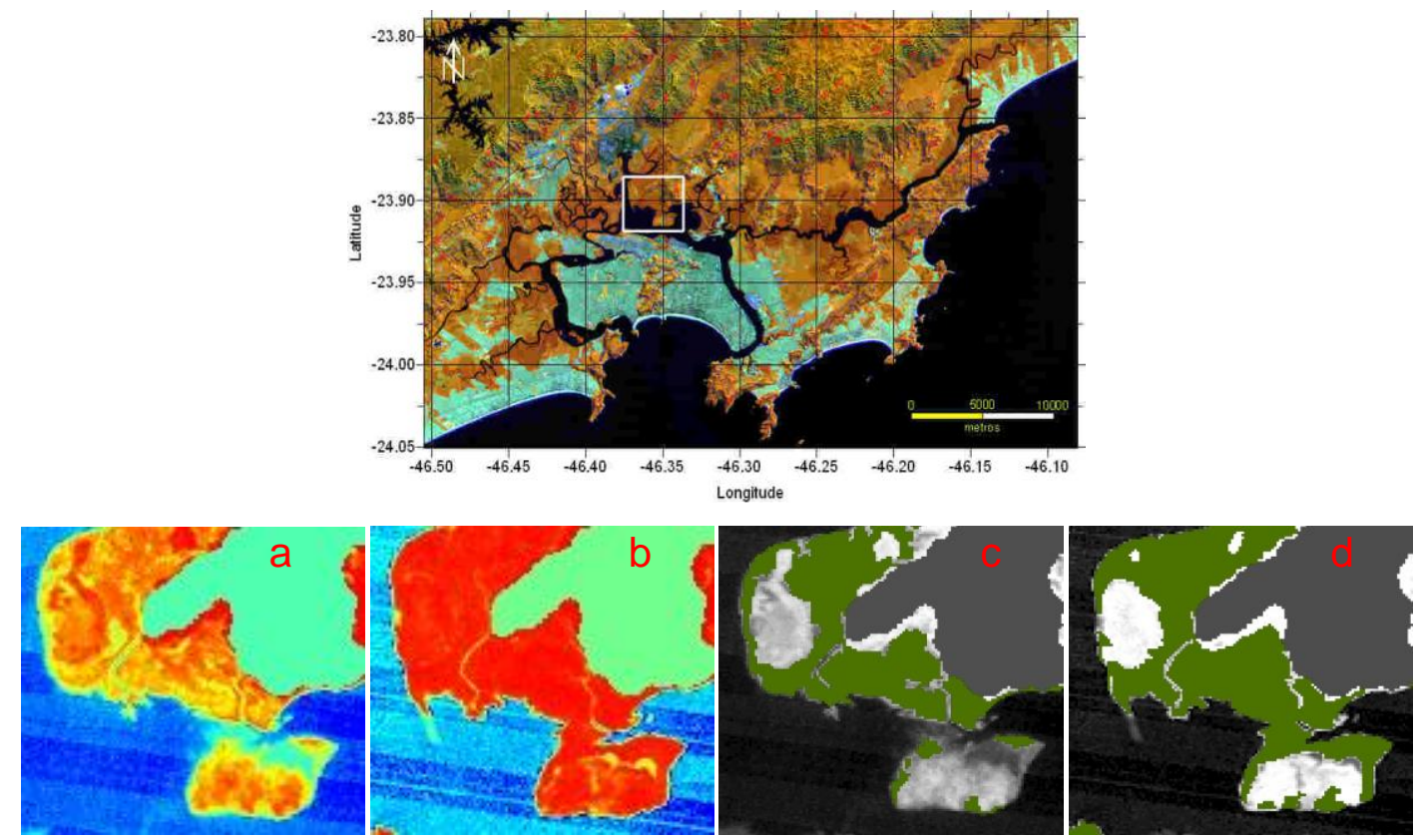

Figura 29 Manguezais associados a Ilha dos Bagres e ao leste do Canal da Cosipa. A esquerda as imagens de NDVI em pseudocor e a direita as respectivas classificações (a-c:1985 e b-d: 2010). 
Retomando a análise da figura 19, é verificado na porção sudeste da Ilha Barnabé, que após a recomposição de manguezais entre 1985 e 2005, a partir de 2008 os mesmos são suprimidos, em área relacionada ao empreendimento do Terminal da Embraport, conforme descreve Costa (2005) e mostra a figura 30 .

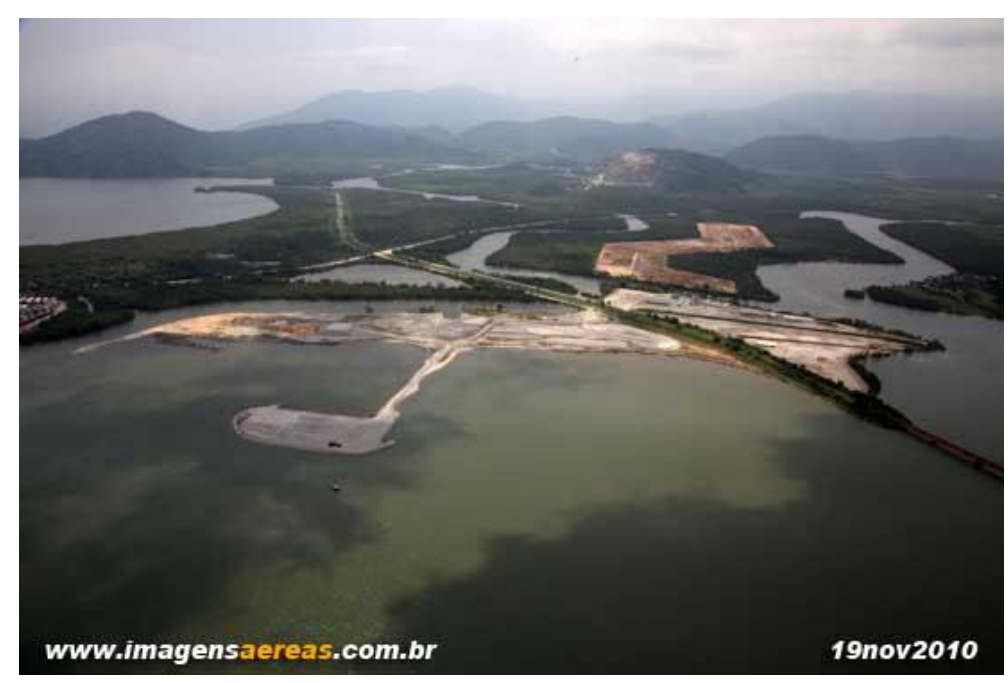

Figura 30 Fotografia aérea oblíqua do empreendimento da Embraport - supressão de manguezais verificados a partir da imagem de 2008. (Fonte: www.imagensaereas.com.br).

A área que apresentou mais dinâmica no que se refere a mudanças de cobertura de manguezal na área de estudo indica uma recuperação de manguezais e eventualmente algum outro tipo de vegetação associada de aproximadamente $6 \mathrm{~km}^{2}$, nos domínios do município de Cubatão, mais especificamente entre o Canal da Cosipa e a saída da Via Anchieta, como mostram as figuras 31 e 32 . É importante ressaltar que essa área, embora apresente respostas espectrais de mangue, ela pode não somente estar associada a este ecossistema, podendo conter vegetações secundárias. Neste caso, além das imagens de alta resolução e fotografias aéreas oblíquas, são necessárias missões de campo no intuito de avaliar o quão representativo na regeneração de vegetação são os manguezais nessa área.

O que pode se afirmar com segurança é que tal área sofreu um processo de colonização de vegetação no período analisado, como mostram todas as figuras do anexo A e a figura 31. Na porção noroeste dessa região 
houve um considerável replantio de mudas de mangue, descritos em Menezes et al. (2005).

O fato é que esta área conferiu alta representatividade nas análises de mudança e nas métricas de estrutura da paisagem, como será tratado no item 5.4 .

Considerando características gerais de uso e ocupação do solo nas proximidades do Sistema Estuarino de Santos, tomando por base todos os mapas do anexo A, é verificado algumas áreas de manguezais que sofreram supressão no decorrer do tempo analisado, tais como em áreas de Cubatão próximas a rodovias e áreas internas situadas na llha de São Vicente, além de outras áreas locadas nas proximidades do Rio Mariana e Rio Piaçabuçu. No Rio Piaçabuçu ainda é verificado uma dinâmica de recomsição de áreas de manguezal na sua conjunção com o Mar Pequeno.

$\mathrm{Na}$ região da llha de Santo Amaro também é verificado áreas de supressão de manguezais em canais estuarinos secundários ao Canal de Santos.

A figura 33 assinala tais áreas, onde a dinâmica de mudança de manguezais principalmente por ocupação urbana desordenada é notada nos mapas do Anexo A.

A conversão de áreas de manguezal em áreas de ocupação humana foi constatada, além pela análise de mudança pela pós-classificação, comparando-se os valores de NDVI, uma vez que áreas urbanas possuem valores negativos desse parâmetro, em contraste aos valores positivos inerentes a maior parte da vegetação. 

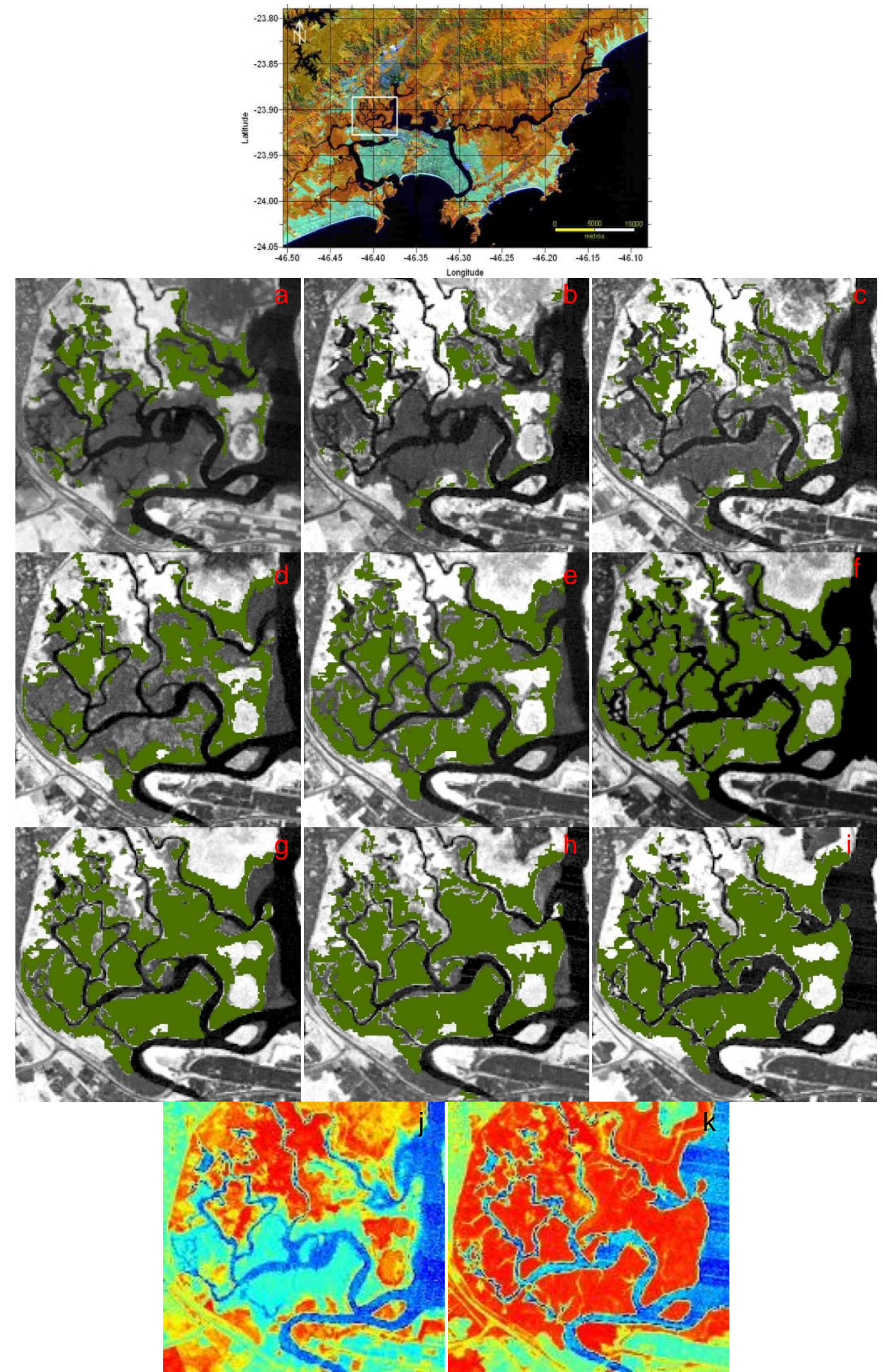

Figura 31 Estágios sucessionais na cobertura de área classificada como manguezal em área na porção oeste do Canal da Cosipa. De 1985 a 2010 (a-i), contendo toda a série de imagens analisadas, e NDVI em pseudocor do ano de 1985 (j) e 2010 (k). 


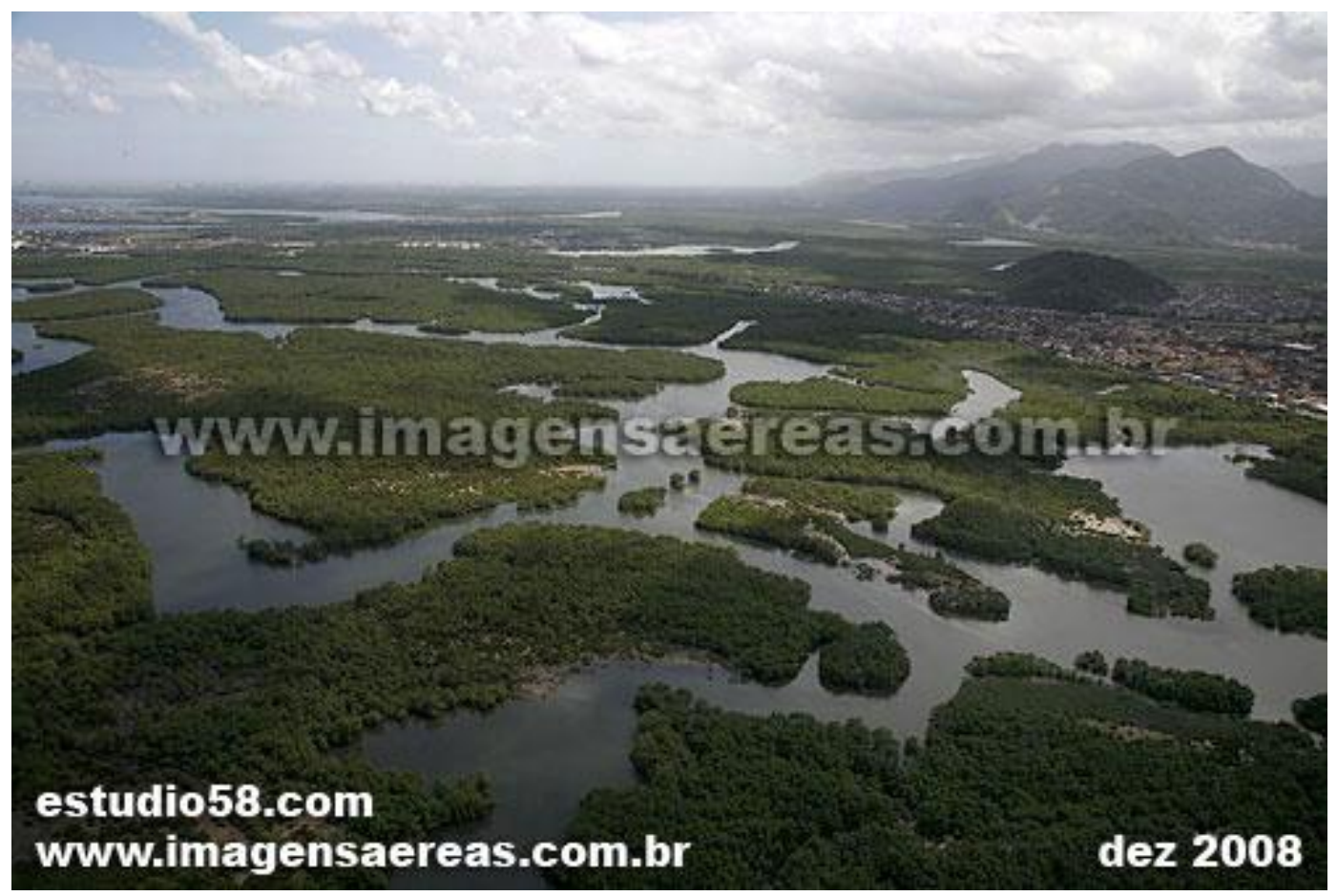

Figura 32 Detalhe em fotografia aérea obliqua da região com alta dinâmica de recomposição de vegetação mostrada na figura 32 . (Fonte: www.imagensaereas.com.br).

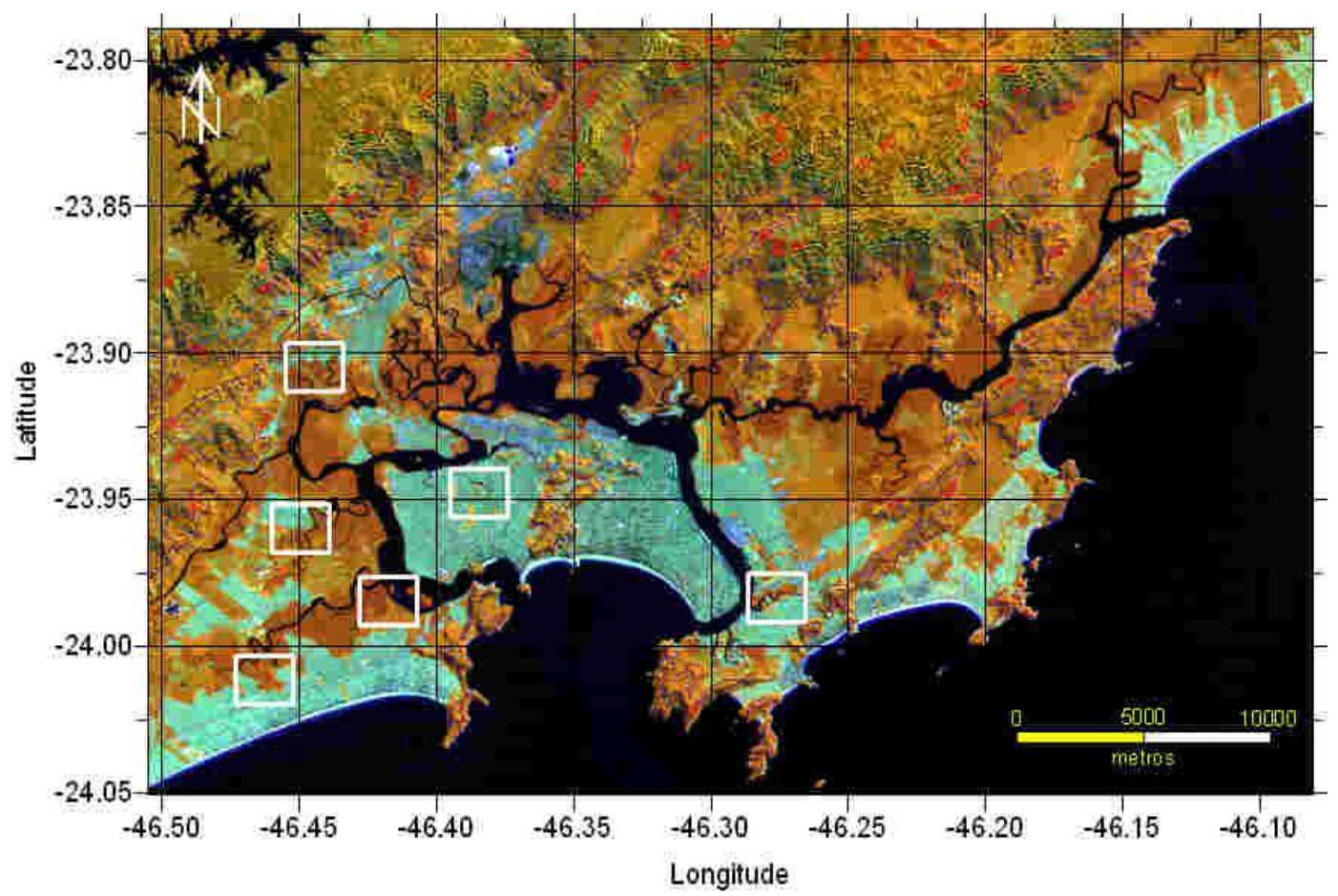

Figura 33 Principais áreas (assinaladas em branco) da área de estudo onde houve dinâmica no uso e ocupação do solo, relacionadas principalmente a supressão de manguezais pela ocupação urbana desordenada. As mudanças ocorridas podem ser verificadas nos mapas do Anexo A. 
Outro resultado de grande relevância para a área de estudo no que se refere a supressão de manguezais é em uma porção do Canal da Bertioga, como mostra a figura 34. As margens do canal sofreram grande erosão de 1985 a 2010, gradativamente. Tal fato pode estar associado a passagens de embarcações em altas velocidades, dada a proximidade de algumas marinas, gerando ondas que remobilizam os sedimentos das margens, causando tal erosão (Tessler, contato pessoal).
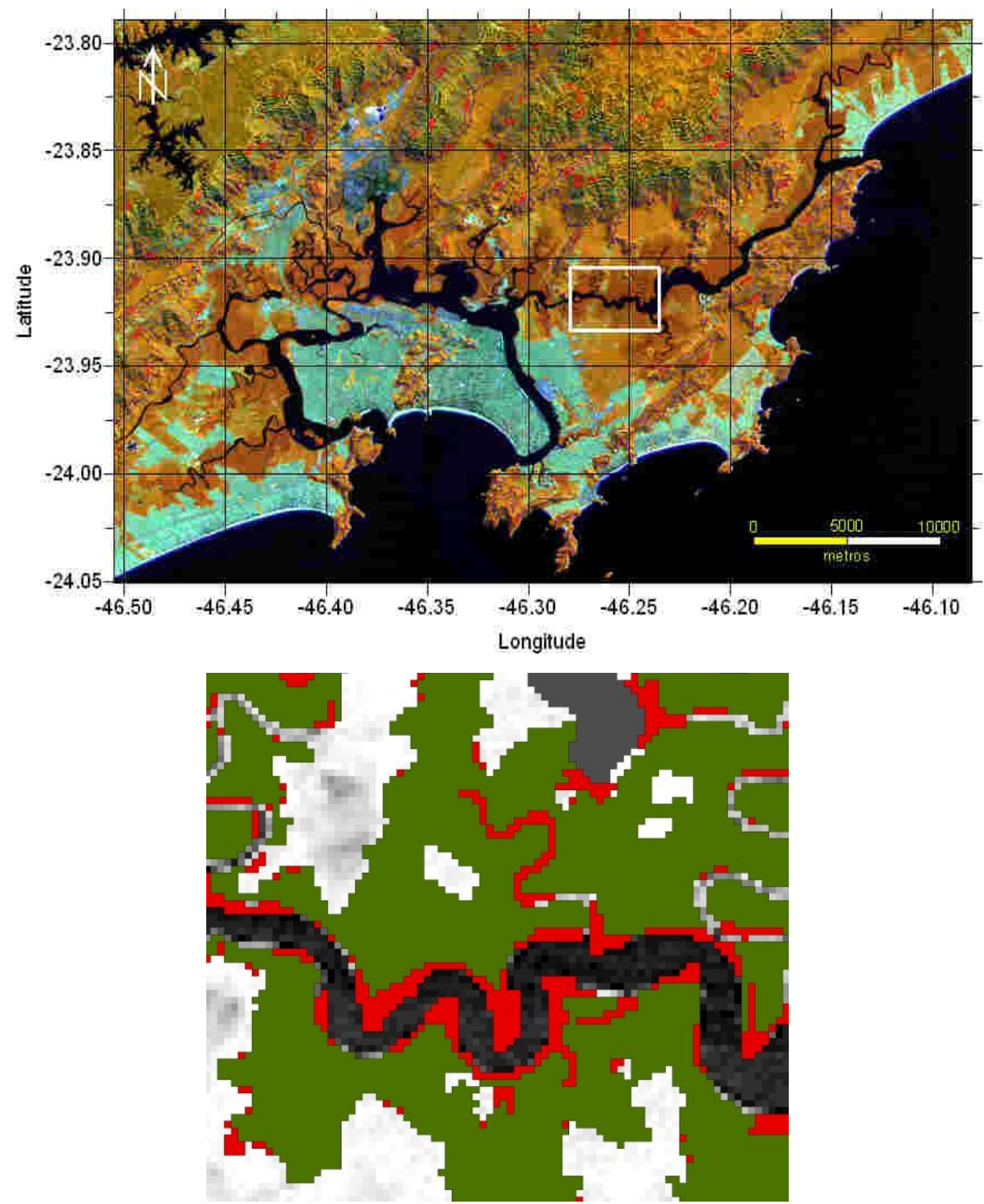

Figura 34 Detalhe da área de manguezais no Canal da Bertioga. Em verde são os manguezais classificados para o ano de 2010, e em vermelho as áreas ocupadas por manguezais em 1985. 
De modo geral, não foram verificadas mudanças significativas em manguezais da porção leste do Canal da Bertioga e do Rio Itapanhaú, salvo exceção feita ao bosque que se encontra na conjunção dos mesmos, entre os anos de 1985 e 1989, como mostra os mapas 19 e 27, onde uma considerável área não foi atribuída como mangue na classificação do ano de 1989, provavelmente associado a uma área de supressão, mas já no ano de 1992 essa área apresentava padrões de recomposição.

\subsection{Métricas da estrutura da paisagem ao nível da classe "manguezal" para o Sistema Estuarino de Santos}

Embora muitos parâmetros de métrica são obtidos quando executado o programa Patch Analyst, poucos possuem relevado interesse ecológico, ou pelo menos pouco se conhece.

No intuito de caracterizar os manguezais do Sistema Estuarino de Santos como um todo, foram levadas em conta as medidas relativas a esta classe considerando a área total, soma das bordas (TE, perímetro total), número de manchas (NP), tamanho médio das manchas (MPS) e índice médio de forma (MSI). Os resultados são apresentados na tabela 6 , acrescentando os dados de NDVI (média de todos os bosques para cada ano), e maré.

Em termos de área total (figura 35), é observado um considerável incremento até o ano de 1995, partindo de $67,63 \mathrm{~km}^{2}$ em 1985, e chegando a $85,75 \mathrm{~km}^{2}$ nesta data. Após este ano a região como um todo exprimiu um comportamento relativamente estável em termos de área, com poucas flutuações. Este fato pode ser atribuído á relativa regeneração de bosques em áreas específicas da região (como discutido no item 5.3), principalmente na região situada a oeste do Canal da Cosipa.

Os valores de área após 1995 se aproximam e chegam até a superar levemente aqueles obtidos por Herz (1991), mostrado na tabela 3, em se tratando das classes de mangue apresentadas neste estudo como "sadios". 
Tabela 6 Métricas da estrutura da paisagem da classe "manguezal" para o Sistema Estuarino de Santos no decorrer do período analisado. Também inclusos as médias de NDVI e alturas de maré.

\begin{tabular}{|c|c|c|c|c|c|c|c|}
\hline DATA & $\begin{array}{l}\text { Altura da } \\
\text { Maré (m) }\end{array}$ & $\begin{array}{l}\text { NDVI } \\
\text { médio }\end{array}$ & Área $\left(\mathrm{km}^{2}\right)$ & TE (km) & NP & $\operatorname{MPS}\left(\mathrm{km}^{2}\right)$ & MSI \\
\hline 06/Out/1985 & 1,62 & 0,45 & 67,63 & 786,22 & 367 & 0,18 & 1,69 \\
\hline 13/Jul/1989 & 1,59 & 0,50 & 73,11 & 821,84 & 341 & 0,21 & 1,69 \\
\hline 05/Jul/1992 & $1,50^{22}$ & 0,50 & 81,36 & 839,88 & 321 & 0,25 & 1,74 \\
\hline 28/Jun/1995 & 0,75 & 0,56 & 85,75 & 924,54 & 302 & 0,28 & 1,78 \\
\hline 26/Ago/1999 & 0,48 & 0,39 & 84,45 & 872,17 & 301 & 0,28 & 1,76 \\
\hline 07/Jun/2002 & 1,75 & 0,20 & 83,41 & 905,82 & 325 & 0,26 & 1,78 \\
\hline 23/Jun/2005 & 0,81 & 0,62 & 85,15 & 859,89 & 288 & 0,30 & 1,78 \\
\hline 17/Jul/2008 & $0,90^{20}$ & 0,61 & 86,41 & 845,06 & 286 & 0,30 & 1,75 \\
\hline 04/Mai/2010 & $1,80^{20}$ & 0,67 & 84,66 & 823,06 & 264 & 0,32 & 1,76 \\
\hline
\end{tabular}

\footnotetext{
${ }^{22}$ Altura de maré aproximada, estimada visualmente por comparação através do grau de exposição de baixios, como discutido no item 5.2 .
} 


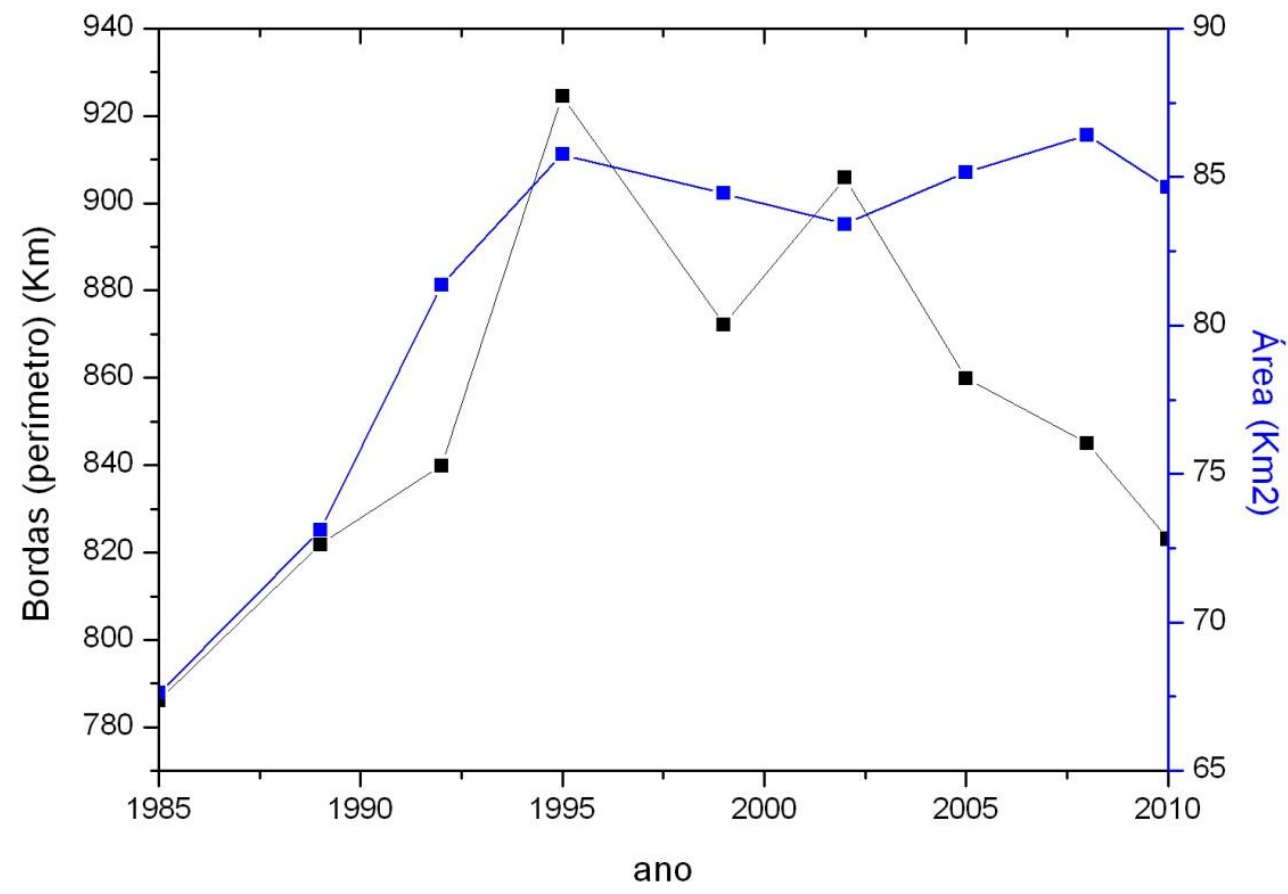

Figura 36 Gráfico mostrando a evolução temporal da área e do perímetro total dos manguezais no período estudado.

A relativa estabilização na medida de área após 1995 ocorre provavelmente devido a variações locais de recuperação / degradação, não passíveis de detectar em uma análise generalista como quando analisado o sistema todo.

O crescimento no valor das bordas (perímetros, figura 36) das áreas de mangue, até 1995, pode ser explicado também pela "recuperação" de bosques, exprimidas pelo fator "área total", ou seja: o perímetro total das áreas de mangue cresceram acompanhando aumento das áreas. A partir de 1995 ocorre um decréscimo nos valores de perímetro (a exceção do período 19992002), o que pode levar a entender que houve tendência das bordas dos bosques de manguezais tornarem-se mais retilíneas, ou "menos complexas".

Tal fato também pode ser corroborado com o número de manchas (figura 37) obtido pro período, que mostra claramente uma tendência de diminuição, embora a área, a partir de 1995, pouco mudou. Este fator pode indicar o agrupamento dessas manchas, não conferindo mudanças na área total, mas diminuindo o perímetro. 


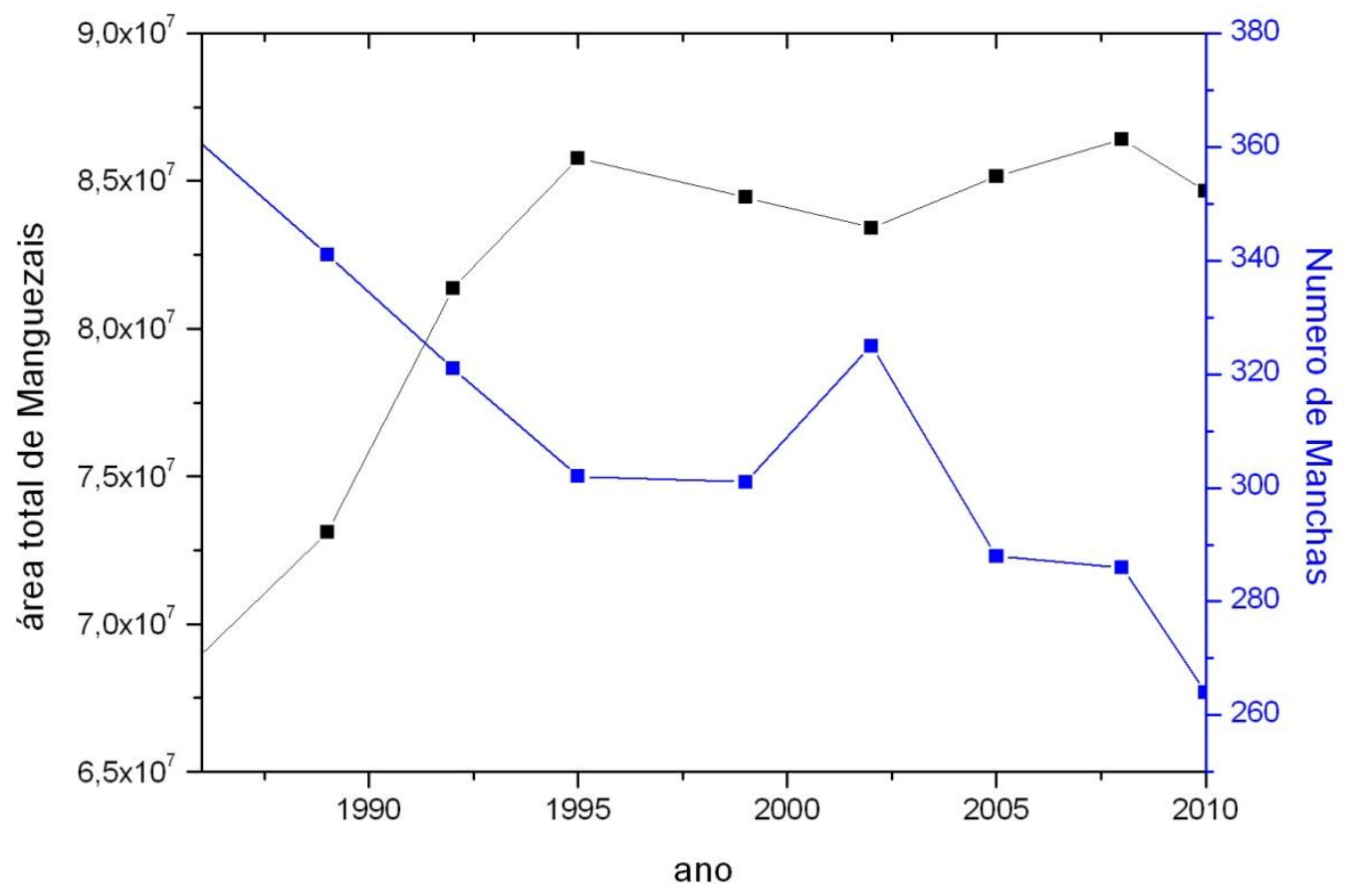

Figura 37 Gráfico mostrando a evolução temporal da área e do número de manchas dos manguezais no período estudado.

Ao que tudo indica, não parece haver relação direta entre a altura da maré e a média geral de NDVI, como mostra a figura 38. É importante ressaltar os baixos valores dessas médias pra os anos de 1999 e 2002. No primeiro caso, esta característica pode estar associada a uma situação de maré baixa extrema, mas maiores informações são necessárias pra confirmar esta hipótese (e.g. como uma outra imagem com condições de maré semelhantes). Já em 2002 a hipótese mais provável é de que se trata de erros referentes a variações nos parâmetros de aquisição do sensor, evidenciando discrepâncias importantes, mesmo tendo-se realizado operações de correção atmosférica, já que esta é a única imagem derivada do sensor ETM+. Possivelmente, operações mais complexas de correção atmosférica e normalização de reflectância (como descritos no item 4.2.3.) poderiam possibilitar uma maior confiança na utilização desta imagem.

Já no que diz respeito ao tamanho médio das manchas, o sistema como um todo apresentou uma tendência crescente nos valores, ou seja, os bosques de mangue apresentaram ganho gradativo em área, em contrapartida com o decrescente número de manchas, evidenciando também o que fora discutido até agora (figura 39). 
O índice médio de forma (figura 40) apresentou comportamento compatível com o da área total, ou seja, um incremento em seu valor até 1995 seguido de uma estabilização. $O$ incremento de seu valor significa formas menos arredondadas, o que em termos de manguezais é esperado, uma vez que a forma dos bosques está diretamente ligada às características topológicas dos canais estuarinos, de formas mais alongadas e contínuas.

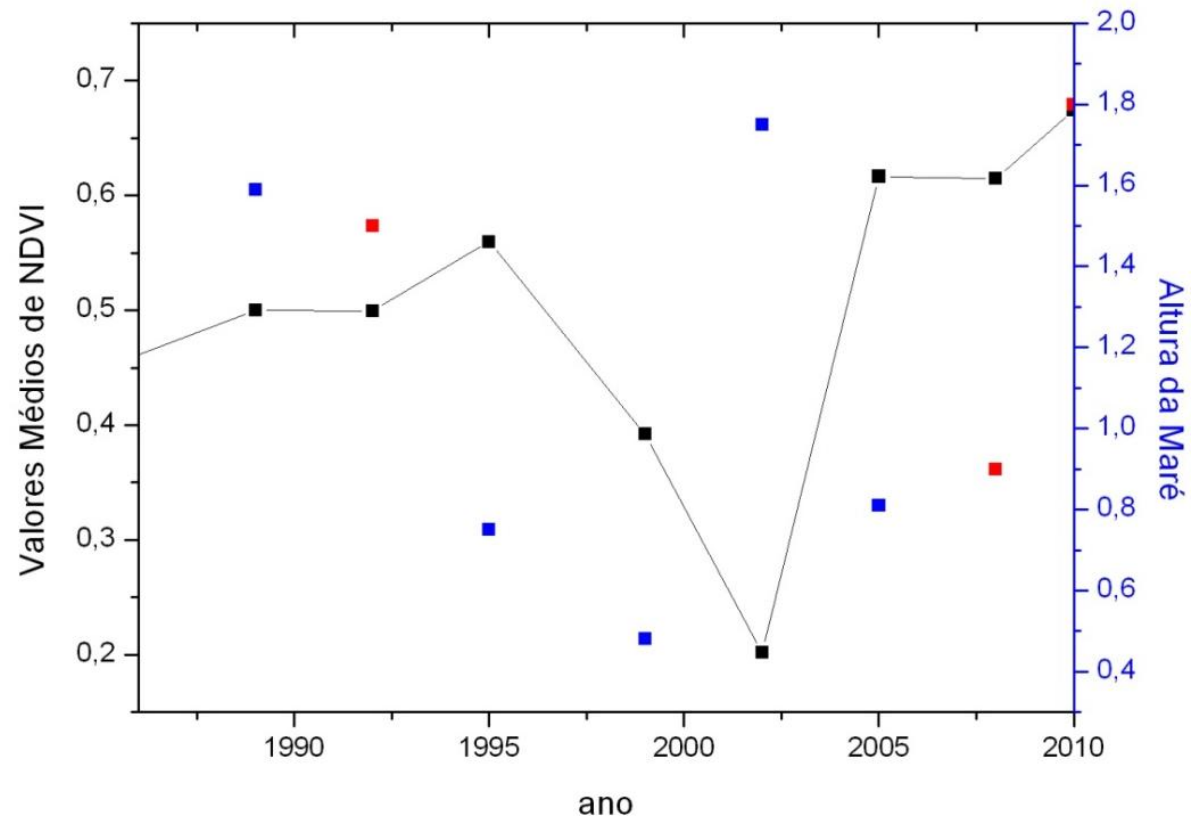

Figura 38 Gráfico do comportamento da maré e dos valores médios de NDVI no período estudado.

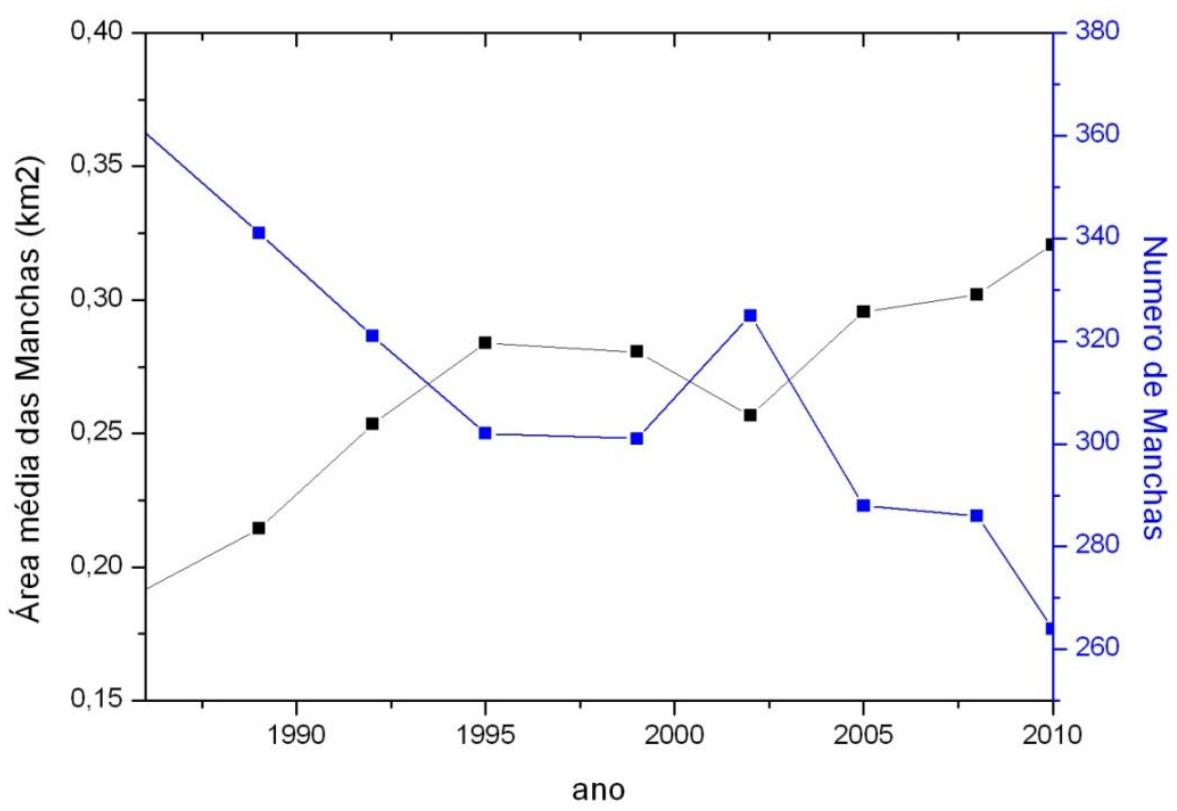

Figura 39 Gráfico mostrando a evolução temporal das áreas médias de "manchas" de mangue e de seu número no período estudado. 
Finalmente, foi realizada uma comparação entre os valores médios totais de greeness e NDVI, como mostra a figura 41. Analisando os valores médios para o sistema, parece haver uma correlação positiva nos valores de greeness quanto de NDVI. Ambos os parâmetros mostraram uma tendência geral de incremento ao longo do tempo exceção feita ao ano de 1999 e 2002 em que os valores de NDVI sofrem um sensível declínio.

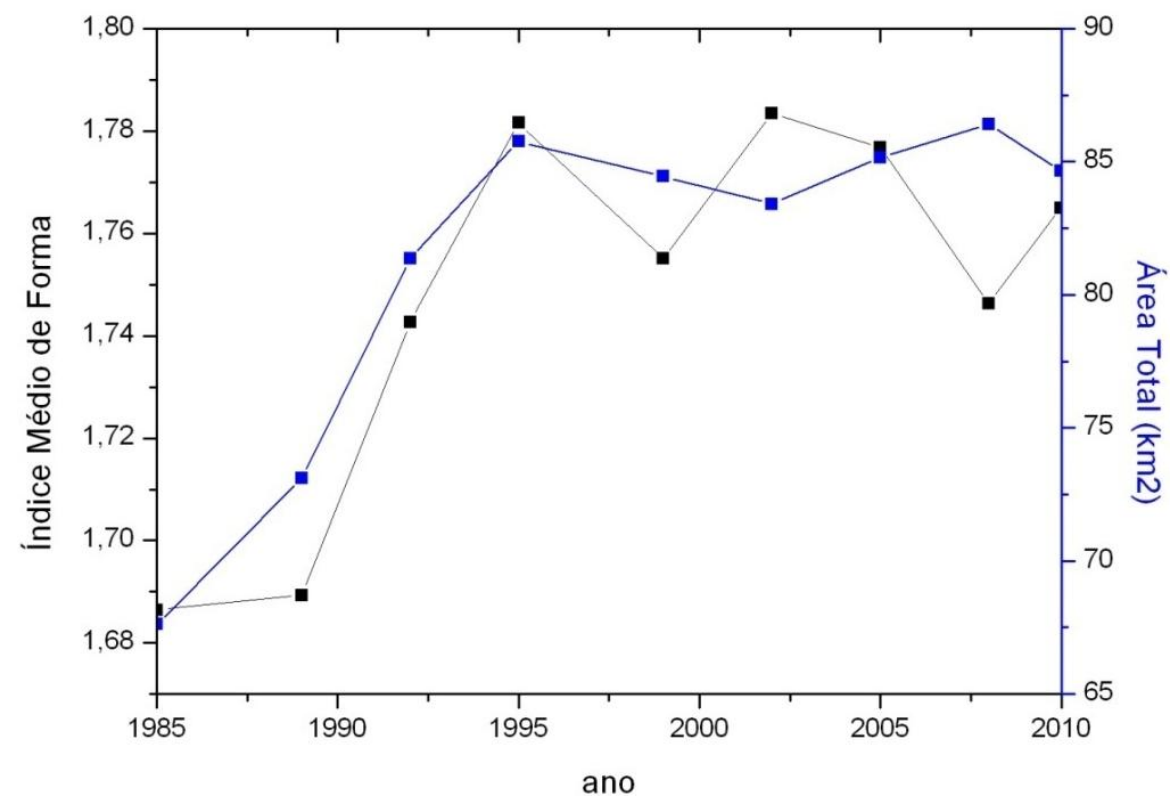

Figura 40 Gráfico mostrando a evolução temporal do índice médio de forma e a área total dos manguezais no período estudado.

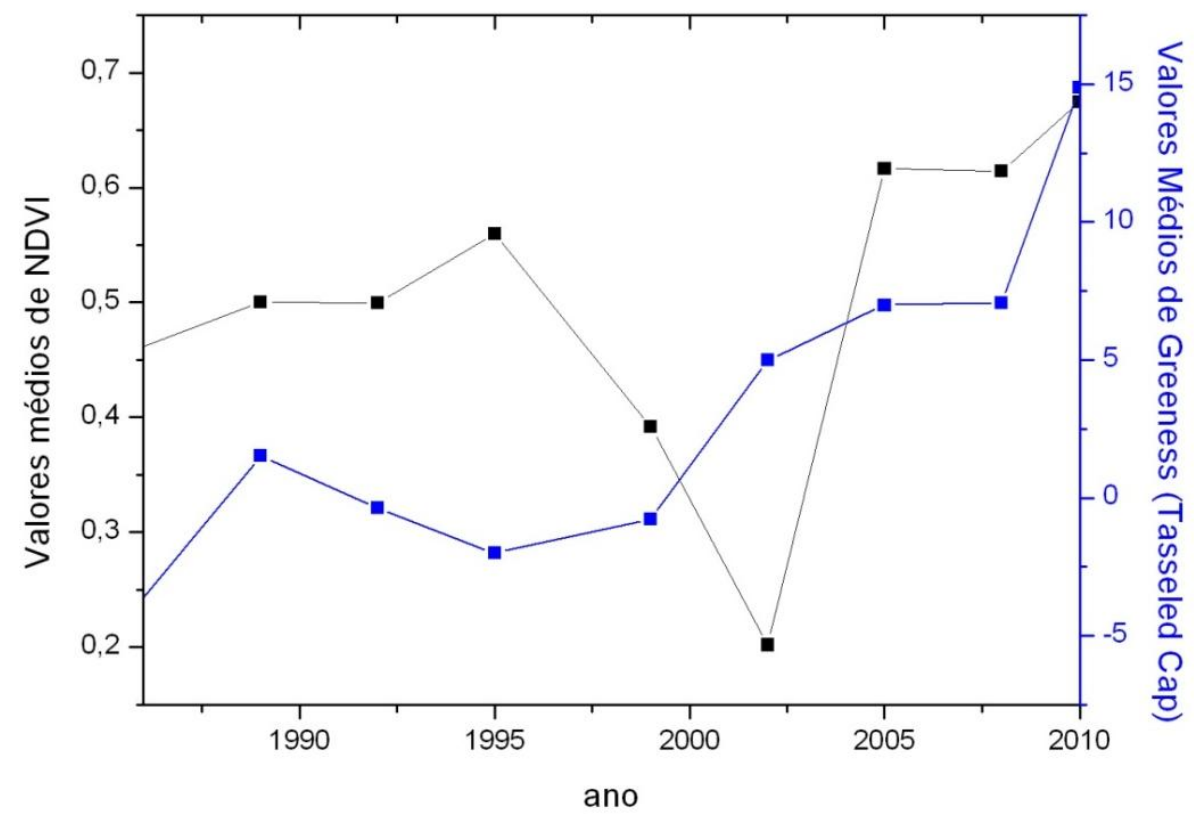

Figura 41 Gráfico mostrando a evolução temporal do NDVI médio e greeness médio para os manguezais do Sistema Estuarino de Santos. 
Embora não seja possível estabelecer uma correlação direta na análise de valores médios para o sistema como um todo, analisando-se ao nível de manchas, i.e., comparando os valores de NDVI médio e greeness para cada mancha (figura 25), em algumas datas, é verificada uma correlação alta. Notase claramente, ainda, na evolução temporal que houve uma tendência de incremento nesses valores, indicando um possível adensamento na cobertura dos dosséis. Em uma análise mais pormenorizada, entretanto, é possível observar uma peculiaridade no comportamento dos dois parâmetros: enquanto até 2005 os valores de NDVI e greeness tendam a apresentar um incremento contínuo e correlato, há uma aparentemente estabilização no NDVI (variando entre 0,5 e 0,75$)$ em 2005 enquanto os valores de greeness continuam a apresentar sensível aumento. Há, também, uma clara tendência de "homogenização" dos valores ao longo do tempo, possível de ser observada a partir da ampla distribuição das manchas de 1985, em contrapartida a uma maior concentração em 2010.

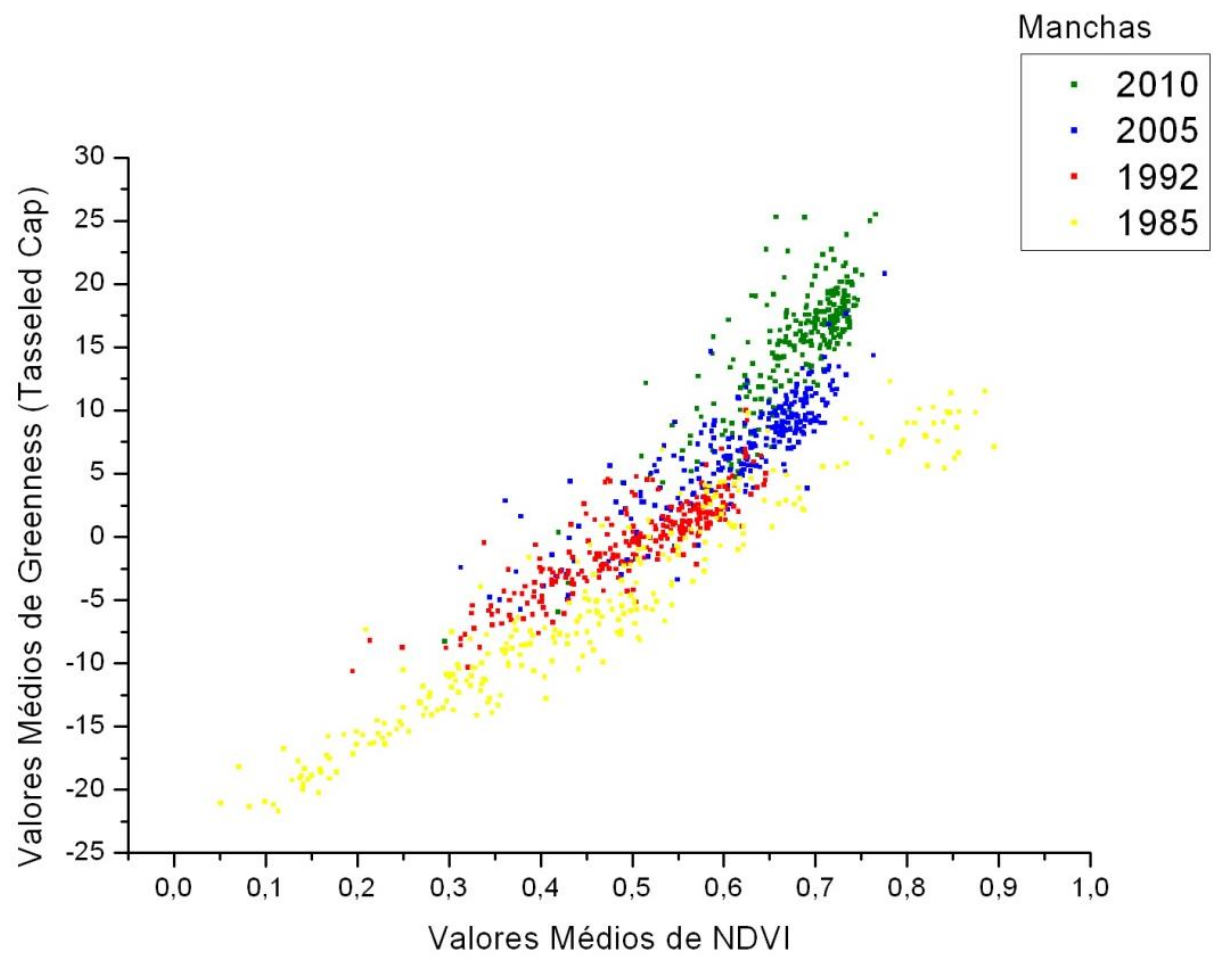

Figura 42 Gráfico mostrando a evolução temporal do NDVI médio e greeness médio, ao nível de manchas 
É importante ressaltar que, embora calculado as métricas de estrutura de paisagem ao nível de manchas no programa Patch Analyst, as mesmas não foram utilizadas por não serem objetivos deste trabalho. Ainda, no Anexo B é mostrado um exemplo de tabela contendo todos os índices relativos a estas métricas, juntamente com a análise zonal de valores de NDVI e da transformação tasseled cap, para cada mancha.

Estas tabelas estão associadas às figuras de manguezais (vetorizadas) para cada ano, e é sugestão para utilização em trabalhos futuros, realizando uma análise estatística exploratória mais robusta, envolvendo análises multivariadas. 


\section{CONCLUSÕES}

A avaliação da dinâmica da cobertura vegetal do tipo manguezal no Sistema Estuarino de Santos utilizando imagens multitemporais TM / ETM+ Landsat foi realizada com êxito.

O espaçamento temporal escolhido permitiu realizar análises relativamente acuradas, verificando tendências, no que diz respeito às mudanças ocorridas e também na estrutura da paisagem "manguezal" da área de estudo, ao longo de aproximadamente 25 anos.

As técnicas de processamento digital de imagens aplicadas a produtos de sensoriamento remoto se mostraram, adequadas aos objetivos propostos. Os cuidados de pré-processamento, entretanto, são essenciais para conduzir as análises de mudança, tanto qualitativa como quantitativamente de modo que processos criteriosos de aquisição e pré-processamento devem ser cuidadosamente realizados para que a metodologia possa ser aplicada com sucesso.

A classificação supervisionada por regiões (CSR) se apresentou como uma poderosa ferramenta na obtenção dos contornos dos manguezais na região de estudo, fato este que possui implicações para outras áreas, podendo este método ser testado em outras regiões costeiras. Embora tenham sido realizadas técnicas "clássicas" de classificação supervisionadas e não supervisionadas (pixel a pixel) como testes, no presente trabalho, as CSR mostraram-se sensivelmente mais acuradas, principalmente em áreas específicas mais suceptíveis a confusão na interpretação espectral, tais como áreas de sombras e baixios colonizados por vegetação secundária.

As informações adicionais, como imagens de alta resolução espacial e fotografias aéreas oblíquas, disponíveis na rede, desempenharam crucial importância nas análises sendo constantemente utilizadas na validação dos resultados obtidos.

Quanto as informações a respeito da maré no momento de aquisição das imagens, o trabalho mostrou que ainda são necessários maiores estudos no intuito de verificar e quantificar a influência das mesmas em índices de vegetação, fato este de grande importância para fins de monitoramento. Os 
resultados do trabalho mostraram importantes discrepâncias em valores de NDVI em imagens mesmo após criteriosa correção atmosférica o que pode, em parte, ser explicado por uma situação de maré extrema que pode influenciar nas características espectrais do substrato, "contaminando" os valores de reflectância. Tais características também poderiam ser associadas a situações ambientais peculiares (como condições climatológicas do período anterior a aquisição da imagem) ou mesmo variações de calibração do sensor.

Nas análises de mudança, o NDVI mostrou-se como uma importante ferramenta auxiliar nas análises pós-classificação, mesmo tendo apresentado variações e flutuações não bem compreendidas, como mencionado anteriormente. Outros índices de vegetação, incluindo o fator greeness da transformada Tasseled Cap podem, eventualmente, se mostrar mais efetivos para a caracterização do estado geral da vegetação.

As medidas de métricas relativa a estrutura da paisagem refletiram, de maneira bastante elucidativa, o comportamento geral dos manguezais no contexto do sistema estuarino. A partir de análises relativamente simples e diretas, realizadas em aplicativos de SIGs, foi possível estabelecer tendências gerais do comportamento dos padrões da vegetação, podendo ser utilizadas, desta forma, como uma importante ferramenta de análise prévia de uma área, indicando, por exemplo, qual a resolução temporal ideal para a aquisição de imagens na caracterização de mudanças ambientais de menor escala.

O Sistema Estuarino de Santos apresentou condições de relativa recomposição natural de manguezais, evoluindo de vários núcleos separados e isolados para áreas maiores e mais densas, também sustentada pelo aumento gradativo de área e de valores médios de NDVI e greeness, apontando para um processo de melhoria das condições dos bosques do sistema, sugerindo uma maior proximidade da cobertura dos dosséis, principalmente ate o período correspondente a meados da década de 90 do Século XX.

Embora esta melhoria nas condições dos manguezais tenha sido evidenciada em virtualmente todos os aspectos analisados, muitas áreas tiveram a vegetação suprimida ou apresentaram uma piora nos valores dos índices de vegetação no decorrer do período analisado, principalmente no que 
diz respeito a processos de ocupação humana desorganizada e a processos erosivos generalizados, como na região do Canal da Bertioga.

Os resultados obtidos mostraram-se adequados, em uma análise generalista, para o monitoramento de áreas de manguezal nesta escala de trabalho, fornecendo subsídios para estudos mais detalhados e também pra atuação de tomadores de decisão, uma vez que estas áreas são protegidas por lei.

A metodologia proposta e os resultados obtidos, sendo armazenados em um banco de dados baseado em Sistemas de Informação geográfica (SIG), representaram a possibilidade de uniformização de todos os dados $\mathrm{e}$ metadados para fins de monitoramento e pesquisas futuras, seja em uma escala global, a exemplo da Rede Internacional de Atlas Costeiro (ICAN, da sigla em inglês), como base para estudos mais específicos e pormenorizados sustentados por experimentos de campo e por séries temporais mais adensadas. 


\section{REFÊRENCIAS BIBLIOGRÁFICAS}

AFONSO, M. C. 2006. A paisagem da Baixada Santista. Ed. EDUSP / Fapesp. 223p.

ANDRADE, M.A.B \& LAMBERTI, A. 1965. A vegetação. In: Azevedo, A. (org). A Baixada Santista: Aspectos Geográficos, Ed. EDUSP, vol 1: 151-179.

ASCHBACHER, J.; OFREN, R.; DELSOL, J.P.; SUSELO, T.B.; VIBULSRESTH, S. \& CHARRUPAT, T. 1995. An integrated comparative approach to mangrove vegetation mapping using advanced remote sensing and GIS technologies: preliminary results. Hydrobiologia, 295: 285-294.

AZEVEDO, A. (org). 1965. A Baixada Santista: Aspectos geográficos. São Paulo, EDUSP, 4V.

BENFIELD, S.L.; GUZMAN, H.M. \& MAIRA, J.M. 2005. Temporal mangrove dynamics in relation to coastal development in Pacific Panama. Journal of Environmental Management, 76: 263-276.

BINS, L.S.; FONSECA, L.M.G.; ERTHAL, G.J. \& MITSUO II, F. 1996. Satellite imagery segmentation: a region growing approach. In: Simpósio Brasileiro de Sensoriamento Remoto. Anais... VIII SBSR. Salvador, p.: 221-223.

BLASCHKE, T. 2010. Object based image analysis for remote sensing. ISPRS Journal of Photogrammetry and Remote Sensing, 65: 2-16.

BLASCO, F.; GAUQUELIN, T.; RASOLOFOHARINORO, M.; DENIS, J.; AIZPURU. M. \& CALDAIROU, V. 1998. Recent advances in mangrove studies using remote sensing data. Marine and Freshwater Research, 49: 287-296.

BLASCO, F.; AIZPURU, M. \& GERS, C. 2001. Depletion of the mangroves of Continental Asia. Wetlands Ecology and Management, 9: 245-256.

BONETTI FILHO, J. 1996. Sensoriamento Remoto aplicado à análise de ambientes costeiros impactados - Avaliação metodológica: Baixada 
Santista. Tese de doutorado. Universidade de São Paulo, Faculdade de Filosofia, Letras e Ciências Humanas, 260p + anexo.

CÂMARA, G.; SOUZA, R.M.C., FREITAS, U.M. \& GARRIDO, J. 1996. SPRING: Integrating remote sensing and GIS by object-oriented modelling. Journal of Computers \& Graphics, 20: 395-403.

CAMERON, W.M. \& PRITCHARD, D.W. 1963. "Estuaries". In Hill, M. N. The Sea, ideas and observations on progress in the study of the seas. New York, Intescience: p.: 306-324.

CARVALHO, E.V.T.; ZAGAGLIA, C.R. \& FERREIRA, E. 2007. Avaliação de áreas de mangues e apicuns, nos anos de 1938 e 2004, localizados na Ilha de Santa Catarina. In: Simpósio Brasileiro de Sensoriamento Remoto, Anais... XIII SBSR, Florianópolis, p. 3805-3811.

CETESB. 1988. Estudo dos manguezais da Baixada Santista - Relatório Final. São Paulo: CETESB, 70p.

CETESB. 1990. Ação da CETESB em Cubatão: situação em Janeiro de 1990. CETESB, Relatório Técnico, São Paulo, 33p.

CETESB. 1991. Avaliação do estado de degradação dos ecossistemas da Baixada Santista - SP. Relatório Técnico, São Paulo, 45p.

CHANDER, G.; MARKHAM, B.L. \& HELDER, D.L. 2009. Summary of current radiometric calibration for Landsat MSS, TM, ETM+ and EO-1 ALI sensors. Remote Sensing of Environment, 113: 893-903.

CHAUVAUD, S.; BOUCHON, C. \& MANIERE, R. 1998. Remote sensing techniques adapted to high resolution mapping of tropical coastal marine ecosystems (coral reefs, seagrass beds and mangrove). International Journal of Remote Sensing, 19(18): 3625-3639.

CHAVEZ, P.S.Jr. 1988. An improved dark-object subtraction technique for atmospheric scattering correction of multispectral data. Remote Sensing of Environment, 24: 459-479. 
CHAVEZ, P.S.Jr, 1996. Image-based atmospheric corrections - revisited and improved. Photogrammetric Engineering and Remote Sensing, 62: 1025-1036.

COHEN, M.C.L. \& LARA, R.J. 2003. Temporal changes of mangrove vegetation boundaries in Amazonia: Application of GIS and remote sensing techniques. Wetlands Ecology and Management, 11: 223-231.

COMELLI, F.A.M; PONTE, A.C.E. \& CLARO, S.M.C.A. 1994. Aspectos estruturais de um manguezal de Cubatão, SP, Brasil. In: Simpósio de Ecossistemas da Costa brasileira: Subsídios a um Gerenciamento Ambiental. Anais... III ACIESP, Serra Negra, v 1: 97-103.

CONCHEDDA, G.; DURIEUX, L. \& MAYAUX, P. 2008. An object-based method for mapping and change analysis in mangrove ecosystems. ISPRS Journal of Photogrammetry \& Remote Sensing, 63: 578-589.

COSTA, S.D. 2005. O uso da avaliação ambiental estratégica para definição de políticas portuárias: o caso do Porto de Santos / SP. Monografia de Especialização, Universidade de Brasília, Centro de Desenvolvimento Sustentável, 83p.

DAHDOUH-GUEBAS, F.; VERHEYDEN, A.; DE GENST, W.; HETTIARACHCHI, S. \& KOEDAM, N. 2000. Four decade vegetation dynamics in Sri Lankan mangroves as detected from sequential aerial photography: A case study in Galle. Bulletin of Marine Science, 67(2): 741-769.

DAHDOUH-GUEBAS, F.; ZETTERTRÖM, T.; RÖNNBÄCK, P.; TROELL, M.; WICKRAMASINGHE, A. \& KOEDAM, N. 2002. Recent changes in land use in the Pambala-Chilaw lagoon complex (Sri Lanka) investigated using remote sensing and GIS: conservation of mangroves vs. development of shrimp farming. Environment, Development and Sustainability, 4: 185-200.

DAHDOUH-GUEBAS, F.; VAN POTTELBERGH, I.; KAIRO, J.G.; CANNICCI, S. \& KOEDAM, N. 2004. Human-impacted mangroves in Gazi (Kenya): predicting future vegetation based on retrospective remote sensing, 
social surveys, and tree distribution. Marine Ecology Progress Series, 272: 77-92.

DAHDOUH-GUEBAS, F.; VERHEYDEN, A.; KAIRO, J.G.; JAYATISSA, L.P. \& KOEDAM, N. 2006. Capacity building in tropical coastal resource monitoring in developing countries: A re-appreciation of the oldest remote sensing model. International Journal of Sustainable Development \& World Ecology, 13: 62-76.

ESPÍNDOLA, G.M.; CÂMARA, G.; REIS, I.A.; BINS, L.S. \& MONTEIRO, A.M. 2006. Parameter selection for region-growing image segmentation algorithms using spatial autocorrelation. International Journal of Remote Sensing, 27(14): 3035-3040.

ESPINOZA, H.C.F. \& ROSA, M.M.P.T. 2009. Evolução temporal da cobertura vegetal do manguezal do Rio Tavares (Florianópolis-SC) empregando técnicas de sensoriamento remoto. In: Simpósio Brasileiro de Sensoriamento Remoto, Anais... XIV SBSR, Natal, p. 2705-2712.

EVERITT, J.H.; YANG, C.; SRIHARAN, S. \& JUDD, F.W. 2008. Using High Resolution Satellite Imagery to Map Black Mangrove on the Texas Gulf Coast. Journal of Coastal Research, 24(6): 1582-1586.

FIELD, C. D. 1995. Impact of expected climate change on mangroves. Hydrobiologia, 295: 75 - 81.

FONSECA, L.M.G.; FEDOROV, D.; MANJUNATH, B.S.; KENNEY, C.; CASTEJON, E. \& MEDEIROS, J.S. 2006. Automatic registration and mosaicking system for remotely sensed data. Revista Brasileira de Cartografia, 58(1): 49-61.

FORMAN, R.T.T. \& GODRON. 1986. Landscape Ecology, Cambridge University Press, Cambridge.

FUKUMOTO, M.M.. 2007. Determinação da história deposicional recente no Alto Estuário Santista, com base nos teores de metais e na susceptibilidade magnética dos sedimentos. Universidade de São Paulo, Instituto Oceanográfico, Tese de Doutorado, 123p. 
FÚLFARO, V.J.; SUGUIO, K. \& PONÇANO, W.L. 1974. A gênese das planícies costeiras paulistas. In: Congresso Brasileiro de Geologia, Porto Alegre. Anais... SBG, 28(3): 37-42.

FÚLFARO, V.J. \& PONÇANO, W.L. 1976. Sedimentação atual do estuário e baía de Santos: Um modelo geológico aplicado a projetos de expansão da zona portuária. In: Congresso Brasileiro de Geologia de Engenharia, Rio de Janeiro. Anais... ABGE, 2: 67-90.

GAO, J. 1998. A hybrid method toward accurate mapping of mangroves in a marginal habitat from SPOT multispectral data. International Journal of Remote Sensing, 19(10): 1887-1899.

GAO, J. 1999. A comparative study on spatial and spectral resolutions of satellite data in mapping mangrove forests. International Journal of Remote Sensing, 20(14): 2823-2833.

GHERARDI,.D.F.M. \& CABRAL, A.P (coord.). 2007. Atlas de sensibilidade ambiental ao óleo da Bacia Marítima de Santos. Brasília, MMA, SMQC, $116 p$.

GIRI, C.; PENGRA, B.; ZHU, Z.; SINGH, A. \& TIESZEN, L.L. 2007. Monitoring mangrove forest dynamics of the Sundarbans in Bangladesh and India using multi-temporal satellite data from 1973 to 2000. Estuarine, Coastal and Shelf Science, 73: 91-100.

GIRI, C.; ZHU, Z.; TIESZEN, L.L; SINGH, A.; GILLETTE, S. \& KELMELIS, A. 2008. Mangrove forest distributions and dynamics (1975-2005) of the tsunami-affected region of Asia. Journal of biogeography, 35: 519-528.

GIRI, C. \& MUHLhAUSEN, J. 2008. Mangrove Forest Distributions and Dynamics in Madagascar (1975-2005). Sensors, 8: 2104-2117.

GREEN, E.P.; MUMBY, P.J.; EDWARDS, A.J.; CLARK, C.D. \& ELLIS, A.C. 1997. Estimating leaf area index of mangroves from satellite data. Aquatic Botany, 58: 11-19.

GREEN, E.P.; CLARK, C.D.; MUMBY, P.J.; EDWARDS, A.J. \& ELLIS, A. C. 1998. Remote sensing techniques for mangrove mapping. International Journal of Remote Sensing, 19(5): 935-956 
GUIMARÃES, A.S.; TRAVASSOS, P.; SOUZA FILHO, P.W.M. \& COSTA, F. 2009. A participação da aqüicultura na conversão de áreas de manguezal em viveiros no litoral norte do estado de Pernambuco/Brasil: uma análise a partir de dados de sensoriamento remoto e SIG. In: Simpósio Brasileiro de Sensoriamento Remoto, Anais... XIV SBSR, Natal, p. 4599-4606.

GÜRTLER, S.; EPIPHANIO, J.C.N.; LUIZ, A.J.B. \& FORMAGGIO, A.R. 2005. Planilha eletrônica para o cálculo de refllectância em imagens TM e ETM+ Landsat. Revista Brasileira de Cartografia, 57(2): 162-167.

HADLICH, G.M.; UCHA, J.M. \& OLIVEIRA, T.L. 2009. Distribuição de apicuns e de manguezais na Baía de todos os Santos, Bahia, Brasil. In: Simpósio Brasileiro de Sensoriamento Remoto, Anais... XIV SBSR, Natal, p. 4607-4614.

HARARI, J.; MESQUITA, A.R.; MARONE, E.; FRANÇA, C.A.S.; CAMARGO, R.; PEREIRA, J.E.R.; ADÃO, C.J.G.P. \& SÁ JÚNIOR, I.L. 1990. Techical report of the project: "Flow Measurements in the Bay of Santos". FUNDESPA. São Paulo, 56p.

HELD, A.; TICEHURST, C.; LYMBURNER, L. \& WILLIAMS, N. 2003. High resolution mapping of tropical mangrove ecosystems using hyperspectral and radar remote sensing. International Journal of Remote Sensing, 24(13): 2739-2759.

HERZ, 1991. Manguezais do Brasil. São Paulo, Instituto Oceanográfico da USP. $54 p+$ mapas.

HOMER, C.; HUANG, C.; YANG, L.; WYLIE, B. \& COAN, M. 2004. Development of a 2001 National Land Cover Database for the United States. Photogrammetric Engineering and Remote Sensing, 70: 829840.

HOSKING, E. J.; BACH, C. S.; APPLEGATE, R. J.; KARFS, R. A. \& WALLACE, J. F. 2001. Mangrove Monitoring using Sequences of Landsat Imagery in the Mary River wetlands. IEEE Transactions on Geoscience \& Remote Sensing, 2241 - 2243. 
INSTITUTO DE PESQUISAS TECNOLÓGICAS DO ESTADO DE SÃO PAULO - IPT. 1981. Mapa Geomorfológico do Estado de São Paulo. 2V (Relatório IPT, 1183).

JENSEN, J.R. 2009. Sensoriamento Remoto do Ambiente: Uma perspectiva dos recursos terrestres. Oficina de Textos, $+598 p$.

JUSOFF, K. 2006. Individual mangrove species identification and mapping in port Klang using airbone hyperspectral imaging. Journal of Sustainability Science and Management, 1(2): 27-36.

KAMPEL, M.; AMARAL, S. \& SOARES, M.L.G. 2005. Imagens CCD/CBERS e TM/Landsat para a análise multi-temporal de manguezais no Nordeste brasileiro. Um estudo no litoral do Ceará. In: Simpósio Brasileiro de Sensoriamento Remoto, Anais... XII SBSR, Goiânia, p. 979-986.

KANNIAH, K. D.; WAI, N.G. \& SHIN, A.L.M. 2007. Per-pixel and sub-pixel classifications of high-resolution satellite data for mangrove species mapping. Applied GIS, 3(8): 1-22.

KAIRO, J.G.; KIVYATU, B. \& KOEDAM, N. 2002. Apllication of remote sensing and GIS in the management of mangrove forests within and adjacent to Kiunga marine protected area, Lamu, Kenia. Environment, Development and Sustainability, 4: 153-166.

KOVACS, J. M.; WANG, J. \& BLANCO-CORREA, M. 2001. Mapping disturbances in a mangrove forest using multi-date Landsat TM imagery. Environmental Management, 27(5): 763-776.

KOVACS, J.M.; WANG, J. \& FLORES-VERDUGO, F. 2005. Mapping mangrove leaf area index at the species level using IKONOS and LAI-2000 sensors for the Agua Brava Lagoon, Mexican Pacific. Estuarine, Coastal and Shelf Science, 62: 377-384.

KOVACS, J.M.; VANDERBERG, C.V. \& FLORES-VERDUGO, F. 2006. Assessing fine beam RADARSAT-1 backscatter from a white mangrove (Laguncularia racemosa (Gaertner)) canopy. Wetlands Ecology and Management, 14:401-408. 
KRUG, L.A. \& NOERNBERG, M.A. 2007. O sensoriamento remoto como ferramenta para determinação de batimetria de baixios na Baía das Laranjeiras, Paranaguá - PR. Revista Brasileira de Geofísica, 25(1): 101-105.

LAMPARELLI, C.C. 1995 Dinâmica da serapilheira em manguezais da Bertioga. Tese de Doutorado. Universidade de São Paulo, Faculdade de Saúde Pública, 138p + anexos.

LANG, S. \& BLASCHKE. 2009. Análise da Paisagem com SIG. Ofifcina de Textos, São Paulo, 424p.

LIU, K.; LI, X.; SHI, X. \& WANG, S. 2008. Monitoring mangrove forest changes using remote sensing and GIS data with decision-tree learning. Wetlands, 28(2): 336-346.

LONG, B.G. \& SKEWES, T.D. 1996. A Technique for Mapping Mangroves with Landsat TM Satellite Data and Geographic Information System. Estuarine, Coastal and Shelf Science, 43: 373-381.

LU, D.; MAUSEL, P.; BRONDIZIO, E. \& MORAN, E. 2002. Assessment of atmospheric correction methods for Landsat TM data applicable to Amazon basin LBA research. International Journal of Remote Sensing, 23(13): 2651 - 2671.

LU, D.; MAUSEL, P.; BRONDÍZIO, E. \& MORAN, E. 2004. Change detection techniques. International Journal of Remote Sensing, 25(12): 2365 2401.

LUCAS, R.M.; ELLISON, J.C.; MITCHELL, A.; DONNELLY, B.; FINLAYSON, M. \& MILNE, A.K. 2002. Use of stereo aerial photography for quantifying changes in the extent and height of mangroves in tropical Australia. Wetlands Ecology and Management, 10: 161-175.

LUCAS, R.M.; MITCHELL, R.M.; PROISY, C. \& MELIUS, A. 2003. Characterising and Mapping Mangroves in Northern Australia Using Stereo Aerial Photography and Hyperspectral CASI Data. In: Geoscience and Remote Sensing Symposium, IGARSS '03, Toulouse, France, 4: 2380-2382. 
LUCAS, R.M.; MITCHELL, A.L.; ROSENQVIST, A.; PROISY, C.; MELIUS, A. \& TICEHURST, C. 2007. The potential of L-band SAR for quantifying mangrove characteristics and change: case studies from the tropics. Aquatic Conservation: Maine and Freshwater Ecosystems. 17: 245-264.

LUEDERWALDT, H. 1919. Os manguesaes de Santos. São Paulo. Revista do Museu Paulista, 11: 309-408.

LUIZ-SILVA, W.; MATOS, R. H. R. \& KRISTOCH, G. C. 2002. Geoquímica e índice de geoacumulação de mercúrio em sedimentos de superfície do estuário de Santos - Cubatão (SP). Química Nova, 25: 753 - 756.

MANSON, F.J.; LONERAGAN, N.R.; MCLEOD, I.M. \& KENYON, R.A. 2001. Assessing techniques for estimating the extent of mangroves: topographic maps, aerial photographs and Landsat TM images. Marine and Freshwater Research, 52(2): 787-792.

MANSON, F.J.; LONERAGAN, N.R. \& PHINN, S.R. 2003. Spatial and temporal variation in distribution of mangroves in Moreton Bay, subtropical Australia: a comparison of pattern metrics and change detection analyses based on aerial photographs. Estuarine, Coastal and Shelf Science, 57: 653-666.

MAS, J.F. 1999. Monitoring land-cover changes: a comparison of change detection techniques. International Journal of Remote Sensing, 20(1): 139-152.

MAS, J.F. 2004. Mapping land use/cover in a tropical coastal area using satellite sensor data, GIS and artificial neural networks. Estuarine, Coastal and Shelf Science. 59: 219-230.

MENGHINI, R.P. 2004. Ecologia de manguezais: Grau de perturbação e processos regenerativos em bosque de mangue da llha Barnabé. São Paulo, Brasil. Dissertação de Mestrado. Universidade de São Paulo, Instituto Oceanográfico, 96p.

MENGHINI, R.P. 2008. Dinâmica de recomposição natural em bosques de mangue impactados: Ilha Barnabé (Baixada santista), SP, Brasil. Tese 
de doutorado. Universidade de São Paulo, Instituto Oceanográfico, 222p.

MENGHINI, R.P.; CUNHA-LIGNON, M.; COELHO JÚNIOR, C. \& SCHAEFFERNOVELLI, Y. 2007. Análise temporal dos impactos antrópicos e da regeneração natural em manguezais da ilha Barnabé (Baixada Santista, SP, Brasil) obtida através de fotografias aéreas. In: Simpósio Brasileiro de Sensoriamento Remoto, Anais... XIII SBSR, Florianópolis, p. 4037-4044.

MENEZES, G.V.; SCHAEFFER-NOVELLI, Y.; POFFO, I.R.F. \& EYSINK, G.G.J. 2005. Recuperação de manguezais: Um estudo de caso na Baixada Santista de São Paulo, Brasil. Brazilian Journal of Aquatic Science and Technology, 9(1): 67-74.

MIRANDA, L.B. DE; CASTRO, B.M. DE \& KJERVE, B. 1998. Circulation and mixing due to tidal forcing in the Bertioga Channel, São Paulo, Brazil. Estuaries, 21(2): 204-214.

MIRANDA, L.B. de; CASTRO, B.M. DE \& KJERVE, B. 2002. Princípios de Oceanografia Física de Estuários. São Paulo, Edusp. 414 p.

MITCHELL, A. \& LUCAS, R.M. 2001. Integration of Aerial photography, Hyperspectral and SAR data for Mangrove Characterization. 2001. In: Geoscience and Remote Sensing Symposium, IGARSS '01, Sydney, Australia, 5: 2193-2195.

MITCHELL, A.L.; LUCAS, R.M.; DONELLY, B.E.; PFITZNER, K.; MILNE, A.K. \& FINLAYSON, M. 2007. A new map of mangroves for Kakadu National Park, Northern Australia, based on stereo aerial photography. Aquatic Conservation: Marine and Freshwater Ecosystems, 17: 446-467

MOUGIN, E.; PROISY, C. MARTY, G.; FROMARD, F.; PUIG, H.; BETOULLE, J.L. \& RUDANT, J.P. 1999. Multifrequency and Multipolarization Radar Backscattering from Mangrove Forests. IEEE Transactions on Geoscience and Remote Sensing, 37(1): 94-102.

NASA. 2004. National Aeronautics and Space Administration. Chapter 6 - Data Products. Disponível em: http://tpwww.gsfc.nasa.gov//AS/handbook/ 
handbook_htmls/chapter6/chapter6.html. Acessado em Outubro de 2010.

OLIVEIRA, M.L.J; VIDAL-TORRADO, P.; OTERO, X.L. \& FERREIRA, J.R.. 2007. Mercúrio total em solos de manguezais da Baixada Santista e Ilha do Cardoso, estado de São Paulo. IEEE Química Nova, 30(3): 519524.

PALING, E.I.; KOBRYN, H.T. \& HUMPHREYS, G. 2008. Assessing the extent of mangrove change caused by Cyclone Vance in the eastern Exmouth Gulf, northwestern Australia. Estuarine, Coastal and Shelf Science, 77: 603-613.

PANAPITUKKUL, N.; DUARTE, C.M.; THAPANYA, U.; KHEOWVONGSRI, P.; SRICHAI, N.; GEERTZ-HANSEN, O.; TERRADOS, J. \& BOROMTHANARATH, S. 1998. Mangrove Colonization: Mangrove Progression Over the Growing Pak Phanang (SE Thailand) Mud Flat. Estuarine, Coastal and Shelf Science, 47: 51-61.

PASQUALINI, V.; ILTIS, J.; DESSAY, N.; LOINTIER, M.; GUELORGET, O. \& POLIDORI, L. 1999. Mangrove mapping in North-Western Madagascar using SPOT-XS and SIR-C radar data. Hydrobiologia: 413: 127-133.

PONTE, A.C.E.; FONSECA, I.A.Z. \& CLARO, S.M.C.A. 1987. Impacto causado por petróleo no manguezal do Canal da Bertioga - estrutura da vegetação. In: Simpósio sobre os Ecossistemas da Costa Sul e Sudeste: Síntese dos Conhecimentos, Anais... ACIESP. Cananéia, v2: 103-107.

PONTE, A.C.E.; FONSECA, I.A.Z. \& CLARO, S.M.C.A. 1990. Produção de serapilheira em mangue impactado por petróleo. In: Simpósio sobre os Ecossistemas da Costa Sul e Sudeste: Estrutura, Função e Manejo, Anais... II ACIESP. Águas de Lindóia, v 2: 247-253.

POZZI-NETO, D. 2001. Baixada santista, manguezal e vazamentos de óleo: uma valoração econômico-ecológica. Dissertação de Mestrado. Universidade de São Paulo, Programa de Ciências Ambientais, 114p. 
PRITCHARD, D. W. 1955. Estuarine circulation patterns. Proc. Am. Soc. Civ. Eng. 81:711:1-11.

PRITCHARD, D. W. 1967. What is an Estuary: Physical Viewpoint. In: Lauff, G. H. (ed.). Estuaries. Washington, D. C., American Association for the Advance of Science. Publication 83: 3-5.

PROISY, C.; MOUGIN, E. \& FROMARD, F. 1996. Investigating correlations between radar data and mangrove forests characteristics. In: Geoscience and Remote Sensing Symposium, IGARSS '96, Lincoln, USA, 1: 27-31.

PROISY, C.; MOUGIN, E. \& FROMARD, F. 2001. Radar remote sensing of mangroves: results and perspectives. In: Geoscience and Remote Sensing Symposium, IGARSS '01, Sydney, Australia, 7: 3056-3058.

PROISY, C.; MOUGIN, E.; FROMARD, F.; TRICHON, V. \& KARAM, M.A. 2002. On the influence of canopy structure on the radar backscattering of mangrove forests. International Journal of Remote Sensing, 23(20): 4197-4210.

PROISY, C.; COUTERON, P. \& FROMARD, F. 2007. Predicting and mapping mangrove biomass from canopy grain analysis using Fourier-based textural ordination of IKONOS images. Remote Sensing of Environment, 109: 379-392.

PROISY, C.; GRATIOT, N.; ANTHONY, E.J.; GARDEL, A.; FROMARD, F. \& HEURET, P. 2009. Mud bank colonization by opportunistic mangroves: A case study from French Guiana using lidar data. Continental Shelf Research, 29: 632-641.

RAMÍREZ-GARCÍA, P.; LÓPEZ-BLANCO, J. \& OCAÑA, D. 1998. Mangrove vegetation assessment in the Santiago River Mouth, Mexico, by means of supervised classification using Landsat TM imagery. Forest Ecology and Management, 105: 217-229.

RAMSEY, E. W. \& JENSEN, J.R. 1996. Remote Sensing of Mangrove Wetlands: Relating Canopy Spectra to Site-Specific Data. Photogrammetric Engineering \& Remote Sensing, 62(8): 939-948. 
RAMSEY, E.W.; NELSON, G.A. \& SAPKOTA, S.K. 1998. Classifying coastal resources by integrating optical and radar imagery and color infrared photography. Mangroves and Salt Marshes, 2: 109-119.

RANGEL, M.E.S.; KUX, H.J.H.H.; SANTOS, J.R. \& FEITOSA, A.C. 2001. Sensoriamento remoto e GIS na análise de modificações da paisagem em manguezais. In: Simpósio Brasileiro de Sensoriamento Remoto, Anais... X SBSR, Foz do Iguaçu, p. 1721-1733.

RASOLOFOHARINORO, M.; BLASCO, F.; BELLAN, M. F.; AIZPURU, M.; GAUQUELIN, T. \& DENIS, J. 1998. A remote sensing based methodology for mangrove studies in Madagascar. International Journal of Remote Sensing, 19(10): 1873-1886.

REDDY, C.S.; PATTANAIK, C. \& MURTHY, M.S.R. 2007. Assessment and monitoring of mangroves of Bhitarkanika Wildlife Sanctuary, Orissa, India using remote sensing and GIS. Current Science, 92(10): 14091415.

RODRIGUES, F.O.; MOURA, D.O.; \& LAMPARELLI, C.C. 1990. Evolução das alterações estruturais e funcionais provocadas por óleo no manguezal do Rio Iriri. In: Simpósio sobre os Ecossistemas da Costa Sul e Sudeste: Estrutura, Função e Manejo, Anais... II ACIESP. Águas de Lindóia, v 2: 194-208.

SAENGER, P.; HEGERL, E. J. \& DAVIE, J. D. S. 1983. Global status of mangrove ecosystems. IUCN Commission on Ecology/UnitedNations Environment Program / World Wildlife Fund. The Environmentalist, 3, supplement $n^{\circ} 3$.

SAITO, H.; BELLAN, M. F.; AL-HABSHI, A.; AIZPURU, M. \& BLASCO, F. 2003. Mangrove research and coastal ecosystem studies with SPOT-4 HRVIR and TERRA ASTER in the Arabian Gulf. International Journal of Remote Sensing, 24(21): 4073 - 4092.

SALEH, M. A. 2007. Mangrove vegetation on Abu Minqar island of the Red Sea. International Journal of Remote Sensing, 28(23): 5191 - 5194. 
SANTOS, L.C.M.; CUNHA-LIGNOM, M. \& SCHAEFFER-NOVELLI, Y. 2007. Áreas de manguezal em um trecho do Canal da Bertioga (Baixada Santista, Brasil): Alterações espaço-temporais pela introdução de estruturas náuticas. In Congresso Latino Americano de Ciências do Mar. Anais... XII Colacmar, Florianópolis. CD-ROM, 3p.

SCHAEFFER-NOVELLI, Y. 1995. Manguezal: Ecossistema entre a terra e o mar. Caribean ecological research, São Paulo, 64p.

SCHAEFFER-NOVELLI, Y.; CINTRON-MOLERO, G.; ADAIME, R. R. \& CAMARGO, T. M. de. 1990. Variability of mangrove ecosystems along the Brazilian coast. Estuaries, 13(2): 204-218.

SCHMIEGELOW, J.M.M. 2009. Manguezais do Sistema Estuarino de Santos. Tese de Doutorado. Universidade de São Paulo, Instituto Oceanográfico, 161p.

SCHOWENGERDT, R. A. 2007. Remote Sensing: Models and Methods for Image Interpretation. Third edition. Academic Press, $509 \mathrm{p}$.

SERY, F.; DUCROT-GAMBART, D., MOUGIN, E.; FROMARD F. \& RUDANT J.P. 1995. Mapping on mangrove forest using multisource data. In: Geoscience and Remote Sensing Symposium, IGARSS '95, Firenze, Italy, 2: 1222-1224.

SIMARD, M.; ZHANG, K.; RIVERA-MONROY, V.H.; ROSS, M.S.; RUIZ, P.L.; CASTAÑEDA-MOYA; TWILLEY, R.R. \& RODRIGUEZ, E. 2006 Mapping Height and Biomass of Mangrove Forests in Everglades National Park with SRTM Elevation Data. Photogrammetric Engineering \& Remote Sensing, 72, (3): 299-311.

SIMARD, M.; RIVERA-MONROY, V.H.; MANCERA-PINEDA, J.E.; CASTAÑEDA-MOYA, E. \& TWILLEY, R.R. 2008. A systematic method for 3D mapping of mangrove forests based on Shuttle Radar Topography Mission elevation data, ICEsat/GLAS waveforms and field data: Application to Ciénaga Grande de Santa Marta, Colombia. Remote Sensing of Environment, 112: 2131-2144. 
SOARES, M.L.G. 1997. Estudo da biomassa aérea de manguezais do sudeste do Brasil - análise de modelos. Tese de Doutorado. Universidade de São Paulo, Instituto Oceanográfico. 2V.

SONG, C.; WOODCOCK, C.E.; SETO, K.C.; LENNEY, M.P. \& MACOMBER, S.A. 2001. Classification and change detection using Landsat TM data: When and how to correct atmospheric effects? Remote Sensing of Environment, 75: 230-244.

SOUZA FILHO, P.W.M. 2005. Costa de manguezais de macromaré da Amazônia: cenários morfológicos, mapeamento e quantificação de áreas usando dados de sensores remotos. Revista Brasileira de Geofísica, 23(4): 427-435.

SOUZA FILHO, P.W.M. \& PARADELLA, W.R. 2002. Recognition of the main geobotanical features along the Bragança mangrove coast (Brazilian Amazon Region) from Landsat TM and RADARSAT-1 data. Wetlands Ecology and Management, 10: 123-132.

SOUZA FILHO, P.W.M. \& PARADELLA, W.R. 2005. Use of RADARSAT-1 fine mode and Landsat-5 TM selective principal component analysis for geomorphological mapping in a macrotidal mangrove coast in the Amazon Region. Canandian Journal of Remote Sensing, 31(3): 214224.

SOUZA FILHO, P.W.M.; MARTINS, E.S.F.M. \& COSTA, F.R. 2006. Using mangroves as a geological indicator of coastal changes in the Bragança macrotidal flat, Brazilian Amazon: A remote sensing data approach. Ocean \& Coastal management, 49: 462-475.

SPALDING, M.; KAINUMA, M. \& COLLINS, L. 2010. World Atlas of Mangroves. Earthscan, 319p.

SUGUIO, K. \& MARTIN, L. 1978. Quaternary marine formations of the states of São Paulo and Southern Rio de Janeiro. In: International Symposium on Coastal Evolution in the Quaternary. Spec. Pub. n. 1: 55 p. - The Brazilian national Working Group for the IGCP; Project 61, Instituto de Geociências da USP. 
SULONG, I.; MOHD-LOCKMAN, H.; MOHD-TARMIZI, N. \& ISMAIL, A. 2002. Mangrove mapping using Landsat imagery and aerial photographs: Kemaman District, Terengganu, Malaysia. Environment, Development and Sustainability, 4: 135-152.

TAM, N.F.Y.; WONG, Y.S.; LU, C.Y. \& BERRY, R. 1997. Mapping and characterization of mangrove plant communities in Hong Kong. Hydrobiologia, 352: 25-37.

TERCHUNIAN, A.; KLEMAS, V.; SEGOVIA, A.; ALVAREZ, A.; VASCONEZ, B. \& GUERRERO, L. 1986. Mangrove Mapping in the Ecuador: the impact of shrimp pond construction. Environmental Management, 10(3): 345350 .

THEVAND, A. \& GOND, V. 2005. Uso do sensoriamento remoto óptico para a compreensão da dinâmica dos manguezais no contexto amazônico. In: Simpósio Brasileiro de Sensoriamento Remoto, Anais... XII SBSR, Gôiania, p. 3387-3394.

THIRION, L.; CHÊNERIE, I. \& GALY, C. 2003. Study of the backscattering coefficient and the interferometric coherence of Mangrove forests. In: Geoscience and Remote Sensing Symposium, IGARSS '03, Toulouse, France, 7: 4217-4219.

THU, P.M. \& POPULUS, J. 2007. Status and changes of mangrove forest in Mekong Delta: Case study in Tra Vinh, Vietnam. Estuarine, Coastal and Shelf Science, 71: 98-109.

TONG, P.H.S.; AUDA, Y.; POPULUS, J.; AIZPURU, M.; HABSHI, A.AL \& BLASCO, F. 2004. Assessment from space of mangroves evolution in the Mekong Delta, in relation to extensive shrimp farming. International Journal of Remote Sensing, 25(21): 4795-4812.

TOUTIN, T. 2004. Geometric processing of remote sensing images: models, algorithms and methods. International Journal of Remote Sensing, 25(10): 1893-1924. 
TUCKER, J.; GRANT, D.M. \& DYKSTRA, J.D. 2004. NASA's global orthorectified Landsat data set. Photogrammetric Engineering and Remote Sensing, 70: 313-322.

VAIPHASA, C.; SKIDMORE, A.K. \& DE BOER, W. F. 2006. A post-classifier for mangrove mapping using ecological data. ISPRS Journal of Photogrammetry \& Remote Sensing, 61: 1-10.

VALERIANO, M.M. 2008. Topodata: guia de utilização de dados geomorfométricos locais. São José dos Campos: INPE.

VERHEYDEN, A.; DAHDOUH-GUEBAS, F.; THOMAES, K.; DE GENST, W.; HETTIARACHCHI, S. \& KOEDAM, N. 2002. High resolution vegetation data for mangrove research as obtained from aerial photography. Environment, Development and Sustainability, 4: 113-133.

WALSH, G. 1974. Mangrove forests: a review. In: Reinold, R.J. \& Queen, W.H. (eds.). Ecology of Halophytes. New York, Academic Press.

WANG, Y. \& IMHOFF, M. L. 1993. Simulated and observed L-HH radar backscatter from tropical mangrove forests. International Journal of Remote Sensing, 14(15): 2819-2828.

WANG, Y.; BONYNGE, G.; NUGRANAD, J.; TRABER, M.; NGUSARU, A.; TOBEY, J.; HALE, L.; BOWEN, R. \& MAKOTA, V. 2003. Remote sensing of mangrove change along the Tanzania coast. Marine Geodesy, 26: 35-48.

WANG, L.; SOUSA, W.P. \& GONG, P. 2004a. Integration of object-based and pixel-based classification for mapping mangroves with IKONOS imagery. International Journal of Remote Sensing, 25(24): 5655-5668.

WANG, L.; SOUSA, W.P.; GONG, P. \& BIGING, G.S. 2004b. Comparison of IKONOS and QuickBird images for mapping mangrove species on the Caribbean coast of Panama. Remote Sensing of Environment, 91: 432440.

ZAGAGLIA, C.R.; CARVALHO, E.V.T. \& SANTOS, R.N.A. 2007. Mapeamento de manguezais do Brasil: subsídio ao projeto GEF Mangue. In: 
Simpósio Brasileiro de Sensoriamento Remoto, Anais... XIII SBSR, Florianópolis, p. 4343-4350.

ZHANG, K. 2008. Identification of gaps in mangrove forests with airborne LIDAR. Remote Sensing of Environment, 112: 2309-2325. 


\section{ANEXO A - MAPAS}

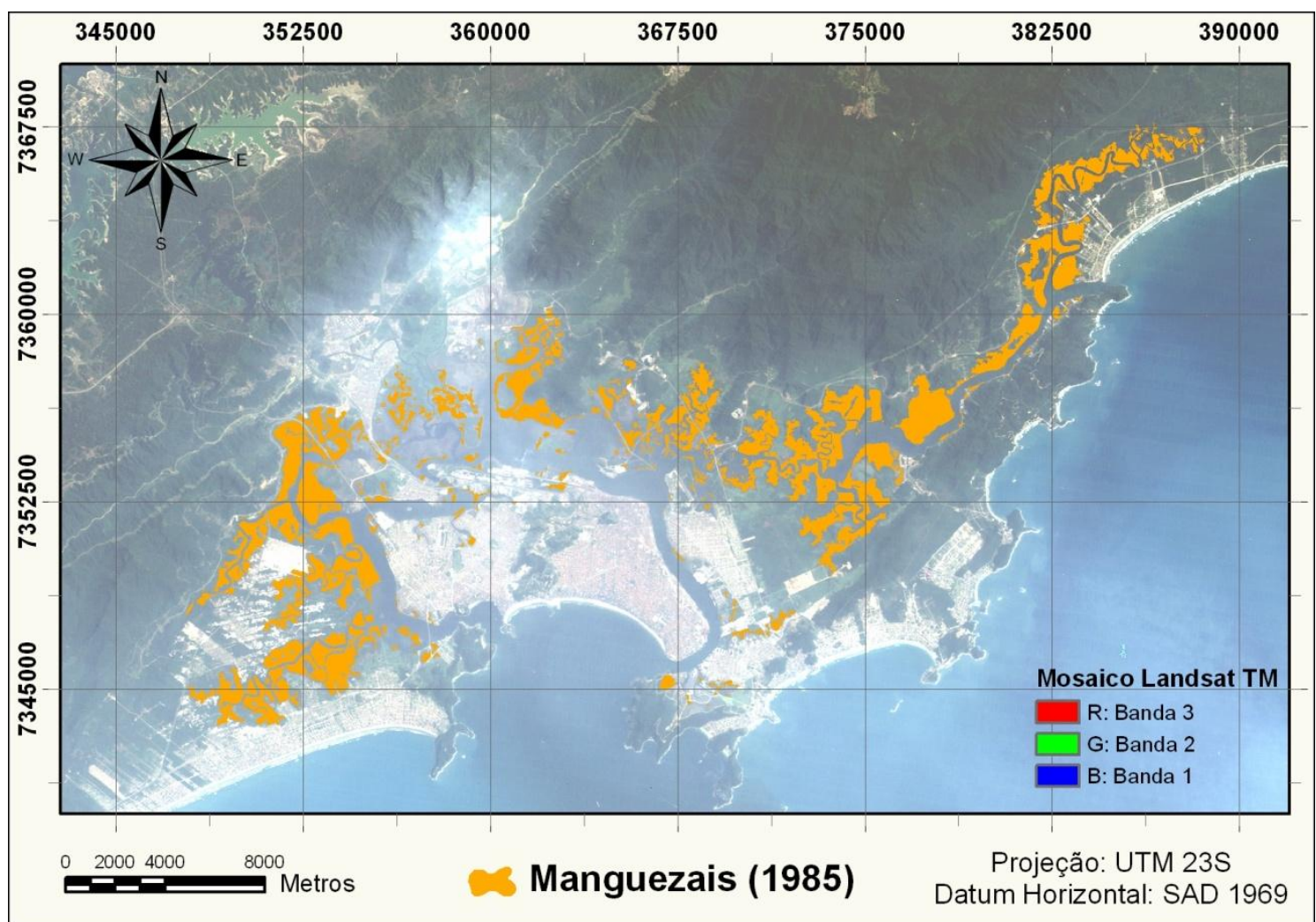

Mapa 1 Distribuição dos manguezais no ano de 1985.

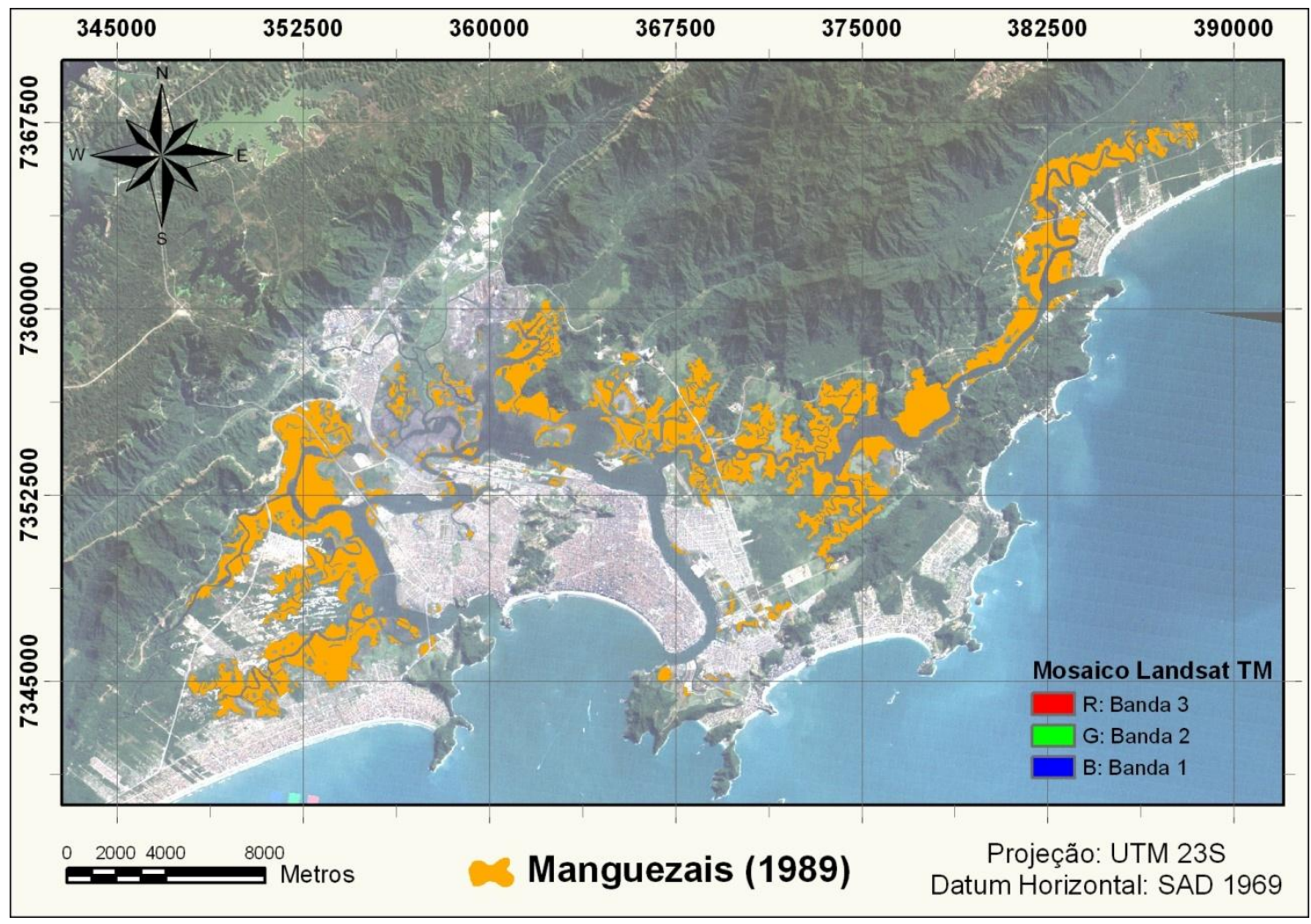

Mapa 2 Distribuição dos manguezais no ano de 1989. 


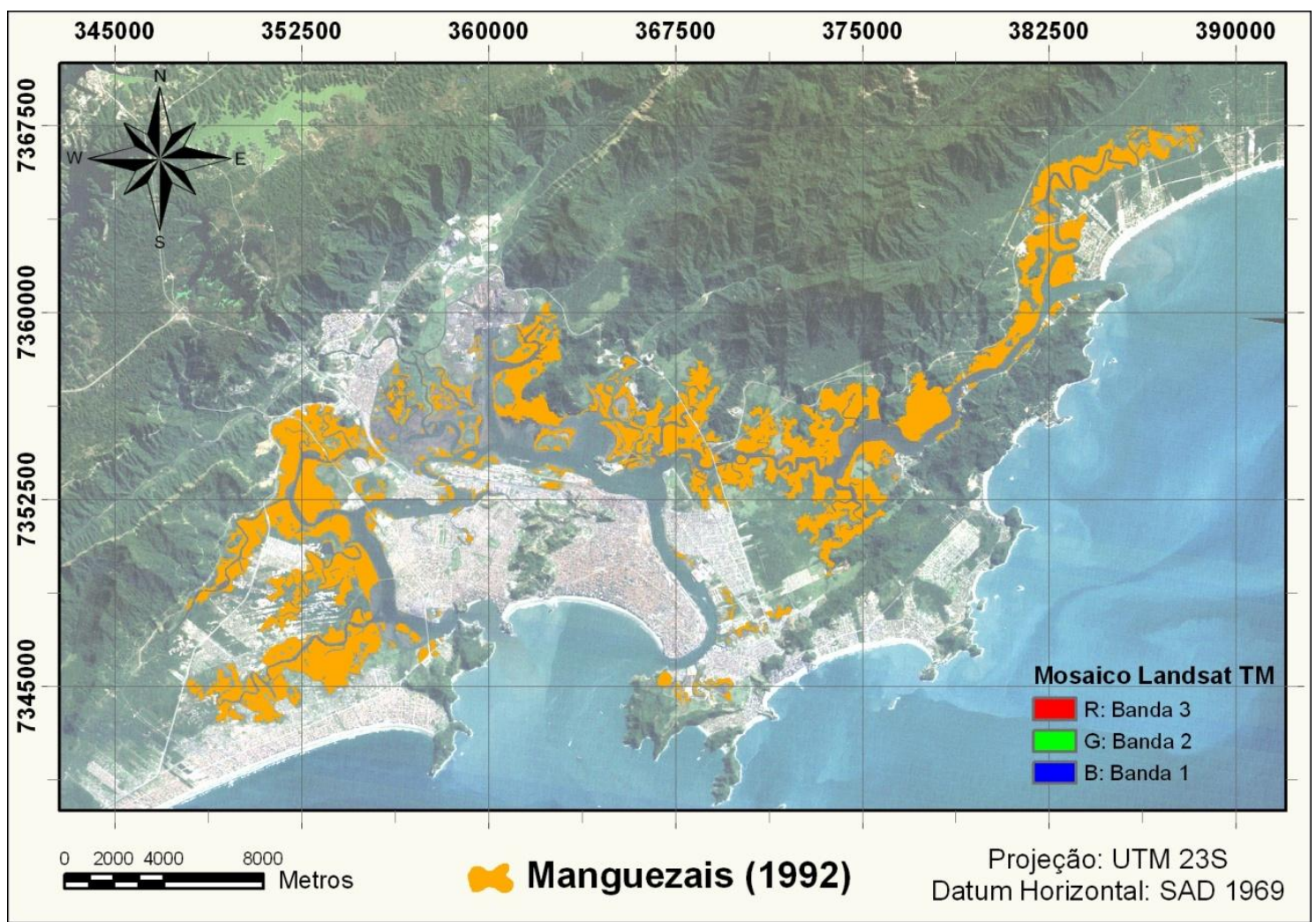

Mapa 3 Distribuição dos manguezais no ano de 1992.

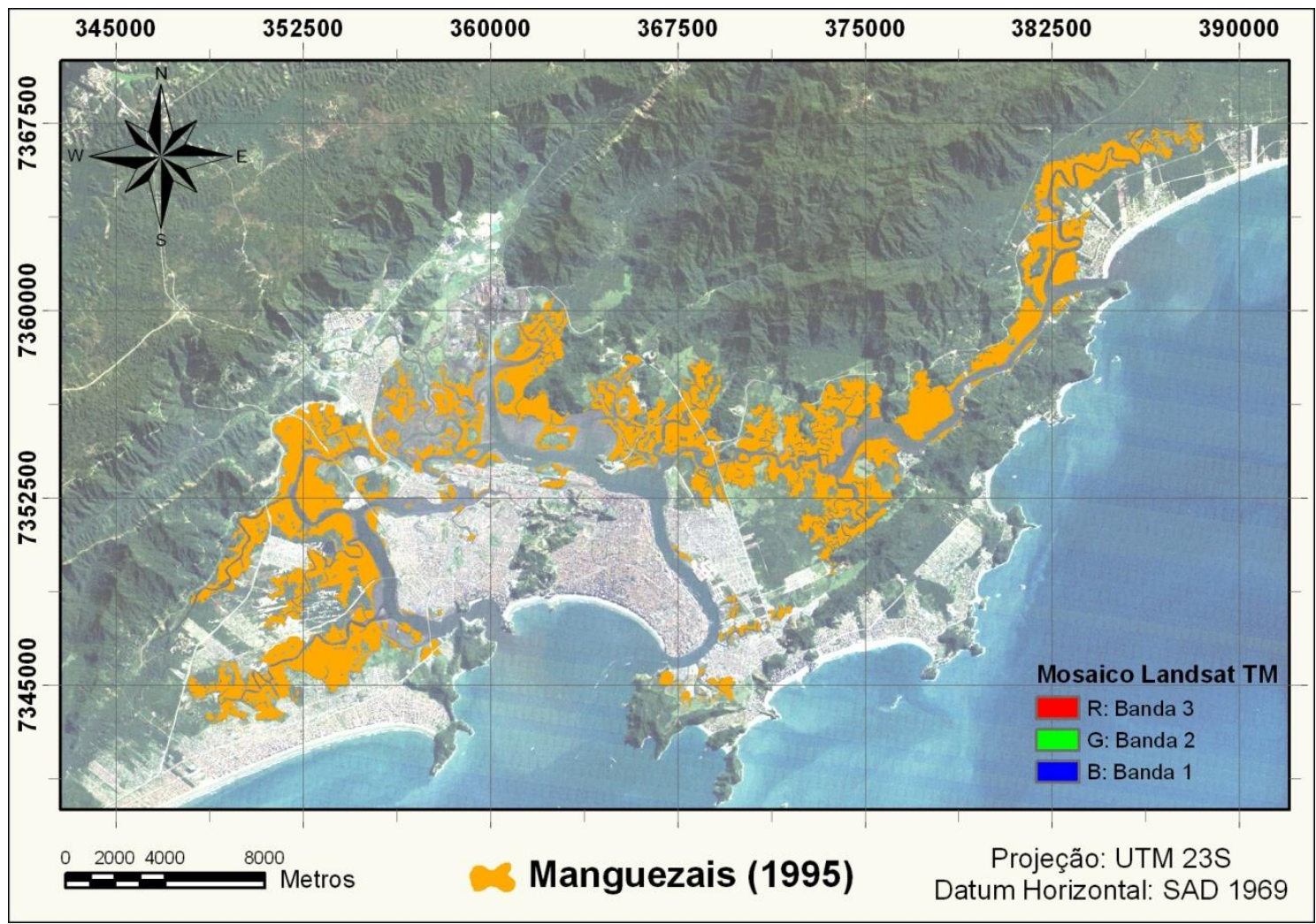

Mapa 4 Distribuição dos manguezais no ano de 1995. 


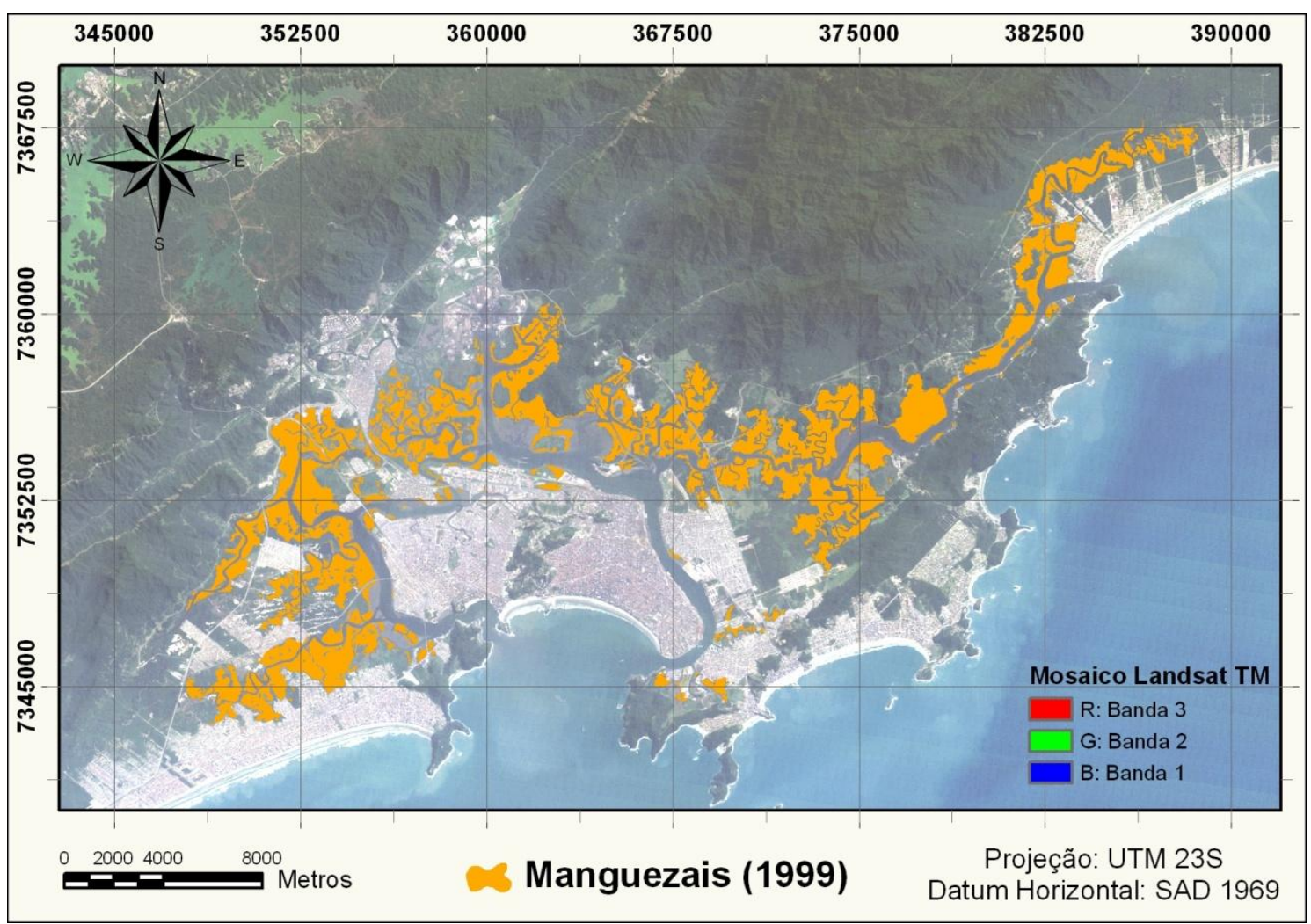

Mapa 5 Distribuição dos manguezais no ano de 1999.

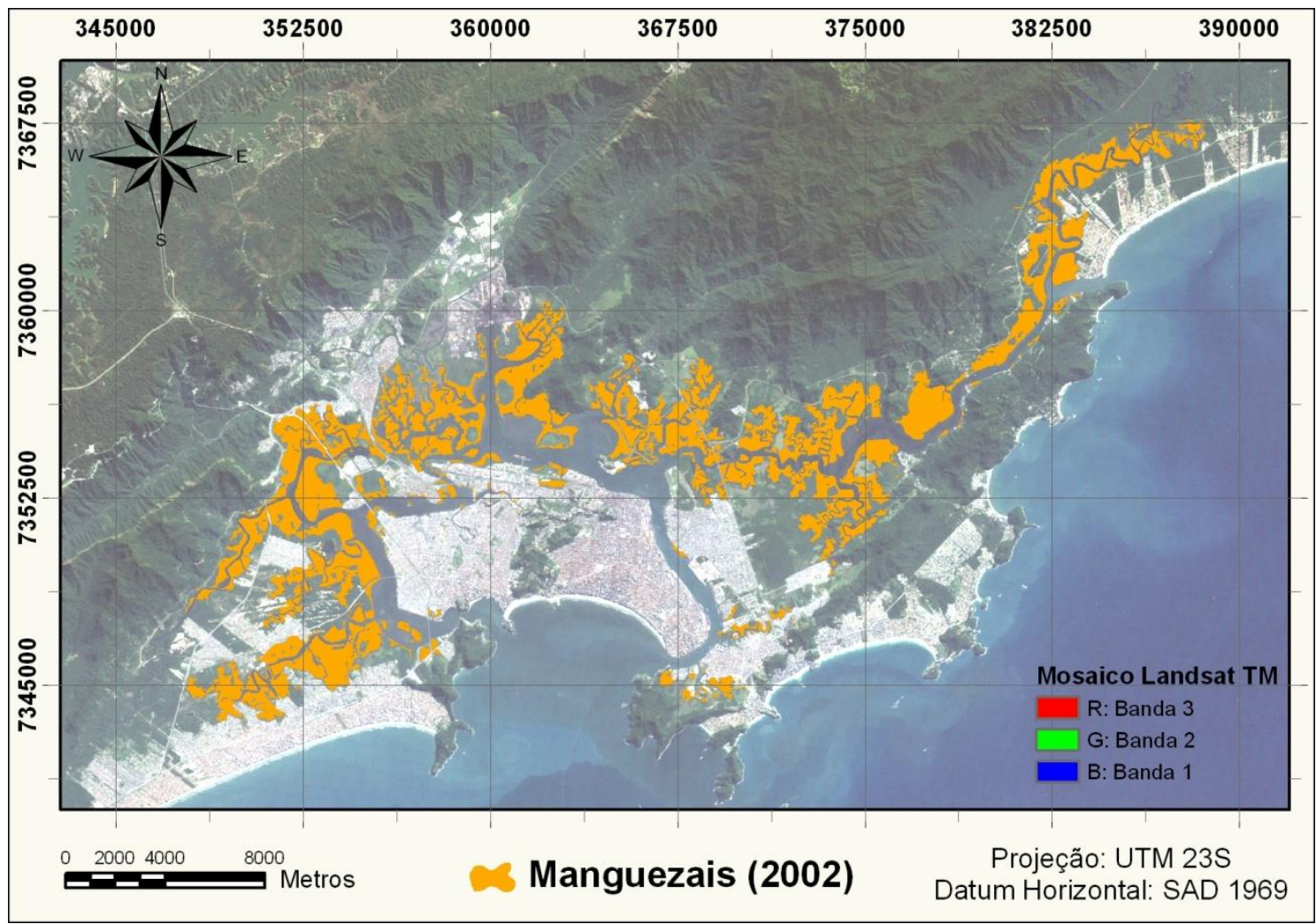

Mapa 6 Distribuição dos manguezais no ano de 2002. 


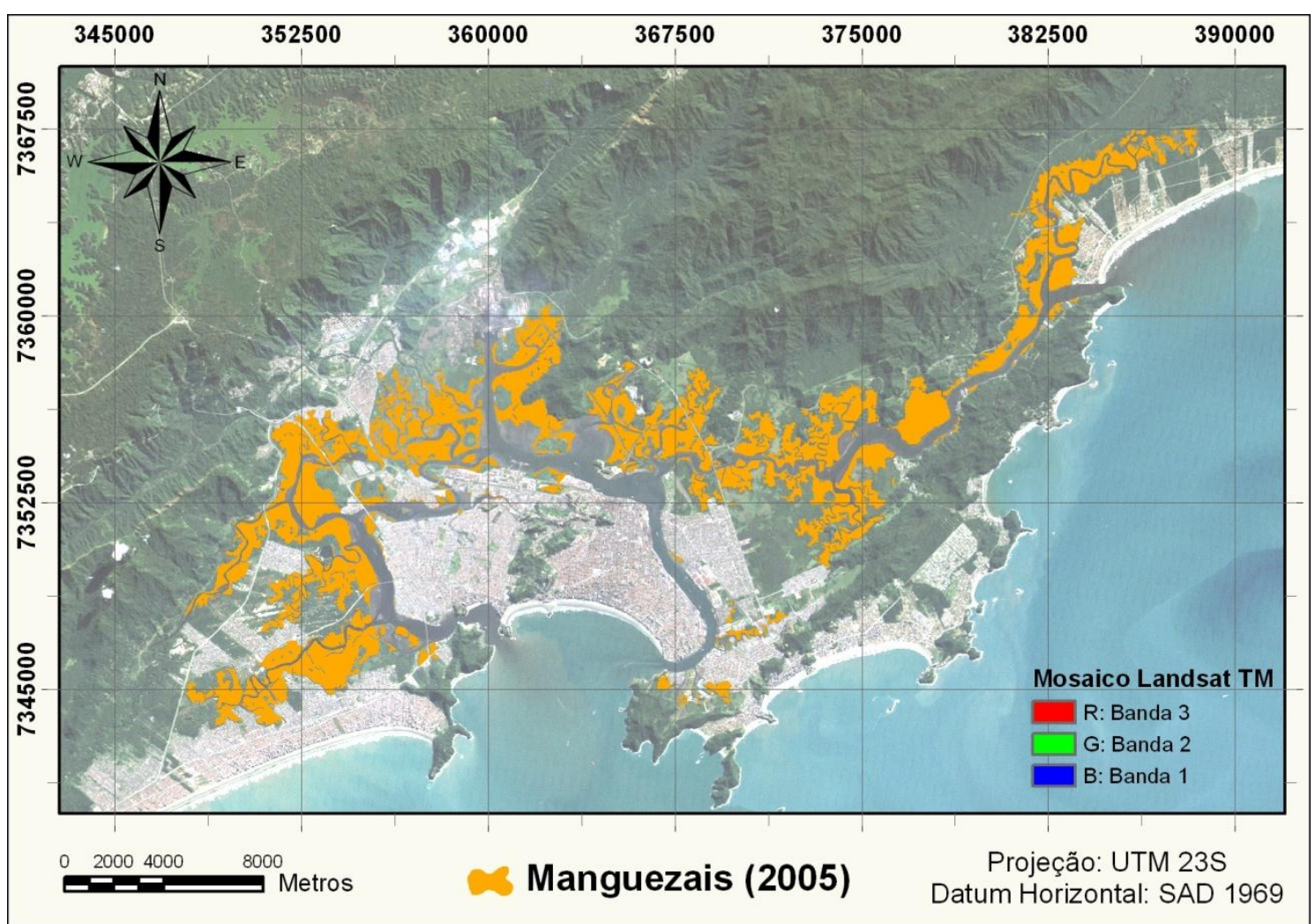

Mapa 7 Distribuição dos manguezais no ano de 2005.

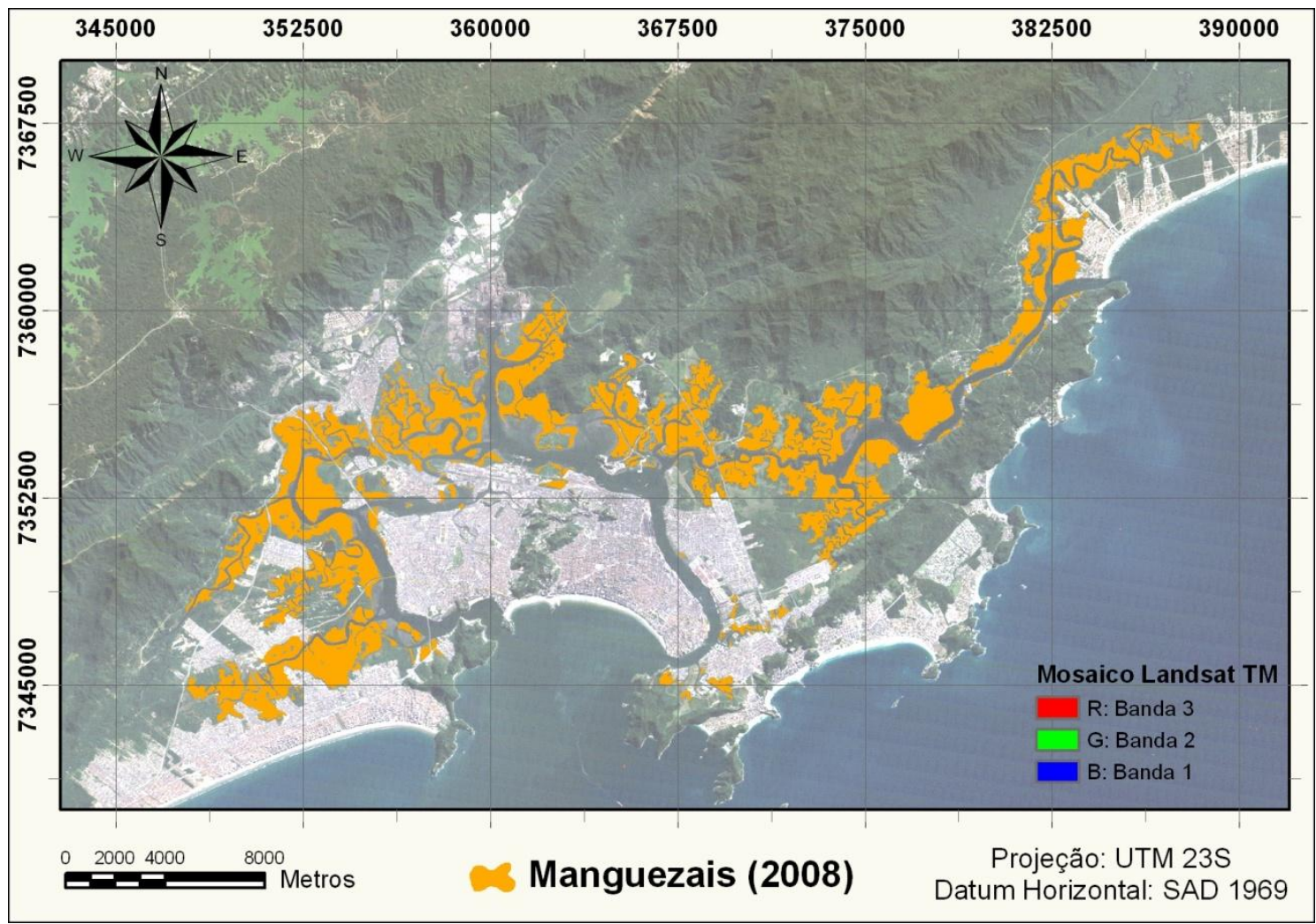

Mapa 8 Distribuição dos manguezais no ano de 2008. 


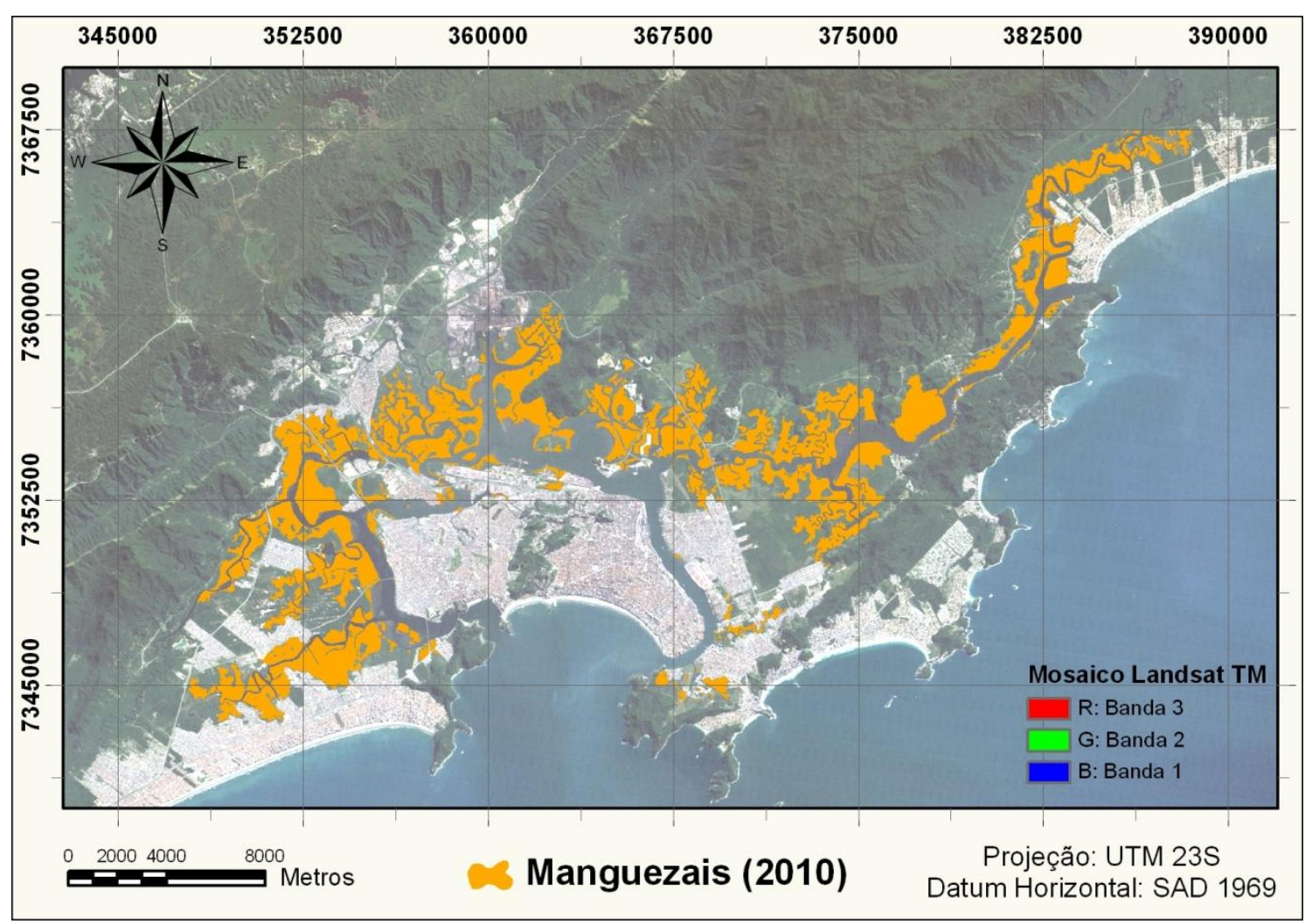

Mapa 9 Distribuição dos manguezais no ano de 2010.

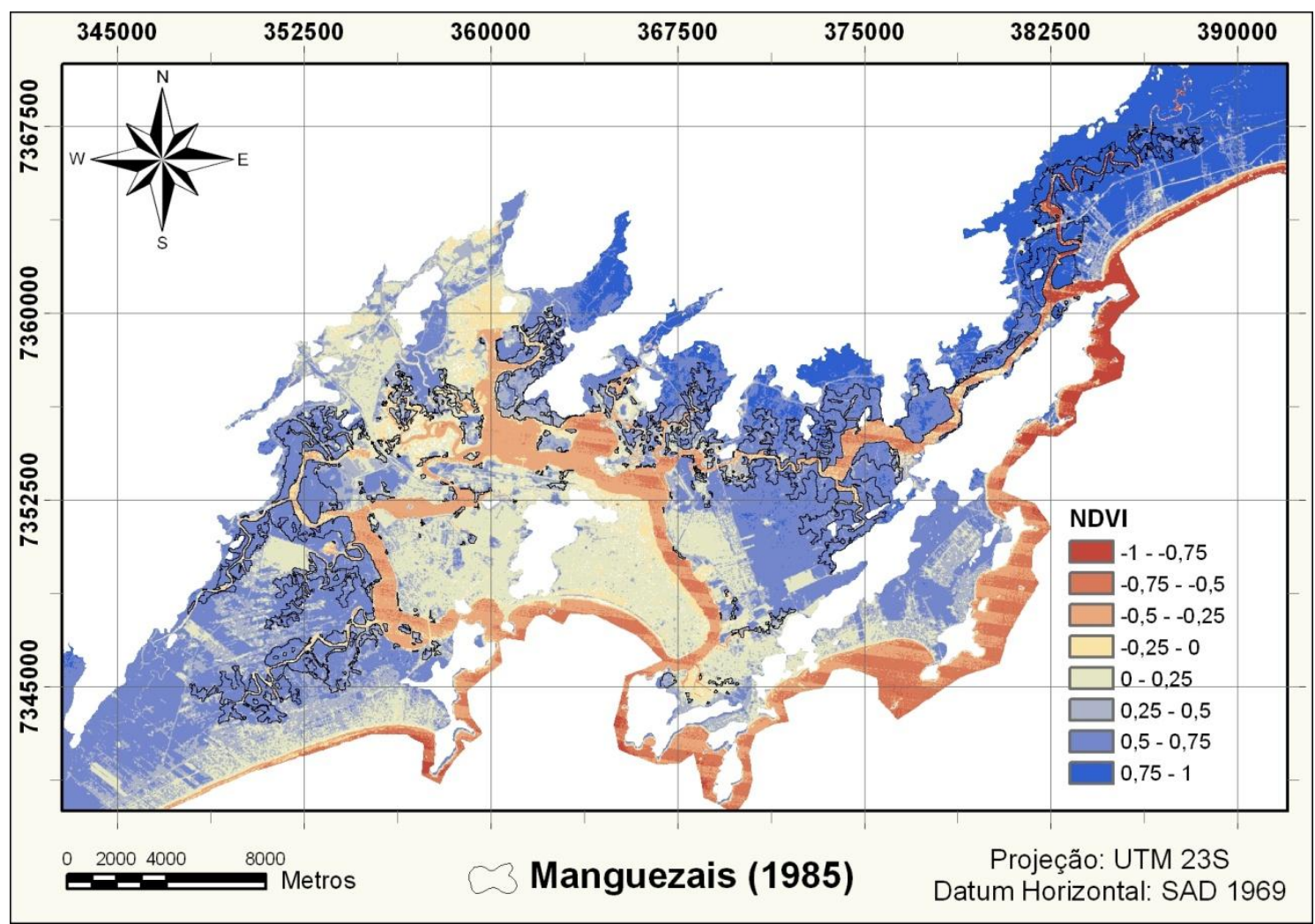

Mapa 10 NDVI para o ano de 1985. 


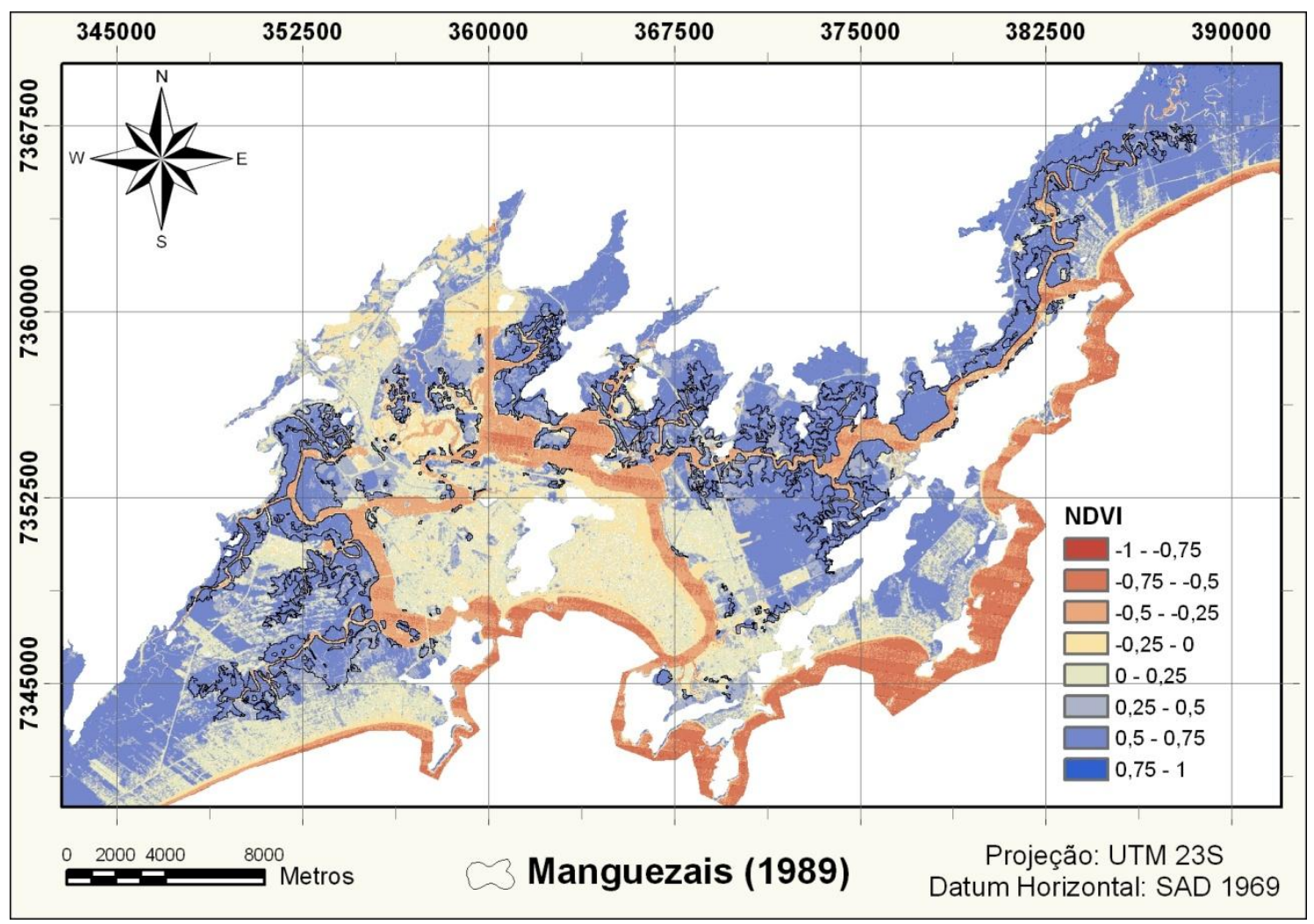

Mapa 11 NDVI para o ano de 1989.

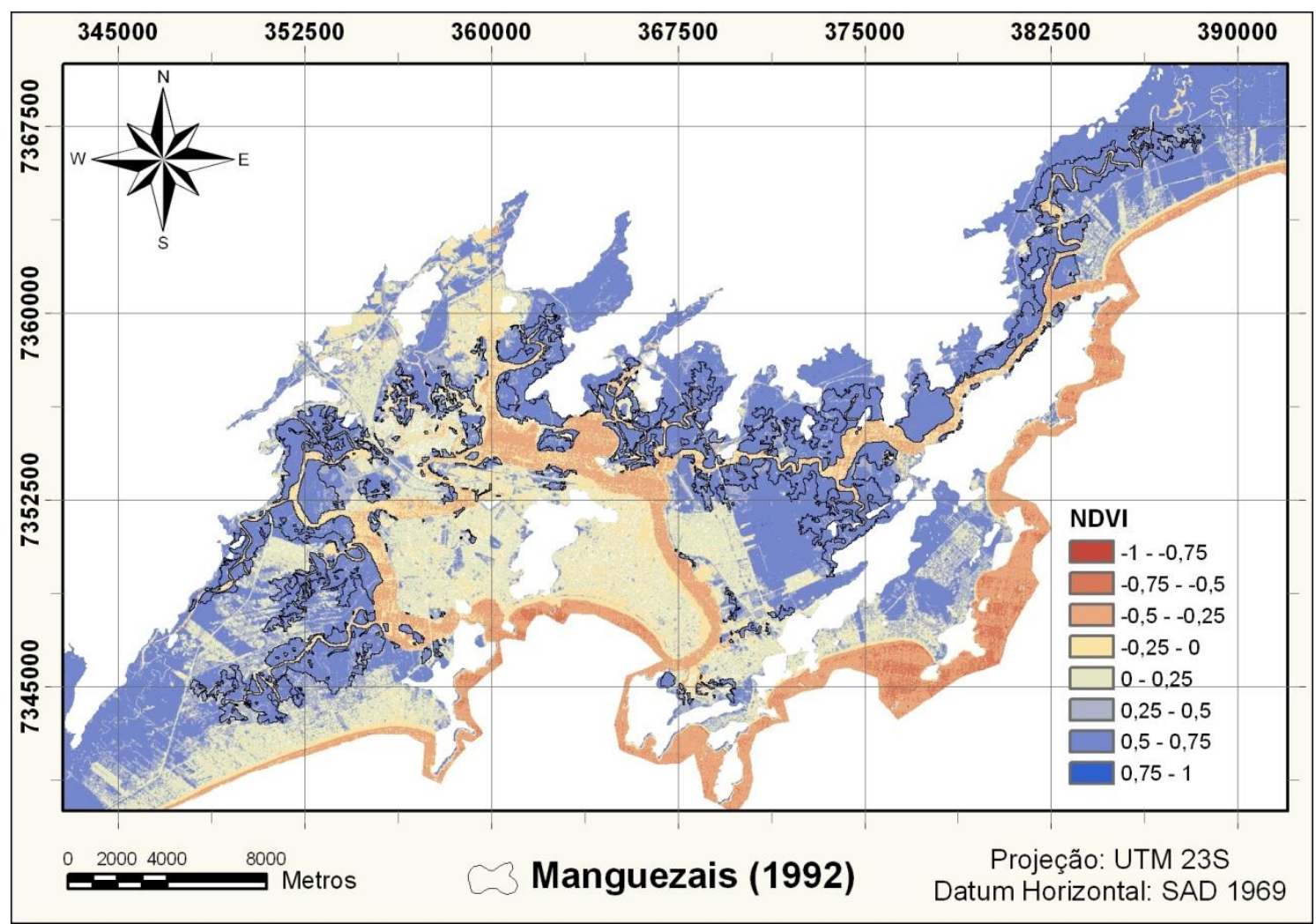

Mapa 12 NDVI para o ano de 1992. 


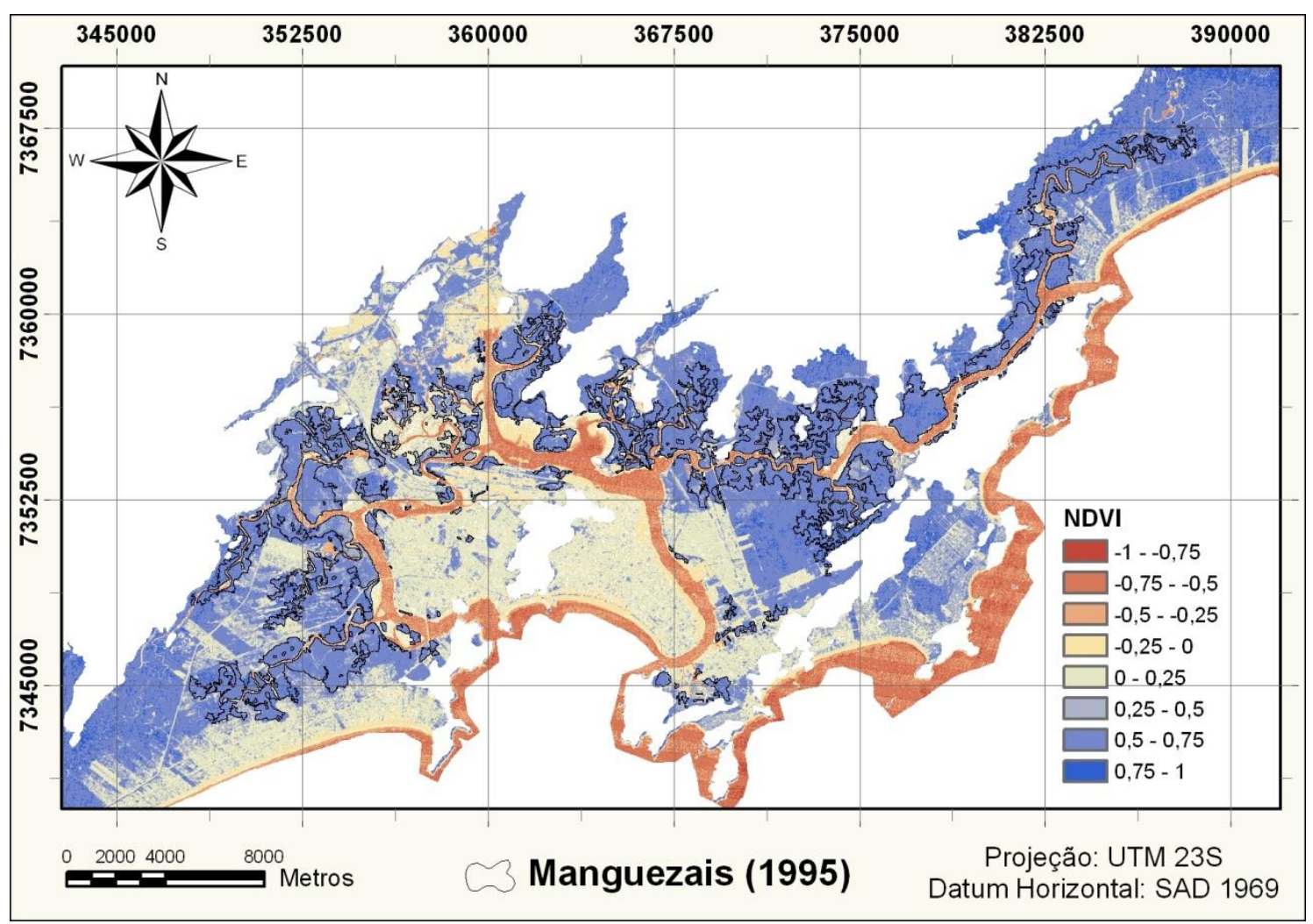

Mapa 13 NDVI para o ano de 1995.

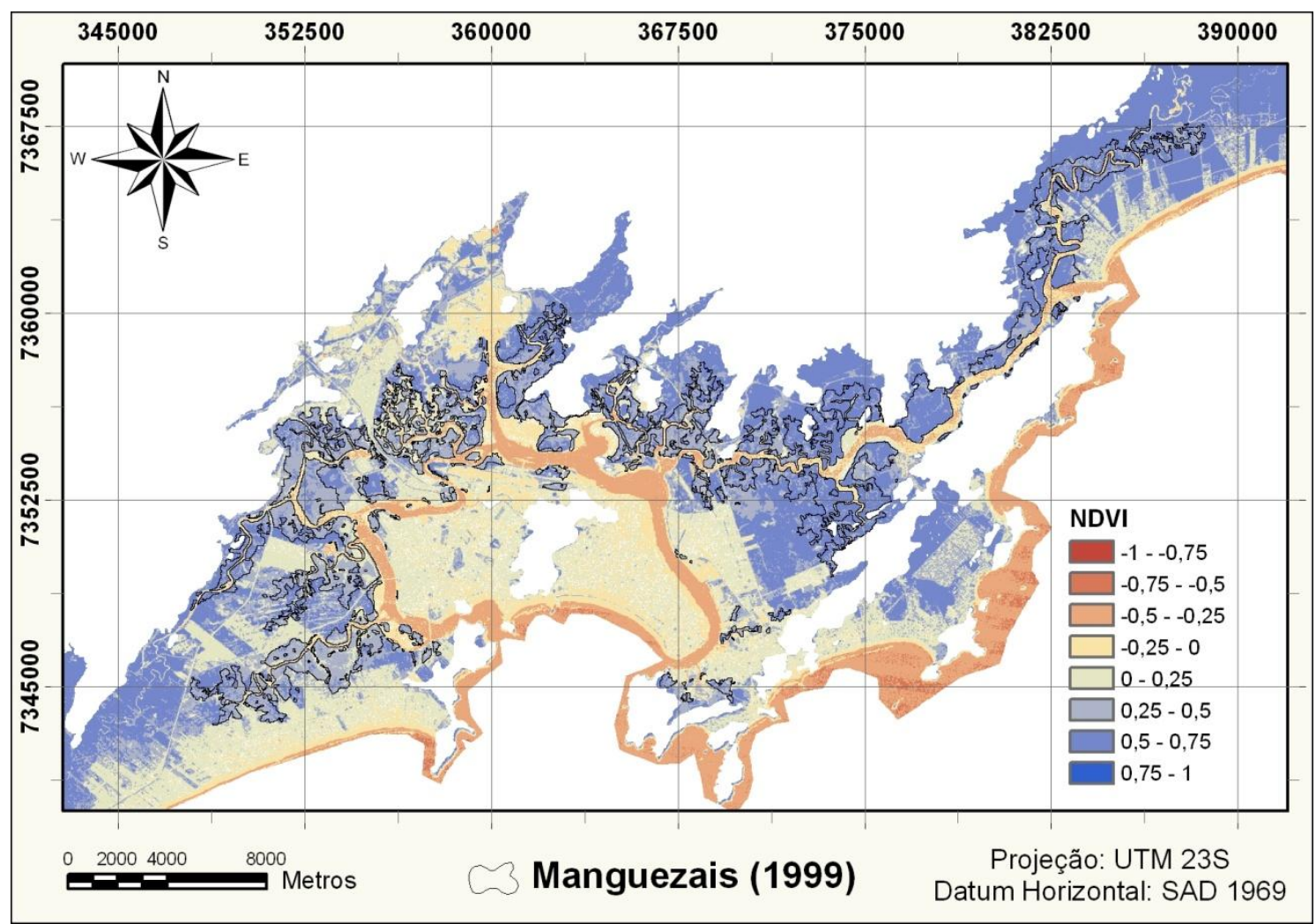

Mapa 14 NDVI para o ano de 1999. 


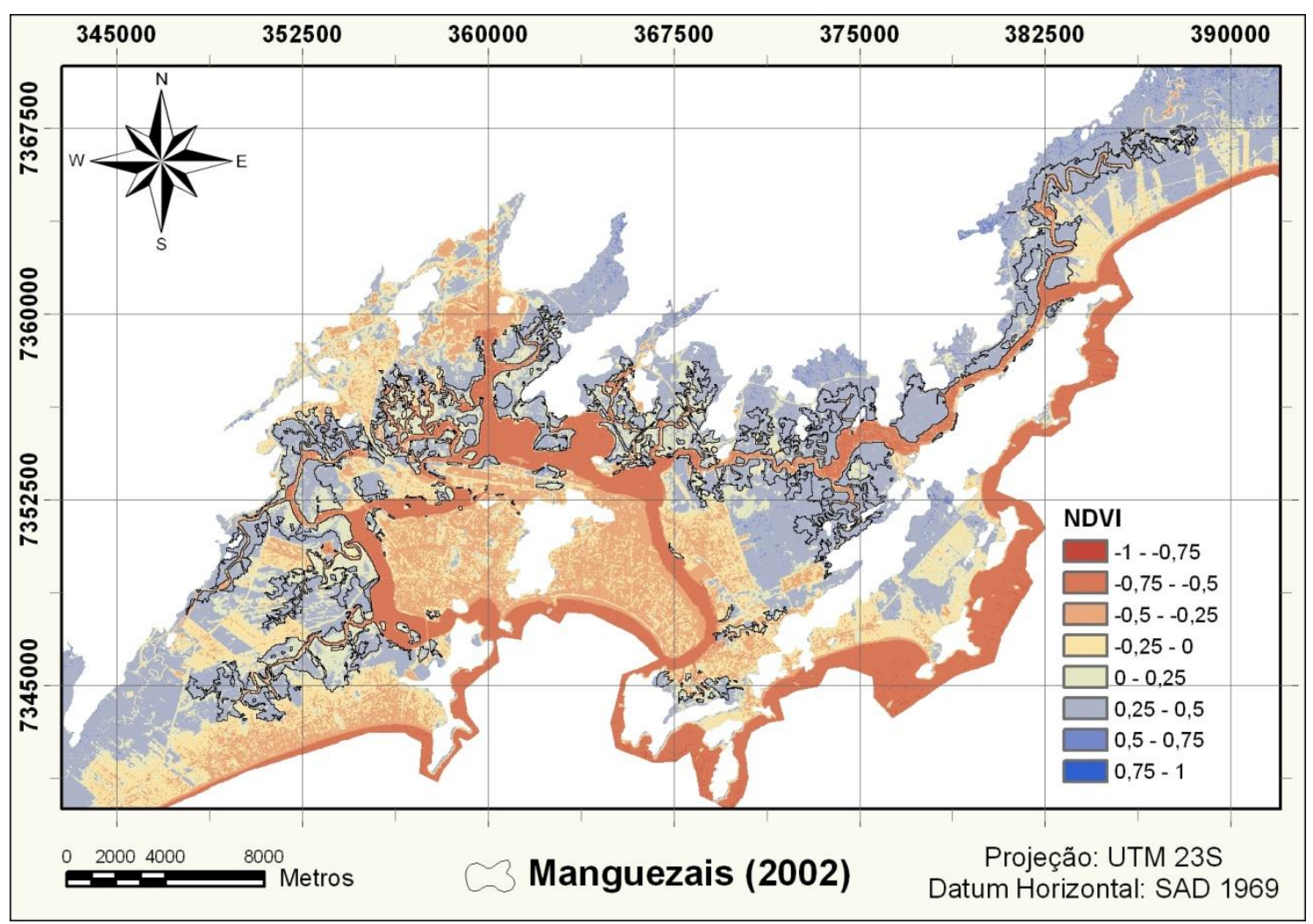

Mapa 15 NDVI para o ano de 2002.

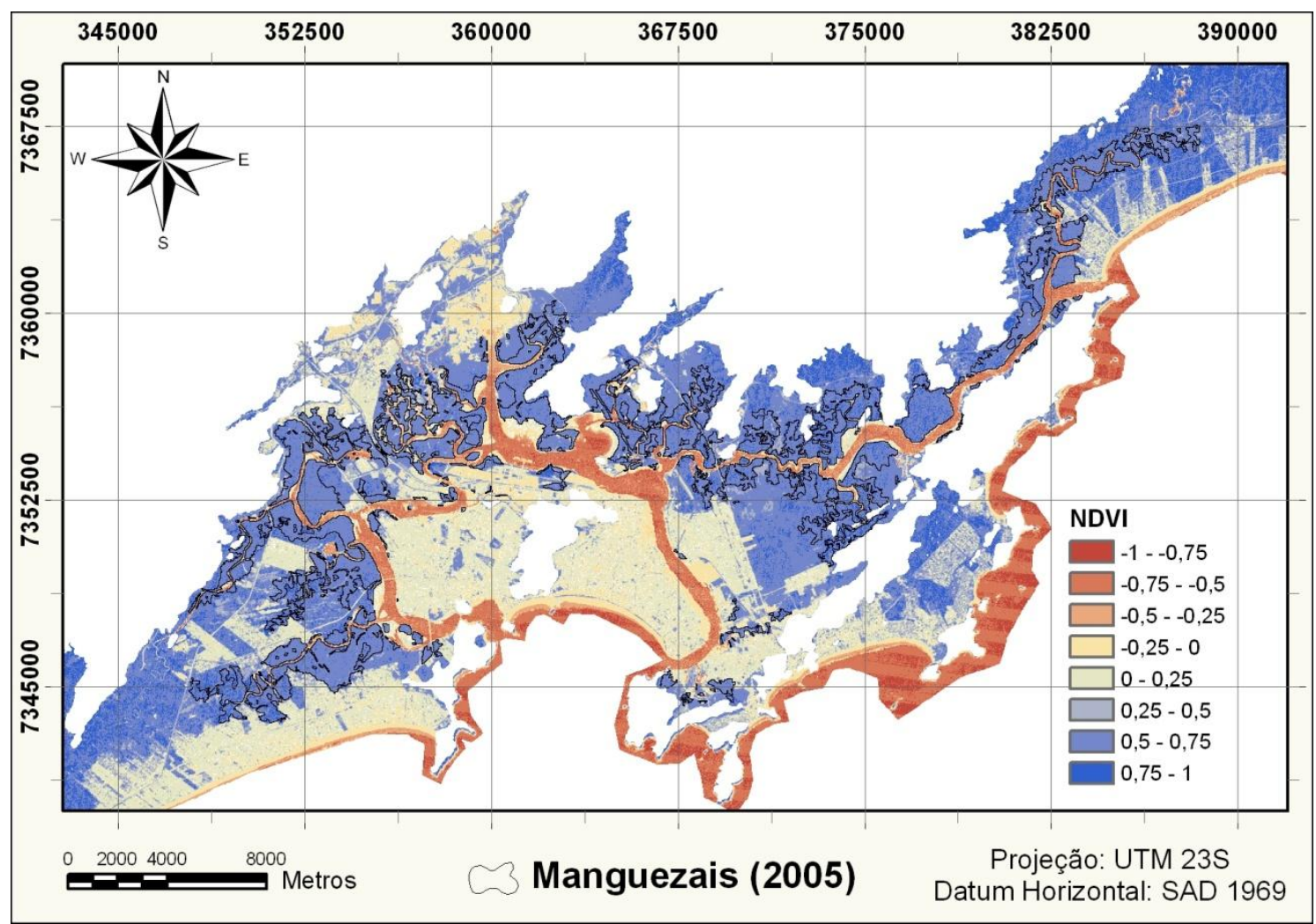

Mapa 16 NDVI para o ano de 2005. 


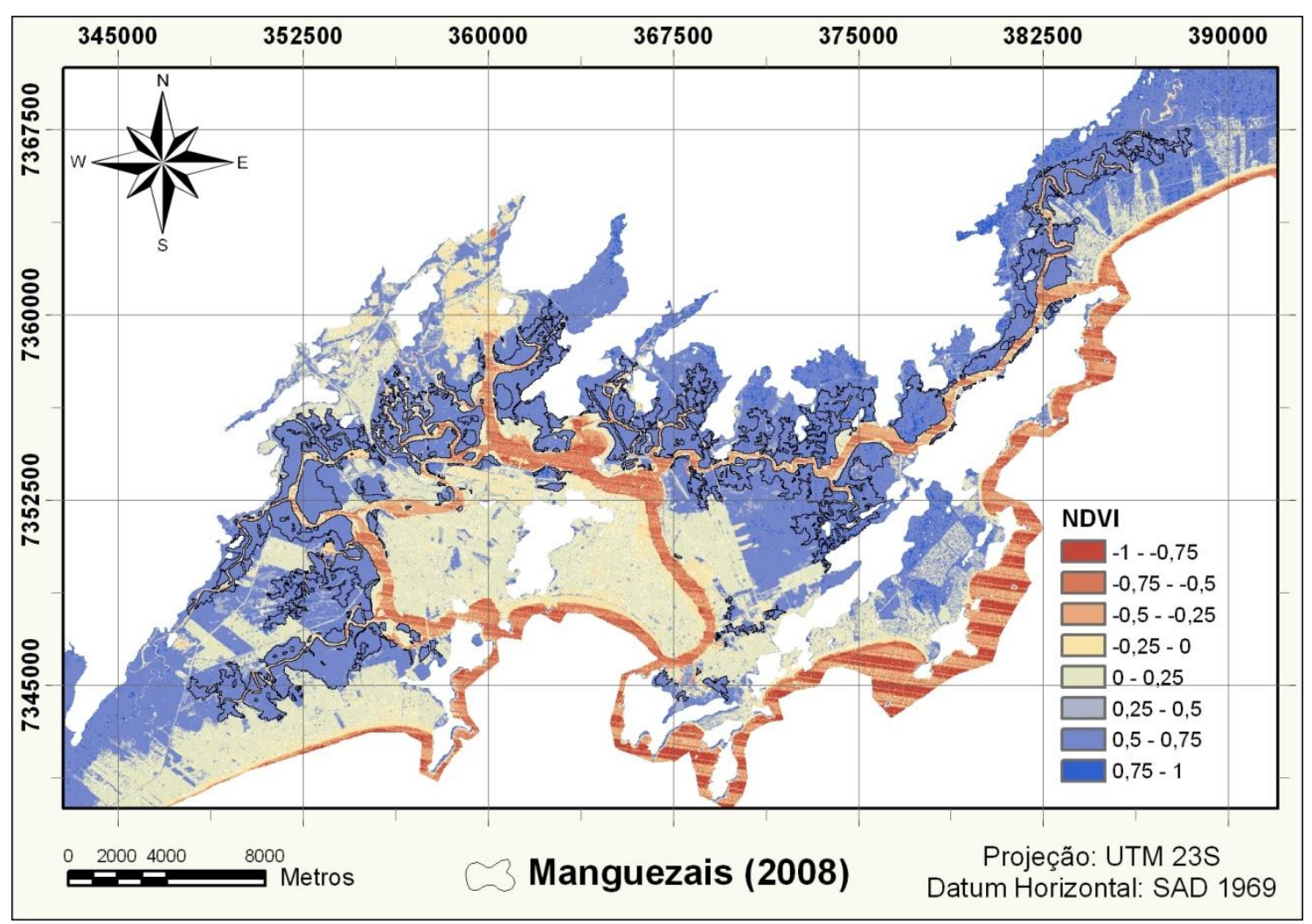

Mapa 17 NDVI para o ano de 2008.

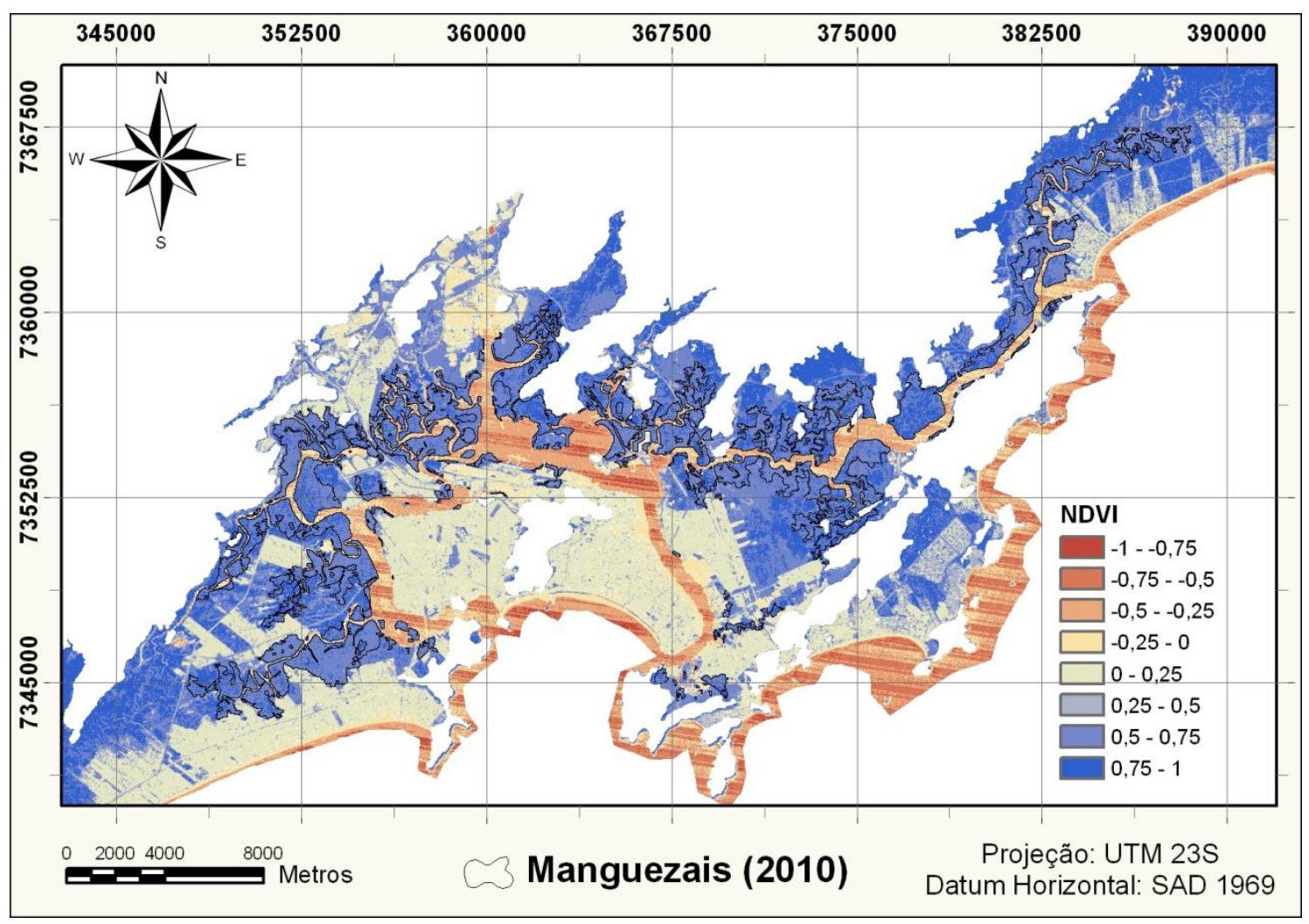

Mapa 18 NDVI para o ano de 2010. 


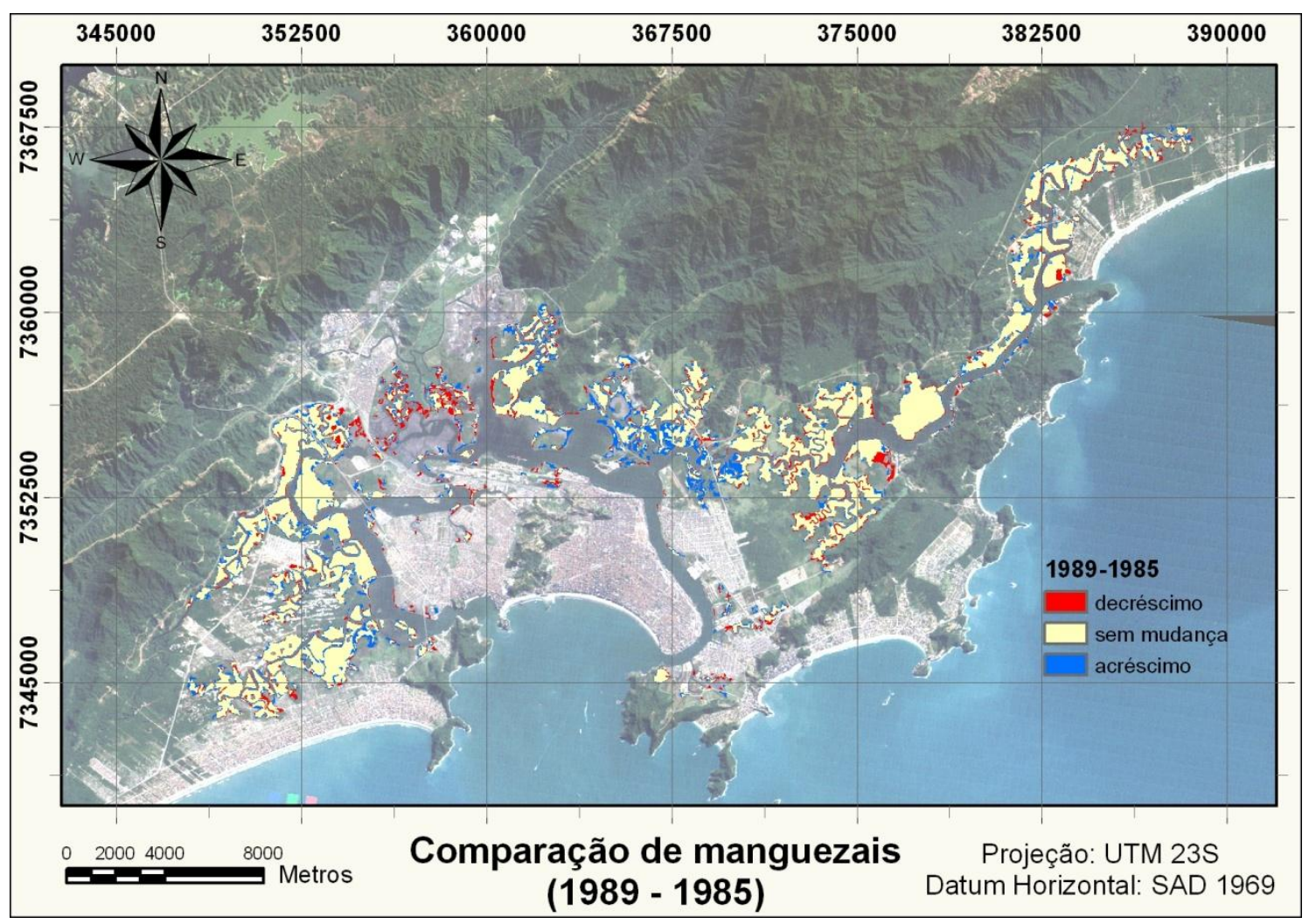

Mapa 19 Comparação pós-classificação entre os anos de 1989 e 1985.

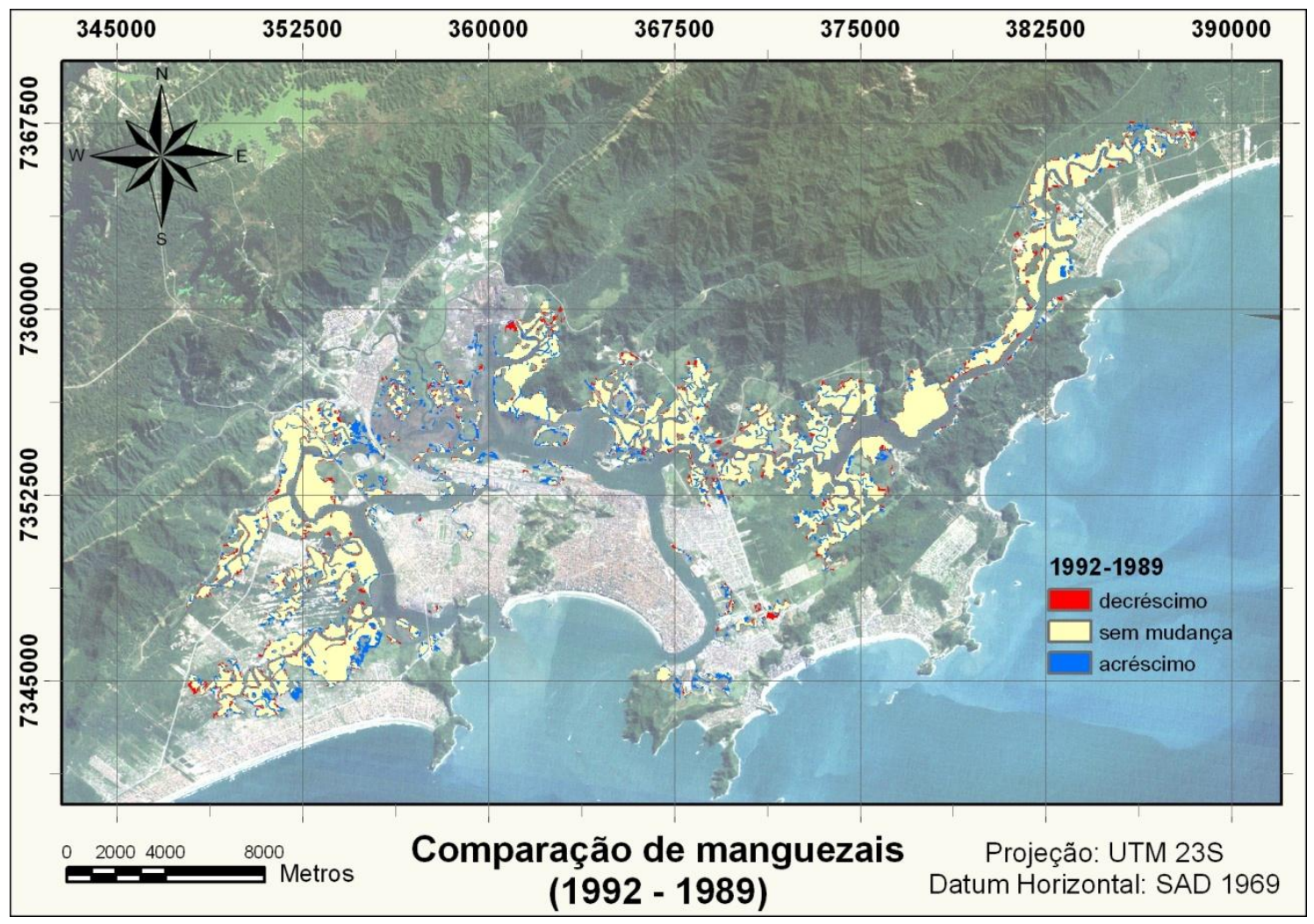

Mapa 20 Comparação pós-classificação entre os anos de 1992 e 1989. 


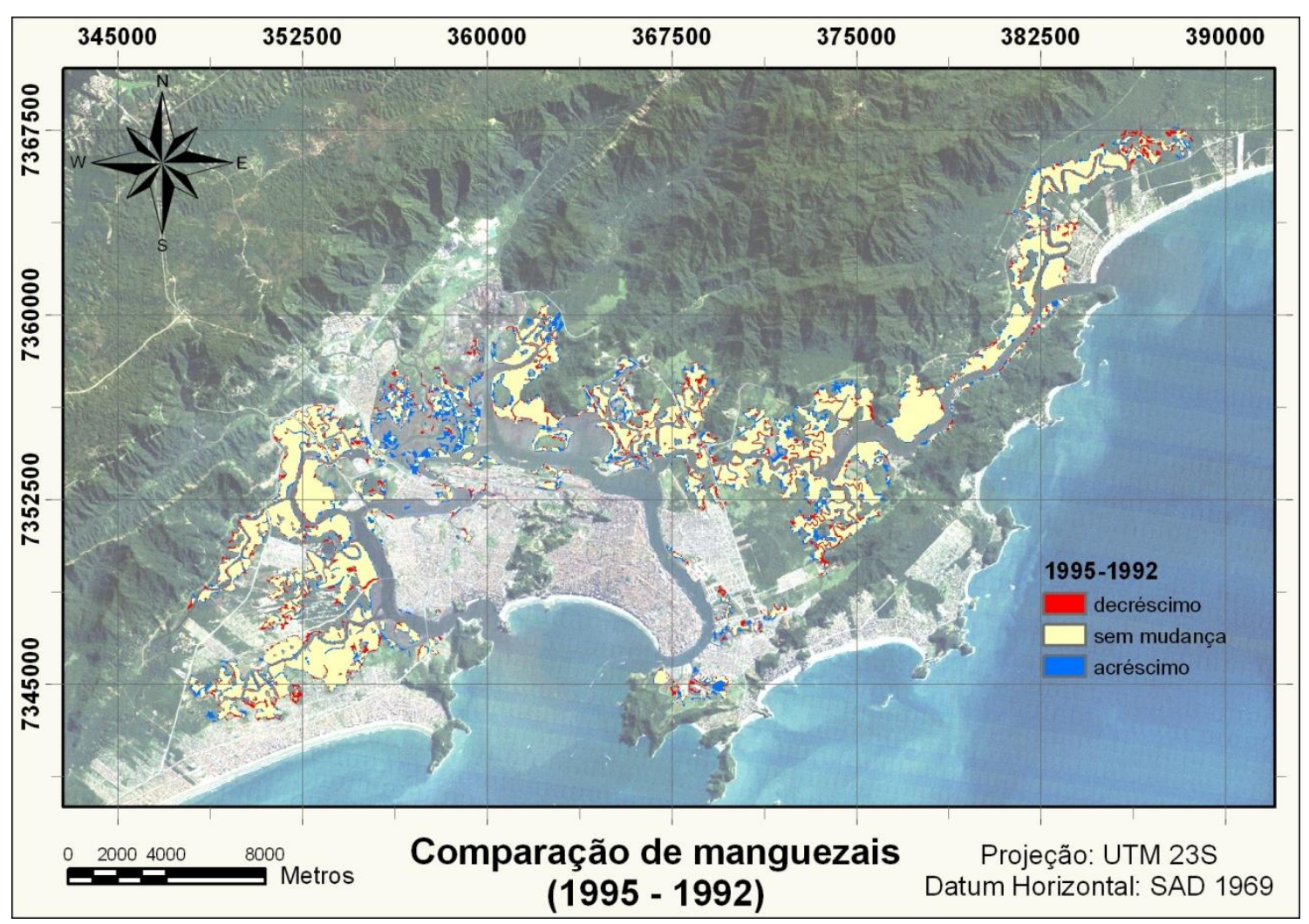

Mapa 21 Comparação pós-classificação entre os anos de 1995 e 1992.

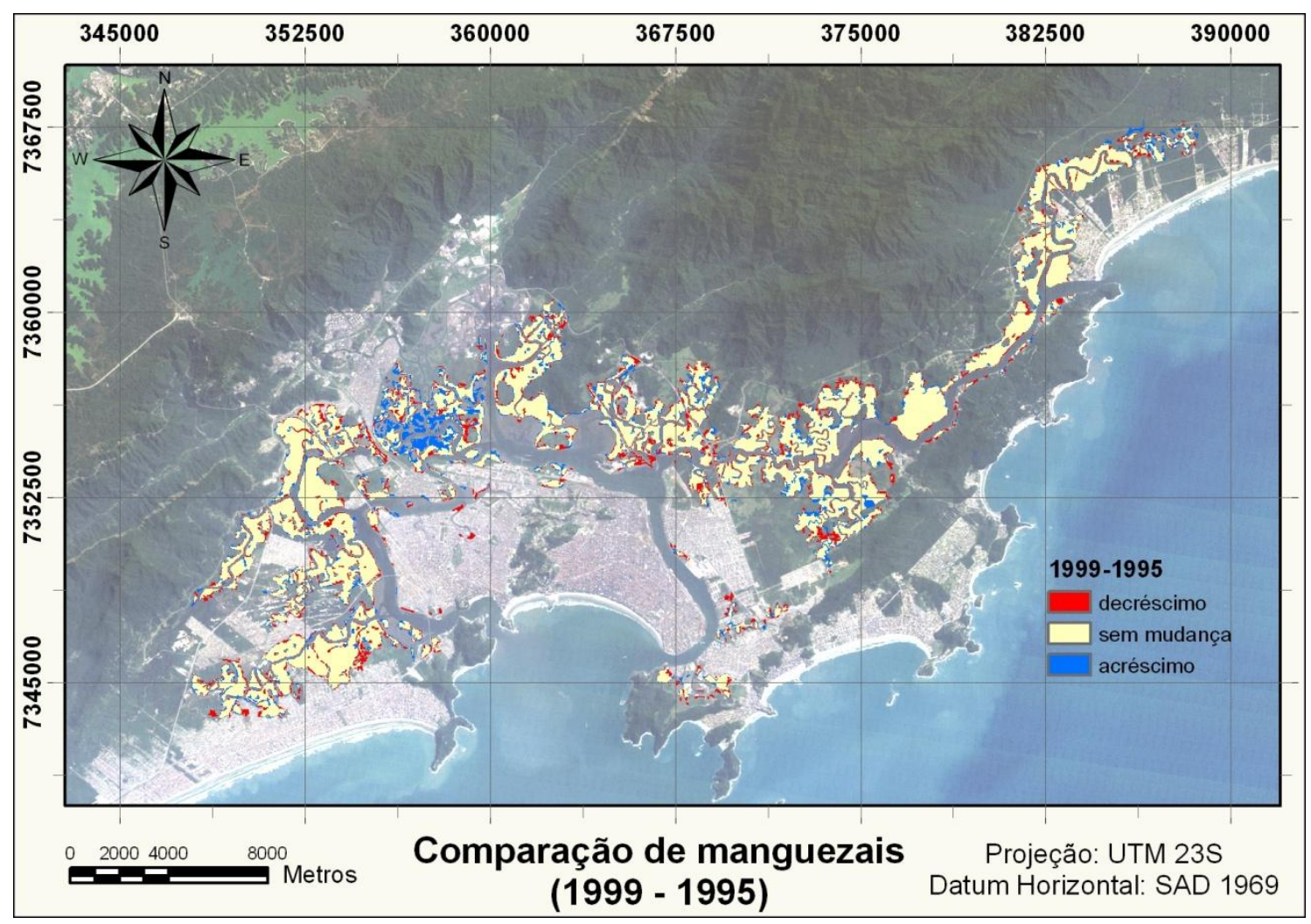

Mapa 22 Comparação pós-classificação entre os anos de 1999 e 1995. 


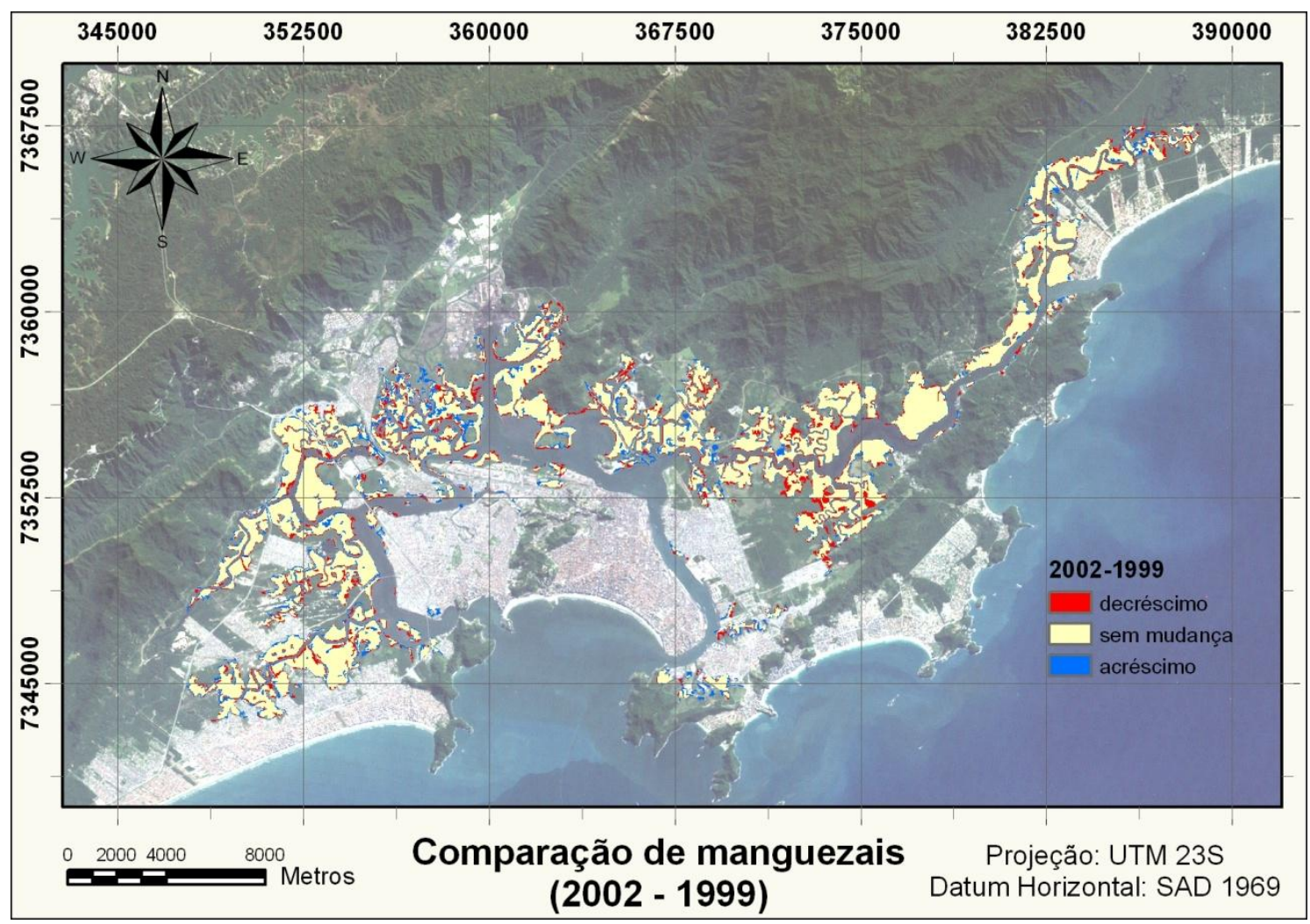

Mapa 23 Comparação pós-classificação entre os anos de 2002 e 1999.

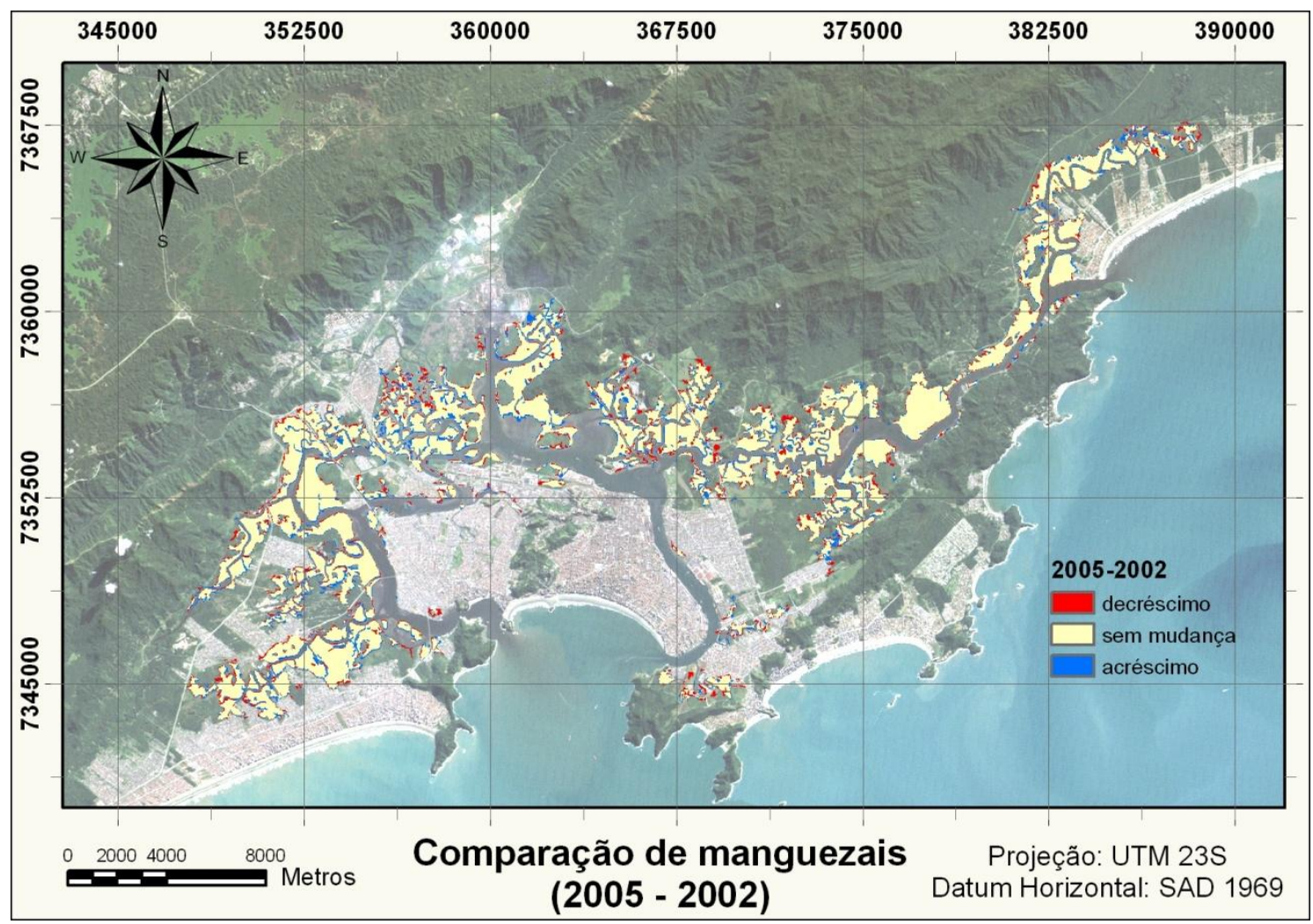

Mapa 24 Comparação pós-classificação entre os anos de 2005 e 2002. 


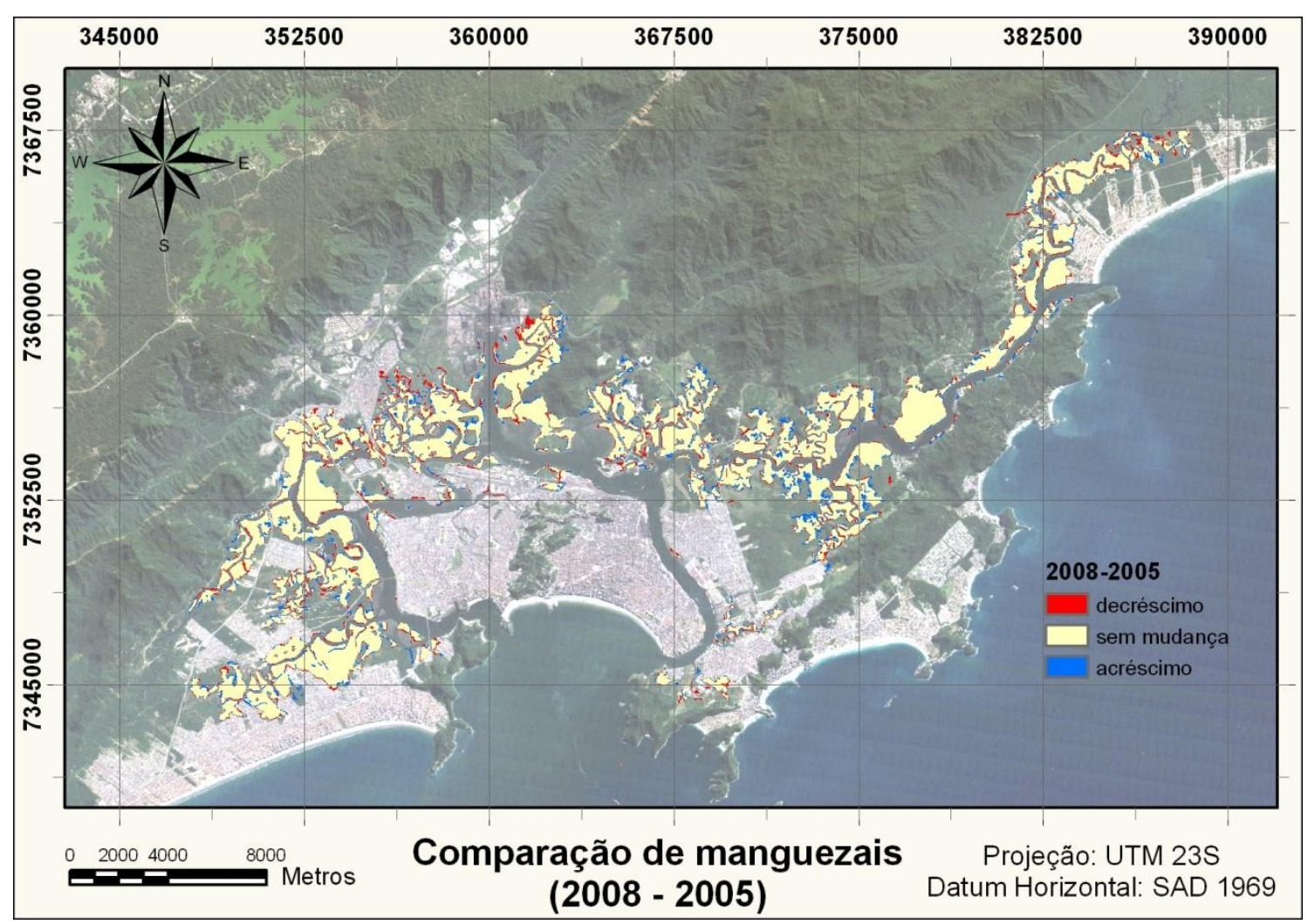

Mapa 25 Comparação pós-classificação entre os anos de 2008 e 2005.

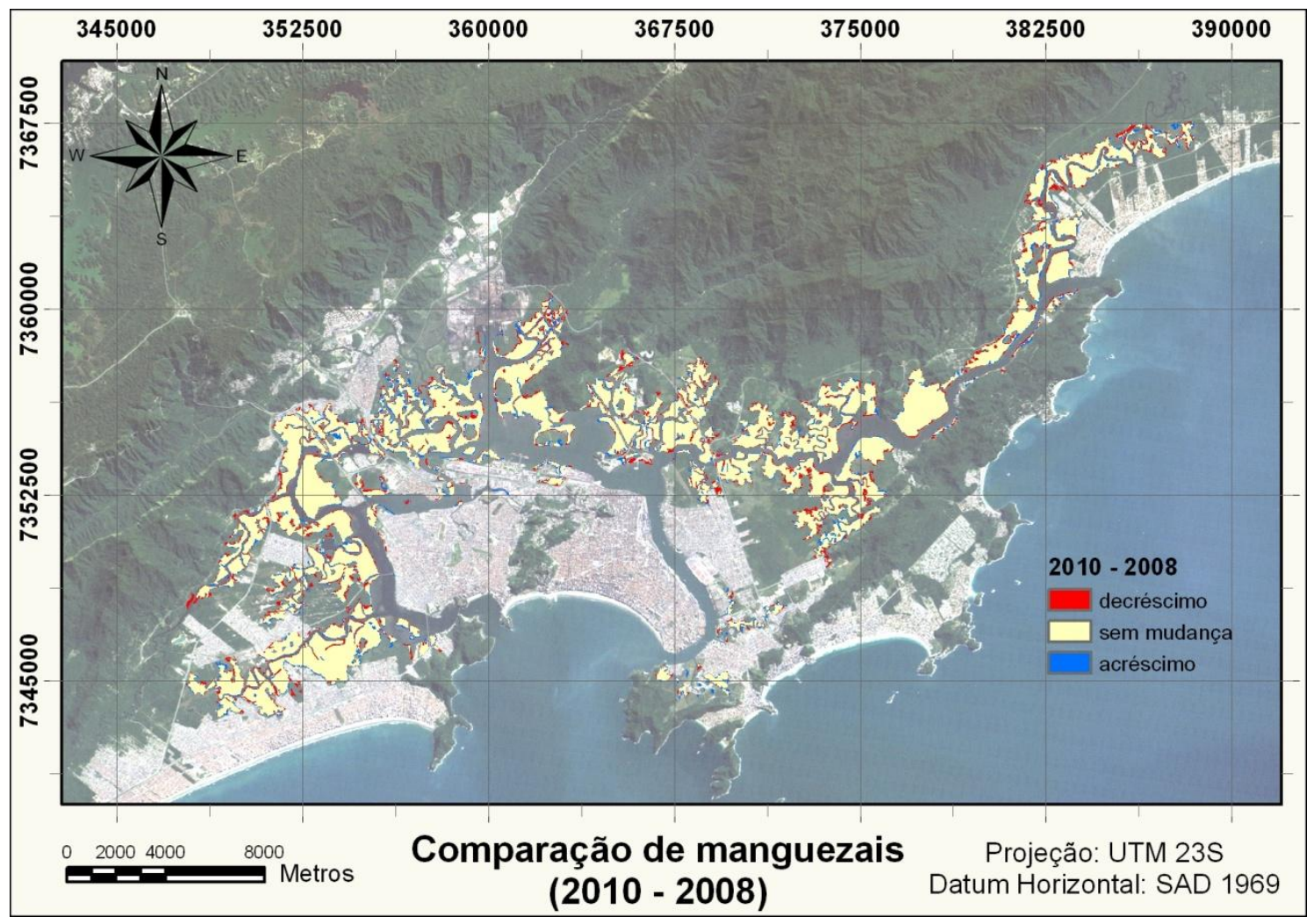

Mapa 26 Comparação pós-classificação entre os anos de 2010 e 2008. 


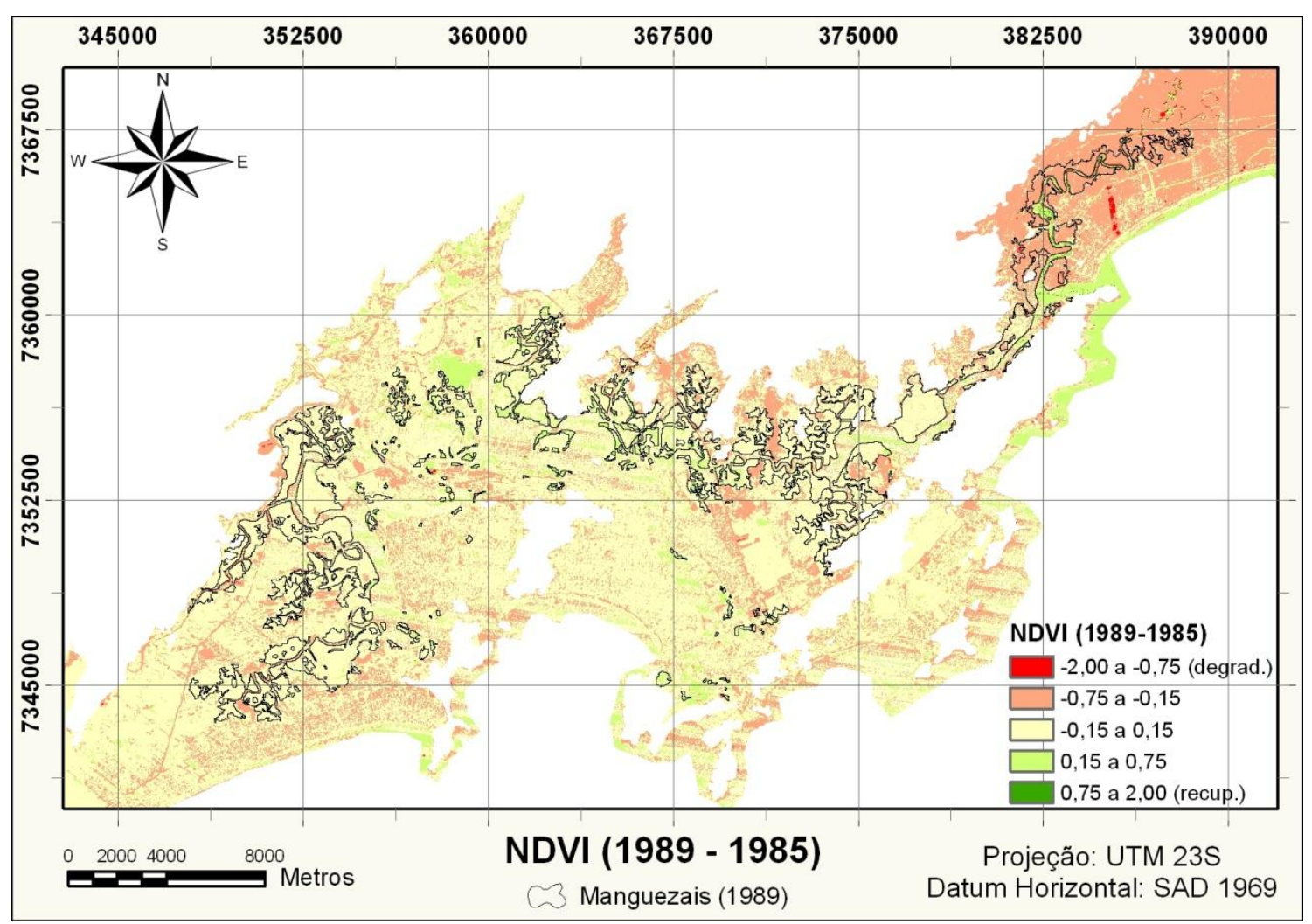

Mapa 27 Comparação dos valores de NDVI entre os anos de 1989 e 1985.

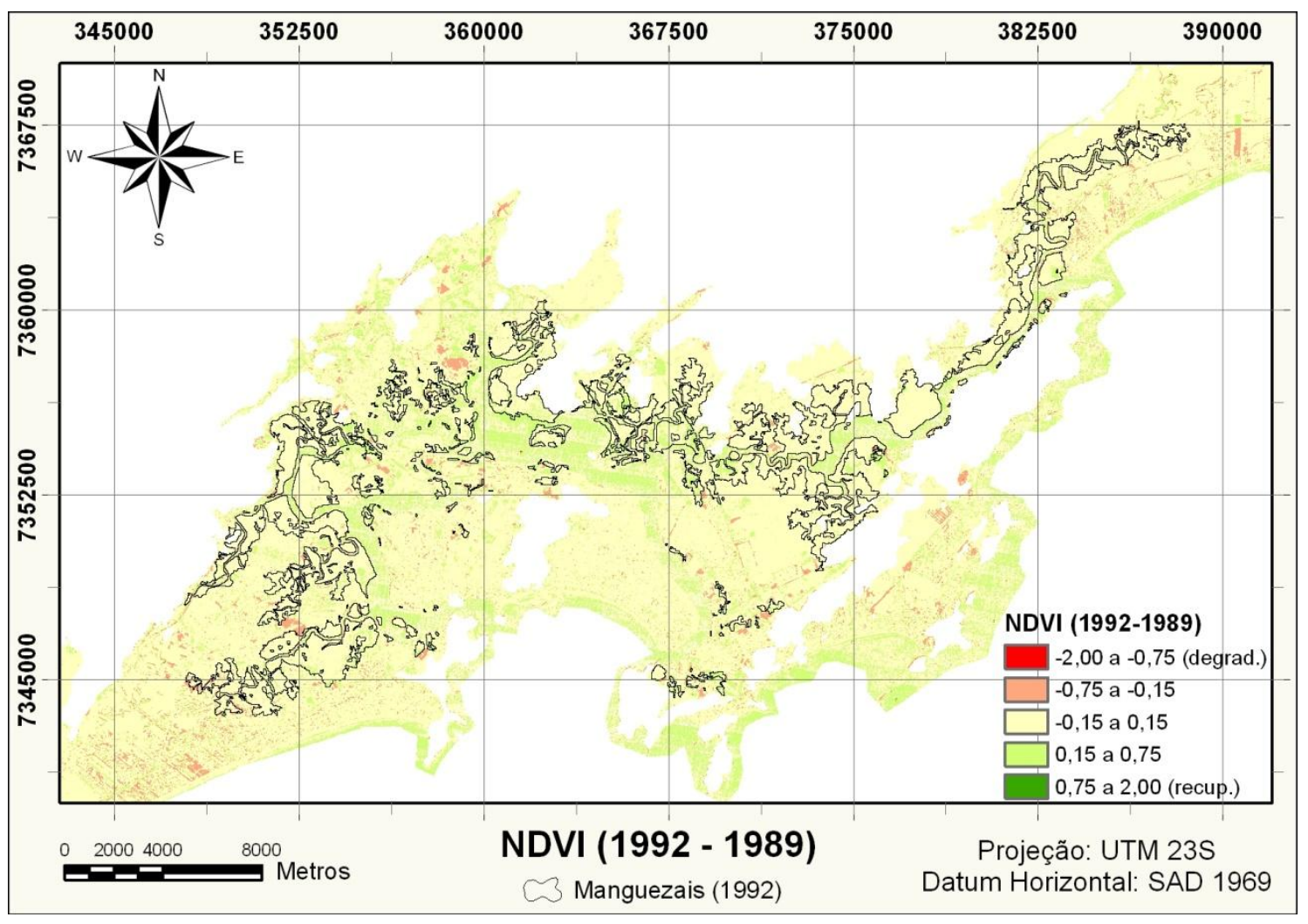

Mapa 28 Comparação dos valores de NDVI entre os anos de 1992 e 1989. 


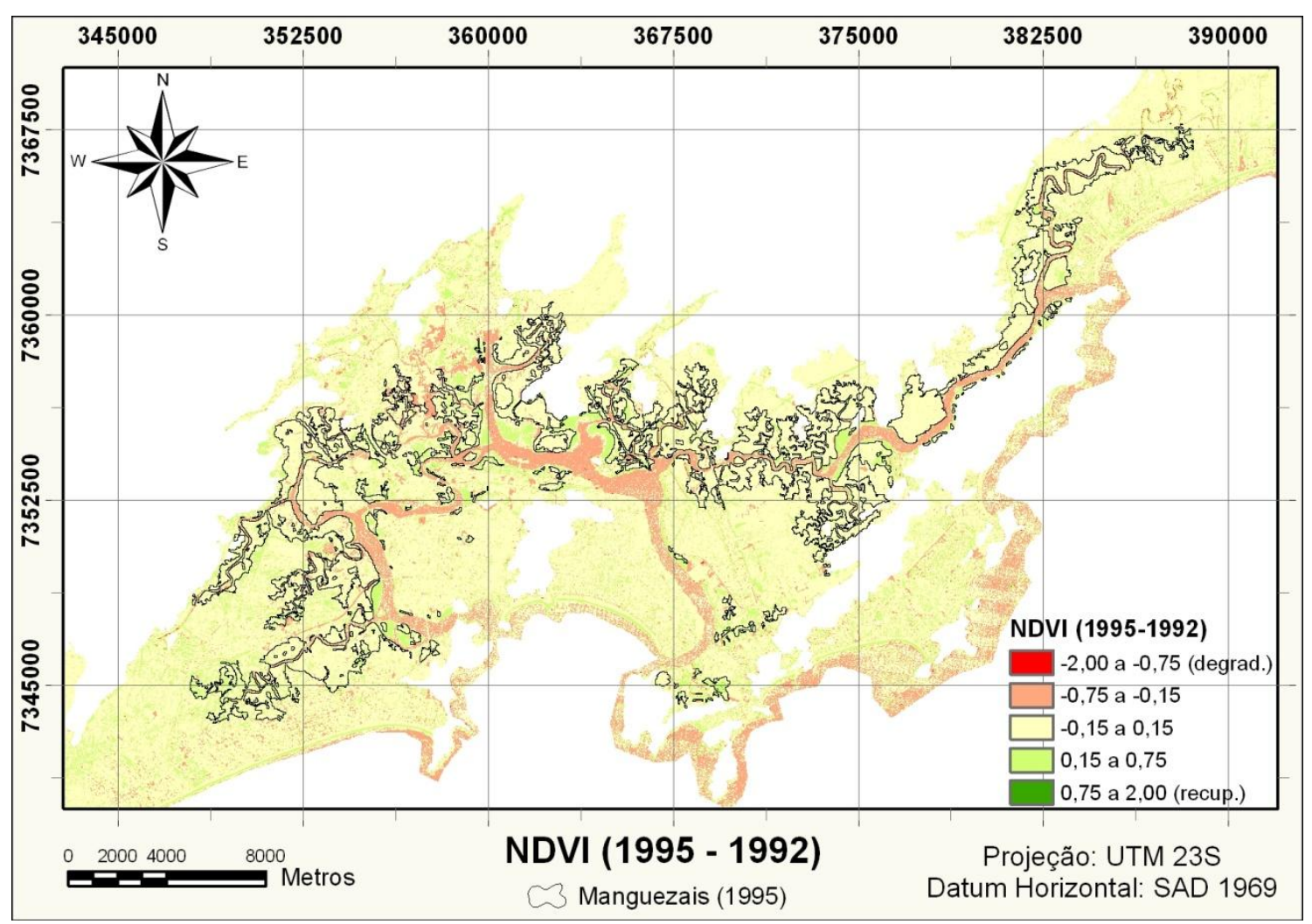

Mapa 29 Comparação dos valores de NDVI entre os anos de 1995 e 1992.

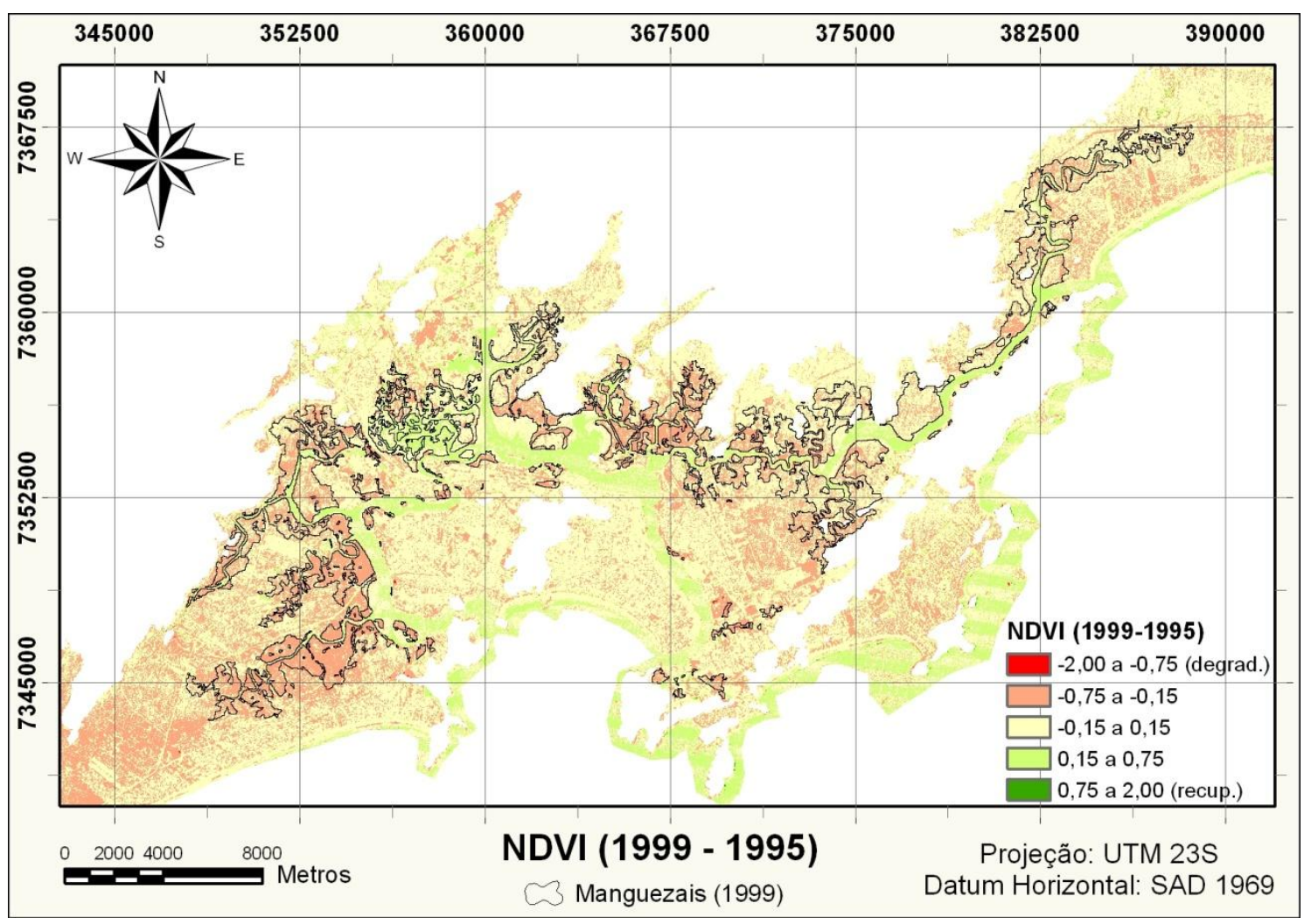

Mapa 30 Comparação dos valores de NDVI entre os anos de 1999 e 1995. 


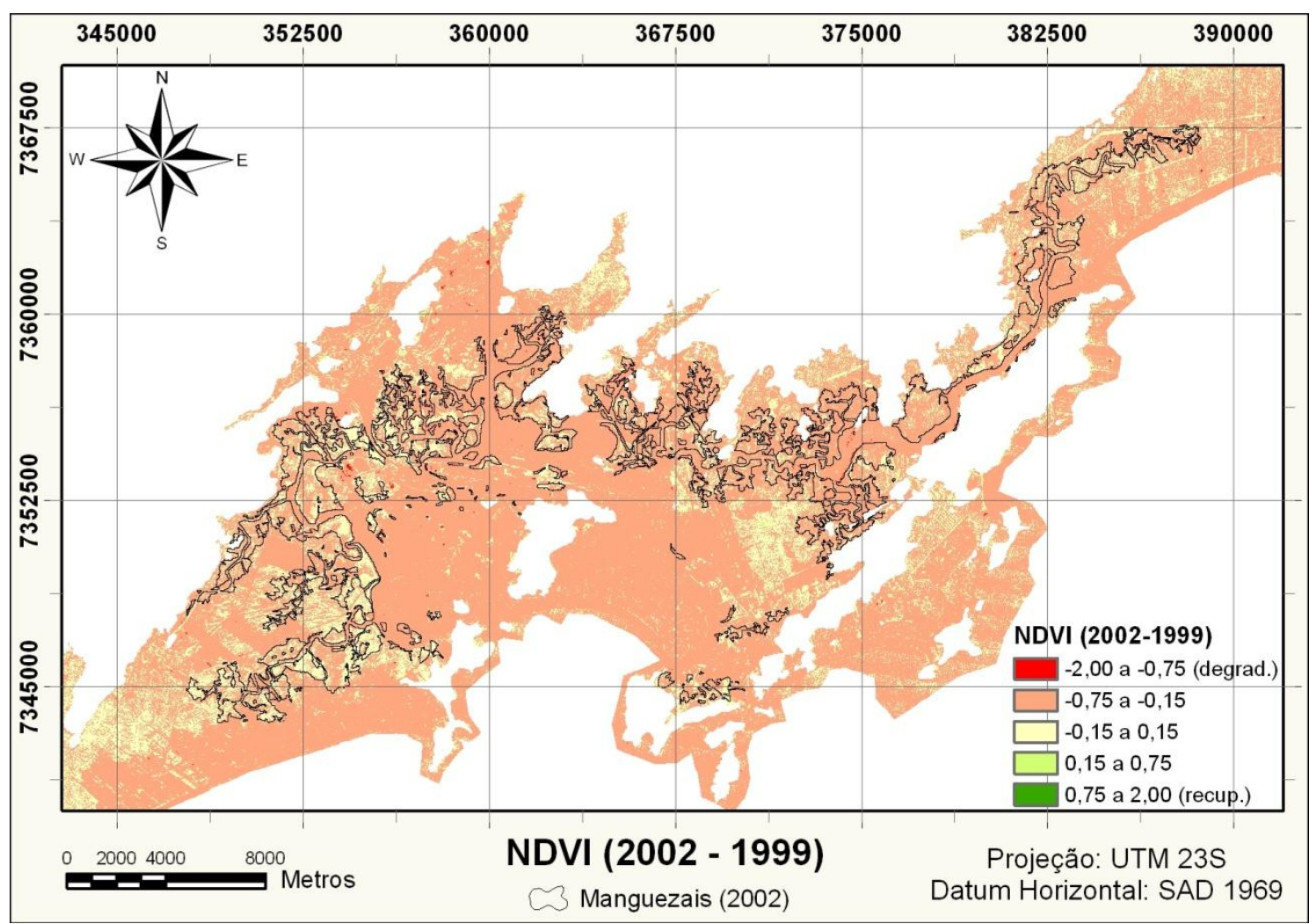

Mapa 31 Comparação dos valores de NDVI entre os anos de 2002 e 1999.

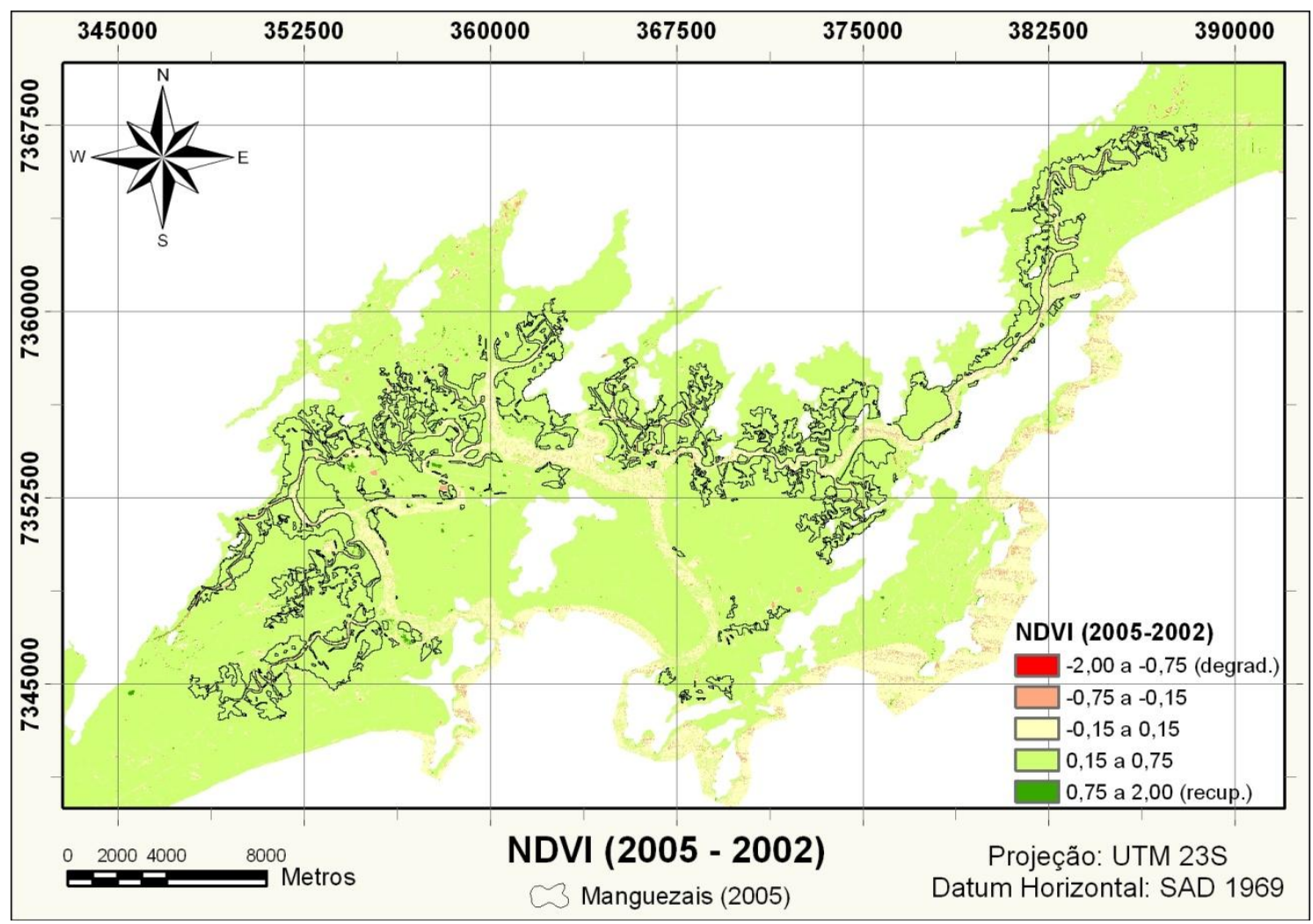

Mapa 32 Comparação dos valores de NDVI entre os anos de 2005 e 2002. 


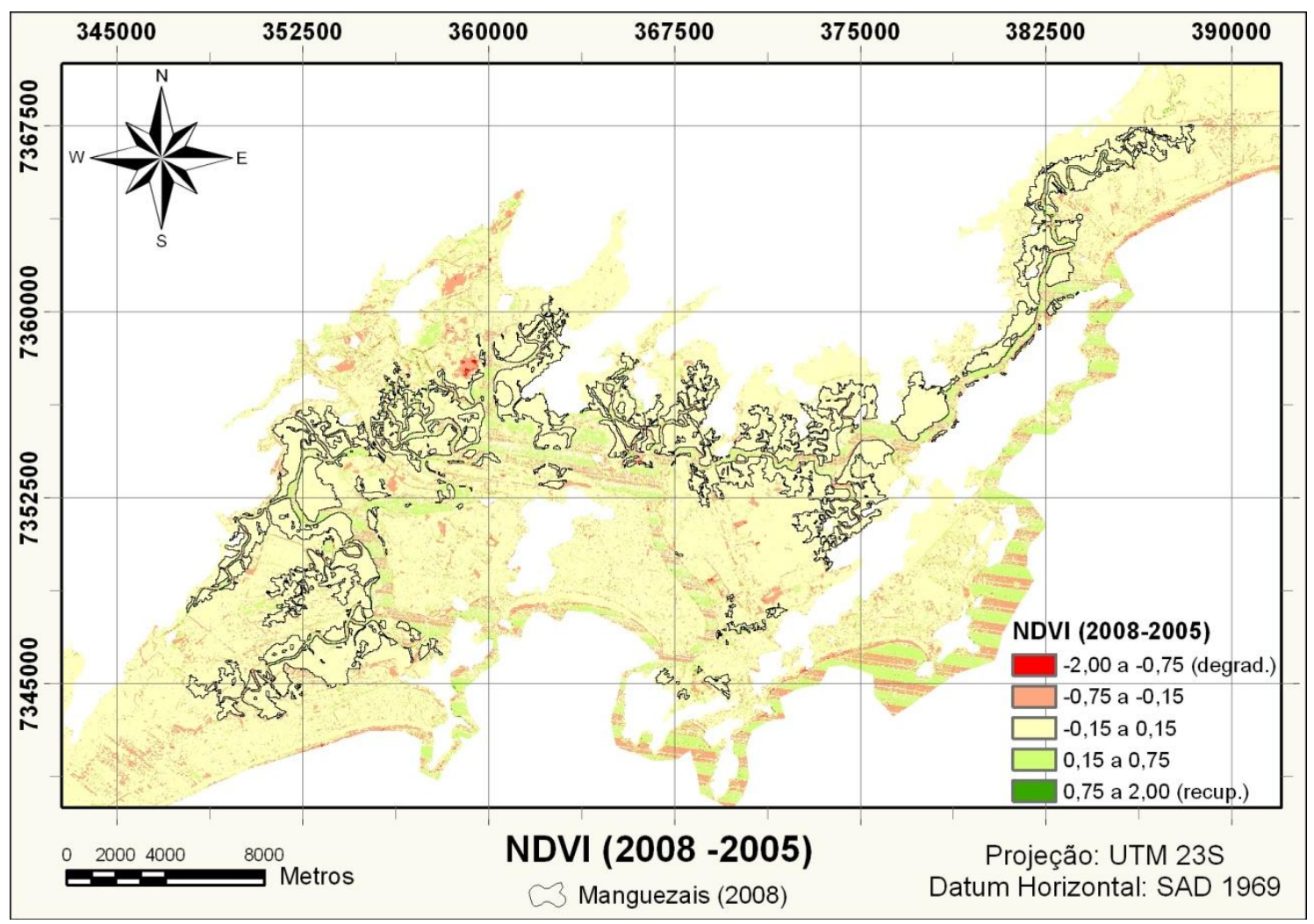

Mapa 34 Comparação dos valores de NDVI entre os anos de 2008 e 2005.

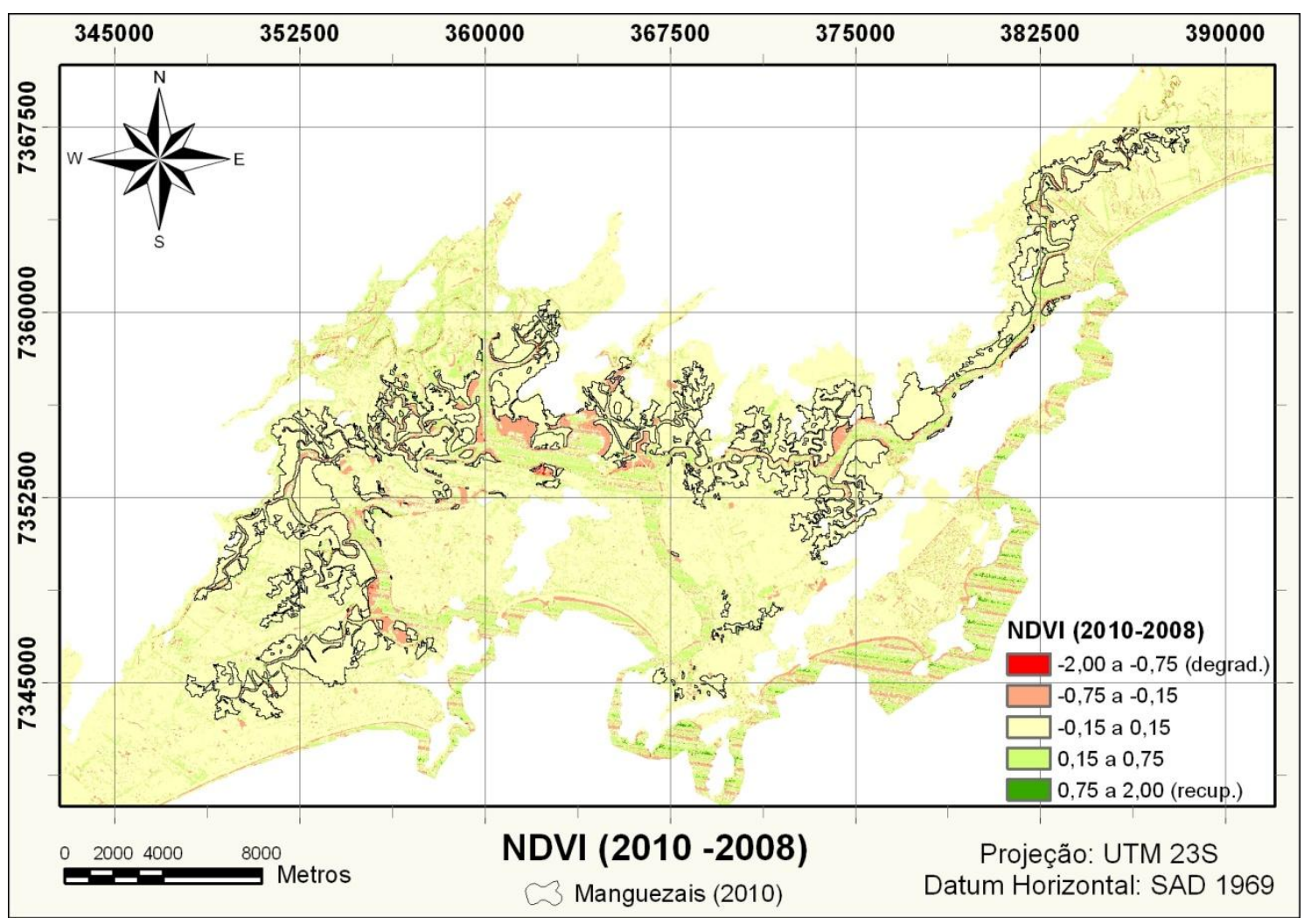

Mapa 35 Comparação dos valores de NDVI entre os anos de 2010 e 2008. 


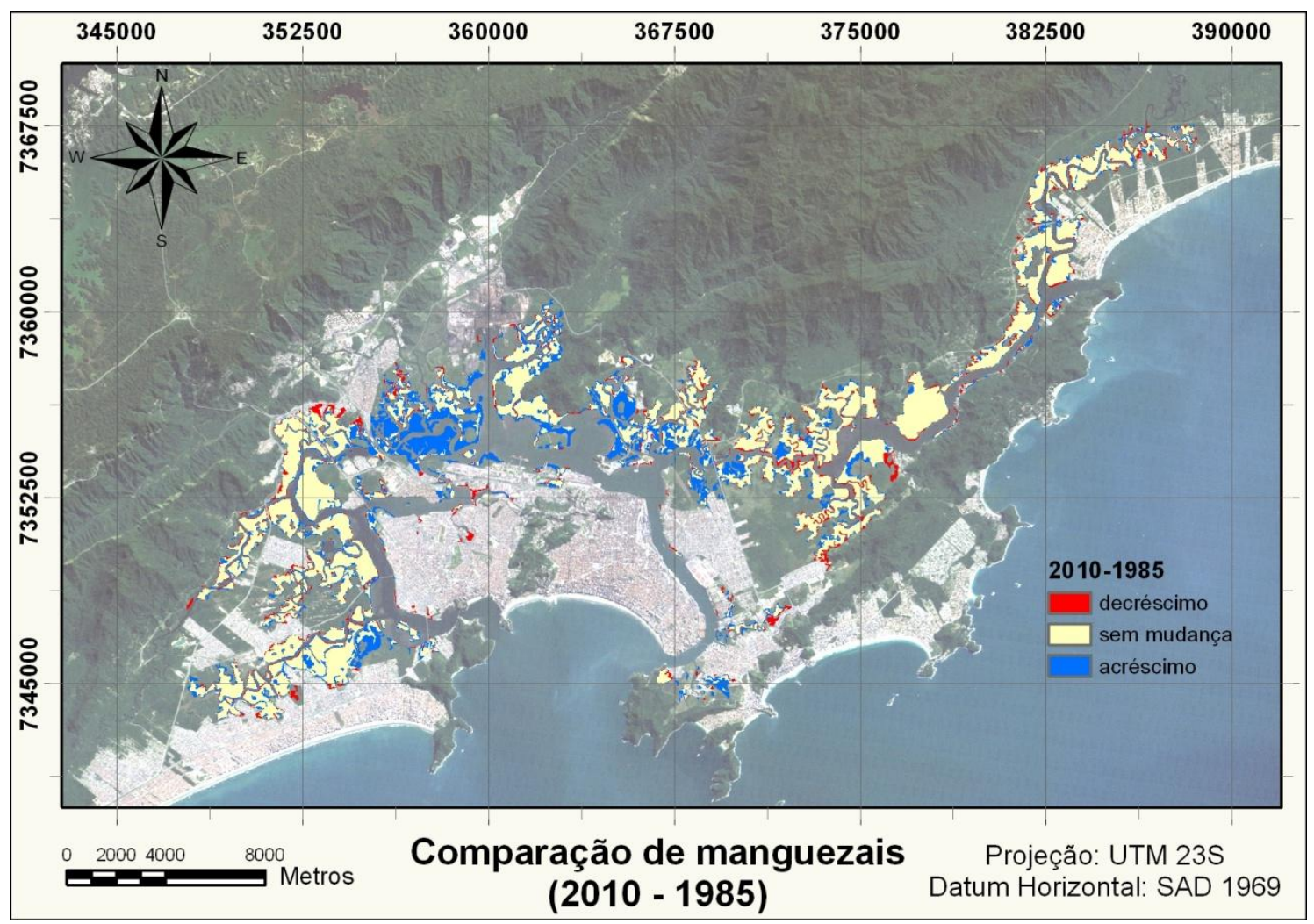

Mapa 36 Comparação pós-classificação entre os anos de 2005 e 2002.

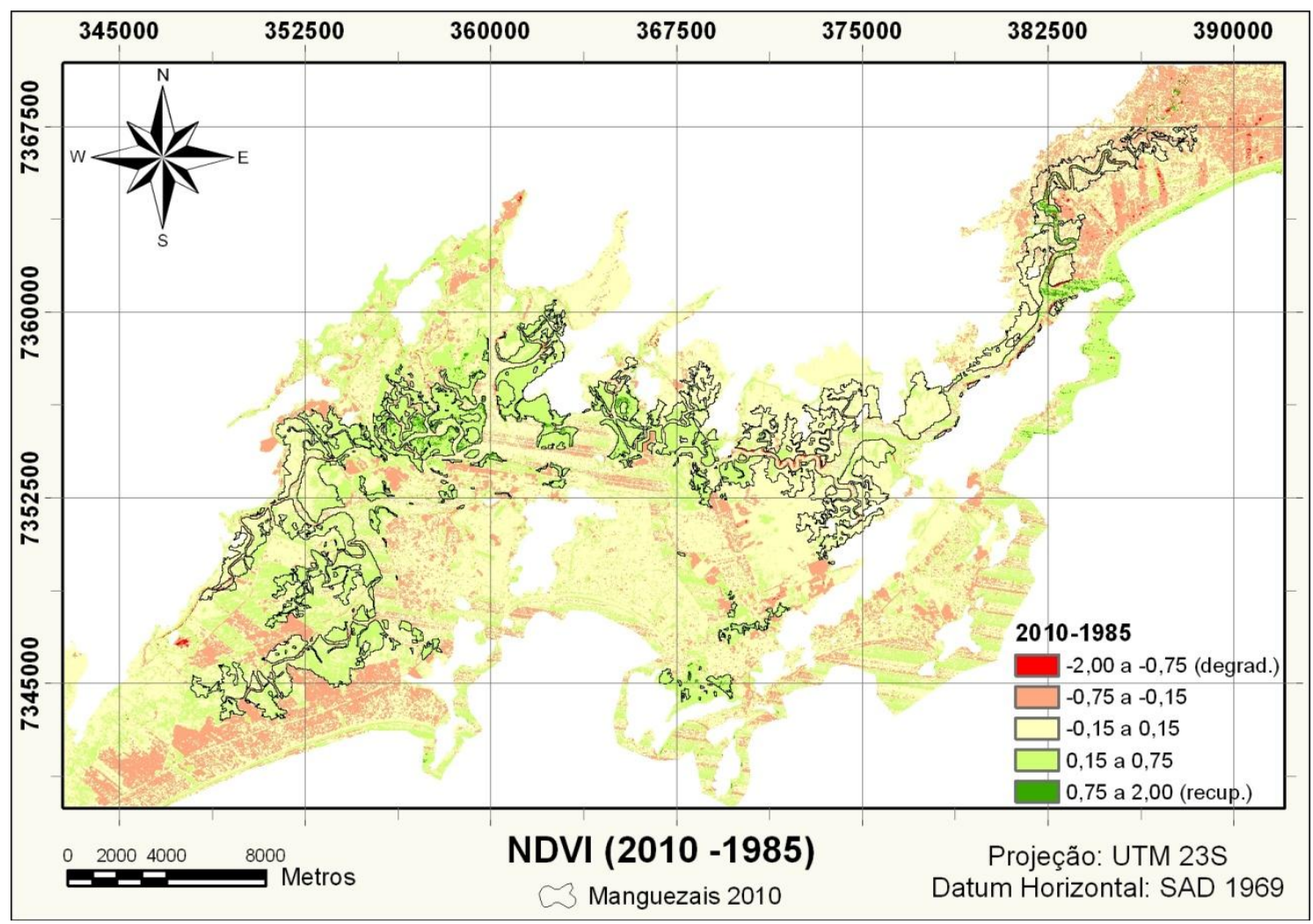

Mapa 37 Comparação dos valores de NDVI entre os anos de 2010 e 1985. 
ANEXO B - TABELA ILUSTRATIVA

Exemplo da estrutura do banco de dados associado a uma imagem de manguezais vetorizada, em formato shapefile (ESRI).

\begin{tabular}{|c|c|c|c|c|c|c|c|c|c|c|c|c|c|c|}
\hline \multirow{2}{*}{$\begin{array}{c}\text { Mancha } \\
1\end{array}$} & \multirow{2}{*}{$\begin{array}{c}\text { Contagem } \\
\text { (em pixels) } \\
17\end{array}$} & Área $\left(\mathrm{m}^{2}\right)$ & \multicolumn{2}{|c|}{ Perímetro } & $\begin{array}{c}\text { Índice } \\
\text { de } \\
\text { forma }\end{array}$ & $\begin{array}{c}\text { Razão } \\
\text { do } \\
\text { perímetro } \\
\text { pela área }\end{array}$ & \multicolumn{2}{|c|}{$\begin{array}{c}\text { Dimensão } \\
\text { fractal }\end{array}$} & $\begin{array}{c}\text { Soma } \\
\text { das } \\
\text { bordas }\end{array}$ & $\begin{array}{l}\text { Densidade } \\
\text { das bordas }\end{array}$ & $\begin{array}{l}\text { Índice } \\
\text { de } \\
\text { áreas- } \\
\text { núcleo }\end{array}$ & $\begin{array}{l}\text { NDVI } \\
\text { mín }\end{array}$ & $\begin{array}{l}\text { NDVI } \\
\text { máx }\end{array}$ & $\begin{array}{l}\text { NDVI } \\
\text { médio }\end{array}$ \\
\hline & & 12621 & \multicolumn{2}{|c|}{836,04} & 2,10 & 0,06624 & \multicolumn{2}{|c|}{1,43} & 836,04 & 0,12 & 1,26 & 0,67 & 0,92 & 0,82 \\
\hline 2 & 30 & 26570 & \multicolumn{2}{|c|}{745,68} & 1,29 & 0,02806 & \multicolumn{2}{|c|}{1,30} & 745,68 & 0,11 & 2,66 & 0,71 & 0,96 & 0,83 \\
\hline 3 & 15 & 12220 & \multicolumn{2}{|c|}{704,52} & 1,80 & 0,05765 & \multicolumn{2}{|c|}{1,39} & 704,52 & 0,10 & 1,22 & 0,71 & 0,91 & 0,82 \\
\hline$\cdots$ & $\ldots$ & $\ldots$ & .. & & $\cdots$ & $\ldots$ & & & $\ldots$ & $\ldots$ & $\ldots$ & $\ldots$ & $\cdots$ & $\ldots$ \\
\hline 427 & 436 & 391797 & 4694 & 24 & 2,12 & 0,01198 & & & 4694,24 & 0,69 & 39,18 & 0,25 & 0,67 & 0,56 \\
\hline $\begin{array}{l}\text { NDVI } \\
\text { desvio } \\
\text { padrão }\end{array}$ & $\begin{array}{c}\text { Brightness } \\
\text { mín }\end{array}$ & $\begin{array}{l}\text { Bri. } \\
\text { máx }\end{array}$ & $\begin{array}{c}\text { Bri. } \\
\text { médio }\end{array}$ & $\begin{array}{r}B r \\
\text { des } \\
\text { padr }\end{array}$ & & $\begin{array}{l}\text { àreeness } \\
\text { mín }\end{array}$ & $\begin{array}{l}\text { Gre. } \\
\text { máx }\end{array}$ & $\begin{array}{l}\text { Gre. } \\
\text { média }\end{array}$ & $\begin{array}{c}\text { Gre. } \\
\text { desvio } \\
\text { padrão }\end{array}$ & $\begin{array}{c}\text { Wetness } \\
\text { mín }\end{array}$ & & & $\begin{array}{c}\text { Wet. } \\
\text { médio }\end{array}$ & $\begin{array}{c}\text { Wet. } \\
\text { desvio } \\
\text { padrão }\end{array}$ \\
\hline 0,07 & 52,34 & 78,17 & 64,61 & 9,1 & & $-7,37$ & 18,02 & 5,62 & 8,97 & $-56,85$ & -45 & & $-50,41$ & 3,85 \\
\hline 0,06 & 57,80 & 74,90 & 67,87 & 5,2 & & $-0,32$ & 21,60 & 10,24 & 5,79 & $-56,91$ & -43 & & $-50,73$ & 2,99 \\
\hline 0,05 & 56,77 & 75,38 & 65,59 & 6,1 & & $-4,32$ & 14,44 & 8,03 & 5,47 & $-54,38$ & -45 & 21 & $-49,04$ & 3,25 \\
\hline$\cdots$ & $\cdots$ & $\ldots$ & $\ldots$ & $\cdots$ & & $\ldots$ & $\ldots$ & $\ldots$ & $\ldots$ & $\ldots$ & & & $\ldots$ & $\ldots$ \\
\hline 0,07 & 73,05 & 109,78 & 89,09 & 5,0 & & $-14,87$ & 15,46 & 5,01 & 6,01 & $-59,15$ & -30 & 74 & $-38,83$ & 3,27 \\
\hline
\end{tabular}

